Portland State University

PDXScholar

\title{
A Mixed-Methods and Multi-Level Investigation of the Effects of a Crew Chief Intervention on Job Attitudes, Occupational Stress, and Organizational Commitment
}

Michael Charles Leo

Portland State University

Follow this and additional works at: https://pdxscholar.library.pdx.edu/open_access_etds

Part of the Industrial and Organizational Psychology Commons, and the Social Psychology Commons Let us know how access to this document benefits you.

\section{Recommended Citation}

Leo, Michael Charles, "A Mixed-Methods and Multi-Level Investigation of the Effects of a Crew Chief Intervention on Job Attitudes, Occupational Stress, and Organizational Commitment" (2006).

Dissertations and Theses. Paper 2758.

https://doi.org/10.15760/etd.2759

This Dissertation is brought to you for free and open access. It has been accepted for inclusion in Dissertations and Theses by an authorized administrator of PDXScholar. Please contact us if we can make this document more accessible: pdxscholar@pdx.edu. 


\section{A MIXED-METHODS AND MULTI-LEVEL INVESTIGATION \\ OF THE EFFECTS OF A CREW CHIEF INTERVENTION}

ON JOB ATTITUDES, OCCUPATIONAL STRESS,

AND ORGANIZATIONAL COMMITMENT

by

MICHAEL CHARLES LEO

A dissertation submitted in partial fulfillment of the requirements for the degree of

DOCTOR OF PHILOSOPHY

in

SYSTEMS SCIENCE: PSYCHOLOGY

Portland State University

2006 


\section{DISSERTATION APPROVAL}

The abstract and dissertation of Michael Charles Leo for the Doctor of Philosophy in Systems Science: Psychology were presented June 16, 2006 and accepted by the dissertation committee and the doctoral program.

COMMITTEE APPROVALS:

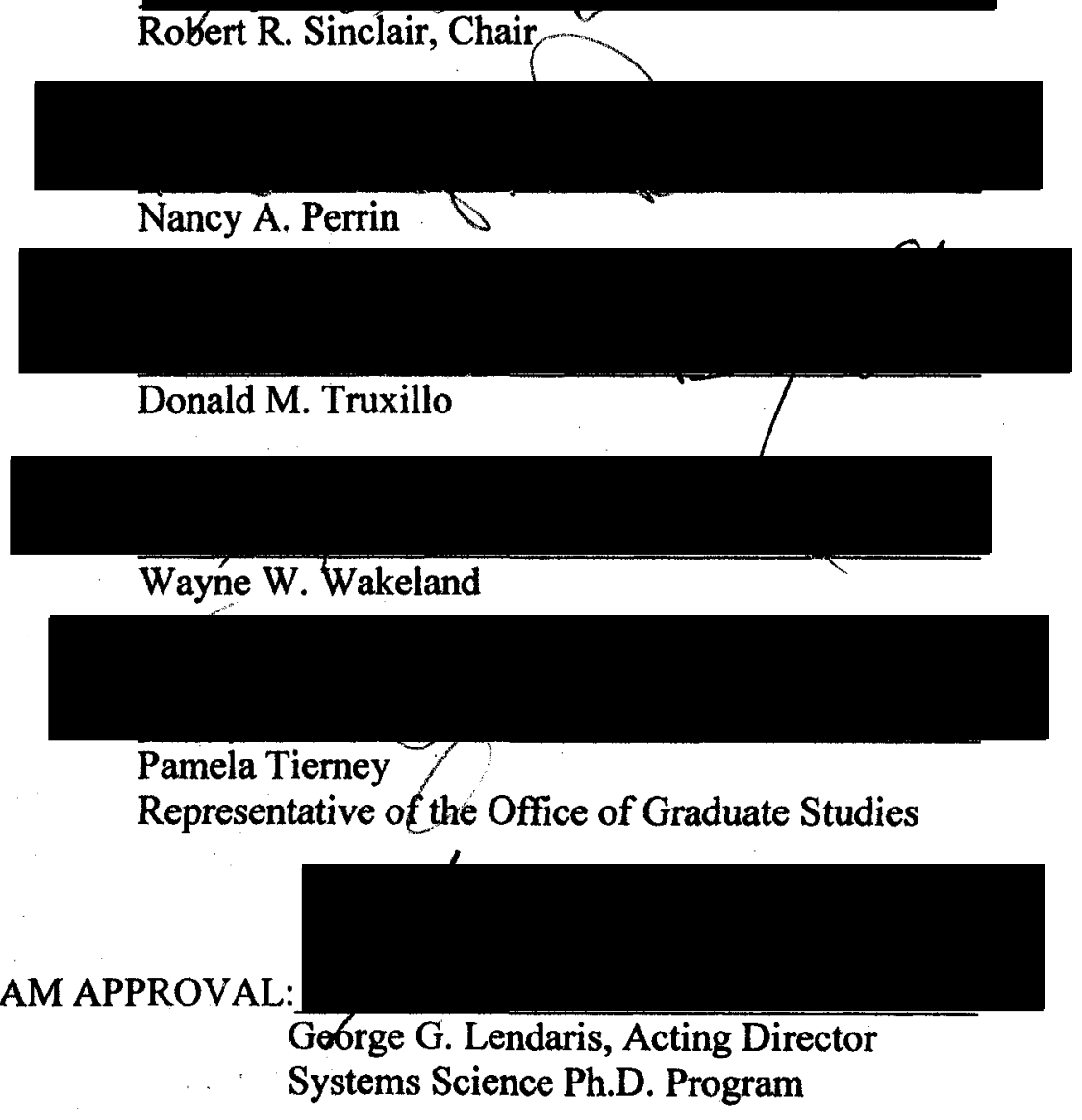




\begin{abstract}
An abstract of the dissertation of Michael Charles Leo for the Doctor of Philosophy in Systems Science: Psychology presented June 16, 2006.

Title: A Mixed-Methods and Multi-Level Investigation of the Effects of a Crew Chief Intervention on Job Attitudes, Occupational Stress, and Organizational Commitment
\end{abstract}

High-profile instances of workplace violence and increased pressure from competitors have threatened the viability of one of the nation's largest employers, the United States Postal Service (USPS). As a result, the USPS began a massive change effort in the early 1990's. One of the initiatives implemented to improve labormanagement relations was a derivative of the self-managed work team known as the crew chief program. This study provides a mixed-methods and multi-level approach to understand the impact this unique program had on organizational attitudes.

The first aim of this study was to investigate whether the crew chief program reduced employees' stress and strain and improved job and supervisory satisfaction and company and union commitment, while controlling for the nesting of employees within sites and employee demographic characteristics. The second aim was to replicate and extend the stressor-strain-outcome (SSO) model of stress and to determine whether employee perceptions of crew chief support moderated the relationships between stressors, strain, and outcomes. 
I evaluated Aim 1 using data from 177 mail processors from 27 units matched from baseline to one-year follow-up with hierarchical linear modeling. This was followed up with an implementation analysis of qualitative data to determine the extent to which the program was implemented compared to the original design. I evaluated Aim 2 using structural equation modeling from 538 mail processors who participated at follow-up.

There was little quantitative support for Aim 1. However, the results of the implementation analysis suggested that the crew chief program was not functioning as conceived. Aim 2 received strong support, with almost all of the main effects of the SSO model replicated. However, there was no support for the moderator effects. Additionally, I found role ambiguity to have direct relationships with other organizational outcomes beyond the indirect effects via strain and that crew chief support was strongly related to stressors and outcomes.

These findings reinforce the notion that employing both quantitative and qualitative methods can dramatically improve the quality of organizational research. Based on these findings, I describe several suggestions for improvements to this specific program and for improving future initiatives aimed at enhancing labormanagement relations. 


\section{ACKNOWLEDGMENTS}

There are several people that I would like to acknowledge and thank who have helped me achieve this great accomplishment.

Thank you Robert Sinclair, my advisor and committee chair, for providing guidance and support not only on my dissertation, but throughout my graduate school career. I especially appreciate the time and effort you put into shaping and reviewing my dissertation, along with much of the other scholarly work that I have been a part of. Not only have you taught me about the subject matter, but you have also helped to improve my writing and presentation skills. I have learned a tremendous amount from you and will continue to learn more with future projects that we may collaborate on.

Thank you Nancy Perrin, my supervisor and committee member, for your mentorship and feedback during this effort. I appreciate you always being there to answer all my questions, as well as the motivation and opportunity you provided for me to work on my dissertation. I have learned so much from working with you, and you have helped me grow as a scholar and a professional.

Thanks to the other members of my dissertation committee: Pam Tierney, Donald Truxillo, and Wayne Wakeland. Your insight and counsel have helped develop my research aims into a successful dissertation. I truly had the "dream team" when it comes to dissertation committees. Donald and Wayne, I also appreciate all that I have learned from your classes and for your service on my comprehensive exams committee. 
Thank you Jim Martin, you graciously offered me an amazingly rich dataset for use in my dissertation. I appreciate the time and effort you devoted to execute the original study, as well as your assistance in providing me with the critical supporting documentation and availability for answering all of my questions regarding the data. In addition, I would like to thank the United States Postal Service and the American Postal Workers Union for their support in the evaluation effort.

Thanks to the Doctoral Scholars Program and the Southern Regional Education Board for their generous financial support that allowed me to focus on classwork and research in the formative years of my graduate school career, and for their mentorship and dedication to the success of minority graduate students like myself. I would also like to give a special acknowledgement to Ansley Abraham, the director of the Doctoral Scholars Program, whose leadership has been instrumental to the success of the program.

Thank you my family and friends for your love and support throughout my educational years, from kindergarten to my doctorate. Your belief in me has been integral to my achievements thus far. I would like to give a special thanks to my parents, Charles and Gloria Leo. They have always been there for me and have supported me in all my endeavors. Finally, thank you my loving wife, Magda, who I met and fell in love with during graduate school, for all of your support throughout this journey. 
LIST OF TABLES .viii

\section{LIST OF FIGURES}

$\mathrm{X}$

CHAPTER 1. INTRODUCTION..............................................................................

CHAPTER 2. BACKGROUND AND CONTEXT .......................................................... 7

HISTORY OF LABOR-MANAGEMENT PROBLEMS .................................................. 10

LABOR-MANAGEMENT PROBLEMS AT THE USPS AS OF 1994 .................................. 12

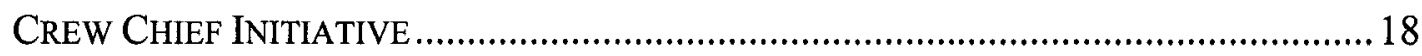

\section{CHAPTER 3. EMPOWERMENT, SELF-MANAGED WORK TEAMS, AND}

LEADER-SUBORDINATE RELATIONS ....................................................22

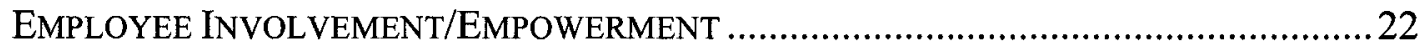

Teamwork and Empowerment........................................................................24

Evidence for SMWT's Positive Effects on Organizational Effectiveness and Employee Quality of Work Life .......................................................................226

The Role of Formal Supervisors in SMWT and the Importance of Supervisor

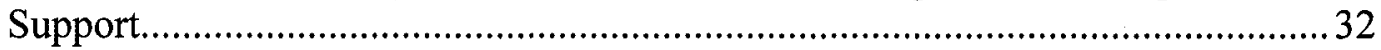

Employee Involvement Programs and Organizational Climate ...........................35

SOCIAL EXCHANGE PROCESSES.................................................................. 40

Leader-Member Exchange (LMX) ............................................................. 41

Leader-Member Relationship Quality and Supervisor Support .........................42

The Importance of Trust ................................................................................ 44

The Role of Leader-member Similarity in Developing Trust ............................49

The Relationship between Climate and Leader-Member Relations.....................50 
CHAPTER 4. JOB SATISFACTION, ORGANIZATIONAL COMMITMENT, UNION PARTICIPATION, UNION COMMITMENT, AND LABOR

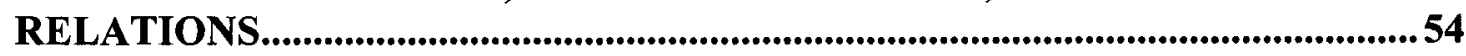

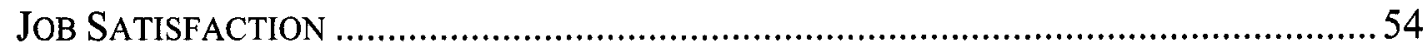

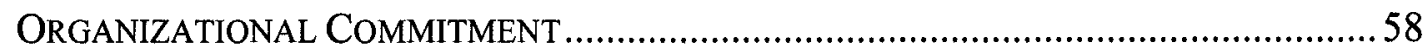

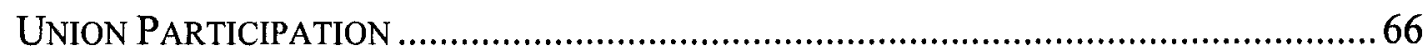

EMPLOYEE COMMITMENT TO THE UNION .................................................... 70

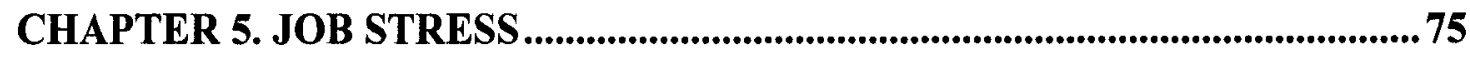

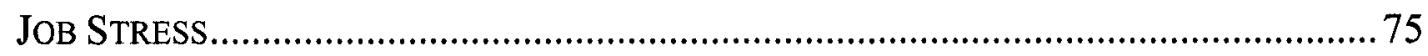

STRESSOR-STRAIN-OUTCOME (SSO) MODEL..................................................... 77

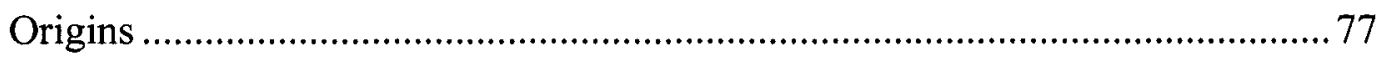

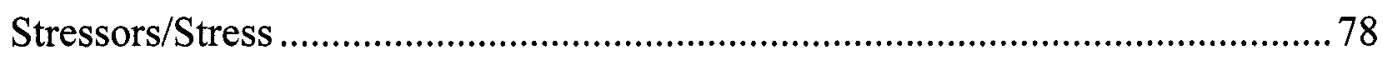

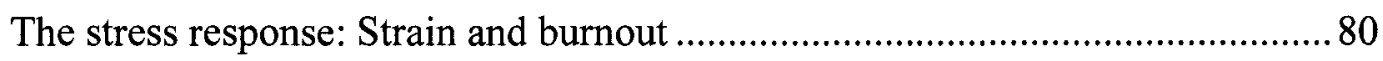

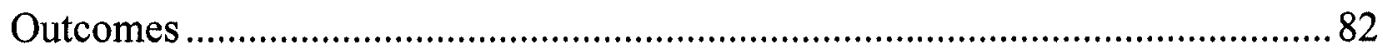

The main effects of crew chief support in the SSO model ............................... 84

The buffering effects of crew chief support in the SSO model .........................8 87

Relationships among outcomes .....................................................................99 90

The relationship between job satisfaction and company commitment ............90

The relationship between job satisfaction and union commitment. ................ 91

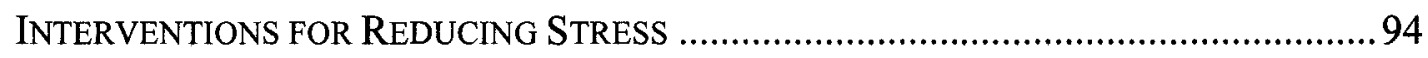

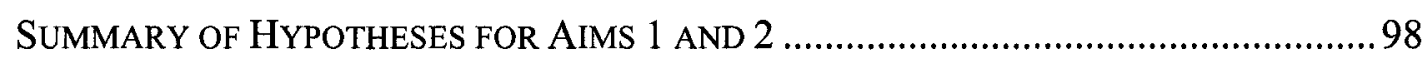

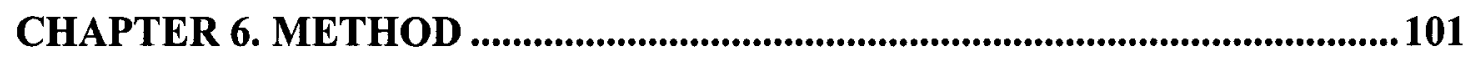

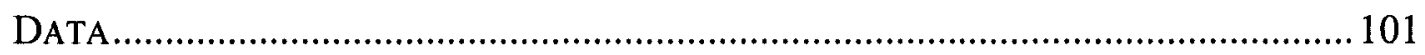

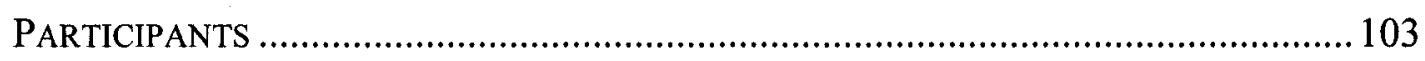

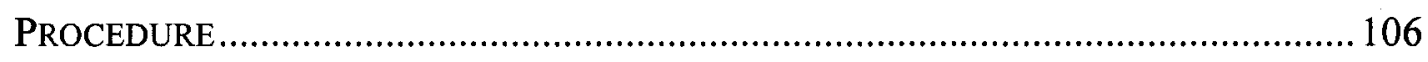

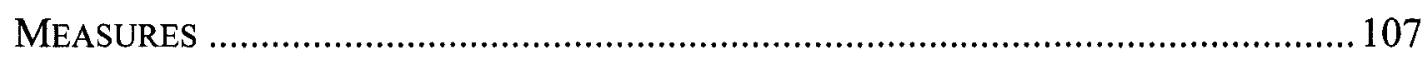

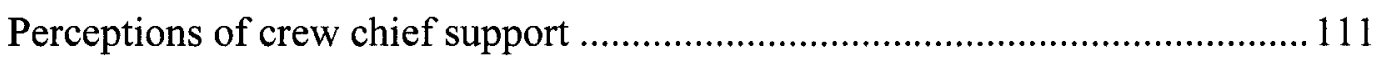

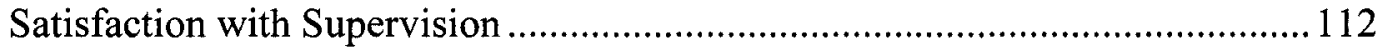

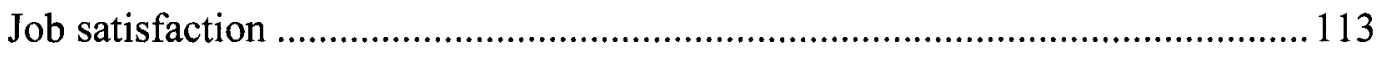

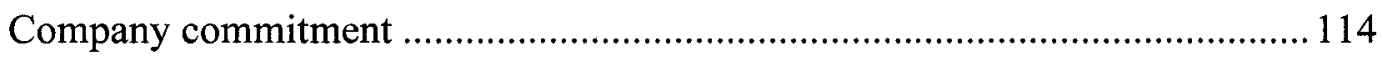

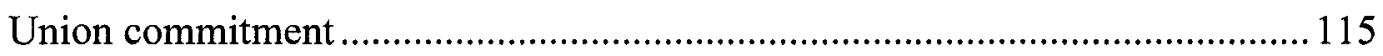




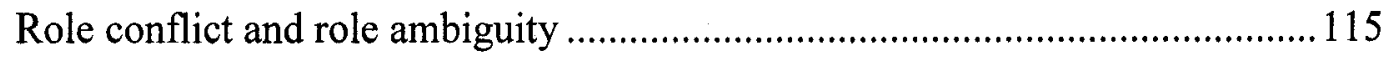

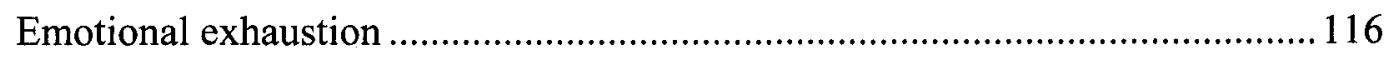

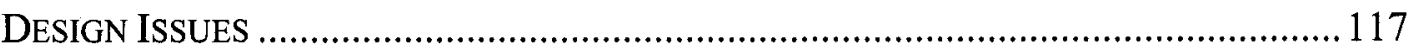

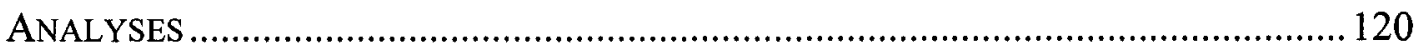

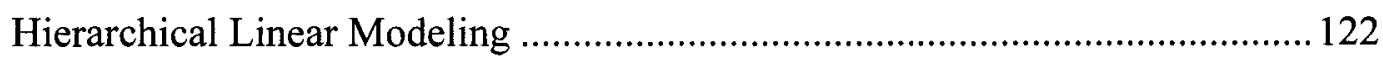

Structural Equation Modeling …………….................................................... 127

CHAPTER 7. RESULTS .......................................................................................................... 131

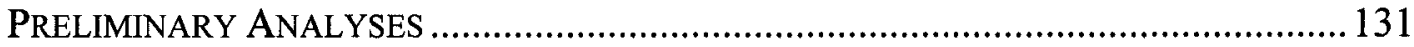

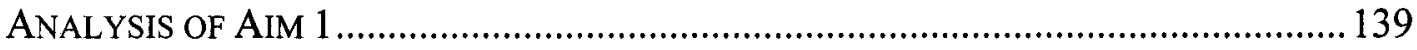

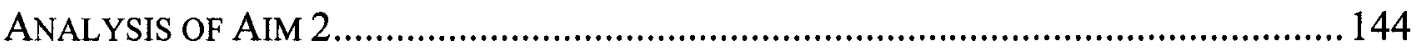

CHAPTER 8. IMPLEMENTATION ANALYSIS ....................................................157

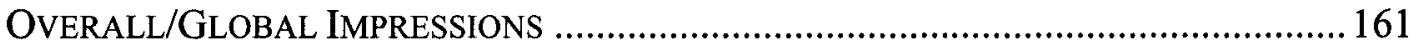

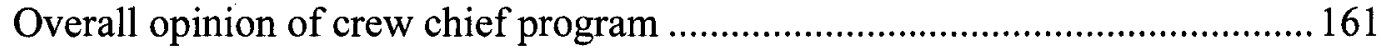

Change in labor-management relations in the past year............................................. 163

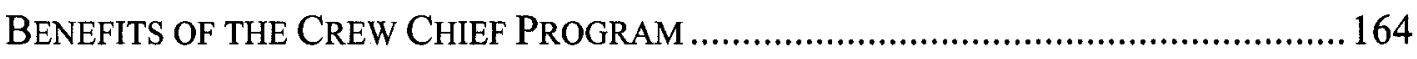

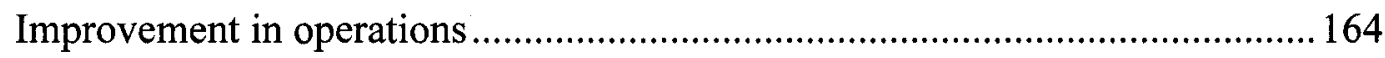

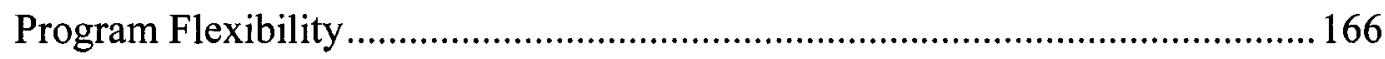

More time for supervisors to accomplish other tasks ............................................ 167

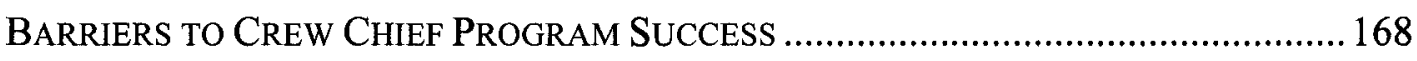

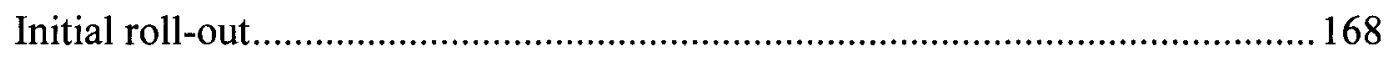

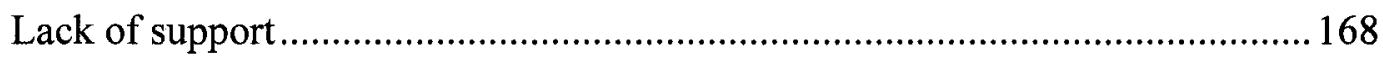

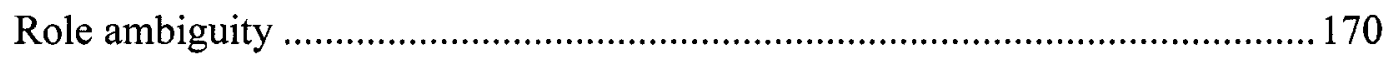

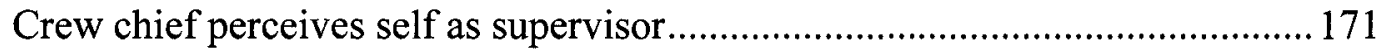

Crew chief not spending enough time on machines .............................................171

Ineffective Supervisors and/or Crew Chiefs..................................................... 172

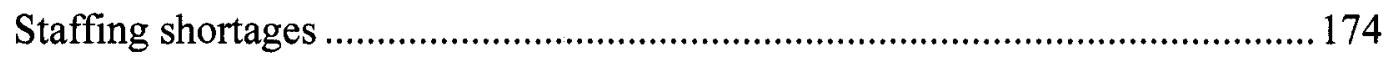

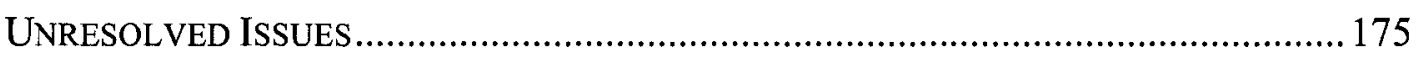

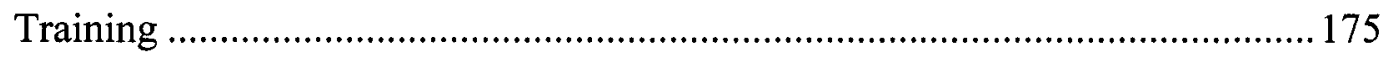

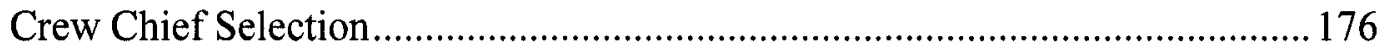

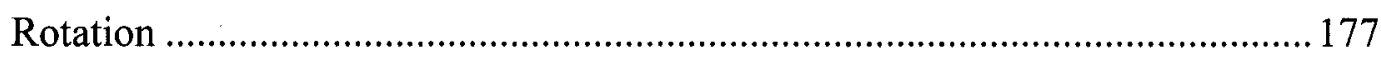

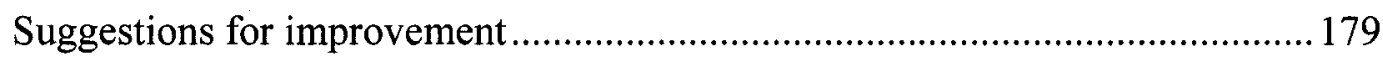

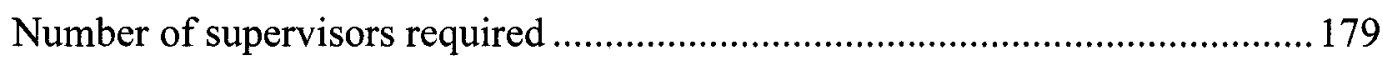


ADDITIONAL QUESTIONNAIRE FINDINGS ..................................................... 180

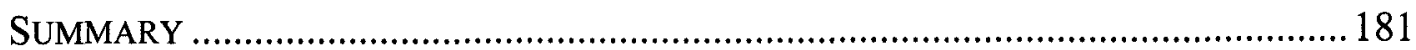

CHAPTER 9. DISCUSSION ........................................................................................ 185

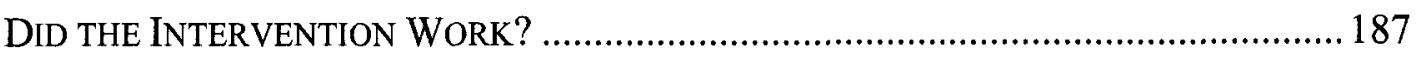

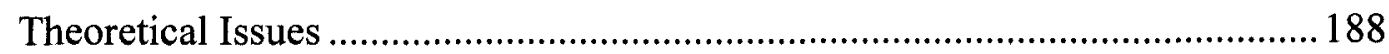

Is an empowerment intervention inappropriate for the current context? ...... 188

Were all employees really empowered? ................................................... 189

Did crew members have direct control over their work? ............................. 189

Are intact work groups critical to building empowerment?......................... 191

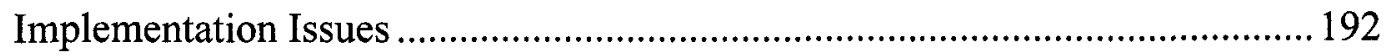

Lack of support from supervisors.............................................................. 192

Were labor-management relations too poor at baseline? ............................ 193

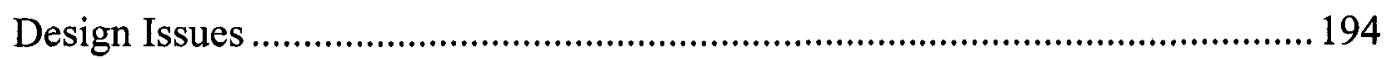

Lack of power. ................................................................................ 194

Did enough time elapse to detect changes in outcomes? ............................ 195

Absence of key mediator............................................................................. 195

Were there other (unmeasured) outcomes that the crew chief program may have affected? ........................................................................................ 196

Unsupported Hypotheses of Aim 2 ................................................................ 197

Crew chief support and emotional exhaustion. ........................................... 197

Moderating effects of crew chief support................................................ 197

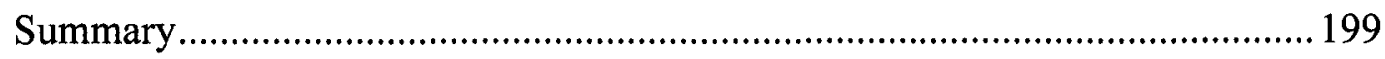

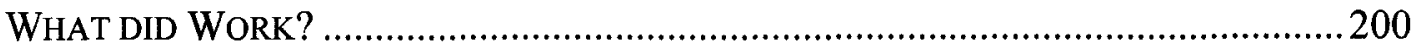

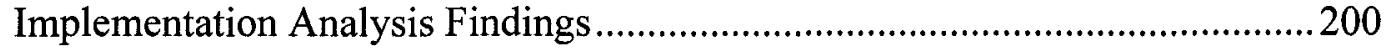

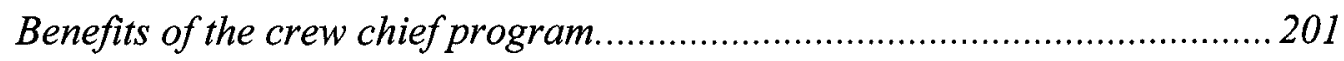

Positive characteristics of the crew chief program.................................... 202

Importance of Crew Chief Support ...............................................................204

Prominence of Role Ambiguity .................................................................. 205

Evaluation of Direct and Indirect Effects ....................................................207

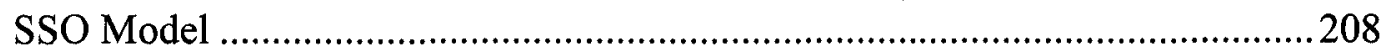

Job Satisfaction and Company and Union Commitment.................................209

IMPROVING THE CREW CHIEF PROGRAM ........................................................2211

How Does THE CURRENT STUdy DifFERS FROM PREVIOUS PUBLISHED RESEARCH

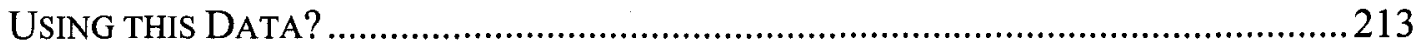

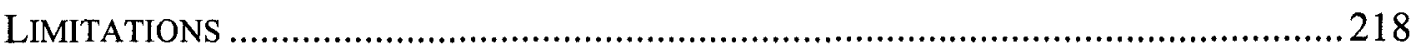




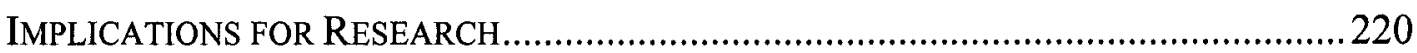

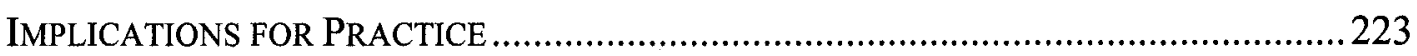

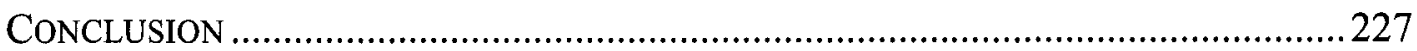

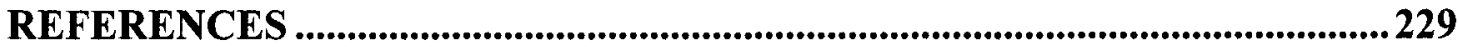

APPENDIX A. SURVEY RESULTS FOR TIME 1 AND TIME 2 ACROSS ALL INTERVENTION AND CONTROL SITES FOR MAIL PROCESSORS AND CREW CHIEFS............................................................................................................. 255

APPENDIX B. AMERICAN POSTAL WORKERS UNION REPORTS ...........279

APPENDIX C. INTERVIEW FORM AND TRANSCRIPTS...................................289 


\section{LIST OF TABLES}

TABLE 1. Number of Strongly Matched Participants by City and Tour 105

TABLE 2. Number of Participants at Each Mail Processing Site for Time 1 and Time 2

TABLE 3. Summary of Measures Used. 109

TABLE 4. Summary of Measures Given at Time 1 and Time 2 110

TABLE 5. Demographic Characteristics by Group and for Total Sample at Baseline 132

TABLE 6. Means, Standard Deviations, Coefficient Alphas, and Intercorrelations Among Study Variables for Total Sample at Time 1.....134

TABLE 7. Means, Standard Deviations, Coefficient Alphas, and Intercorrelations Among Study Variables for Total Sample at Time 2.....135

TABLE 8. Intercorrelations Among Study Variables for Matched Sample at Time 1 and Time 2

TABLE 9. Means and Standard Deviations of Study Variables for Matched Sample at Time 1 and Time 2

TABLE 10. Overall Model Results of the Unconditional Random-Coefficients Regression Models for Each Outcome Variable

TABLE 11. Overall Model Results of The Intercepts-as-Outcomes RandomCoefficients Regression Models for Satisfaction with Supervision and Job Satisfaction

TABLE 12. Parameter Estimates of the Intercepts-as-Outcomes Models for Satisfaction with Supervision and Job Satisfaction 
TABLE 13. Intercorrelations Among Study Variables for Mail Processors in Experimental Sites at Time 2

TABLE 14. Overall Fit Statistics for Structural Equation Models 148

TABLE 15. Parameter Estimates for Final Structural Equation Model 150

TABLE 16. R-Squared Estimates for the Endogenous Variables in the Final Structural Equation Model 153

TABLE 17. Total Standardized and Unstandardized Effects for Final Structural Equation Model 


\section{LIST OF FIGURES}

FIGURE 1. Stressor-Strain-Outcomes Model Including the Buffering Effects of Mail Processor Perceptions of Crew Chief Support.

FIGURE 2. Variables Measured at Time 1 and Time 2 for Mail Processor Experimental and Control Groups.

FIGURE 3. Structural Equation Model Illustrating the Hypotheses Comprising Aim 2.

FIGURE 4. Final Structural Equation Model with Parameter Estimates. 
Introduction 1

Effects of a Crew Chief Empowerment Intervention on Job Satisfaction, Job Stress, and Company and Union Commitment

\section{Chapter 1. Introduction}

The globalization of the U.S. economy has led to increased competition for companies in many industries. Along with increased globalization, rapid and extraordinary developments in technology have revolutionized the way organizations conduct business. Technological changes in organizations are usually accompanied by structural changes, one of the most common of which is the adoption of team-based structures (Osterman, 1994), such as self-managing work teams (Ankarlo, 1994 as cited in Elmuti, 1997; Kulisch \& Banner, 1993; Schilder, 1992). For example, Schilder (1992) cites the results of a survey published by the American Productivity and Quality Center that found 7\% of 476 U.S. Fortune 1000 companies were organized in teams, and that half of these companies indicated that they intend to use teams more frequently in the future. Job attitudes such as employee job satisfaction and commitment to the organization, which research has linked to important organizational outcomes, are likely to be affected by changes to team-based structures. Thus, a major challenge for organizations is to maintain and develop satisfaction and commitment, which are essential for employees to work effectively in organizations using teamwork (Dessler, 1999). 
Introduction 2

One industry that has become extremely competitive in recent years is the document and parcel shipping industry. The dominant organization in this business has traditionally been the United States Postal Service (USPS). Until recently, the USPS was the nation's largest employer and currently has over 800,000 employees. With the increasing popularity of e-mail as a communication tool and the increasing use of electronic methods of bill payment, the Postal Service has seen the volume of first class mail (e.g., traditional paper envelopes) and business class mail (e.g., product and service solicitations) decrease. Although the USPS continues to hold a quasimonopoly on these mail services, internet and e-mail can be thought of as indirect competitors that have negatively affected the USPS's revenues.

Another major portion of the services provided by the USPS is the shipping of express mail and packages. Unlike regular mail, the USPS does not hold a monopoly on these services and finds itself in a very competitive field with organizations such as the United Parcel Service, Federal Express, and DHL Express, which had recently merged with Airborne Express. Although e-mail is delivered virtually instantaneously, there are still many legal and corporate documents that need to be physically delivered. However, this will probably change in the future as digital signature technology and advanced security mechanisms are developed and accepted. Also, with the boom of internet commerce, there are more packages than ever that need to be delivered to business and residential customers (Simons \& Blackmon, 1998; Torres, 2004). The cumulative effect of these changes has and will continue to erode the 
USPS's traditional dominance in the shipping services industry and the USPS will need to adapt to these changes to remain competitive.

Given the large size of the USPS, it should be no surprise that it has a bureaucratic structure. Bureaucratic organizations can be characterized as hierarchical and not very responsive to changes in the business environment (Burns \& Stalker, 1994; Mintzberg, 1979). The present economic environment, which is rapidly changing as a result of technological advances, makes it extremely difficult for bureaucratic organizations like the USPS to prosper, or even survive. Without change in its structure to adapt to the changing environment, the USPS would likely see its market share continue to decline and eventually find itself obsolete. However, successful change can be difficult, and is usually more challenging for larger organizations (Porras \& Robertson, 1992). In addition, the USPS has also had a poor history of labor relations with the unions that represent its employees, which can make organizational change that much more difficult. Thus, beginning in the late 1980's, the USPS found itself in a precarious situation, one that threatened its very existence.

In 1992, Postmaster General Marvin Runyon recognized the need for change and proposed several organizational change initiatives in an effort to improve the USPS's viability. Some of the more important early initiatives centered on improving labor-management relations, as this was identified by the United States General Accounting Office (GAO) as one of the most significant problems facing the USPS, and the GAO believed that relations needed to be improved before commencing with other change efforts (United States General Accounting Office, 1994a, 1994b). From 
the perspective of the GAO, improving labor relations was important for three reasons. First, more positive relations should result in a higher quality of work life for employees in the form of increased job satisfaction (Kelloway, Barling, \& Shah, 1993) and reduced stress (Heaney et al., 1993). Second, improved relations should lead to improved organizational performance in the form of reduced tardiness, absenteeism, and turnover (Cooke, 1990; Katz, Kochan, \& Weber, 1985). Finally, improved labor relations should result in higher employee motivation, lower employee resistance and greater employee acceptance of other organizational change initiatives (Emery \& Summers, 1996; Zammuto \& O'Connor, 1992).

One major source of poor labor relations at the USPS was conflict between employees and supervisors (United States General Accounting Office, 1994a, 1994b). Therefore, one of the first initiatives implemented at the USPS to improve labor relations was the crew chief program. The crew chief position was intended to provide employees with opportunities to share in the decision making process on how their work is performed, in turn empowering them, which was expected to send a message to employees that they were valued. The crew chief program provided the opportunity for employees to become team leaders who would be responsible for coordinating the activities of their crew. In addition to this type of "direct" empowerment, the USPS also hoped that employees would receive more support and build better relationships with their direct reports (i.e., crew chiefs) when the person who leads their work group was "one of their own." The crew chief also was intended to serve as a liaison between 
the work group and the supervisor, and supervisors continued to maintain control of human resource and administrative duties.

The primary aim of the present study was to conduct a program evaluation of the effects of the crew chief program on postal employees in areas related to their experienced role stressors, job strain, job satisfaction, and company and union commitment. More specifically, I investigated whether mail processors showed improvement in these variables from baseline to one year after baseline, while controlling for facility location and shift and employee demographic characteristics. The second aim of this research was to replicate the stressor-strain-outcome model of stress and to extend the model by examining the main and moderating effects of mail processor perceptions of support from crew chiefs.

The hypotheses I developed to examine these research aims, and the analyses that I used to test them, were based on a systems perspective. General systems theory (Boulding, 1956) can be considered a form of inquiry that is concerned with emergent properties, where the "whole is greater than the sum of its parts." This is in contrast to traditional scientific epistemology, where knowledge is obtained by reducing phenomena to its component parts.

A multilevel perspective recognizes the importance of examining the properties of the whole as well as the parts themselves. Studying these properties, as well as the influence of the whole on its parts and the influence of the parts on the whole, provides a more comprehensive and complete picture of the phenomena under study than any one level by itself. Thus, the purpose "of the multilevel perspective in 
Introduction 6

organizational science is to identify principles that enable a more integrated understanding of phenomena that unfold across levels in an organization" (Kozlowski \& Klein, 2000, p. 7).

Although most major theories of organizational behavior view organizations as multilevel systems, the influence of these theories on organizational research have been mostly metaphorical (Kozlowski \& Klein, 2000), Most previous organizational research focused on just one level of analysis, usually the individual level. In contrast, the current research incorporates the multilevel nature of the context and analyzed data at multiple levels. The data for the proposed study were collected from individual employees who were nested within teams, or crews. The first research aim focuses on whether the crew chief program was successful in improving job attitudes and reducing stress, while taking into account the nested nature of the organization. The systems perspective that is reflected in the second aim is based on the interactions that are investigated. That is, rather than exclusively examining the relationships among parts of the system in isolation, I tested hypotheses that examine the effects of one part of the system on the relationships between other parts of the system. 
The U.S. Postal Service is one of the nation's largest civilian employers with over 800,000 employees (Norquist, 2003). In September of $1993,89 \%$ of the Postal Service's 691,723 employees were represented by unions (United States General Accounting Office [GAO], 1994b). These employees are referred to as "bargaining unit" or "craft" employees. Approximately $80 \%$ of craft employees are union members, with almost all (99.7\%) members belonging to one of four unions. The unions represent employees according to the nature of their work, also referred to as a craft line. The largest union, representing approximately $50 \%$ of craft employees, is the American Postal Workers Union (APWU). The craft lines represented by the APWU include clerks, maintenance workers, special delivery messengers, and motor vehicle operators. General managers, postmasters, and supervisors, which totaled 57,240 in September of 1993, are represented by three management associations. Although these associations cannot bargain with the Postal Service and do not have the right to file grievances, they are consulted by executive management and represent their member interests by lobbying Congress. An 11 member board of governors is responsible for running the Postal Service, which consists of nine governors, the Postmaster General, and the Deputy Postmaster General.

Postal field operations are organized according to two divisions: (1) mail processing and distribution and (2) customer service. Each division is further divided into 10 area offices. The ten area offices in the mail processing and distribution 
Background and Context 8

division oversee 271 processing and distribution centers, 21 bulk mail centers, and 60 airport mail centers. These facilities handled over 171 billion letters and parcels in 1993 that were collected and delivered by 39,392 Post Offices (GAO, 1994b). Mail processing centers operate on a three shift (also known as a tour), 24 hour a day, 7 day a week schedule to separate, sort, and transport mail between Post Offices. The processing and distribution facilities resemble large factories, using conveyors and machines to sort and route mail and parcels.

The work environment at these facilities resembles assembly line work in manufacturing industries, in that the tasks that make up the work are highly repetitive, there is a rigid and specific division of labor, and operations are closely monitored to ensure that schedules and budgets are met. Like many other unionized manufacturing settings, labor contracts outline the rules of work and most conflicts are resolved by a formal grievance-arbitration procedure.

Of the 221,300 craft employees these centers employed in September of 1993, 124,600 were clerks, which was the largest craft category of employees working in these facilities (GAO, 1994a; GAO, 1994b). Mail processing clerks operate the machines that sort the mail. The clerks process machine readable (non-handwritten), non-barcoded mail with a multi-line optical character reader (MLOCR). The MLOCR prints a barcode on the mail and is capable of handling 16 pieces of mail per second (Peoples, 1998). Once the mail is assigned a barcode, the mail is combined with prebarcoded mail that is sorted by zip code with bar code sorter (BCS) and delivery bar code sorter (DBCS) machines. These highly automated machines are capable of 
processing 32,000 pieces of mail per hour (Anthes, 1993). The main duties of the mail processor are to feed the mail into the machine and clear out the sorted mail. Handwritten mail and mail rejected by the machines are routed to letter-sorting machines (LSM), where mail processors read the address and enter a two or three digit code that designates the destination Post Office.

Supervisors at these facilities are responsible for checking attendance, assigning employees to specific work stations, ensuring that machines are programmed and ready to run, scheduling employee breaks, and determining whether overtime is needed to complete the required work. Supervisors are also responsible for making sure employees comply with contract terms and standard operating procedures, as well as enforcing safety regulations and disciplining employees. For the most part, union contracts prohibit employees from working outside their crafts, so they are usually assigned to the same work unit. However, some employees do not know what work they will be doing or who they will be working with until they report for work. This occurs when there is no work available in the employee's craft, in which case the supervisor can assign the employee to any available work at the employee's wage level. Union contracts also stipulate how craft employees should perform their jobs, work hours, pay and benefits compensation, assignment of overtime, and disciplinary procedures. 
Background and Context 10

\section{History of Labor-Management Problems}

Poor working conditions have been present at the Postal Service since the early $19^{\text {th }}$ century. According to an 1890 national survey, $90 \%$ of Post Office clerks worked an average of 14 hours a day (as cited in GAO, 1994b). Clerks worked in environments that were filthy and had polluted air, where tuberculosis was so common that it was referred to as "clerks' sickness." These poor working conditions led to postal workers becoming one of the first federal departments to unionize in large numbers. In the formative years of the early 1900 's, the postal unions focused on lobbying Congress to enact workplace improvements, since Congress was responsible for the USPS. However, this all began to change in 1962 with the issuance of Executive Order 10988, which granted unions representing federal employees the power of limited collective bargaining.

During the 1960's, the Post Office saw a dramatic increase in mail volume, increasing budget deficits, and frequent customer complaints of late deliveries. This culminated in the cessation of operations at the nation's largest Post Office in Chicago, a 13-story, 60 acre facility that was backlogged with over two weeks worth of mail. This event led to the creation of the President's Commission on Postal Organization, also known as the Kappel Commission, which was charged with determining whether the postal system was capable of adapting to the expanding population and economy. In June 1968, the Kappel Commission concluded that the postal system needed to be reorganized to remain viable. More specifically, the commission recommended that the Postal Service be replaced by a corporation owned 
by the federal government (The President's Commission on Postal Organization, 1968).

At that time, the postal unions were opposed to any reorganization of the Post Office, but President Nixon made compensation increases for postal employees contingent on Congress passing a bill to reorganize the Postal Service. This led to a strike by USPS employees in 1970 in which over 200,000 employees participated in a nine day work stoppage. At the time, this was the largest strike by federal employees in U.S. history.

In August of 1970, Congress passed the Postal Reorganization Act, which followed the recommendation of the Kappel Commission to establish the Postal Service as an independent entity charged with providing "prompt, reliable, and efficient mail service to the entire United States" (section 101, ๆ a). This act also instituted a labor relations framework that resembled those in private industries, where collective bargaining over compensation, working conditions, and formal grievance procedures was established, and regulated by the National Labor Relations Board. However, there are four important differences in labor relations in the Postal Service from labor relation systems in private corporations; (1) union membership is voluntary, (2) strikes are prohibited, (3) disagreements on collective bargaining are resolved with binding arbitration, and (4) associations that represent supervisors and management are consulted in decisions affecting them, although they do not have power to engage in collective bargaining (GAO, 1994b). 
Background and Context 12

Labor-Management Problems at the USPS as of 1994

At the national level, one indicator of the poor relationship between labor and management at the USPS has been the inability to resolve bargaining deadlocks without the assistance of an external arbitrator (GAO, 1994a; GAO, 1994b). National contracts are usually negotiated every three or four years, with three $(1978,1984$, and 1990) of the last five contracts (as of 1990) requiring interest arbitration. Interest arbitration is a process where an independent third party resolves disputes in the labor contract between the union and management. For the 1990 negotiations, it took three years and two arbitration hearings to resolve all the disagreements. The issues of disagreement also seem to reappear at each negotiation, with the unions demanding increases in compensation and job security and management seeking flexibility in employment practices (GAO, 1994b).

Another indicator of the poor labor relations that existed at the Postal Service is the large number of grievances that were filed and appealed, which both unions and management agreed was a problem. A grievance, as defined by the collective bargaining agreement, is "a dispute, difference, disagreement, or complaint between the parties related to wages, hours, and conditions of employment" (GAO, 1994b, p. 32). Grievances are handled through either a 4 or 5 (for those involving interpretation of the national agreement) step process. The last step for any grievance is binding arbitration, where the decision by an independent third party after considering the facts of a grievance case must be accepted by all parties involved. As of 1993, the inability of management and the unions to resolve grievances before reaching arbitration has 
Background and Context 13

caused anywhere from a 228 day backlog in one region to nearly a 2 year wait in another region (GAO, 1994a, 1994c). In contrast, only 1,000 grievances were not resolved at the plant level for the 800,000 members of the United Auto Workers (Stamps, 1996).

The high volume of grievances was costly to the USPS. The estimated cost for processing grievances in 1992 was $\$ 197$ million and more than \$253 million in 1993 (GAO, 1994b). The inefficiency of the system also could have had a negative effect on employee attitudes, such that they may have perceived this avenue for voice as being essentially ineffective (Cappelli \& Chauvin, 1991; Klaas, 1989; Klaas, Heneman, \& Olson, 1991). The perceived loss of voice may have lead to counterproductive behaviors, such as increased turnover and absenteeism, and lead to reduced work effort. The Postal Service management blamed the high number of grievances on the unions' desire to bring attention to a particular issue and to demonstrate that the union was "working" for the employees. The unions believed that the backlog existed because management at lower levels was unwilling to settle disputes and just "passed the buck" (Brooks, 2001; GAO, 1994b).

Another reason for the poor state of labor-management relations had to do with the autocratic organizational culture, acknowledged by both the unions and top Postal Service management (GAO, 1994a, 1994b, 1994c). This culture was manifested by an authoritarian management style that had been cultivated and maintained through the Postal Service's history. In fact, the management style of the USPS has often been compared to the rigid, hierarchical style of the military (Anonymous, 1993). New 
supervisors tended to treat employees the way they were treated, which usually involved motivating employees via punitive actions and an almost exclusive focus on meeting the "numbers" rather than human relations. This was further reinforced by the lack of training in human relations skills when employees became supervisors (Stamps, 1996; GAO, 1994b).

The physical and economic environment of these facilities also contributed to the maintenance of an autocratic culture (GAO, 1994c). Many supervisors claimed that the high noise levels at the mail processing plants required them to raise their voices to communicate to their employees. Supervisors also stated that there was limited time to meet with employees about their concerns because of the timesensitive nature of the work (GAO, 1994c).

To better understand the strengths and weaknesses of the Postal Service as viewed by employees, the USPS sponsored a questionnaire known as the employee opinion survey (EOS), which was intended to be given every year, beginning in 1992. The USPS intended to use this information to identify sources of labor-management problems and formulate solutions to deal with those problems. In 1992, over 586,000 employees returned the questionnaire for an overall response rate of $80 \%$. In general, the results indicated that employees were satisfied with their compensation and were proud to work for the Postal Service, but were dissatisfied by the way they were treated by management (GAO, 1994b, 1994c). More specifically, the EOS of 1992 
indicated that employees had less than $25 \%$ favorable ratings (combined very good/good) on the following five items from the EOS index ${ }^{1}$ :

Postal service management...

1) Treats employees with respect and dignity. (21\%)

2) Takes employee interests into account when making important decisions. $(13 \%)$

3) Listens to your problems, complaints, and ideas. (16\%)

4) Does something about your problems, complaints and ideas. (16\%)

5) When things go well on the job, how often is your contribution recognized. $(13 \%)$

Further, the results indicated that the mail processing division had much less favorable ratings of the Postal Service management than the customer service division, and that craft employees were less positive than non-craft employees (GAO, 1994b).

An analysis of labor-management relations at the mail processing plants by the United States General Accounting Office (GAO, 1994a, 1994b, 1994c) found that there were three main sources of dissatisfaction: (1) accountability of employee performance, (2) reactions of management to employee absences, and (3) lack of employee participation in determining how to carry out their work. Failure to hold poor performing employees accountable was cited by both employees and supervisors as a source of tension between management and labor. Most employees ( $83 \%)$ believed that "some do most of the work while others do just enough to get by" (GAO,

\footnotetext{
${ }^{1}$ This index is the mean of select items that the Postal Service believes is under the control of unit
} 
1994b, p. 64). Many supervisors reported that it was almost impossible for them to fire an ineffective employee. Since there was no formal performance appraisal process for employees, supervisors had to resort to taking disciplinary action to address poor performance. However, there was almost always a grievance filed for every disciplinary action, causing many cases to be overturned at higher levels of the grievance process to avoid arbitration costs. Interestingly, the GAO report of the EOS results stated that employees seemed to resent management's lack of action against poor performers, in that they felt that the retention of poor performers created more work for everyone else and decreased workplace safety, which in turn caused employees much stress. Employees also believed that the Postal Service tolerated poor performance from supervisors (GAO, 1994b; GAO, 1994c). Finally, according to the GAO report on the EOS, employees believed that they were not rewarded for good performance. In fact, a majority believed that performing well just led to more work. They also did not view promotional opportunities as a performance reward because the most important criteria for advancement in the Postal Service is seniority.

Despite the fact that mail processing operations are highly automated, adequate staffing is critical for the machines to operate effectively. Thus, employee absences can have a detrimental effect on the ability of the Postal Service to process and deliver mail in a timely manner. Because of the pressure for management at these facilities to meet schedule requirements, supervisors were overly strict and harsh with employees who took unscheduled leave, even though the reasons for the leave may have been 
legitimate. In fact, most grievances filed by employees dealt with attendance related issues. This behavior by supervisors had a negative effect on employee morale and reinforced a perception by employees that management did not care about them (GAO, 1994b).

Another source of the poor labor-management relations at mail processing facilities was the perception shared by many employees, as indicated by the EOS and the findings of the GAO report, that management did not value employee input in how employees performed their work and that supervisors did not treat employees with dignity and respect. According to interviews with management and supervisors, some acknowledged that there were supervisors with inadequate social skills who have embarrassed employees by correcting them, or even belittling them in front of their peers. Some of the comments made by employees and supervisors on the 1992 EOS survey illustrate these concerns (as cited in GAO, 1994b):

As a supervisor...I felt that middle management...wanted line supervisors to harass employees and initiate discipline even when they knew it was not in compliance with the National Agreement.

Management seems to be more concerned with harassing and disciplining employees than with actually accomplishing the real objectives of the Postal Service.

Management has a "black-list" of employees they don't like and go out of their way to make life hard for these people. These "examples" of what can be done to "bad" employees may keep the rest of us in line but they destroy morale.

Management fails to treat employees with dignity, not giving employees respect and consideration. Employees feel that there is no concern for their working conditions or morale. They are not given credit, only criticism... 
These issues also surfaced in the 1993 postal violence focus group meetings. These meetings were a forum for employees to express their concerns and feelings on workplace safety following the shootings at postal installations in Dearborn, MI and Dana Point, CA. Further, the GAO (1994a, 1994b) found communication between employees and supervisors to be extremely poor. Supervisors viewed most employees as not taking their work seriously and believed that employees did not feel responsible for their work. However, employees felt they should be given more input since they were most familiar with how to solve the work problems in their area. Here are some of the employee comments from the 1992 EOS on this issue (as cited in GAO, 1994b):

Employees are micro-managed to the point that they lose interest in doing a better job or making any decisions.

I feel that upper management has a big ego and that they feel that any suggestions by craft are less than desirable.

Employees have ideas, since we do the same work everyday. We know the problems of our work area. We should have more input in the running of operations.

Supervisors do not accept that tasks can be done differently and still be correct.

\section{Crew Chief Initiative}

Given the potential detrimental impact that poor labor-management relations can have on the continued existence of the Postal Service, both management and the union recognized that steps needed to be taken to improve relations. One such initiative was the crew chief program, which would allow employees to accomplish their work with less supervision. This program was first suggested by the APWU during the discussions of the 1990 collective bargaining agreement, as the APWU was 
concerned with the growing ratio of supervisors to clerks and believed that empowering clerks to reorganize how their work is performed would be one effective strategy for improving labor relations (Martin, 2001).

The crew chief initiative was developed as a formal pilot program outlined by a June 1991 Memorandum of Understanding between the APWU and the USPS (Martin, 2001). The crew chiefs were craft employees who were responsible for selected duties, usually those which were more interpersonally-based (e.g., delegation of tasks, informal feedback on task performance), that were previously performed, albeit poorly from the employees' perspective, by the supervisor. Crew chiefs were also responsible for directing crew members, delegating work assignments, providing administrative support, and scheduling overtime. Unlike supervisors, they were allowed to work with other employees in accomplishing their work. The crew chief initiative was inspired by similar successful programs in some private sector organizations, such as American Airlines and Auto Alliance (Mazda) (Babson, 1993; 1995; Luby, 1995 as cited in Martin, 2001). Proponents of the crew chief program also believed that employees would feel more comfortable taking instructions and expressing concerns to a crew chief, who is "one of them," rather than supervisors. However, supervisors would still be responsible for approving leave and taking disciplinary action.

To evaluate this program, the APWU contracted with James E. Martin, Ph.D., who is a professor at the School of Business Administration at Wayne State University and is a specialist in labor-relations research. Crew chief trials were established in six 
automated mail Processing and Distribution Centers in various parts of the country. Control trials were established at three Processing and Distribution centers. Dr. Martin and his research team collected data concerning job and supervisory satisfaction, company and union commitment, role stressors, job strain, and employee perceptions of supervisors and crew chiefs. Data on these variables were collected at baseline and one year after implementation at both experimental and control sites, and data on attitudes toward the crew chief were collected one year after implementation at the experimental sites. After collecting the Time 2 data from each site, the APWU and USPS met to "decide whether the program should be expanded, remain at status quo, or be terminated due to lack of success in relation to the parties' goals of greater opportunity for craft employees and improved efficiency for the USPS" (Collective Bargaining Agreement Between APWU, AFL-CIO and USPS, 1991: 138-139 as cited in Martin, 2001). The details of the procedure for collecting the evaluation data are presented in Chapter 6.

The USPS provided a research setting that is an appropriate and unique context for examining my research questions. The crew chief program was a jointly sponsored initiative by the union and management in an effort to end the poor labor relations that have plagued the USPS. The quasi-experimental nature of the research design allowed stronger causal inferences to be made on the effectiveness of the crew chief program, which is in essence a form of an autonomous, self-managed work team, to improve labor relations, job and supervisory satisfaction, company and union commitment. The incorporation of variables at the individual and group levels allowed for assessing the 
role both levels play in shaping the attitudes of mail processors. Finally, the current context allowed for the examination on how effective an empowering form of organizational redesign was as an intervention for reducing stress and strain at the workplace that resulted from poor relations between labor and management.

The review of the literature is divided into three chapters. Chapter 3 begins with a discussion on employee involvement and empowerment, and how these concepts form the framework upon which the crew chief program was based. That is, the potential benefits of the crew chief program are believed to arise from giving employees more control over their work. The chapter then proceeds to discuss the central role immediate supervisors play in employees' work lives through the quality of their relationships with employees. Chapter 4 focuses on the job attitudes that are the outcomes of interest in this study, including job satisfaction, company commitment, and union commitment, and explains the reasoning why the crew chief program was expected to improve these outcomes. Chapter 5 contains the review of the literature on job stress, and discusses the components of the stressor-strainoutcome model that comprise the hypotheses for the second aim of the study. The chapter concludes with a discussion of stress interventions and makes the case that the crew chief intervention may also be considered a stress intervention at the organizational level. 
Chapter 3. Empowerment, Self-Managed Work Teams, and LeaderSubordinate Relations

\section{Employee Involvement/Empowerment}

Power is important in organizational life because those who have power are more likely to obtain valued outcomes than those with less power (Conger \& Kanungo, 1988). Power is also important for individuals who have a strong internal need to control their environment (i.e., internal locus of control (Rotter, 1966)). When employees believe they have inadequate power, they may not be able to perform their work as well. If employees feel that desired outcomes are not a result of their effort and behavior, then their work motivation will be reduced (Vroom, 1964). Lowered motivation will lead to less effort on the job, which leads to poorer performance. Because having a lack of power is undesirable for many employees, they may engage in behaviors that increase their levels of perceived power, and some of those behaviors may be detrimental to the organization. For example, employees may take more frequent and/or longer breaks during their work shift to increase their perceived power. Thus, in an effort to avoid employee performance decrements and avoid negative employee behaviors to increase perceived power, many organizations in recent years have taken steps to ensure that their employees feel they have adequate power to perform their jobs and meet their goals (Conger \& Kanungo, 1988).

Empowerment is defined as a "process of enhancing feelings of self-efficacy among organizational members through the identification of conditions that foster powerlessness and through their removal by both formal organizational practices and 
by informal techniques of providing efficacy information" (Conger \& Kanungo, 1988, p 474). The primary goals of empowerment programs are usually to simultaneously increase decision making at lower levels of the organization and enrich employees' lives, which provide benefits to both the employee and the organization (Elmuti, 1997; Leana, Ahlbrandt, \& Murrell, 1992; Liden, Wayne, \& Sparrowe, 2000). Employee involvement initiatives are an important means that organizations use to increase empowerment.

Employee involvement initiatives aim to increase the sharing of power between management and employees (Spreitzer \& Kizilos, 1997). Involving employees in making work decisions usually made by management is intrinsically rewarding to employees in that it engenders a sense of ownership of the employees' work, provides employees with opportunities to better understand and improve their work, and allows employees to better understand management's perspective on business operations (Leana et al., 1992; Miller \& Monge, 1986). Employee involvement programs have been found to have a positive effect on employee job satisfaction and performance (Alutto \& Acito, 1974; Cotton, Vollrath, Froggatt, Lengnick-Hall, \& Jennings, 1988; Graham \& Verma, 1991; Miller \& Monge, 1986; Pun, Chin, \& Gill, 2001; Wagner, 1994; Wagner \& Gooding, 1987). Because of its potential benefits, many organizations now use some form of employee involvement (Lawler, Mohrman, \& Ledford, 1992 as cited in Tesluk, Vance, \& Mathieu, 1999). The context at the time the USPS was considering change made the USPS a good candidate for the implementation of employee involvement programs to increase 
empowerment. Block (1987) argued that bureaucratic organizations with an authoritarian culture like the USPS inherently foster powerlessness. This occurs because these organizations are less likely to provide employees with control and discretion about how they perform their work and are more likely to create dependency on management for achieving desired goals. Not surprisingly, these contexts are ripe for adversarial relations between labor and management, where labor attempts to gain power and control through contentious collective bargaining negotiations. Thus, by empowering employees, the USPS should benefit by easing tensions between labor and management by sharing power with employees, which will hopefully in turn establish a more cooperative culture to meet future environmental demands.

\section{Teamwork and Empowerment}

Teamwork is one of the more commonly used interventions for improving group performance in organizations (Guzzo \& Dickson, 1996; Porras \& Berg, 1978).

One form of teamwork that is based on employee involvement is the use of selfdirected, or self-managed, work teams (Elmuti, 1997; Kirkman \& Shapiro, 2001; Randolph, 2000). Self-managed work teams (SMWT) usually take over traditional supervisory processes such as planning, organizing, directing, and staffing (Kirkman \& Shapiro, 2001; Kulisch \& Banner, 1993) and represents an effective form of participative management (Harris, 1992). SMWT allows the team, rather than one supervisor, to deal with the problems encountered during work (Harris, 1992). 
Empowerment 25

Although the use of self-directed teams is currently very popular and on the rise, there is relatively little empirical knowledge concerning the effects of these teams on employee attitudes (Elmuti, 1997). Also, much of the research on employee involvement has not been conducted in the public sector (Kahnweiler \& Thompson, 2000). Thus, one of the purposes of this study is to contribute to the literature in these important areas.

Based on his review of the literature on SMWTs, Harris (1992) concluded that there are seven consistent benefits of SMWTs when implemented properly. First, SMWTs lead to an improvement in work methods. Employees can use their extensive knowledge of the job to develop more productive and safer ways to accomplish their work. Second, SMWTs lead to the increased attraction and retention of quality employees. Potential employees will be more likely to accept a position and current employees are more likely to stay when autonomy is high, based on the assumption that employees prefer to work in an autonomous work environment. Third, implementing SMWTs results in increased staffing flexibility. This occurs because SMWTs usually involve the cross training of team members on other members' tasks and duties. In the case of the USPS, flexibility is achieved by rotating crew members to form crews that meet the daily needs of the processing facility. Fourth and fifth, service and product quality and productivity improve as a result of improved work methods discussed above and increased work motivation to perform well. Sixth, SMWTs results in better decision-making. This is based on the assumption that employees who have the most job knowledge have better information on which to 
Empowerment 26

base work decisions on compared to supervisors who are not as familiar with actual operations. Finally, with SMWTs there is a reduced need of supervision and staff support. This is because teams manage themselves by taking on many of the traditional duties of the supervisor and support staff, and thus there is less need for these formal positions.

Evidence for SMWT's Positive Effects on Organizational Effectiveness and Employee Quality of Work Life

Whirlpool implemented a SMWT initiative similar to that of the USPS's crew chief program at Whirlpool's factory in Oxford, Mississippi, such that teams were responsible for performing their work without direct supervision. The 445 employees at the Whirlpool plant were organized into teams of ten to fifteen people. Each team assigned a leader for each of the following five areas: (1) overall policy and procedures for the group, (2) hiring and disciplining of peers, (3) maintaining the work area, (4) tracking team finances and other logistical concerns, and (5) monitoring production. The unit manager was responsible for approving the dismissal of employees. Unlike the USPS's crew chief program, the front line supervisor position at the Whirlpool plant was eliminated. Four former supervisors were retained as team trainers for the plant. Since implementing the program, Whirlpool has reported that its teams consistently find more efficient ways of operating (Sandelands, 1994).

As discussed above, the number of grievances filed by USPS employees represented a tremendous cost and continuing source of conflict. One of the goals of the crew chief program was to reduce the number of grievances filed, and there was 
precedence for the expectation that the crew chief program would be successful in this regard. For example, Harris (1992) reported that after seven years of using SMWTs, General Motors realized a reduction in grievances from 2,000 a year to just 32 ! Moses and Stahelski (1999) conducted a study to determine whether the implementation of problem solving teams, which usually consist of voluntary members whose primary goal is to study and recommend solutions to problems affecting their work, would improve objective productivity at a large aluminum manufacturing plant. Similar to the design of the crew chief program, these teams were led by one of the employees who also had supervisory responsibilities on the factory floor. Using a single group, reversal design, with 1982 to 1986 data as the initial baseline (no teams), 1988 to mid-1993 as the initial implementation period (teams), mid-1993 to mid-1994 as the withdrawal of teams as a result of budgetary constraints (no teams), and mid-1994 to 1997 as a continuation of teams, the authors found significant improvements in five different measures of productivity in the two time periods that used teams compared to that of the initial time periods before the existence of teams, even after ruling out the effects of technology, the fluctuating price of finished aluminum during the study period, and differences in the number of employees throughout the study period. The authors did not find significant differences between the withdrawal period and the time periods that had teams. The authors explain this finding by suggesting that the team mentality became embedded in the culture. In fact, the authors revealed that many of the teams continued to meet informally during the withdrawal period. Although other confounds may exist given 
that there was no control group, the results of this study demonstrate that self-directed teams not only have a positive impact on employee attitudes, but can also have a positive effect on objective indicators of performance.

In another study that examined the effects of SMWTs on productivity, Wellins (1995) reported that Texas Instruments realized a 50\% decrease in product cycle time, a $60 \%$ reduction in waste, and a $30 \%$ increase in productivity after implementing SMWTs. Researchers also have found SMWTs to be positively associated with job satisfaction (Cordery, Mueller, \& Smith, 1991; Wall, Kemp, Jackson, \& Clegg, 1986), organizational commitment (Cordery et al., 1991), and performance (S. G. Cohen \& Ledford, 1994). In sum, much of the research on SMWTs has shown that SMWTs are associated with positive organizational outcomes.

Belanger, Edwards, and Wright (2003) reported a case study examining the impact of the implementation of a teamwork initiative at a Canadian aluminum smelter. The situation at this facility was similar to that of the USPS in that the initiative had the support of the union and management, took place in a factory setting, and involved a move away from a traditional command and control hierarchy. Although the initiative differs from the crew chief program in that there was no assigned team leader, the fact that the team was given increases responsibility for making production related decisions is a key similarity. The following discusses some of the findings from the Belanger et al. (2003) study that shed light on why the crew chief initiative is likely to be successful at the USPS. 
When employees of the plant in the study discussed above were asked whether the absence of supervision had any drawbacks, many reported that it was not a problem and exclaimed that they [the employees] "know what needs to be done!" (Belanger et al., 2003, p. 242). Belanger et al. also suggested that the introduction of modern process technology to the plant contributed to the success of the program because of the high degree of automation and the information provided by the systems. In effect, employees became the "supervisors" by monitoring the machine "workers," and supervisors relied on the data generated by the systems for productivity and other work-related information. The implementation of self-directed teamwork at this plant shifted managerial control from the level of work execution to a higher level of conceptualization and monitoring of production (Belanger et al., 2003). The environment of the USPS was similar in this regard in that it had modernized its machines for sorting and processing mail, thus increasing the degree of automation.

Belanger et al. (2003) also concluded that the union played a key role in the plant's success in using self-directed teams. By comparing their study with other similar studies, they concluded that plants with union support were more likely to succeed in using teams. In the present research, the APWU was a strong supporter and originator of the crew chief program. Thus, I expected the APWU's support of the crew chief program would increase the probability that the crew chief program would be successful.

Another important finding of the Belanger et al. (2003) study that informs the present research concerns work team members' attitudes toward their newly assigned 
Empowerment 30

responsibilities. Work team members were dissatisfied with the more administrative duties, such as following up with health and safety regulation reports and administering a limited budget. They continued to view these as managerial responsibilities and were more interested in those activities that were directly related to their work. In the present study, crew chiefs were responsible for the day-to-day operations and interpersonal issues on the workroom floor, while supervisors maintained responsibility of administrative and disciplinary duties. In summary, Belanger et al. (2003) highlighted what appeared to be some fundamental characteristics for a successful empowerment intervention. Providing employees with the ability to determine how the work is done while leaving the responsibility of administrative decisions to management, as well as having strong union support, are key ingredients for a meaningful empowerment initiative. These characteristics are also present in the USPS crew chief program. Belanger et al.'s findings, along with the strong similarity in the context of the plants that they studied and that of the USPS, suggests that the crew chief program should have been successful in positively affecting outcomes.

According to the results of a survey of team members and managers in organizations that use self-managed work teams conducted by the Association of Quality and Participation, Development Dimensions International, and Industry Week, Kulisch and Banner (1993) reported that the top three benefits indicated by team members were increased team involvement and performance, sense of ownership over their work, and commitment to their work. Participating managers reported that self- 
Empowerment 31

managed work teams resulted in improved quality, productivity, and morale. Barriers to team success included lack of training, incompatible human resource systems (e.g., compensation for individual performance in a team environment), and lack of union support.

In summary, previous research demonstrates that SMWT's should not be regarded as just another management "fad," as this form of teamwork has delivered consistent benefits to both organizations and employees in contexts that resemble the USPS setting. However, the crew chief program is not a "pure" form of SMWT. A pure SMWT is by definition leaderless, in that the group as a whole is responsible for making all operational and administrative decisions. In the crew chief program, teams are led by a designated leader, the crew chief. Thus, only crew chiefs, and not other mail processors, can be considered directly empowered, whereas with a SMWT all team members are directly empowered. It is important to note that in my review of the literature on SMWTs that leaderless SMWTs seemed to be the exception rather than the rule. Most of the studies that empirically examined SMWTs were SMWTs with a designated leader and/or coordinator, and are noted in my discussion of the relevant studies in this chapter. The SMWTs employed in much of the research reviewed and the USPS crews share many characteristics that are central to creating a sense of empowerment in employees. Thus, the crew chief program should deliver many of the same benefits as SMWT's have in other organizations. 
The Role of Formal Supervisors in SMWT and the Importance of Supervisor Support

Supervisory effectiveness is critical in large, complex organizations

(Donaldson \& Hilmer, 1998). When implementing empowerment initiatives that lead to a reduction in the number of managers or the scope of managerial authority, organizations must be careful to not undermine supervisory effectiveness (Elmuti, 1997). Organizations that become too flat can lose the ability to grow effectively because the increased number of tasks and duties required by employees may induce employees to be overly concerned with the issues of the present rather than planning for the future (Donaldson \& Hilmer, 1998). Thus, it is important to balance tactical responsibilities of day-to-day operations with the strategic responsibilities of how operations should proceed in the future.

Considering the time sensitive nature of the USPS's services and personnel requirements for maintaining its operations, it was important that current supervisory positions were not eliminated. Crew chiefs were still required to process mail while they performed their supervisory duties. Taking on the full spectrum of supervisory duties would have prevented crew chiefs from processing mail effectively. In fact, the crew chief program allowed supervisors to focus more attention on administrative matters, which hopefully led to increased productivity in this area. Crew chiefs were expected to focus on the interpersonal aspects and day-to-day management on how the work was performed. In fact, the separation of these broad duties into specialized positions was implemented to prevent the potential problem of crew chiefs feeling pressured to avoid dealing with punitive administrative decisions, such as terminating 
an employee. This separation also should have preserved the autonomy of nonsupervisory employees by eliminating the threat of a co-opting of the union by management (Davis \& West, 1979). That is, mail processors should have been less likely to perceive crew chiefs as part of management if crew chiefs were not involved with making administrative decisions, particularly those with negative consequences. This strategy of partitioning the responsibility for operations on the work floor from administrative duties should have allowed the work group to be empowered while at the same time preserving a management structure that maintained the boundary conditions for these self-directed teams. The crew chiefs and mail processors were empowered because they were allowed to make decisions regarding day-to-day operations while supervisors were responsible for aligning the overall goals of the crews with the USPS and administrative decisions regarding crew chiefs and mail processors. This division of supervisory labor has been found to be desirable by employees in a similar setting, as is evident in the findings of Belanger et al. (2003) study discussed previously. However, it is still important to acknowledge that with the introduction of any team system, supervision necessarily plays a lesser role (Kerr, Hill, \& Broedling, 1986).

Supervisor support is key to the successful implementation of employee involvement programs such as SMWTs. Pun et al. (2001) found management's commitment to employee involvement programs to be a critical factor in the successful adoption of employee involvement. Thus, it is critical that supervisors not perceive that they will no longer be useful and potentially let go, or that they will lose 
all of their power and status in the organization (Kulisch \& Banner, 1993; Pun et al., 2001). In fact, resistance from middle management is one of the most commonly cited impediments to successfully implementing employee involvement programs (Klein, 1984; Lawler \& Mohrman, 1987). For example, Klein (1984), reporting data from 139 first-line supervisors at eight manufacturing plants, found that $72 \%$ of supervisors believed that employee involvement programs were beneficial to the company and $60 \%$ of supervisors believed that the programs benefited employees, while only $31 \%$ of supervisors believed that these programs would benefit supervisors themselves. There is much potential for supervisor resistance to have occurred at the USPS because the association ${ }^{2}$ representing the interests of middle management viewed the initiative as a threat to supervisors' job security. Thus, it was important to communicate that although crew chiefs would assume some supervisory responsibilities, it was a separate position with a different focus and presented no threat to supervisors' job security.

Another important factor for the success of empowerment efforts is management's willingness to share power (Gomez \& Rosen, 2001). The willingness to share power sends a message to employees that management is willing to trust them, which can initiate a positive feedback loop that further increases trust between management and employees. This sharing of power, as discussed previously, should also provide supervisors with more time to focus on strategic tasks.

\footnotetext{
${ }^{2}$ As discussed in the previous chapter, these associations perform similar functions to unions except that the association cannot engage in collective bargaining.
} 


\section{Employee Involvement Programs and Organizational Climate}

Although all employees at the experimental sites in the proposed study participated in this empowerment initiative, individual employees' motivation and interest are important factors to the success of the program. Uninterested employees may be more difficult to deal with in a team setting, in that they may not be interested in assuming more responsibility, thus forcing interested employees to bear more of the load. Another possibility is that employees may view the intervention as yet another "fad" that will come and go (Elmuti, 1997). However, some research suggests that there is strong interest in participation initiatives by workers in blue collar industries (Kochan, Katz, \& Mower, 1984). For instance, in a study using a representative sample of wage and salaried employees across the United States from the 1977 Quality of Employment Survey, which collected data on variables such as demographic variables, job characteristics, job satisfaction, union support and attitudes toward participation, Fenwick and Olson (1986) found union membership explained the most variance in participation attitudes. They explained this finding by using what they called the "underdog principle" of distributive justice, in that those with the least amount of resources are more likely to support initiatives that equalize the distribution of power. Since unions represent a model of participation where workers have control, members are likely to support organizational changes that expand their control.

Leana et al. (1992) examined the effects of a worker involvement program on organization and union attitudes, comparing employees who participated, did not participate, and who did not participate but would like to participate in the future. 
Interestingly, they found that the most positive attitudes, such as job satisfaction, job involvement, organizational commitment, and union satisfaction were held by the group who did not participate but wanted to participate in the future. This suggests that it may be interest in the program, rather than actual participation, that is important for understanding differences in company and union attitudes (Leana et al., 1992). Also, participants in the program did not believe that their perceived influence in decision making increased as a result of the program, implying that the program may not have achieved its intended effects. Similarly, Fields and Thacker (1992) found a moderator effect that provides evidence for the effects of employee perceived effectiveness of the initiative, such that they found positive effects for participation initiatives when participants believed the program "worked."

Leana et al. were not able to ascertain whether there were differences across time among the three groups, as data were collected at only one time point after program implementation. Without baseline data, it is impossible to ascertain whether the groups were similar in job attitudes before program implementation; thus, it is unknown whether the program actually changed employee attitudes. The proposed study differs from Leana et al.'s study in that participation was only voluntary if one wanted to become a crew chief, but not in choosing whether to be part of a work team that involved a crew chief.

Shadur, Kienzle, and Rodwell (1999) found that a supportive organizational climate was positively related to employee perceptions of involvement, even after controlling for organizational commitment, perceptions of stress, and job satisfaction. 
The effects held across three different types of participation: degree of decision making, teamwork, and communications. The authors concluded that the culture and climate of the organization need to be taken into account when designing and implementing interventions to increase employee involvement. More supportive environments are more likely to foster perceptions of involvement. The crew chief program seeks to change the climate by providing more interpersonal support to employees via the crew chief. Also, support for the initiative from the supervisor is important for the success of this intervention given that as agents of the organization, supervisors convey to employees the degree of support for change by the larger organization (Kozlowski \& Doherty, 1989).

A qualitative study by Vallas (2003) also supports the importance of the climate being commensurate with the change initiative in order for change to be successful. Vallas (2003) investigated the impact of the implementation of a SMWT initiative at four manufacturing plants in the 1990's. The myopic focus on the production outcomes by management at these plants resulted in a climate that was incompatible with the use of SMWTs. For example, management's focus on standardization did not allow teams to make decisions independent of standard operating procedures. Because of this incompatibility, labor-management relations at these plants continued to be strained after the initiative was implemented as workers felt frustrated and betrayed, and the promised benefits of the SMWTs never materialized. However, it is worth noting that one plant was successful; this plant had more autonomy from central corporate control and allowed participation by the union. 
Empowerment 38

The union found that its participation actually led to greater employee involvement in union affairs, and management felt that the program was successful in rebuilding worker trust. The results of this study not only demonstrate that the climate needs to be commensurate with the nature of the intervention, but that participation by the union may be important to the success of organizational change initiatives. This will be discussed in more detail in the next chapter.

Tesluk et al. (1999) took a systems approach in examining the effects of climate on perceptions of participatory involvement. The setting of their research was a state department of transportation with 12,000 employees, organized into to 11 districts and 88 units. Data were collected at each of these three levels: individual ( $n=$ $483)$, unit $(n=88)$, and district $(n=11)$. The authors examined the cross-level effects of higher-level attitudes toward participation on outcomes such as job satisfaction and organizational commitment. What the authors found amounts to a cascading effect of support, such that support at the district level was associated with support for employee involvement at the unit level. The authors also found district climate to be positively related to organizational commitment, even after controlling for unit climate, and found unit climate to be positively related to job satisfaction, even after controlling for district climate. Both unit and district climate were uniquely predictive of employee participation in program activities. Tesluk et al. also found an interaction effect such that employees were most active when they were in highly supportive units in highly supportive districts. Interactions of unit climate with district climate were also found for predicting extrinsic job satisfaction and the belief that organization 
improvements were possible, such that a participative district climate buffered the effect of a poor unit climate on these outcomes. Thus, the overall results of this study demonstrate the importance of taking into account variables at multiple levels of analysis, as this strategy provides a more holistic view of the impact of unit climate on individual attitudes. Two methodological weaknesses of this study included the crosssectional nature of the data and the use of cross-level multiple regressions to analyze the data. Using multiple regression in evaluating variables at multiple levels of analysis fails to account for shared error variance within groups, which violates the independence of errors assumption required for multiple regression.

In summary, the crew chief program is a form of SMWT, which is a teamwork initiative focusing on building employee empowerment. The preceding literature review on the impact of employee involvement programs on valued organizational outcomes demonstrated that SMWTs are consistently associated with improved employee attitudes and organizational performance. However, the empirical research in this area remains sparse, particularly with public sector organizations that are usually more bureaucratic and employ individuals who have different characteristics than their counterparts in the private sector.

The current study contributes to this literature by evaluating the impact of the crew chief program on outcomes of value to the organization and employees. In this section, I described the unique aspects of the crew chief program compared to other SMWT initiatives, most importantly the retention of the formal supervisor that has authority over administrative decisions. My review of the literature in this area 
suggests that retaining supervisors should have facilitated the implementation of the crew chief program by allowing crew chiefs to focus on the more interpersonal and operational aspects of supervisory responsibilities. Finally, I reviewed the literature concerning the contexts in which employee involvement initiatives take place and discussed those characteristics of the environment at the USPS that are expected to be associated with successful implementation of the crew chief program. The remainder of this chapter focuses on the process by which the crew chief program is expected to affect employee attitudes.

\section{Social Exchange Processes}

Social exchange theory posits that many relationships in life are governed by principles of reciprocity (Blau, 1964). Exchanges that are social in nature are based on a trust that gestures of goodwill will be reciprocated at some point in the future. Reciprocation occurs because recipients of positive actions experience a sense of indebtedness that is aversive and that may be reduced through reciprocation. Employees tend to take a long term approach to social exchange relationships at work, with the pattern of reciprocity over time determining the perceived balance in exchanges (Wayne, Shore, \& Liden, 1997). In general, social exchange theory suggests that beneficial actions directed at employees by the organization and/or its representatives contribute to the establishment of high-quality exchange relationships and create obligations for employees to reciprocate in a positive manner. The two main ways that social exchange processes have been conceptualized in the literature is 
that between organization and member (perceived organizational support), and member and leader (LMX).

Given the hierarchical structure of most organizations, supervisors represent some of the most influential individuals in employees` work lives (Dienesch \& Liden, 1986; Kozlowski \& Doherty, 1989). The relationship an employee develops with his or her supervisor will determine to a large degree his or her role within his or her work unit and organization (Dienesch \& Liden, 1986). Deci, Connell, and Ryan (1989) argue that the supervisor plays a crucial role in establishing an empowerment climate. Thus, it is not surprising that the quality of the relationship between the supervisor and his/her employees has an important impact on employee attitudes and organizational outcomes.

\section{Leader-Member Exchange (LMX)}

Leader-Member Exchange (LMX) developed out of Vertical Dyad Linkage theory (Dansereau, Cashman, \& Graen, 1973; Dansereau, Graen, \& Haga, 1975) and is a departure from the Average Leadership Style (ALS) approach (Dienesch \& Liden, 1986). The ALS approach contends that leaders behave in a consistent manner toward all their subordinates, and thus focuses on identifying general patterns of leader behavior and linking them to outcomes. Thus, deviations in employee perceptions of leadership style are considered error variance rather than true differences (Dienesch \& Liden, 1986). The essential premise of LMX is that leaders develop differential relationships with subordinates over time through a series of exchanges. These 
Empowerment 42

exchanges result in differential relationships such that the leader develops stronger relationships with some employees (in-group) than with other employees (out-group) (Dansereau et al., 1975). A high-quality LMX relationship consists of mutual trust, loyalty, and going beyond the call of duty for the supervisor, while employees in a low-quality LMX relationship do the minimum that is required of them (Brower, Schoorman, \& Tan, 2000).

\section{Leader-Member Relationship Quality and Supervisor Support}

A key tenet of social exchange theory, which also applies to its derivative $\mathrm{LMX}$, is that reciprocity is fundamental to maintaining high-quality relationships (Blau, 1964). In LMX relationships, one benefit the leader provides is support. Supervisor support is the extent to which supervisors provide encouragement and assistance to their subordinates (Griffin, Patterson, \& West, 2001). The following discussion describes the outcomes of perceived supervisor support and the quality of relationships between supervisors and employees found in the literature.

In a panel design study of 314 alumni of a Belgium university employed in a variety of jobs, Eisenberger, Stinglhamber, Vandenberghe, Sucharski, and Rhoades (2002) examined the relationships between perceived organizational support and perceived supervisor support. Perceived organizational support can be considered the organization's commitment to the employee (Eisenberger, Huntington, Hutchison, \& Sowa, 1986). Perceived organizational support develops from the personification of the organization, which is represented by the accumulation over time of rewards and 
punishments the employee has received from other more powerful organizational members (Eisenberger et al., 1986). Eisenberger et al. (2002) found perceived supervisor support to be associated with temporal change in perceived organizational support, but did not find perceived organizational support to be related to change in perceived supervisor support. This suggests that perceived supervisor support influences perceived organizational support. In a follow-up study with 493 employees of a large electronics store chain, (Eisenberger et al., 2002) found perceived organizational support completely mediated the relationship between perceived supervisor support and voluntary turnover. Thus, perceived supervisor support leads to increased organizational support, which in turn leads to increased retention of employees.

According to LMX theory, the quality of the supervisor-subordinate relationship should influence outcomes at the individual, group, and organization level. Gerstner and Day (1997) conducted a meta-analysis on 85 studies concerning the correlates of LMX. Overall, the results suggest that having a high-quality relationship with one's supervisor positively affects the entire work experience, including performance and affective outcomes. More specifically, Gerstner and Day found the quality of leader-member relations to correlate with performance ratings of the subordinate $(r=.30)$, satisfaction with supervision $(r=.71)$, job satisfaction $(r=$ $.50)$, organizational commitment $(r=.42)$, role clarity $(r=.43)$, and role conflict $(r=$ .31). The quality of the leader-member relationship has also been positively associated 
with organizational citizenship behaviors (Deluga, 1994; Townsend, Phillips, \& Elkins, 2000).

It is important to realize that there can be negative consequences associated with low-quality relationships between leaders and subordinates. That is, not only does low-quality leader-member relationships lead to an absence of positive outcomes, but can also lead to the development of negative behaviors such as retaliatory behaviors (Skarlicki \& Folger, 1997). In fact, Townsend et al. (2000) found individuals who reported lower quality leader-member relationships to be more likely to report that they engaged in retaliatory behaviors toward the organization. Thus, developing and maintaining high-quality leader-member relationships is not only important for promoting positive outcomes, but also to avoid negative consequences.

\section{The Importance of Trust}

Trust is an essential component to the development of high-quality relationships between leaders and subordinates (Bauer \& Green, 1996; Brower et al., 2000; Schriesheim, Castro, \& Cogliser, 1999). According to Blau (1964), a major distinction between social exchange relationships and economic exchange relationships is that the former entails "unspecified obligations" (p. 93). An economic exchange relationship makes explicit the terms of the contract that both parties agree to honor. In contrast, social exchange is based on expectations of a future return that is not necessarily predetermined in advance. Economic exchanges do not require trust, since the contract is explicit and can be enforced by a third party to ensure that all 
Empowerment 45

obligations are met. For social exchange relationships, such as LMX relationships, trust is critical given the unspecified nature of future reciprocation. That is, it is not entirely clear when and how the benefits of one's actions will be reciprocated in the future. When employees' trust in the leader is strong, they are more likely to exert effort on behalf of the leader because they believe that their effort will be rewarded in the future. If trust is minimal, employees are likely to focus on the economic exchange aspects of their relationship by providing the minimum effort necessary to accomplish their tasks because of the uncertainty that more effort will be rewarded. Trust in one's supervisor has been found to be more strongly related to performance, intentions to quit, and job satisfaction than trust in leadership at higher levels (Dirks \& Ferrin, 2002). Trust has also been linked to an employee's satisfaction with their supervisor (Butler, Cantrell, \& Flick, 1999). Thus, trust must be present for employees to develop high-quality relationships with their leaders. The following studies demonstrate the importance of supervisor trust for leader-member relationship quality and its direct effects on outcomes.

In a study of 412 staff nurses, Laschinger et al. (2001) found trust to be positively related to job satisfaction, affective commitment, and perceptions of workplace empowerment. Although not specifically tested, the model they present of the relationships among these three constructs suggests that trust partially mediates the relationship between workplace empowerment and organization commitment and the relationship between workplace empowerment and job satisfaction. 
In a study examining changes in employee perceptions during an organizational change initiative, Weber and Weber (2001) found perceptions of employee involvement to be positively related to trust in management. The authors also collected longitudinal data before and after ( 6 months from baseline) the implementation of a quality management initiative that contained an employee participative component. They found perceptions of management trust increased from Time 1 to Time 2. Study data were obtained from a public organization that was similar in structure; a fire department that was described as bureaucratic and paramilitary in nature. Unfortunately, the study did not employ a control group, reducing confidence that it was the change effort that led to increased trust.

Gomez and Rosen (2001) conducted a study among 128 employee-manager dyads across 13 organizations to examine the role LMX plays between the managerial trust-employee perceptions of empowerment relationship. A strength of their study was the use of managers as the source of data on trust perceptions and employees as the sources for LMX and empowerment perceptions, thus reducing the potential for the confounding of results with common-method variance. The authors found that employees who report higher quality exchanges also were more likely to experience psychological empowerment. They also found that employees who were more strongly trusted by their managers were more likely to report a better quality exchange with their managers. Further, Gomez and Rosen (2001) found that the quality of the leadermember relationship completely mediated the relationship between managerial trust and perceptions of empowerment. 
Liden et al, (2000) conducted a study examining the relationships among job characteristics, LMX, team-member exchange (TMX), empowerment, organizational commitment, job satisfaction, and job performance. Their main hypothesis was that empowerment would mediate the relationship between the interpersonal relationship variables (TMX and LMX) and job characteristics and work outcomes. Data for this study were collected from 337 employees and supervisors who were members of 60 intact groups of an organization that recently implemented an intervention similar to the crew chief intervention. The organization attempted to increase the level of empowerment by delegating certain supervisory duties, such as determining work assignments, to work groups. However, like the crew chief program, these work groups were not true self-managed teams, as supervisors remained and were responsible for human resource decisions.

Liden et al. found empowerment to be positively related to each of the outcome variables, even after controlling for job characteristics and the interpersonal relationship variables. However, they only found support for complete mediation effects between job characteristics and organizational commitment and partial mediation effects between job characteristics and work satisfaction. They did not find any significant relationships between TMX and any of the empowerment dimensions, and found two of the four empowerment dimensions to be positively related to LMX. LMX and TMX were positively related to organizational commitment and TMX was positively related to performance, even after controlling for job characteristics and empowerment. This suggests that LMX and TMX exert their positive effects on work 
Empowerment 48

outcomes via their effect on empowerment, and the results support that positive interpersonal relationships at work as well as improvements in empowerment contribute uniquely to improving important organizational outcomes.

Liden et al. (2000) also suggest that the three most critical elements of leadermember relations are the degree of emotional support provided by the leader, the level of decision-making authority the employee has, and amount of task challenge given to the employee. The implementation of the crew chief program should directly enhance perceptions of the latter two, given that the position of crew chief provides increased task challenge and decision making authority to the crew chief, although not necessarily to the mail processors. As for the implications for mail processors, crew chiefs may be more likely to provide their crew members with more decision making latitude than supervisors did and also more likely to provide more emotional support to employees than the supervisor provided. This is because crew members and crew chiefs should be more likely to identify with and relate to each other given that they are more likely to be familiar with each other, that they all work together in the same area, whereas supervisors were not allowed to work alongside craft employees and have had a history of adversarial relations with craft employees.

Good relationships between supervisors and employees are a potentially important precursor to employee empowerment perceptions. Empowerment is based on sharing authority to increase employee self-efficacy, which is best accomplished in a climate of positive relations between the leader and subordinates. If there is distrust among the leaders and subordinates, then it becomes practically impossible to share 
power in a meaningful way. Given that only crew chiefs were directly and formerly empowered, the crew chief program was expected to increase mail processor perceptions of empowerment by improving trust and leader-member relations. Thus, an essential component of the crew chief program was to choose members of the rankand-file as crew chiefs, where the likelihood of building trust and establishing good relations would be high.

The Role of Leader-member Similarity in Developing Trust

A key antecedent to the development of trust is the similarity in values between the leader and subordinate. In fact, research has found shared values to be a predictor of trust (Hart, Capps, Cangemi, \& Caillouet, 1986; Martin, 1998 as cited in Weber \& Weber, 2001). Given that crew chiefs were current employees and union members, they were more likely to share common values and experiences and thus had an important basis for establishing trust that is critical to developing high-quality leader-member relationships. A meta-analysis by Dirks and Ferrin (2002) of 106 independent samples with 27,103 individuals also found the presence of participatory decision making to be positively correlated with trust in supervisor, as well as a smaller but significant relationship with trust in organizational leadership, suggesting that the voice mechanism the crew chief program offered could have provided a foundation for building trust.

Similarity between supervisors and subordinates also affects other important variables. Turban and Jones (1988) compared four types of similarity: subordinate 
perceived similarity, supervisor perceived similarity, perceptual congruence (degree to which supervisor and subordinate share similarity perceptions), and demographic similarity. Subordinate perceived similarity was found to be positively related to job satisfaction and supervisor ratings of job performance. Subordinate perceived similarity was also found to be strongly positively related to confidence and trust in supervisor, and negatively related with perceptions of role conflict and role ambiguity. Supervisor perceived similarity and perceptual congruence were also found to be positively related to subordinate's trust in supervisor and negatively related to subordinate's role ambiguity. These results suggest that having crew chiefs who were more similar to mail processors than supervisors as the mail processors' direct report would positively affect mail processor trust in the crew chief and improve job satisfaction.

\section{The Relationship between Climate and Leader-Member Relations}

Tierney (1999), in a study involving 157 dyads of employees and supervisors, found that the quality of LMX and TMX was positively related to employee perceptions of the change climate. That is, better relationships between employees and their supervisors and coworkers were associated with employee beliefs that the organization was amenable to change, such as risk taking, open communication, trust, autonomy, and employee development. This is an important finding in that it suggests that if the crew chief program improves labor-management relations, this would in turn facilitate future organizational change that the USPS plans to implement. In other 
words, not only is the crew chief an organizational change initiative, but a successful crew chief program should serve as a catalyst for future successful change.

Another important finding of Tierney's (1999) study is the significant interaction between LMX quality and climate perceptions of the supervisor. Employee climate perceptions were most positive when there was a high-quality LMX relationship and the supervisor also had positive climate perceptions. Employee climate perceptions were most negative when there was a poor quality LMX relationship and supervisors had a more positive perception of the climate. Tierney interpreted this finding by reasoning that supervisors who perceive the climate as change conducive were more likely to provide change opportunities to employees when supervisors had positive relationships with them. Employees who have poor relations with their supervisors may have resented that employees in the in-group benefited from the change climate, and thus these employees perceive the climate as less change conducive. These results suggest that employees who have high-quality relationships with their supervisors are more likely to have congruent views with their supervisor on the change climate. Thus, if crew chiefs perceive the climate as empowering and develop high-quality relationships with their crew members, then this perception should also be shared by crew members because crew chiefs are likely to shape the group climate as one that is empowering. This effect of group climate perceptions of empowerment, as well as the greater likelihood of crew chiefs to share in the decision making of day-to-day operations with mail processors, should all contribute to mail processors believing they are empowered as well. 
Empowerment 52

In summary, the perceived quality of leader-member relationships has been found to play a key role in affecting employee and supervisor attitudes. One of the foundations of developing a high quality leader-member relationship is trust, and a key factor for developing trust is perceived similarity between the employee and supervisor. Based on the fact that crew chiefs are likely to have a similar history of experiences and values, trust should be more easily and rapidly developed between crew chiefs and mail processors. Although this effect of trust will not be specifically tested in the current study, it is the mechanism that explains why leader-member relations should be stronger between crew chiefs and employees. Improvement in leader-member relations should lead to positive changes in satisfaction with supervision, job satisfaction, organizational and union commitment, and reduced stress and strain. I also reviewed literature on the benefits of participation programs on overall labor-management relations, which should have set the stage for the success of other organizational change efforts.

As discussed in Chapter 2, supervisors at the USPS were largely perceived by mail processors as not caring about developing good relationships with mail processors and were mainly concerned with the technical aspects of the job, such as meeting production quotas. Taken together, the review of the literature concerning empowerment and leader-member relations suggests that crew chiefs should be more willing to delegate and share responsibilities with team members and genuinely care about their well being given their many similarities, which are key to developing highquality leader-member relationships. Further, high quality leader-member relations are 
Empowerment 53

positively associated with satisfaction with supervision (Gerstner \& Day, 1997). Thus, mail processors should develop better relationships with crew chiefs than they had with supervisors and become more satisfied with the supervision they receive.

Hypothesis 1: Mail processor satisfaction with their supervision will show a greater increase from Time 1 to Time 2 at the experimental sites than at the control sites. 
Chapter 4. Job Satisfaction, Organizational Commitment, Union Participation, Union Commitment, and Labor Relations

\section{Job Satisfaction}

Job satisfaction is one of the most commonly studied attitudes studied in industrial and organizational psychology (Judge, Parker, Colbert, Heller, \& Ilies, 2002; Locke, 1976). In general, job satisfaction is the extent to which an individual is happy with and likes his/her job. More specifically, Locke (1976) defines job satisfaction as "a pleasurable or positive emotional state resulting from the appraisal of one's job or job experiences" (p. 1304). Job satisfaction has relationships with many important organizational outcomes, such as job performance (Iaffaldano \& Muchinsky, 1985; Judge, Thoresen, Bono, \& Patton, 2001), absenteeism (Scott \& Taylor, 1985), and turnover intentions (Mobley, Horner, \& Hollingsworth, 1978; Tett \& Meyer, 1993). Much of the job satisfaction research has focused on the relationship between job satisfaction and job performance, based on the premise that a happy worker is a productive worker. This proposition, that job satisfaction leads to higher job performance and other organizational outcomes, most likely evolved from broader research in social psychology linking attitudes and behaviors (Judge et al., 2001). When individuals have a positive attitude towards an object, they are more likely to engage in behaviors to support that object (Eagly \& Chaiken, 1993 as cited in Judge et al., 2001). Thus, when employees have positive attitudes toward their job, they are 
more likely to engage in behaviors that are beneficial to the organization that provides the job.

In a meta-analysis of 74 studies with a total sample size of 12,192 , Iaffaldano and Muchinsky (1985) estimated the true correlation between satisfaction and job performance to be .17 . A more recent and larger scale meta-analysis based on 312 samples and a total sample size of 54,417 by Judge et al. (2001) found a stronger relationship between job satisfaction and job performance of .30. Job satisfaction has also been found to be related to withdrawal behaviors such as absenteeism (Scott \& Taylor, 1985) and turnover intentions (Mobley et al., 1978). Based on their metaanalysis, Tett and Meyer (1993) estimated the true correlations between job satisfaction and turnover intentions to be -.58 and job satisfaction and actual turnover to be -.25 . Job satisfaction has also been found to be positively related to organizational commitment (Deery, Iverson, \& Erwin, 1994; Mathieu \& Zajac, 1990; Schaubroeck, Cotton, \& Jennings, 1989; Tett \& Meyer, 1993) and work climate. As a whole, this research demonstrates that job satisfaction has significant relationships with a variety of important organizational outcomes.

The job characteristics model (Hackman \& Oldham, 1976) has probably received the most support in the literature for understanding how job satisfaction develops (Judge et al., 2002). Hackman and Oldham (1976) proposed a theory of work design focusing on how the characteristics of jobs and people interact to determine when a job will lead to beneficial attitudinal and behavioral outcomes. Their job characteristics model consists of five core job dimensions (skill variety, task variety, 
Job Attitudes 56

task significance, autonomy, and feedback) that influence three psychological states (knowledge of results, experienced responsibility, experienced meaningfulness), which in turn lead to a number of beneficial personal and work outcomes. The model postulates that an individual experiences job satisfaction when he or she learns that he or she performed well (knowledge of results) on a task that he or she cares about (experienced meaningfulness) and that his or her actions were the reason for his or her performance (experienced responsibility). The job satisfaction that results serves as an incentive to perform well in the future. That is, job satisfaction serves as a motivator for high performance. This process continues until one or more of the psychological states are no longer present, or when individuals no longer value the outcomes that result from good performance.

Hackman and Oldham (1976) posit that skill variety, task identity, and task significance lead to experienced meaningfulness. Autonomy leads to experienced responsibility, and feedback leads to knowledge of results. Skill variety refers to the extent that the job allows employees to perform different tasks. Task identity is the degree to which employees can see their work from start to finish. Task significance reflects the importance employees assign to their work. Feedback reflects the amount and quality of information that employees have concerning their performance on the job. Autonomy concerns employees' perceptions of independence and the degree of discretion they have to carry out their job duties.

In this study, autonomy is most likely to be influenced by changes in the leader-member relationship as a result of the crew chief program. The degree of 
Job Attitudes 57

autonomy should improve because crew chiefs should have been less likely to micromanage mail processors and would have been less likely create tension on the workroom floor compared to supervisors. Crew chiefs should have strongly identified with the mail processors because crew chiefs were mail processors themselves and continued to perform many of the tasks of the mail processor position in addition to their crew chief responsibilities. That is, crew chiefs knew what it was like to be in the mail processor position, and crew chiefs shared the disdain for micromanagement and strained relations. Also, at many sites, their fellow mail processors had the power to vote out a crew chief if mail processors felt that the crew chief was not meeting the empowerment expectations of crew members. Based on this reasoning, I expect mail processors would have experienced more autonomy under the work floor leadership of crew chiefs. Increased autonomy is one of the mechanisms by which I expect the crew chief program to produce benefits for the employees and USPS.

Some evidence for the positive effects of autonomy in a setting that was similar to the USPS comes from a study by Griffin et al. (2001). In a sample of 48 manufacturing companies with an average of 246 employees, Griffin et al. (2001) found that autonomy partially mediated the relationship between the degree of teamwork and job satisfaction, such that employees who performed more of their work in a team context were more likely to report greater job autonomy, which in turn was positively related to job satisfaction. One major strength of this study was that the authors accounted for both individual (e.g., degree of autonomy) and group level (degree of teamwork) effects. Further evidence for the relationship between autonomy 
and job satisfaction come from a meta-analysis by Fried and Ferris (1987). Based on 20 samples and 7,861 cases, Fried and Ferris (1987) found the corrected mean correlation between job satisfaction and autonomy to be .48 .

Taken together, there is strong research evidence that improving desirable job characteristics is positively related to increased job satisfaction. The crew chief program will most likely affect perceptions of autonomy, which have been found to be linked to job satisfaction. Thus, if the crew chief intervention is successful in expanding job autonomy, then job satisfaction should improve.

Hypothesis 2: Mail processor job satisfaction will show a greater increase from Time 1 to Time 2 at the experimental sites than at the control sites.

\section{Organizational Commitment}

Another job attitude that is of importance to the USPS is organizational commitment. Organizational commitment involves the psychological attachment of the individual to the organization (Mowday, Steers, \& Porter, 1979; Meyer \& Allen, 1984). Steers (1977) defined organizational commitment as the degree to which an employee identifies with and is involved with a particular organization. Strong organizational commitment is characterized by three factors: (1) belief in and internalization of the organization's values, (2) a willingness to exert effort for the organization, and (3) a strong desire to remain a member of the organization. Other organizational commitment researchers define commitment as a multidimensional 
construct consisting of three dimensions: affective, continuance, and normative commitment (Allen \& Meyer, 1990; Meyer \& Allen, 1997).

Affective commitment refers to an employee's emotional attachment to and identification with an organization. Employees with strong affective commitment stay with the organization because they "want" to stay. Researchers often draw from social exchange theory (Blau, 1964) to explain how affective commitment develops. Social exchange theory suggests that attitudes and behaviors toward an organization develop from a person's evaluation of the reciprocity of the person-organization relationship. Hence, people develop strong emotional attachments to the organization when they feel that their organization values and supports them (Eisenberger et al., 1986). Because of the strong relational basis for this construct, as well as the research evidence for the strong relationships affective commitment displays with organizational outcomes discussed below, I focused on affective commitment for this study. Also, I will refer to affective commitment to the employer as company commitment in this paper, because commitment to the union, another organization, is discussed as well. Organizational commitment will be used to refer to the more generalized concept of commitment.

Continuance commitment is based on an evaluation of the costs and benefits associated with leaving the company. Employees who exhibit strong continuance commitment stay with the company because they feel they "have" to stay. Two factors that strongly influence the development of continuance commitment are (1) investment in the job, financial (e.g. pension benefits accrued and relocation costs) and 
Job Attitudes 60

non-financial (e.g. seniority), and (2) the availability of job alternatives (Meyer \& Allen, 1997). Although there is evidence that continuance commitment is a dimension of organizational commitment in the public sector (Liou \& Nyhan, 1994), the proposed intervention does not target the two most influential factors of continuance commitment. Thus, continuance commitment was not included as a variable in this study.

Finally, normative commitment reflects a belief in the importance of being loyal to organizations in general. Individuals high in normative commitment stay with the organization because they feel they "ought" to stay. However, some researchers have failed to find discriminating effects between company and normative commitment, with company commitment usually exhibiting stronger effects on outcome variables (Meyer, Stanley, Herscovitch, \& Topolnytsky, 2002). Thus, some researchers believe normative commitment may be tapping the same construct domain as company commitment (Ko, Price, \& Mueller, 1997). Also, normative commitment is likely to represent a more dispositional form of commitment, given that it centers on loyalty in general, and thus may be more difficult for organizations to influence. For these reasons, the current research does not measure normative commitment.

The dimensions of organizational commitment have been linked to many valued company outcomes. A meta-analysis by Randall (1990) found positive relationships with performance, effort, and intention to remain in the company and organizational commitment. Overall, the estimated corrected correlation of commitment and overall work outcomes was .21. Mathieu and Zajac (1990) also 
Job Attitudes 61

found organizational commitment to be significantly related to performance ratings $(r$ $=.14)$, intentions to leave $(r=-.46)$, and attendance $(r=.10)$. A more recent metaanalysis with a larger and more current sample (111 samples from 92 published studies) by Riketta (2002) estimated the true correlation between company commitment and performance to be .20 .

Research has also shown that company commitment is more strongly linked to company outcomes than continuance or calculative based commitment. For example, in examining potential moderators for the company commitment - work outcomes relationship in his meta-analysis, Randall (1990) found the corrected correlation between commitment and outcomes to be .21 for affectively based measures versus .12 for calculative based measures. Mathieu and Zajac (1990) found affective measures of organizational commitment to correlate more strongly with overall job satisfaction $(r=.69)$ and turnover intentions $(r=-.52)$ than calculative commitment $(r$ $=.23,-.22$, respectively)

There is also research evidence that commitment is related to intentions to leave the company. In a meta-analysis of company commitment and outcomes, Tett and Meyer (1993) report a significant correlation between company commitment and turnover intentions $(\mathrm{r}=-.54)$ and actual turnover $(\mathrm{r}=-.33)$. A study by Jaros $(1995)$ using two independent datasets, one concurrent and the other longitudinal, examined the effects of each of the three dimensions of organizational commitment and turnover intentions. When all dimensions were entered into the regression equation, he found that company commitment alone was negatively related to turnover intentions in both 
datasets. Thus, not only does this study demonstrate the relationship of company commitment to another organizational outcome variable, but also supports the prominence of company commitment compared to the other dimensions of commitment in predicting organizational outcomes.

Suliman (2002) found company commitment partially mediated the relationships between organizational climate and self-rated and supervisor-rated performance in a sample of 783 lower-, middle- and top-level managers working in 20 industrial firms. Employees who perceived a more positive work climate had higher levels of company commitment, and higher levels of company commitment were associated with higher performance ratings. Continuance commitment was only modestly positively related to self-rated performance, and did not fully or partially mediate either of the work climate - performance relationships. These studies provide additional evidence for the prominence of the affective dimension of commitment.

Affective commitment may even be more important for public organizations (Nyhan, 1999; Perry \& Wise, 1990; Romzek, 1990). This is because public organizations usually do not provide as much compensation as their private counterparts, and thus rely heavily on employees' sense of duty and desire to serve the public good. Perry and Wise (1990) posit that affectively committed employees are likely to have increased public service motivation, and that public service motivation is important for organizations in the public sector to be effective.

Cohen (1992) proposed that blue collar employees are more likely to be committed to the company because of extrinsic rewards. However, Young, Worchel, 
Job Attitudes 63

and Woehr (1998) found that for a sample of blue collar employees in a public agency, intrinsic rewards (e.g., job satisfaction, job characteristics) were similarly predictive of organizational commitment as extrinsic rewards (e.g., pay satisfaction, promotion satisfaction). Liou and Nyhan (1994) found that more tenured employees, supervisory employees, and non professional employees were more likely to have greater company commitment, while there were no significant relationships with continuance commitment in a sample of 337 public service employees. This is consistent with the idea that public employee motivation is determined by employees' identification and involvement with the organization (Liou \& Nyhan, 1994). Although the USPS is not entirely a public organization, its mandate and incorporation is based on a public service. Also, as in private organizations, affective commitment in public organizations is important for retaining high-quality employees (Romzek, 1990).

Given the importance of company commitment, its antecedents should be identified and understood. In a meta-analysis focusing on examining the moderating effects of occupational type (blue collar, non-professional and professional white collar) on relationships between various antecedents and company commitment, Cohen (1992) found personal characteristics such as tenure, education, marital status, and gender to have a stronger relationship with commitment in blue collar and non professional employees than professional employees. However, the small magnitudes of these differences, as well as the small or non-existent differences in organizational antecedents such as role conflict, role ambiguity, and job involvement, suggests that employing different strategies for increasing commitment in different occupational 
classes as Cohen recommends may not result in large gains as opposed to implementing the same strategy for all groups. This suggests that the antecedents of commitment found in the literature are also likely to be antecedents of commitment in the current sample, and are likely to exhibit similar effect sizes.

A study by Nyhan (1999) examined the effects of two types of trust and company commitment based on data from three different government organizations. The primary goal of his research was to determine whether systems trust (trust in the organization as a whole) or interpersonal trust (trust of immediate supervisor) explained more variance in company commitment. After controlling for organization, job classification, gender, and tenure, Nyhan (1999) found interpersonal trust to be strongly positively related to company commitment, while there was a nonsignificant relation of systems trust with company commitment. Interpersonal trust was also strongly correlated with systems trust. Taken together, the results of Nyhan's (1999) study are consistent with the crew chief program's focus on employees' relationships with their leaders for building better labor relations and producing positive organizational change.

Based on my analysis of the literature, the crew chief, as a union member and team leader, should be perceived as more trustworthy than the managerial supervisor. Because crew chiefs were more similar to craft employees than to supervisors, and shared in the same work tasks, there should have been greater opportunities for crew chiefs and employees to build trust and develop high-quality relationships. The 
improvement in the leader-member relations should then lead to greater company commitment.

In addition to the improvement in company commitment resulting from positive leader-member relations, the act of providing greater opportunity for participation in making work-related decisions could have served as a symbol that the company trusts and is committed to its employees. Empowerment is likely to lead to commitment because employees will feel obligated to reciprocate to the company (Dessler, 1999; Liden et al., 2000). Perceptions of empowerment have been found to be related to commitment (Laschinger et al., 2001; McDermott, Laschinger, \& Shamian, 1996) and satisfaction (Miller \& Monge, 1986; Wagner \& Gooding, 1987). Further, employee participation in quality circles has been found to be associated with increased identification with the firm (Verma \& McKersie, 1987). Shadur et al. (1999) also found affective commitment to be positively related to three types of employee involvement perceptions including participation in decision making, teamwork, and communications. The implementation of self-managed teams should help create a feeling that the work is shared, which should help build a feeling of community (Dessler, 1999). Creating a sense of community has been suggested as one strategy for increasing affective based commitment (Dessler, 1999). Taken together, the research suggests that the implementation of crew chiefs should result in greater company commitment in mail processors. 
Hypothesis 3: Mail processor company commitment will show a greater increase from Time 1 to Time 2 at the experimental sites than at the control sites.

\section{Union Participation}

Improving labor relations in unionized organizations with a history of adversarial relations is certainly not a simple task. However, the involvement of the union in organizational change initiatives can help improve labor relations. In fact, a study of 92 unionized manufacturing organizations by Cooke (1990) found that improvements in labor relations were positively related to the degree of union involvement in joint union-management programs. Thus, the involvement of the APWU in this initiative should increase the crew chief initiative's probability of success for improving labor relations.

One of the unique aspects of the proposed study is that the crew chief program was initially proposed by the union. In most cases, the organization usually proposes empowerment/employee involvement initiatives. Many unions resist these programs because they believe the primary purpose of these programs is to weaken union support by allowing management to assume the union role of addressing employee concerns (Eaton \& Voos, 1989; Leana et al., 1992). Many unions fear that participation programs also could undermine collective bargaining agreements, increase workers' identification with the organization at the cost of the union, co-opts union leadership, and be used as a strategy to thwart unionization (Arthur \& Dworkin, 
1991; Eaton \& Voos, 1989; Kochan et al., 1984; Verma, 1989). Thus, union support for involvement programs is usually ambivalent at best (Fenwick \& Olson, 1986).

Kahnweiler and Thompson (2000) suggested that employee involvement in the design of an empowerment initiative is important to be able to identify and provide what employees desire from the program and to obtain increased buy-in for the program. Including the union, acting as the representative of the workers, should address this concern and thus enhance the probability of the success of the crew chief program.

Verma (1989) suggested that empowerment initiatives can affect union attitudes via a "selection effect" and a "program effect." In the selection effect, employees who do not have favorable attitudes toward the union may be more likely to participate in the program. Thus, a negative relationship between empowerment initiatives and union attitudes evolves based on self-sorting. The program effect changes employee attitudes toward unions because of the potential for employees to develop more positive attitudes toward the organization as a result of empowerment. This is most likely to occur when the union does not participate in the design and implementation of the initiative (Verma \& McKersie, 1987). However, with participation by the union, it is certainly possible that employees can develop commitment both to the union and organization (Dean, 1954). In the current study, the selection effect is unlikely, but the program effect may occur. However, that may be unlikely as well because employees may attribute the program to the union rather than management. In fact, if poor labor relations persist, it is possible for the program effect 
to work in the opposite direction. That is, employees may only develop increased commitment to the union when they attribute the positive benefits of change to the union and poor labor relations to the company.

A study by Verma and McKersie (1987) of 534 employees of a high technology manufacturing company found employees who were less involved in union activities to be more likely to participate in employee involvement programs. However, they also found that participants desired more union participation in employee involvement programs. Thus, Verma and McKersie (1987) concluded that worker participation in employee involvement programs does not necessarily lead to a decline in attitudes toward the union. Also, Fullagar and Barling (1991) found that having high commitment to either the organization or union did not lead to adverse consequences for the other.

Reshef, Kizilos, Ledford, and Cohen (1999) tested for program and selection effects in a sample of 572 unionized employees of a large telephone company. Approximately half the employees were organized according to self-managed teams while the remainder were traditionally managed employees. They found that participants had more positive attitudes toward the employee involvement program, and that among participants, volunteers had more positive attitudes toward employee involvement than non-volunteers did after controlling for perceived union support of the program. Like Verma and McKersie (1987), Reshef et al. (1999) failed to detect either program or selection effects. On the contrary, Reshef et al. (1999) found that positive attitudes toward employee involvement were associated with an increased 
desire for the union to be involved in the program. Verma (1989) also found that participation by unions in employee involvement programs was associated with increases in union satisfaction.

Participation by unions has been suggested as a correlate to the effective implementation of SMWTs (Fenwick \& Olson, 1986; Vallas, 2003). Kochan et al. (1984) suggests that enthusiasm for these types of involvement initiatives is more likely to endure when unions are actively involved with the participation program. Based on their review of the labor-relations literature, Arthur and Dworkin (1991) also concluded that union involvement in employee participation programs is associated with program success, as well as more positive attitudes toward the union and participation in the union by employees. Also, without union involvement, strong supporters of the union are more likely to avoid participating, and given that the great majority of mail processors are unionized, the program may be doomed to fail. Thus, not only is union involvement preferable, but may be necessary for program success (Eaton, 1994).

Because employee involvement leads to higher company commitment, it becomes even more important for the union to be involved in order to prevent the erosion of union support and commitment. That is, joint involvement of the union and management should increase the likelihood that employees identify the empowerment program with the union as well as the organization (Verma, 1989; Verma \& McKersie, 1987). 
Taken as a whole, the prior literature demonstrates the importance of union participation in the implementation of organizational change initiatives. Programs that have union support are more likely to be successful in achieving the program's goals for the organization and the union. What distinguishes the proposed study from most previous research is that the crew chief program was initiated by the union rather than management. Although the proposed study does not specifically test whether unionsponsored interventions are more likely to be successful than those sponsored by management, the literature reviewed on union participation suggests that the crew chief intervention should have a strong probability for success. This discussion also sets the stage for an attitude of significance to unions that is likely to be impacted by empowerment interventions; union commitment.

\section{Employee Commitment to the Union}

Union commitment is defined as the extent to which a union member identifies with the goals and values of the organization, desires to remain a member of the union, and is willing to exert effort on behalf of the union (Gordon, Philpot, Burt, Thompson, \& Spiller, 1980). Union commitment is an important construct in that it has been associated with several outcomes that are critical to union effectiveness such as member participation in union activities (Agars, Unckless, \& Tesluk, 1998; Bamberger, Kluger, \& Suchard, 1999; Thacker, Fields, \& Barclay, 1990) and voting for political candidates endorsed by the union (Thacker et al., 1990). With the continued decline of the percentage of the labor force that is represented by unions 
Job Attitudes 71

(Arthur \& Dworkin, 1991), union attitudes such as union commitment become even more important for union sustainability.

Like company commitment, union commitment has also been conceptualized as a multidimensional construct (Gordon et al., 1980). The dimension that has probably received the most attention in the literature is union loyalty. Union loyalty reflects the degree to which union members identify with and share the goals and beliefs of the union (Tan \& Aryee, 2002). It has also been defined as the affective attachment a member has with the union (Fullagar, Gallagher, Gordon, \& Clark, 1995), which parallels the construct of company commitment (Fullagar \& Barling, 1989).

Bamberger, Kluger, and Suchard (1999) conducted a meta-analysis testing four models based on competing perspectives on the hypothesized antecedents of union commitment, and union commitment's effect on union participation by members. Using structural equation modeling based on data from 80 independent samples and 59 studies, they found support for an integrative model, such that union instrumentality perceptions, pro-union attitudes, job satisfaction, and company commitment are all directly related to union loyalty, and that union loyalty is positively related to union participation. Further, they also found indirect effects of union loyalty on company commitment through job satisfaction and union loyalty to pro-union attitudes through union instrumentality.

A study of 322 unionized employees from various unions in Singapore by Tan and Aryee (2002) provided additional support for Bamberger et al.'s (1999) 
Job Attitudes 72

integrative model of the causes and consequences of union commitment. Focusing on union loyalty, Tan and Aryee (2002) found that union loyalty predicted both organizationally-directed and individually-directed union citizenship behaviors. They also found union instrumentality perceptions to be directly related to union loyalty as well as indirectly through pro-union attitudes. Company commitment was positively related to union loyalty, and job satisfaction was found to be indirectly related to union loyalty through its positive relationship with company commitment. Iverson and Kuruvilla (1995) also reported a similar finding to that of Tan and Aryee (2002) in that they found company commitment to mediate the relationship between job satisfaction and union loyalty.

In a study of 481 unionized employees of a large communications company, Thacker, Fields, and Barclay (1990) examined a range of antecedents and outcomes of overall as well as the dimensions of union commitment. The antecedents they studied included access to union officials and stewards, perceived mission fulfillment at the national and local level, gender, tenure, and salary grade. Outcomes included union participation and voting behavior favorable to the union. When antecedents were regressed on overall union commitment and the individual dimensions, Thacker et al. found the results for the loyalty dimension strongly paralleled those of overall union commitment. All of the hypothesized antecedents were positively related to union loyalty and overall union commitment with the exception of the demographic variables and access to the union steward. Thacker et al. also found that union loyalty demonstrated stronger relationships with outcomes compared to the other dimensions 
of commitment. The overall pattern of results for union loyalty is similar to that of company commitment, in that it consistently demonstrates the strongest relationships with proposed antecedents and outcomes. Thus, in this paper, when I refer to union commitment, I am actually referring to its affective dimension of union loyalty. Another important predictor of union commitment is perceived union support (Sinclair \& Tetrick, 1995), which refers to the degree to which union members perceived the union to be concerned about union members' well-being (Shore, Tetrick, Sinclair, \& Newton, 1994). This construct is analogous to perceived organizational support (Eisenberger et al., 1986). Based on social exchange theory and research linking perceived organizational support to company commitment (Eisenberger, Armeli, Rexwinkel, Lynch, \& Rhoades, 2001; Eisenberger \& Fasolo, 1990), Sinclair and Tetrick (1995) argued that perceived union support should explain variance in union commitment beyond that accounted for by union instrumentality perceptions. They developed this proposition based on the notion that perceived union support represents the non-economic aspects of the exchange relationship, such as the union being committed to the member as an individual, the union valuing their contributions and participation, and the union caring about their needs. In short, perceived union support reflects the union's commitment to the employee. In their study of 77 unionized university employees, Sinclair and Tetrick (1995) found perceived union support to predict each dimension of union commitment (loyalty, responsibility to union, willingness to work for union, and belief in unionism) after controlling for union instrumentality. 
Building on the employee empowerment literature, the results discussed above are relevant to the current research in that the crew chief program may be viewed by employees as an action by the union. Thus, employees may interpret the program as a sign that the union cares about its members and is seeking and initiating strategies to improve employees' work lives. That is, the advocacy and involvement in developing empowerment initiatives can by viewed by union members as a form of perceived union support (Shore et al., 1994). The consistent findings in the literature that perceived organizational support positively affects company commitment (e.g., Eisenberger et al., 2001; Hutchison, Sowa, Eisenberger, \& Huntington, 1986; Rhoades, Eisenberger, \& Armeli, 2001; Settoon, Bennett, \& Liden, 1996; Tansky \& Cohen, 2001) suggest that perceived union support should positively affect union loyalty. Consistent with this idea, Shore et al. (1994) and Sinclair and Tetrick (1995) found perceived union support to be positively related to union loyalty. Furthermore, paralleling the research on the positive relationship between supervisor support and organizational support (Eisenberger et al., 2002), crew chief support should enhance perceptions of perceived union support, which should lead to increased union commitment and participation in union activities. Thus, these are the mechanisms by which union participation in the crew chief initiatives should lead to higher levels of union commitment.

Hypothesis 4: Mail processor union commitment will show a greater increase from Time 1 to Time 2 at the experimental sites than at the control sites. 
Job Stress 75

\section{Chapter 5. Job Stress}

\section{Job Stress}

Job stress is triggered by the demands and uncertainty a job entails (Quick, Quick, Nelson, \& Hurrell, 1997). Work-related disorders, which include job stress, constitute one of the top 10 occupational health risks in the US (Quick et al., 1997). In Great Britain, stress, depression, and anxiety are the second most commonly reported group of work-related illnesses following musculo-skeletal disorders (A. Smith, 2001).

The performance and financial health of an organization depends upon the physical and psychological health of its workers. The degree of deviation an organization experiences from a healthy, productive level of functioning (e.g., absenteeism, turnover) has been referred to as organizational distress (Quick et al., 1997). Organizational distress can lead to organizational ill health, which is indicated by high insurance and health care costs, poor accident and safety records, low levels of company commitment and job satisfaction, and generally deteriorating labormanagement relations (Cartwright, Cooper, \& Murphy, 1995). One estimate of the cost of job stress to the U.S. economy is as high as $\$ 150$ billion dollars a year (Johnson \& Indvik, 1996).

Disorders that employees can develop as a result of prolonged exposure to job stress include affective disturbances (e.g., job dissatisfaction, anxiety, depression) and chemical dependencies (Sauter, Murphy, \& Hurrell, 1990). Besides the anguish and pain involved, psychological disorders also have a large economic impact, estimated 
to be $\$ 36$ billion in direct care costs in the U.S., and represent a significant cost to other Western nations (Sauter et al., 1990). Note that this estimate does not include the costs of lost productivity.

In addition to the negative effects stress may have on individual strain and organizational attitudes, there is evidence that stress can lead to violence in the workplace (cf. Mack, Shannon, Quick, \& Quick, 1998). Johnson and Indvik (1996) describe violence as "the ultimate manifestation of job stress" (p. 22). The U.S. Department of Justice estimates that 1 million people are victims of violent crime annually (Bachman, 1994). In its most extreme form, workplace violence was responsible for 856 deaths in 1997, and homicide was the second leading cause of work-related deaths (United States Department of Health and Human Services, 1999). Across all categories of workplace violence, the financial burden to the U.S. economy is estimated to be $\$ 75$ billion per year (Johnson \& Indvik, 1996). Although this outcome is not measured in the current study, it is important to mention given the high profile workplace violence cases that have occurred at the USPS, such as the shootings that took place in 1986 at Edmund, OK and in 1991 at Royal Oak, MI (Greengard, 1999). In fact, these cases also contributed to the impetus for organizational change at the USPS (GAO, 1994a; GAO, 1994b). By improving the work environment to reduce stress, the USPS hoped to prevent these violent episodes in the future.

Job stress may also exert negative effects by moderating the relationship between job characteristics and work attitudes. A study of 9,327 UK health service employees by Payne, Wall, Borrill, and Carter (1999) found strain to moderate the 
relationships between job characteristics and attitudes such as company commitment and job satisfaction, such that under higher levels of strain, there was a weaker relationship between work characteristics and work attitudes. These results are consistent with the idea that people under stress and strain respond to the world differently both cognitively and affectively (Payne et al., 1999).

\section{Stressor-Strain-Outcome (SSO) Model}

\section{Origins}

Kahn and Byosiere (1992) posited a model of stress in organizations by integrating seven of the most popular models used in the literature concerning the antecedents and consequences of stress. The basic structure of the model is that stressors lead to strain, which in turn leads to negative outcomes. In other words, strain is believed to mediate the relationship between stressors and outcomes (Koeske \& Koeske, 1993). The stress-strain and strain-outcome relationships are also believed to exhibit moderating effects from social support, such that social support reduces, or buffers, the effects of stress on strain and the effects of strain on undesirable outcomes. There are more elements to Kahn and Byosiere (1992) model than described here, as I only focus on those aspects that have received the most support and are most relevant to my research. Koeske and Koeske (1993) also posited a similar model of stress where stressors lead to strain and strain leads to work-related outcomes. There has been support for this model in many occupational settings (Bedeian \& Armenakis, 1981; Kemery, Bedeian, Mossholder, \& Touliatos, 1985; 
Tetrick, Slack, Da Silva, \& Sinclair, 2000). The components of this model are described in the following sections.

\section{Stressors/Stress}

In general, stress research in the organizational sciences is concerned with how individuals and organizations adjust to their environments, achieve high levels of performance and health, and become distressed (Quick et al., 1997). Stress represents an unfavorable interaction between worker attributes and job conditions that leads to psychological disturbances and unhealthy behaviors, and ultimately to long-term ill health (Sauter et al., 1990). The definition of stress has been a contested issue. Many researchers use the term to refer to objective stimuli, while others use it to refer to the appraisal of those stimuli or the subsequent response to that stimuli (Kahn \& Byosiere, 1992).

For the current study, the stressor (demand) is defined as a physical or psychological stimulus to which a person responds. Stressors involve the perception of objects or situations in the environment that can produce adversity or distress. Examples of physical stressors include noise and air quality. Psychosocial stressors result from psychological stimuli and include role demands and interpersonal demands.

Role demands are dominant and pervasive sources of stress for many individuals (Quick et al., 1997). A role set is composed of all the various individuals (role senders) who have expectations of a particular person. Each role sender places 
unique demands on the individual, and the nature and quantity of these demands determines the level of role stress an individual perceives. Interpersonal demands are concerned with the hassles and burdens involved in the normal course of social, personal, and working relationships in organizations (Quick et al., 1997). They are related to role demands, but different in that they are not based on expected behaviors. For example, stress from interpersonal demands is likely to arise when employees have negative relationships with supervisors and/or coworkers.

The most commonly studied role demands are role ambiguity and role conflict (Kahn, Wolfe, Quinn, Snoek, \& Rosenthal, 1964; Rizzo, House, \& Lirtzman, 1970). Role ambiguity occurs when the priorities, expectations, or evaluation criteria of a job are not clear to the individual. The frustration that results from the uncertainty is what creates tension on the job (Schaubroeck et al., 1989). Further, if employees are not clear on how to perform their duties and tasks effectively, performance improvements and rewards become more difficult to obtain, which leads to less satisfaction (Schaubroeck et al., 1989). Role ambiguity has been found to be negatively related to company commitment (A. Cohen, 1992; Fullagar \& Barling, 1991; Schaubroeck et al., 1989) and positively related to depression (Frone, Russell, \& Cooper, 1995).

An individual experiences role conflict when he or she is faced with incongruent role demands and commitments. There are several forms of role conflict including intrasender, intersender, person-role (incompatibility of values), interrole (e.g., a person as CEO, father, president), and role overload (Quick et al., 1997). Role overload is a special type of role conflict that occurs when an individual's role duties 
exceed what he or she is capable of handling. Role conflict and role overload consistently predict negative affect and physical strain (Kahn \& Byosiere, 1992).

The stress response: Strain and burnout

The stress response, also referred to as strain, can be psychological and/or physiological in nature. In other words, stress represents the quantity and quality of the "load" and strain reflects the outcomes from the load. Examples of psychological strains include anxiety, depression, and burnout. Physiological strains include high blood pressure, dizziness, and gastrointestinal problems.

According to Maslach (1982), burnout consists of emotional exhaustion, depersonalization, and diminished personal accomplishment. Emotional exhaustion involves feelings of being psychologically overextended and exhausted by one's work. Emotional exhaustion is manifested by both physical fatigue and a sense of feeling psychologically and emotionally drained (Leiter \& Maslach, 1988). Depersonalization refers to a state of indifference and callousness towards others. This dimension is best understood in the context of social service occupations where the object of depersonalization is the worker's client (Wright \& Cropanzano, 1998). Finally, diminished personal accomplishment involve feelings of ineffectiveness and incompetence (Leiter \& Maslach, 1988). Although all three components are potentially important, a growing research consensus has concluded that emotional exhaustion is the key component of burnout. The following studies support this contention. 
Lee and Ashforth (1996) conducted a meta analysis on 61 studies examining the relationships between the three dimensions of burnout, stressors such as role ambiguity and role conflict, and outcomes such as company commitment, turnover intentions, and job satisfaction. Compared to the other two burnout dimensions, emotional exhaustion demonstrated the strongest relationships with stressors and outcomes. Koeske and Koeske (1989) also concluded that emotional exhaustion is central to the construct of burnout based on their study evaluating the construct validity of the Maslach Burnout Inventory. Although the factor structure using five different samples was consistent with a tri-dimensional conceptualization of burnout, Koeske and Koeske found inconsistent relationships with hypothesized antecedents and consequences of burnout. They proposed that depersonalization and personal accomplishment should be viewed as separate but closely related to burnout. Further, Koeske and Koeske argued that burnout should be reconceptualized with emotional exhaustion as an indicator of strain. Thus, emotional exhaustion was used to represent strain in this study.

The mechanism by which emotional exhaustion occurs and by which it exerts its effects can be explained by conservation of resources theory (CORT) (Hobfoll, 1989). According to CORT, strain, in this case in the form of emotional exhaustion, can occur when there is an actual resource loss, a perceived threat of resource loss, when resources are inadequate to meet the demands of the situation, or the investment of resources does not bring about expected returns (Hobfoll, 1989; Wright \& Cropanzano, 1998). Resources are defined as "those objects, personal characteristics, 
conditions or energies that are valued by the individual or that serves as a means for attainment of these objects, personal characteristics, conditions, or energies" (Hobfoll, 1989, p. 516). In the workplace, these resources include social support from coworkers and supervisors, and job enhancement opportunities such as autonomy and participation in workplace decisions. Thus, emotional exhaustion reflects a state where individuals feel they no longer have sufficient resources to handle the stressors confronting them.

Wright and Cropanzano (1998) conducted a 1 year longitudinal study of 52 social welfare workers to study the relationships among emotional exhaustion, affectivity, job satisfaction, turnover, and performance. The results were consistent with CORT, in that workers exhibiting emotional exhaustion were more likely to engage in withdrawal behaviors, such as turnover and poor performance, even after controlling for positive and negative affectivity. The patterns of correlations between stressors, resources, and the burnout dimensions observed in the Lee and Ashforth (1996) meta-analysis are also consistent with the CORT.

\section{Outcomes}

Strain leads to negative outcomes, which can be behavioral, psychological, and/or physiological in nature (Koeske \& Koeske, 1993). Behavioral responses can include the degradation and/or disruption of the work role itself in the form of aggressive behavior, flight from the job, and self-destructive behaviors. 
Job Stress 83

A study by O' Driscoll and Beehr (1994) examined three models involving the direct and indirect effects among supervisory behaviors, role ambiguity and conflict, psychological strain, and outcomes such as job satisfaction and turnover intentions. They found the most support for a model in which role ambiguity and role conflict mediated the relationships between supervisory behaviors and outcomes. Supervisory behaviors that were considered to create uncertainty (e.g., lack of clarity of communication, lack of supervisor support in obtaining required resources) were positively related to role conflict and role ambiguity. In turn, role ambiguity was positively related to psychological strain, and negatively related to job satisfaction. Role conflict was positively associated with strain and turnover intentions. This model is consistent with the stressor-strain-outcome model of stress, except that it did not posit mediating effects between psychological strain and outcomes, and did not test for interaction effects of supervisory support.

In a variation of the SSO model, Kelloway and Barling (1991) found role stressors to be predictive of burnout (emotional exhaustion demonstrating the strongest relations) and job satisfaction, and burnout and job satisfaction to be predictive of "context free" mental health, or general well being, in a sample of 720 hospital employees. Kelloway and Barling (1991) also compared the mediation model to a non-mediation model, and found the mediation model to fit better. Overall, their results suggest that strain mediates the relationship between role stressors and general well being. Interestingly, the authors treated job satisfaction as an indicator of job 
related strain. Most research, as well as the current study, treats job satisfaction as an outcome of strain.

The main effects of crew chief support in the SSO model

Two variables identified in the literature that have been found to be related to role stressors at the workplace are participation and social support (Ganster, Fusilier, \& Mayes, 1986; Jackson, 1983; Schaubroeck et al., 1989). Participation in workplace decision making is believed to reduce role conflict because it provides employees with influence over role senders (Schaubroeck et al., 1989). Participation should also provide employees with increased access to job-relevant information, thus reducing role ambiguity (Schaubroeck et al., 1989).

Social support refers to aid and assistance from an individual's social environment, which can take the form of emotional, informational, and/or instrumental support (S. Cohen \& Wills, 1985; LaRocco, House, \& French, 1980). Social support may reduce role conflict because increased support provides the employee with increased ability to reconcile and negotiate the demands from their role (Jackson, 1983). The mechanism of increased communication (i.e., access to job-relevant information) that describes how participation is expected to reduce role ambiguity may also explain how social support reduces role ambiguity (Schaubroeck et al., 1989).

Social support should reduce job strain by helping the employees cope with the strain they are experiencing (S. Cohen \& Wills, 1985; Fisher, 1985). Social support provides the individual with emotional and instrumental resources to combat the 
Job Stress 85

negative experience of strain. For example, talking about one's anxiety with a friend may be an effective coping mechanism for reducing that anxiety.

A study by Edwards et al. (2001) with 206 undergraduate students found negative social exchange, a measure of nonsupportive social interaction, to be strongly positively related to physical symptoms even when positive social support, major life events, and a measure of daily hassles were controlled. However, no interaction effects were found for either positive or negative social support. The implications of these results are that the presence of poor relationships at the workplace, particularly with one's immediate supervisor, can have negative effects on outcomes of significance to the employees and the organization even when positive, supportive relationships are present.

Schaubroeck et al. (1989) tested a form of the SSO model using covariance structure modeling with 249 employees of a federal government manufacturing contractor and 201 blue collar employees of a university maintenance department. The authors tested for buffering effects of social support by conducting moderated hierarchical regression analyses. Out of 28 possible tests, they found only three significant interactions, all involving participation and social support. After conducting additional tests to rule out the possibility of Type I error, only two interactions remained significant and only for their first sample. Thus, the authors concluded that the inclusion of interaction effects would not affect the interpretation of the main effects model. Schaubroeck et al. (1989) did find some support for their version of the stressor-strain-outcome model of stress, in that perceived role stressors 
Job Stress 86

led to increased job tension, increased job tension led to less job satisfaction, decreased job satisfaction led to decreased company commitment, which then led to greater turnover intentions. In addition, they found social support from coworkers to be negatively related to role conflict and role ambiguity, and to directly positively affect job satisfaction.

Schaubroeck et al. also found participation to be strongly negatively related to role ambiguity and positively related to job satisfaction. However, they did not find direct effects of social support and participation on job tension. The pattern of results did suggest indirect effects of social support and participation and job tension via their relationship with role stressors. Finally, the parameter estimates and model fit were similar for two independent samples, increasing the confidence in the generalizability of these results.

A study by Leiter and Maslach (1988) examined the effects of positive and negative interactions with coworkers and supervisors on role conflict, burnout, and company commitment in a sample of 44 non-supervisory nurses and support staff of a hospital. Role conflict and unpleasant supervisory and coworker relations were found to be positively related to emotional exhaustion, even after controlling for positive interactions. Negative relationships with the supervisor were also directly negatively related to company commitment, even after accounting for the significant relationship between emotional exhaustion and commitment and positive coworker interactions and commitment. Also, other research has found that having positive attitudes toward an immediate supervisor is associated with increased company commitment (Bishop 
\& Scott, 2000; McDermott et al., 1996; Putti, Aryee, \& Phua, 1990) and job satisfaction (Griffin et al., 2001). Taken together, this research suggests that to the degree employees view the crew chief as a person employees can turn to for emotional support, as well as a person that can help to acquire instrumental resources, employees will exhibit less stress and strain and have more positive job attitudes.

Hypothesis 5a: Mail processor perceptions of crew chief support are negatively related to mail processor role ambiguity at Time 2 .

Hypothesis 5b: Mail processor perceptions of crew chief support are negatively related to mail processor role conflict at Time 2.

Hypothesis 5c: Mail processor perceptions of crew chief support are negatively related to mail processor emotional exhaustion at Time 2 .

Hypothesis 5d: Mail processor perceptions of crew chief support are positively related to mail processor job satisfaction at Time 2 .

Hypothesis 5e: Mail processor perceptions of crew chief support are positively related to mail processor company commitment at Time 2 .

Hypothesis 5f: Mail processor perceptions of crew chief support are positively related to mail processor union commitment at Time 2.

The buffering effects of crew chief support in the SSO model

There has been less work on the buffering effects of organizational and interpersonal factors. Lee and Ashforth (1996) suggest that resources, such as social support may moderate the demand-burnout relationship. In fact, social support is the 
most studied moderator of this relationship (Kahn \& Byosiere, 1992). Kahn and Byosiere's (1992) review of the research found support for the moderating effects in the stressor-strain relationship, but not the stressor-job satisfaction relationship. Fried and Tiegs (1993) also examined the moderating effects of social support in the SSO model using a dataset based on 112 unionized employees in the auto industry. This study is unique in that it tested for the moderator effects of role stressors on the buffering effect of social support from the shop steward. Fried and Tiegs (1993) proposed that union stewards should be a significant source of support because they have access to unique information from management, the union, and fellow coworkers that may help employees cope with stress at work. Fried and Tiegs found three-way interactions among role conflict, role ambiguity, and union steward social support in predicting job security satisfaction, burnout, psychosomatic complaints, and helplessness. For each of these dependent variables, the effect was such that the buffering effect was strongest at high levels of both role stressors. Interestingly, social support only had a significant main effect for job security satisfaction and none of the two-way interactions involving social support were significant. The results suggest that support from union stewards becomes most salient to employees who are under stress from multiple sources. This makes sense if the union steward is not immediately available or is difficult to access. That is, employees in this sample were likely to seek out support from the union steward only when employees were experiencing high stress from multiple sources because the limited availability and access to union stewards did not warrant the effort to seek out union stewards when employees were 
experiencing less stress. Given that crew chiefs are similar to union stewards in that they have access to supportive information from management and employees, and to a limited extent to the union, and that crew chiefs have higher accessibility and spend more time with employees, I would expect social support from crew chiefs to exert a buffering effect on relationships over a wider range of stress experienced by employees.

Although the research regarding the buffering effects of social support have not been as conclusive as the other relationships in the SSO model, the rationale for the existence of moderator effects remains strong. Therefore, I hypothesize that perceived support from crew chiefs will buffer the stressor-strain and strain-outcome relationships.

Hypothesis 6a: Mail processor perceptions of crew chief support moderates the relationship between mail processor role ambiguity and mail processor emotional exhaustion, such that the relationship is more positive when crew members have poorer relations with the crew chief at Time 2 .

Hypothesis 6b: Mail processor perceptions of crew chief support moderates the relationship between mail processor role conflict and mail processor emotional exhaustion, such that the relationship is more positive when crew members have poorer relations with the crew chief at Time 2.

Hypothesis 6c: Mail processor perceptions of crew chief support moderates the relationship between mail processor emotional exhaustion and mail 
Job Stress 90

processor job satisfaction, such that the relationship is more negative when crew members have poor relations with the crew chief at Time 2 .

\section{Relationships among outcomes}

The relationship between job satisfaction and company commitment. There has been some debate in the literature regarding the causal ordering of job satisfaction and company commitment (Curry, Wakefield, Price, \& Mueller, 1986; Farkas \& Tetrick, 1989; Mathieu \& Farr, 1991; Williams \& Hazer, 1986). A longitudinal study of 129 nursing department employees by Bateman and Strasser (1984) found that job satisfaction at Time 1 did not predict company commitment at Time 2 (five months later), after controlling for commitment at Time 1. In fact, they found Time 1 assessments of company commitment predicted Time 2 levels of job satisfaction, suggesting that job satisfaction is an outcome of company commitment. Bateman and Strasser explain this finding using cognitive dissonance theory, in that employees reevaluate their perceptions of job satisfaction to make them commensurate with their level of commitment to the organization. Otherwise, employees will become distressed over the "dissonance" between their commitment and satisfaction levels. In contrast, Elangovan (2001) tested six competing models involving the causal ordering of stress, satisfaction, company commitment, and turnover intentions using structural equations modeling with a sample of 155 graduate business students. The study found the strongest support in the model where stress affects job satisfaction, job satisfaction leads to company commitment, and where commitment and turnover intentions are 
reciprocally related. However, it is important to note that the results of this study were based on cross-sectional data, and that a longitudinal sample is more appropriate for evaluating causal ordering. Farkas and Tetrick (1989) conducted a longitudinal study and suggested that the relationship between job satisfaction and company commitment may actually be reciprocal. However, most research has positioned job satisfaction as an antecedent to company commitment (e.g., Schaubroeck et al., 1989; Williams \& Hazer, 1986). Therefore, in the proposed research, I hypothesize job satisfaction to be an antecedent to company commitment.

Hypothesis 7a: Mail processor job satisfaction is positively related to mail processor company commitment at Time 2 .

The relationship between job satisfaction and union commitment. The relationship between job satisfaction and union commitment remains unclear. Job satisfaction has been found to be positively related to union commitment in some studies (Gordon et al., 1980; Viswesvaran \& Deshpande, 1993), negatively related to union commitment in other studies (Agars et al., 1998; Bamberger et al., 1999; Fullagar \& Barling, 1989), and has also been found to have no relationship with union commitment (A. Cohen, 1993). In the proposed study, I believe that these variables should be positively related because improvements in job satisfaction should be perceived as a result of a joint union-management initiative. That is, because the crew chief program is a jointly sponsored initiative, satisfied employees should demonstrate 
Job Stress 92

increased commitment to the union as well as the company. Employees reward the union and company with commitment for the increased satisfaction derived from the job. Therefore, I expect job satisfaction to have a positive effect on union commitment. A summary of the hypothesized relationships for evaluating the SSO model is presented in Figure 1.

Hypothesis $7 \mathrm{~b}$ : Mail processor job satisfaction is positively related to mail processor union commitment at Time 2 . 


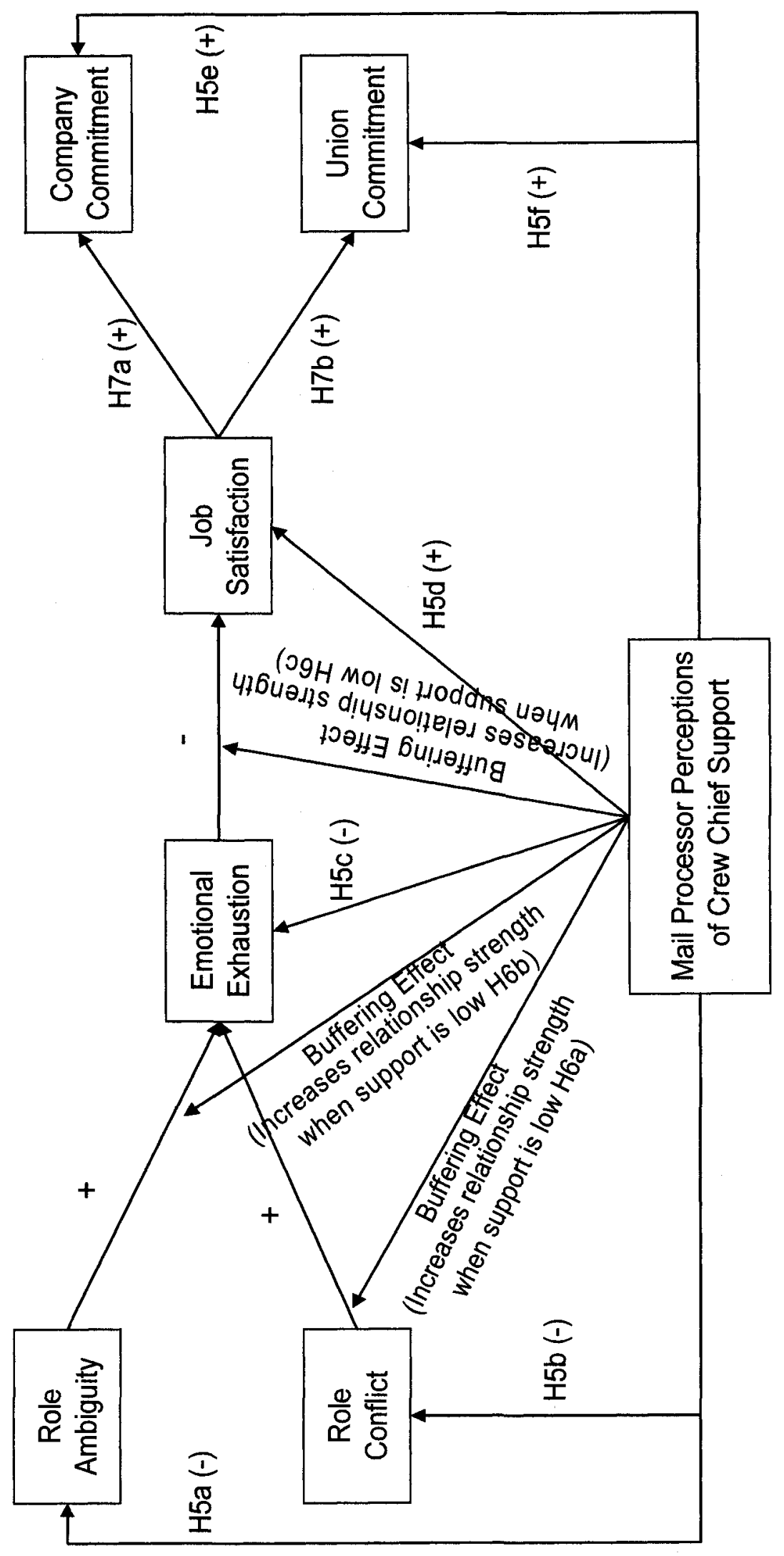

Job Stress 93

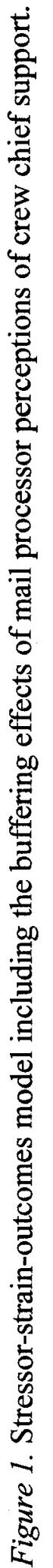




\section{Interventions for Reducing Stress}

In addition to the crew chief program being designed as an intervention to improve job attitudes and labor-management relations, the crew chief program also can be viewed as intervention to reduce stress. Interventions for managing workplace stress occur at three levels: primary, secondary, and tertiary. Primary level interventions focus on the modification of environmental stressors to reduce the occurrence of the stressors (Cartwright et al., 1995). Job design is an example of an organizational development initiative used to reduce the presence of environmental stressors. The latter two levels focus on the outcomes and to a lesser extent the appraisal of potentially stressful stimuli. Secondary level interventions focus on reducing the level of stress and strain, usually through stress management programs that teach alternate forms of appraising stressful stimuli and alleviating strain with techniques such as relaxation exercises. Tertiary level interventions focus on the treatment of the negative outcomes associated with strain, such as psychological disorders, delivered via employee assistance programs and/or medical providers. Many organizations implement interventions at the secondary and tertiary levels because of the commonly held assumption that the onus is on the individual to adapt to stressful environments (Cartwright et al., 1995; Kahn \& Byosiere, 1992). Also, secondary and tertiary interventions are viewed as high profile means by which organizations are seen to be doing something about stress (Cartwright et al., 1995), and are usually less costly to implement than primary level interventions. For these 
reasons, organizations tend to rely on interventions at the secondary and tertiary levels and largely ignore those at the primary level.

In their review of the stress literature concerning the effectiveness of current stress interventions, Cartwright et al. (1995) found EAPs and health promotion programs to reduce stress and strain, but noted that many studies of tertiary level interventions have not been rigorous. Secondary interventions (e.g., stress management training) seem to have a positive effect for reducing stress, but benefits are likely to be eroded if employees return to an unchanged work environment. A meta-analysis of 48 studies by van der Klink, Blonk, Schene, and Dijk (2001) found individual level interventions, which are those at the secondary and tertiary levels, to be successful in reducing psychological and physical strain and improving job satisfaction. However, they did not find significant effects on outcomes for programs at the organizational level. Van der Klink et al. argued that the failure to detect effects may be the result of examining outcomes at the individual level rather than at the level of the organization. They reason that organizational (primary) level interventions may require more time to demonstrate effects at the individual level because of intermediate effects that first must transpire. Unfortunately, the van der Klink et al. (2001) did not describe in detail what those intermediate effects might be. van der Klink et al. (2001) also posited that the current level of decision latitude moderates the relationship between intervention success and perceived control, such that organizational level interventions will have stronger effects when employees perceive a lack of control in their work lives. However, the most likely explanation 
may be methodological; only five of the 48 studies were available for estimating the effect size of organizational level interventions, resulting in a tremendous lack of power. It also demonstrates the lack of research involving organization-focused interventions.

Cartwright et al. (1995) argued that the "one size fit all" nature of secondary and tertiary programs is not appropriate for stress reduction in every organization. There are many potential sources of workplace stress that are not necessarily easy for individuals to identify and deal with effectively. The variety of organization-directed strategies to prevent or limit stress fall in the area of organizational development (Cartwright et al., 1995). The type of action required to reduce or eliminate workplace stressors will vary according to the kinds of stressors operating, level of coping skills of those involved, and the organizational culture. Tailoring action to suit the assessed needs of the organization is likely to be more effective than any broad brush approach.

Interventions at the secondary and tertiary levels are also reactive and recuperative rather than proactive and preventive. Stressor reduction is preferred because it focuses on the source of the problem and not the symptoms (Cartwright et al., 1995; Kahn \& Byosiere, 1992). Thus, effective stress management should include interventions at the primary level to complement interventions at the lower levels (Cartwright et al., 1995). The major leadership challenge is to create organizational cultures and work environments that are productive and healthy (Quick et al., 1997).

In keeping with the recommendations by leading researchers in the field (Cartwright et al., 1995; Quick et al., 1997; Sauter et al., 1990), the crew chief 
program can be viewed as a stress intervention aimed at the primary level, with its primary goal to improve labor-management relations, a potential significant source of stress for employees (Kelloway et al., 1993; Tetrick \& Fried, 1993). The reason it can be considered at the primary level is that it involves a change at the structural level. The primary goals of the crew chief program were to improve labor-management relations via empowerment, increasing satisfaction with supervision, and leader support. These three pathways to improving relations should also result in reducing the level of perceived stressors such as role ambiguity and role conflict, as well as help employees cope with emotional exhaustion.

Hypothesis 8a: Mail processor role ambiguity will show a significant decrease at the experimental sites and will either remain constant or increase at the control sites.

Hypothesis 8b: Mail processor role conflict will show a significant decrease at the experimental sites and will either remain constant or increase at the control sites.

Hypothesis 9: Mail processor emotional exhaustion will show a significant decrease at the experimental sites and will either remain constant or increase at the control sites. 
Summary of Hypotheses for Aims 1 and 2

A summary of the hypotheses that comprise aims 1 and 2 of this paper are restated below:

AIM 1: To perform a program evaluation of the crew chief initiative at the USPS by examining the effects of the crew chief program on mail processors in areas related to their experienced role stressors, job strain, job satisfaction, and company and union commitment.

Hypothesis 1: The difference in mail processor satisfaction with supervision from Time 1 to Time 2 will be greater for the experimental sites than the control sites. Hypothesis 2: Mail processor job satisfaction will show a greater increase from Time 1 to Time 2 at the experimental sites than at the control sites.

Hypothesis 3: Mail processor company commitment will show a greater increase from Time 1 to Time 2 at the experimental sites than at the control sites. Hypothesis 4: Mail processor union commitment will show a greater increase from Time 1 to Time 2 at the experimental sites than at the control sites. Hypothesis 8a: Mail processor role ambiguity will show a greater decrease from Time 1 to Time 2 at the experimental sites than at the control sites. Hypothesis 8b: Mail processor role conflict will show a greater decrease from Time 1 to Time 2 at the experimental sites than at the control sites.

Hypothesis 9: Mail processor emotional exhaustion will show a greater decrease from Time 1 to Time 2 at the experimental sites than at the control sites. 
AIM 2: To replicate and extend the stressor-strain-outcome model of stress and to test the proposition that mail processor perceptions of support from crew chiefs moderates the relationships between stressors and strain and strain and outcomes.

Hypothesis 5a: Mail processor perceptions of crew chief support are negatively related to mail processor role ambiguity.

Hypothesis 5b: Mail processor perceptions of crew chief support are negatively related to mail processor role conflict.

Hypothesis 5c: Mail processor perceptions of crew chief support are negatively related to mail processor emotional exhaustion.

Hypothesis 5d: Mail processor perceptions of crew chief support are positively related to mail processor job satisfaction.

Hypothesis 5e: Mail processor perceptions of crew chief support are positively related to mail processor company commitment.

Hypothesis 5f: Mail processor perceptions of crew chief support are positively related to mail processor union commitment.

Hypothesis 6a: Mail processor perceptions of crew chief support moderates the relationship between mail processor role ambiguity and mail processor emotional exhaustion, such that the relationship is more positive when crew members have poorer relations with the crew chief. 
Hypothesis 6b: Mail processor perceptions of crew chief support moderates the relationship between mail processor role conflict and mail processor emotional exhaustion, such that the relationship is more positive when crew members have poorer relations with the crew chief.

Hypothesis 6c: Mail processor perceptions of crew chief support moderates the relationship between mail processor emotional exhaustion and mail processor job satisfaction, such that the relationship is more negative when crew members have poor relations with the crew chief.

Hypothesis 7a: Mail processor job satisfaction is positively related to mail processor company commitment.

Hypothesis 7b: Mail processor job satisfaction is positively related to mail processor union commitment. 
Chapter 6. Method

\section{Data}

This study used archival data obtained from a study that used a longitudinal, quasi-experimental design. More specifically, the data were collected using an untreated control group design with pretest and posttest (Cook, Campbell, \& Peracchio, 1992). The study design is presented in Figure 2. The hypotheses that constitute Aim 1 rely on the integrity of the design to reach proper conclusions regarding the effectiveness of the crew chief program. In this design, the control group and experimental group are deemed to be similar at baseline and exposed to similar contextual influences with the exception of the intervention. Thus, any differential change between the groups can then be attributed to the intervention. The hypotheses of Aim 2 are cross-sectional in nature, and are not intended to test causation directly, although they do imply underlying causal relationships. Duplicates of the questionnaires, including the frequencies of mail processor responses, are provided in Appendix A. 


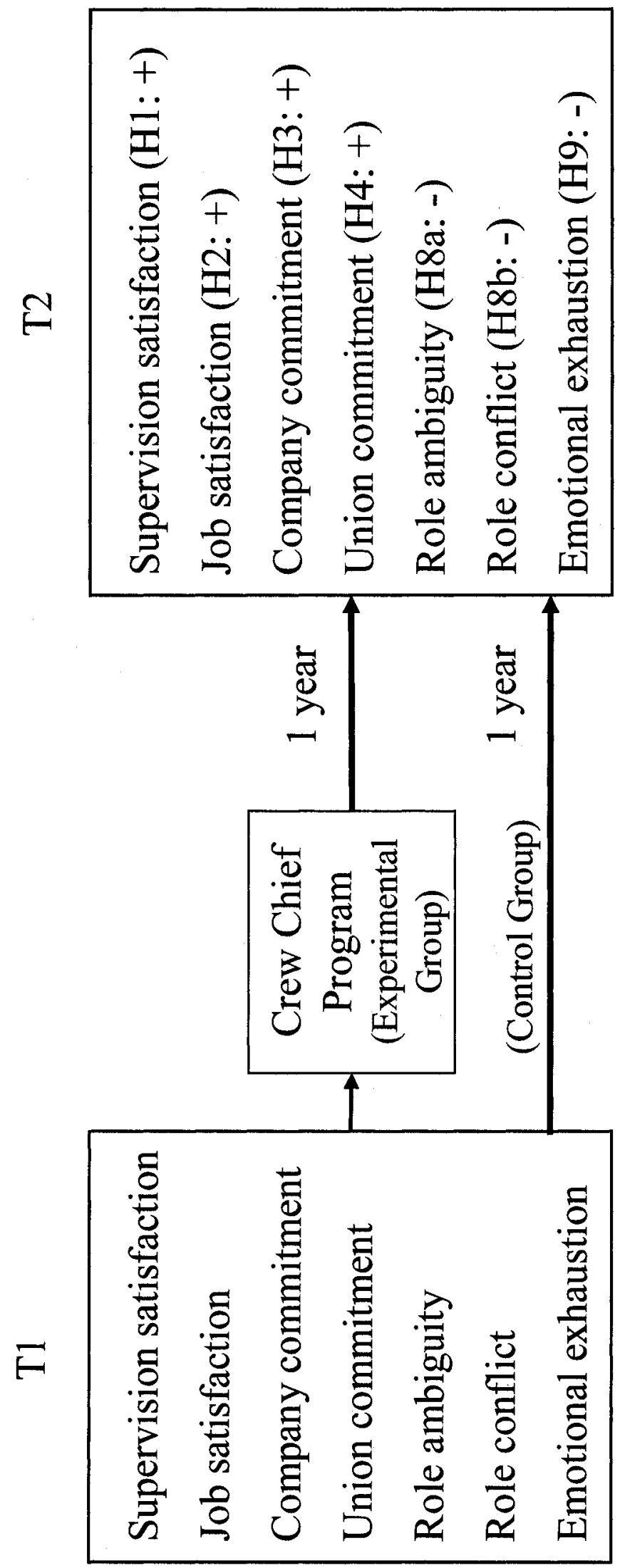

Method 102

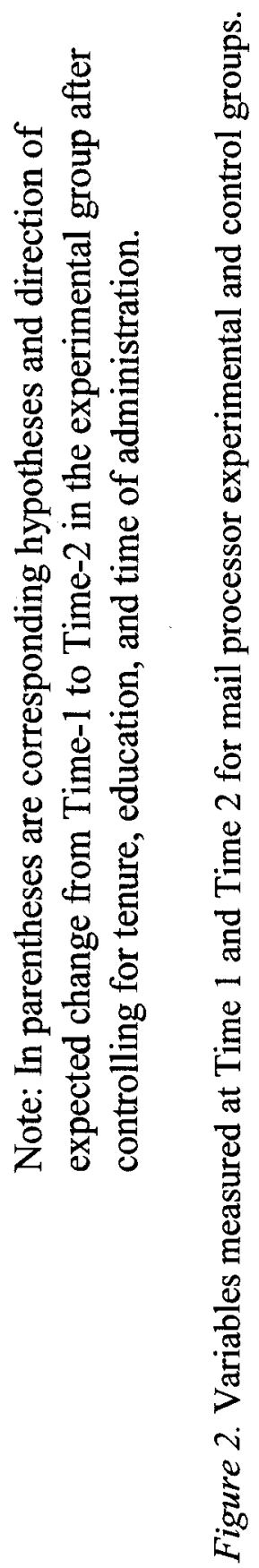




\section{Participants}

Participants were USPS employees who held the mail processor position and/or crew chief position. Chapter 2 provides a detailed description of their job duties and work environment. All employees were surveyed during their working hours at the nine study sites in 1992 and 1993. A total of 661 questionnaires were returned at Time 1, 481 from the experimental sites and 180 from the control sites. The Time 2 surveys were administered in 1993 after the crew chiefs had been in place for almost a year, except for the first site, where the time lag was longer by six months. A total of 961 questionnaires were returned at Time 2, 538 mail processors and 74 crew chiefs from the experimental sites and 350 mail processors from the control sites. These sample sizes represented nearly all employees working in these positions and who were present during the time the data were gathered.

One hundred sixty seven mail processor and 41 crew chief surveys were initially matched from Time 1 to Time 2 for the experimental sites. For participants at the control sites, 95 surveys were initially matched from Time 1 to Time 2 . The remainder of the participants were not matched because they were not employed at both times, filled out the survey anonymously, or refused to participate.

The research team that collected the data compared the demographic data supplied at Time 1 and Time 2 for all participants within a given site, and a pair was considered a match if all of the demographic variables were consistent between the two time points. The strength of each match was either rated as "strong" or "weak." Weak matches were those that the research team was $90 \%$ confident about, and for 
which there was no other potential match. However, during data cleaning, I discovered some discrepancies in the demographic data from Time 1 to Time 2. I also learned that because of the poor state of labor-management relations at the time, respondents were very concerned about being identified. Thus, some employees may have distorted their responses to the demographic items to avoid being identified.

To investigate these data quality issues, I conducted a series of analyses exploring whether there were differences among those who were unmatched, weakly matched, and strongly matched. At Time 1 , there were no differences among the groups on any of the outcome variables. However, at Time 2 those who were not matched reported higher job satisfaction, union and company commitment, and supervisor satisfaction and lower burnout and role conflict than the matched groups. Further examination also revealed that those who were not matched had significantly less tenure and were younger than those who were matched at Time 2, but were not significantly different at Time 1 . There was also no significant group (intervention vs. control) by matched interactions at either time point. These results are consistent with the fact that more employees were hired since Time 1 and it is these new employees that are likely causing the differences in attitudes between the matched and nonmatched groups (i.e., new employees were more likely to be unmatched because they were not available at Time 1). Taken as a whole, these results provide some evidence that mail processors who were matched and unmatched did not differ on the outcomes of interest. 
The research team that collected the data has a very high confidence in the matching of the data from Time 1 to Time 2. Through multiple phone conversations and e-mail communications, Dr. Martin assured me that the matching process was done meticulously and painstakingly, to the point that individual surveys from Time 1 to Time 2 that were established as a potential match were further examined based on the similarity in handwriting between the two timepoints. To ensure an even higher level of data integrity, I limited the sample to those who were strong matches and were consistent in their reported demographic characteristics from Time 1 and Time 2.

Thus, my initial Level $1 N$ of 262 was reduced to 177 . The number of mail processors in each Level 2 unit is presented in Table 1.

Table 1

Number of strongly matched participants by city and tour

\begin{tabular}{lcccc}
\hline & Tour 1 & Tour 2 & Tour 3 & Total \\
\hline Sacramento & 12 & 1 & 11 & 24 \\
San Jose & 5 & 4 & 10 & 19 \\
Minneapolis & 14 & 5 & 9 & 28 \\
St. Paul & 2 & 5 & 6 & 13 \\
Royal Oak & 8 & 1 & 5 & 14 \\
Louisville & 14 & 2 & 8 & 24 \\
Birmingham & 9 & 3 & 9 & 21 \\
Rochester & 6 & 3 & 4 & 13 \\
Valley Forge & 6 & 8 & 7 & 21 \\
Total & 76 & 32 & 69 & 177 \\
\hline
\end{tabular}




\section{Procedure}

A national-level APWU-USPS task force established by the 1991

Memorandum of Understanding (see Chapter 2 for details) was responsible for selecting the location of the six intervention sites and developing the job descriptions and training program for the crew chiefs. The task force chose the locations of the intervention sites based on three criteria: (1) sites needed to be spread out geographically around the country, (2) the local APWU affiliates expressed an interest in becoming an intervention site, and (3) the management members of the national task force believed that management at a site would actually implement the crew chief program as stipulated in the memorandum of understanding. The task force also selected three control sites that were similar in size and geography. The locations of the nine sites where data were collected are presented in Table 2. The crew chief program was also implemented at a seventh site, Lehigh Valley, after the collection period for the baseline data. This site was not included in any of the longitudinal analyses. A steering committee comprised of union members and management at each experimental site was responsible for selecting crew chiefs at its respective site. Although there were some differences among sites in how the sites selected crew chiefs, the majority of sites used seniority as the primary criterion. 
Table 2

Number of participants at each mail processing site for time 1 and time 2

\begin{tabular}{|c|c|c|c|c|c|}
\hline Intervention & $\begin{array}{c}\text { Time } 1 \\
N\end{array}$ & $\begin{array}{c}\text { Time } 2 \\
N\end{array}$ & Control & $\begin{array}{c}\text { Time } 1 \\
N\end{array}$ & $\begin{array}{c}\text { Time 2 } \\
N\end{array}$ \\
\hline Birmingham, AL & 86 & $99(9)$ & Minneapolis, MN & 85 & 194 \\
Louisville, KY & 117 & $154(21)$ & San Jose, CA & 31 & 58 \\
Rochester, NY & 40 & $40(10)$ & Valley Forge, PA & 65 & 98 \\
Royal Oak, MI & 66 & $88(12)$ & & & \\
Sacramento, CA & 95 & $84(11)$ & & & \\
St. Paul, MN & 73 & $72(11)$ & & & \\
\hline
\end{tabular}

Note: Parentheses indicated additional participants who were crew chiefs.

The implementation of the crew chief initiative began at the first site in July 1992. Before the introduction of crew chiefs at the second site, the newly appointed Postmaster General proposed a major reorganization of the USPS, which caused a delay in further deployment of the trials while the details of that reorganization were being formulated and taking place. However, the Time 1 surveying had already been completed at three sites. In early November 1992, the work on the project resumed, and the Time 1 surveying was completed shortly after. The crew chief program was deployed in the five remaining sites in January 1993.

\section{Measures}

Wherever possible, the research team that developed the survey questionnaire chose standard scales or items and scales adapted from previously published work to 
measure the constructs of interest. The research team also collected data on various demographic characteristics, such as tenure and education, at both time periods. All employees at Time 1 received identical surveys, as all of them were mail processors at this time and the crew chief program had not yet been implemented at their respective sites. In fact, there was no mention of the term "crew chief" in the Time 1 survey. At Time 2, there were three versions of the questionnaire. One version pertained to mail processors at the control sites, a second version pertained to mail processors at the intervention sites, and a third version pertained to crew chiefs at the intervention sites. For the most part, the proposed measures used in this study were common to all versions. I note the exceptions in the specific description of each measure. A summary of the measures used, whom they were collected from, and time of administration is presented in Tables 3 and 4. 


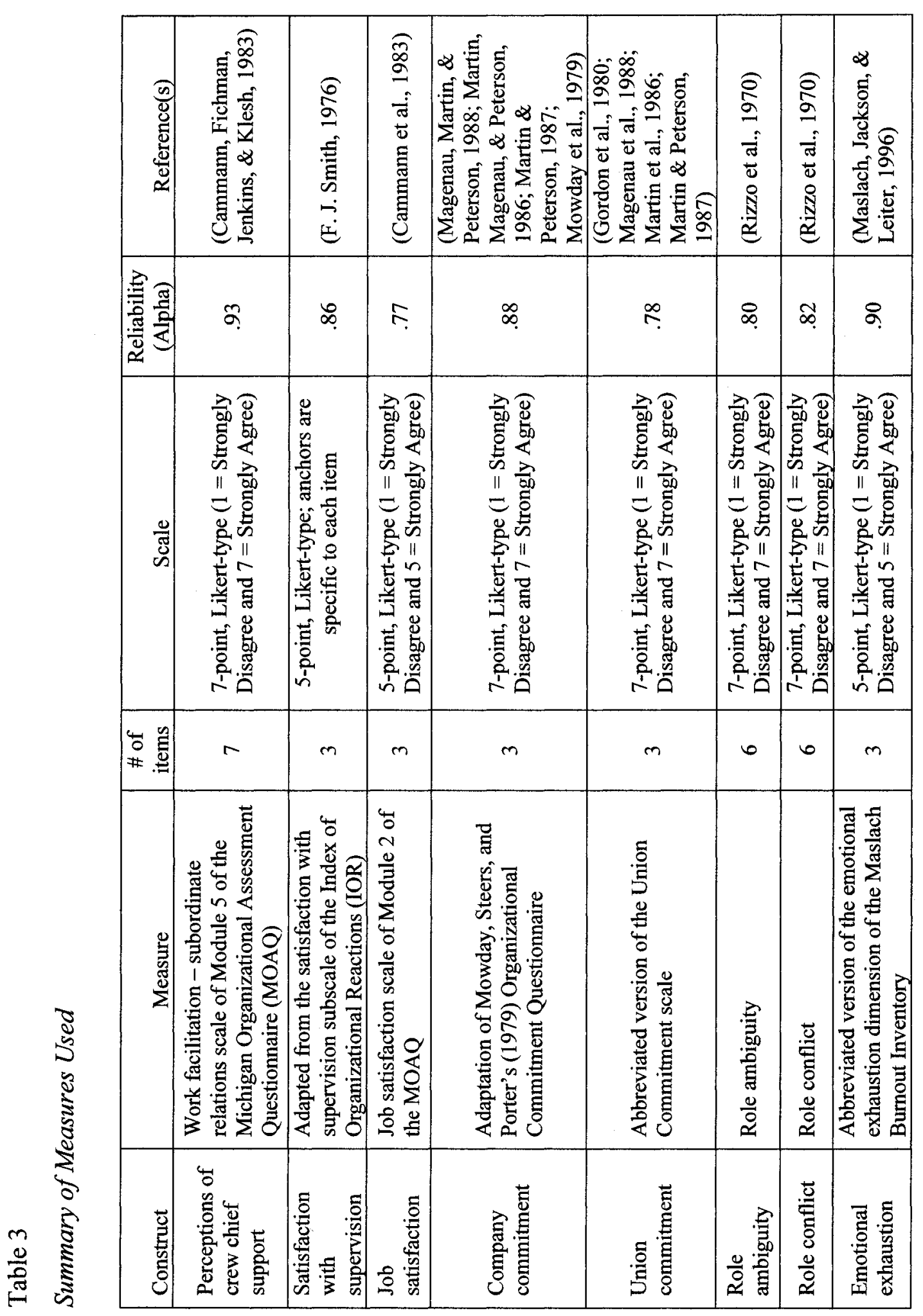


Method 110

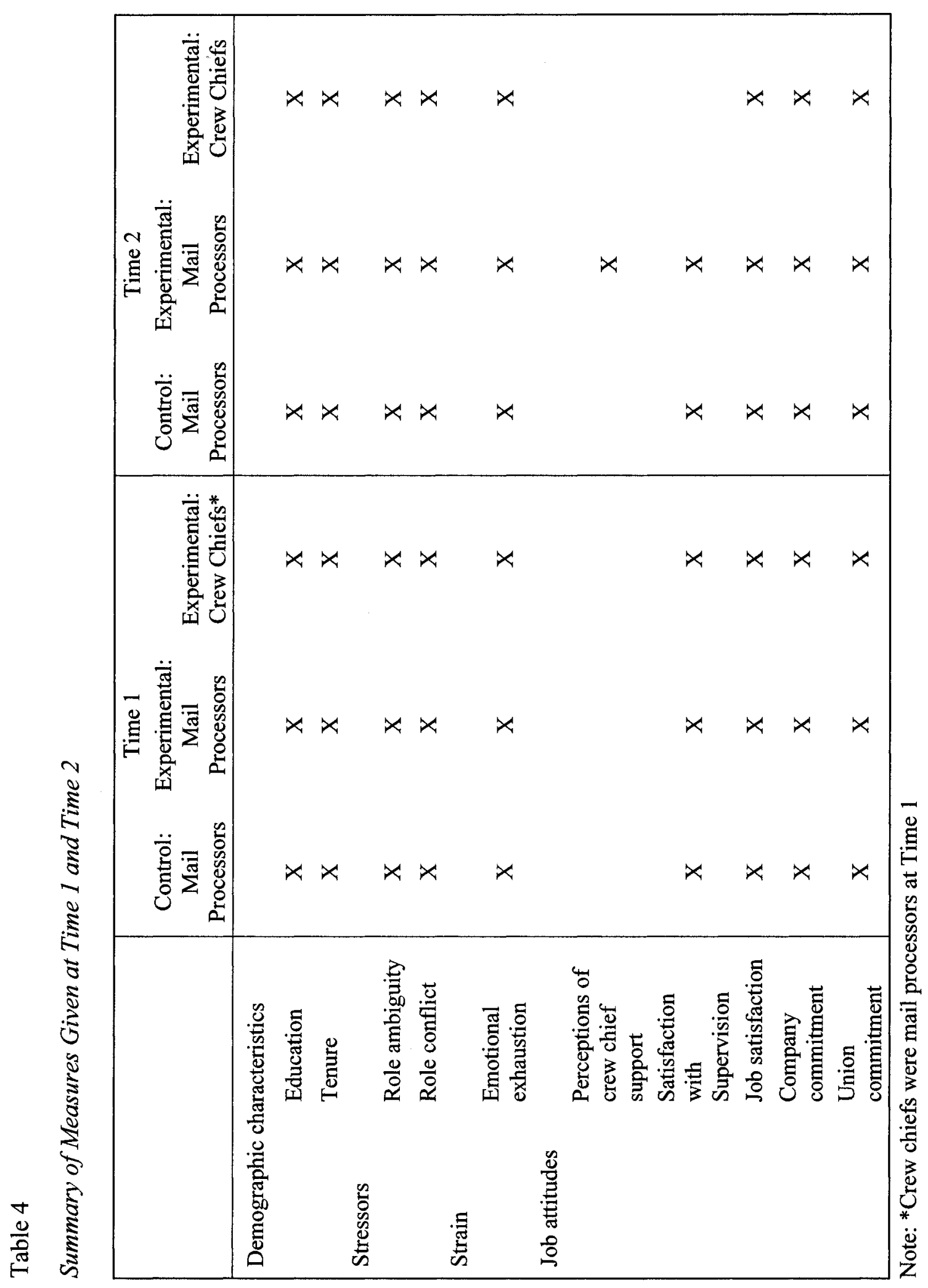


Perceptions of crew chief support

Mail processor perceptions of support from crew chiefs were measured with the work facilitation - subordinate relations scale of Module 5 of the Michigan Organizational Assessment Questionnaire (MOAQ; Cammann et al., 1983). The MOAQ is a well validated tool for assessing organizational characteristics as observed by employees and attitudes regarding the organization and the job. This module of the MOAQ focuses on supervisory behaviors that shape an employee's work environment and provides information on how managerial duties are carried out. The work facilitation - subordinate relations scale measures "the extent to which the supervisor [crew chief] maintains good communication and helpful, equitable relations with subordinates" (Cammann et al., 1983, p. 105). The scale consists of 7 items rated on a 7-point, Likert-type scale ( $1=$ Strongly Disagree and $7=$ Strongly Agree $)$. One item was dropped from the original scale ("tends to play favorites"), which had the lowest factor loading (.36) reported by Cammann et al., and will be replaced with another ("are readily available if I need help") that is more consistent with assessing support perceptions. I computed the mean of the items to create a scale score, with higher scores representing more positive perceptions of crew chief support. The internal consistency for this scale was estimated by Cammann et al. (1983) to be .93 . Mail processors only completed this scale at Time 2. 
Satisfaction with Supervision

Satisfaction with supervision was measured with a three item scale adapted from the satisfaction with supervision subscale of the Index of Organizational Reactions (IOR) (Smith, 1976). The complete IOR is an instrument intended to measure eight facets of job satisfaction and has strong support for its construct validity (Dunham, Smith, \& Blackburn, 1977; Goffin \& Jackson, 1988). The items target employee perceptions concerning whether they would feel better of under different supervision, whether they are satisfied with the supervision they receive, and whether the supervision employees receive motivates them to exert greater effort. It is important to note that this scale has no specific referent, and assumed employees are providing ratings concerning their immediate supervision, whether it was primarily from crew chiefs at the experimental sites at Time-2 or traditional supervisors at Time1 and/or Time- 2 for the control sites. The crew chief survey did not contain these items. Each item is rated on a 5-point, Likert-type scale, however, the anchors are specific to each item in an effort to reduce response bias. The mean of the items was used to represent supervisory satisfaction, with higher scores representing higher satisfaction with one's supervision. The internal consistency estimate for the adapted scale based on the Time-1 data is .86 . 


\section{Job satisfaction}

There are two general ways in which job satisfaction has been measured in prior literature; as a global measure and as one that is the sum of multiple facets (Ironson, Smith, Brannick, Gibson, \& Paul, 1989). Global measures of job satisfaction focus on assessing an individual's holistic evaluation of the job, while facet measures focus on assessing satisfaction with specific areas such as pay, benefits, supervisor, and coworkers. Facet conceptualizations are most useful for studying the different components of job satisfaction with predictors or criteria of similar specificity (Ironson et al., 1989). Research also suggests that aggregating facet attitudes is not equivalent to and is inferior to global assessments for assessing overall job satisfaction (Highhouse \& Becker, 1993; Ironson et al., 1989). This may occur because facet measures may fail to account for factors that contribute to job satisfaction that are implicitly assessed with global measures. However, Tett and Meyer (1993) found no differences between global and facet measures of satisfaction in their relationships with organizational commitment, turnover intentions, and turnover. Given that most of the variables in this study that are proposed to be related to job satisfaction are also global in nature (e.g., emotional exhaustion, organizational commitment, union commitment), it is therefore important to measure job satisfaction at the global level to maintain correspondence among the constructs of interest. In addition, because of the research evidence concerning the psychometric superiority of global measures of job satisfaction over the sum of facet measures for assessing global job satisfaction, I chose to employ a global measure of job satisfaction. 
Employee job satisfaction was measured with the job satisfaction scale of Module 2 of the MOAQ (Cammann et al., 1983). Module 2 of the MOAQ focuses on assessing employee attitudes about various rewards available in the work place. The job satisfaction scale consists of three items, and its internal consistency has been estimated by Cammann et al. (1983) to be .77 . This scale was chosen because it is brief while maintaining acceptable psychometric properties and is a measure of global job satisfaction. Each item is rated on 5-point, Likert-type scale $(1=$ Strongly Disagree and $5=$ Strongly Agree). I used the mean of the items to score this scale, with higher scores representing higher levels of job satisfaction.

\section{Company commitment}

Commitment to the USPS was measured with a three item scale used in previous studies (Magenau et al., 1988; Martin et al., 1986; Martin \& Peterson, 1987). The company commitment scale is an adaptation of Mowday, Steers, and Porter's (1979) Organizational Commitment Questionnaire, and the item content is consistent with the affective dimension of commitment (cf. Allen \& Meyer, 1990; Meyer \& Allen, 1997). In a personal communication dated March $10^{\text {th }}, 1986$, Thacker and Fields (as cited in Martin \& Peterson, 1987; Thacker \& Fields, 1986) reported a correlation of .94 between the abbreviated scale and the positively worded items comprising Mowday et al.'s (1979) scale, providing strong convergent validity evidence. Each item is rated on 7-point, Likert-type scale $(1=$ Strongly Disagree and 7 $=$ Strongly Agree). I computed summary scores as the mean of the items, with higher 
scores indicating higher levels of commitment. Martin and Peterson (1987) reported the internal consistency reliability for this scale was estimated to be .88 .

\section{Union commitment}

Commitment to the union was measured with a three item scale used in previous studies (Magenau et al., 1988; Martin et al., 1986; Martin \& Peterson, 1987). The union commitment scale is an abbreviated version of the union loyalty dimension of the union commitment scale developed by Gordon, Philpot, Burt, Thompson and Spiller (1980). The three items selected to form the union commitment scale were the three that loaded highest on the union loyalty dimension of Gordon et al.'s factor analysis. These items closely parallel those of the company commitment scale. Martin et al. (1986) found the three item scale to correlate .86 with the total score of the 31 items comprising Gordon et al.'s (1980) union commitment scale, which provide evidence for the scale's convergent validity. Each item is rated on 7-point, Likert-type scale $(1=$ Strongly Disagree and $7=$ Strongly Agree $)$. I computed summary scores as the mean of the items, with higher scores indicating higher levels of commitment. Martin and Peterson (1987) reported the internal consistency reliability for this scale to be .78 .

\section{Role conflict and role ambiguity}

Both role stressors were measured using scales developed by (Rizzo et al., 1970). The role conflict scale focuses on the "congruency-incongruency or compatibility-incompatibility in the requirements of the role" (Rizzo et al., 1970, p. 
155). That is, the role conflict scale measures the degree to which an individual perceives that the demands placed on him or her from one role sender interferes with meeting the demands of other role sender. The role ambiguity scale concerns the degree to which role responsibilities are clearly defined and to which the outcomes of one's behavior are predictable. The items that comprise these scales have been found to load on factors that are clearly based on their respective constructs and demonstrate criterion-related validity (Rizzo et al., 1970). There are six items for each scale, which are all rated on 7-point, Likert-type scales $(1=$ Strongly Disagree and $7=$ Strongly Agree). I computed scores by taking the mean of the items for each scale, with higher scores indicating higher levels of role stress. The internal consistency was estimated by Rizzo et al. (1970) to be .82 for the role conflict scale and .80 for the role ambiguity scale.

\section{Emotional exhaustion}

Emotional exhaustion was measured using an abbreviated version of the corresponding dimension of the Maslach Burnout Inventory (Maslach et al., 1996). The emotional exhaustion scale assesses the degree to which an individual feels emotionally overextended and exhausted as a result of his or her work. The original scale consists of nine items, and has an internal consistency estimate of .90 and a testretest reliability based on an interval of 2 to 4 weeks of . 82 (Maslach, Jackson, \& Leiter, 1997). The emotional exhaustion scale has also been demonstrated to have strong construct validity (Koeske \& Koeske, 1989; Maslach et al., 1997). Three items 
were selected to form the abbreviated scale, and these three items had the strongest loadings (all were above .71) on the emotional exhaustion factor based on factor analyses of five separate samples (Koeske \& Koeske, 1989). The items were measured on 5-point, Likert-type scales ( $1=$ Strongly Disagree and $5=$ Strongly Agree $)$. I computed scale scores by taking the mean of the three items, with higher scores reflecting higher levels of emotional exhaustion.

\section{Design Issues}

Establishing internal validity is required to establish that any effects found for the experimental group, in this case those sites that employed crew chiefs, occurred as a result of the treatment, and would not have arisen if crew chiefs were not implemented (Cook et al., 1992). Maturation, statistical regression, and selection were controlled to a large extent by employing a control group. Maturation occurs when participants' responses on the dependent variable change because of changes in participants during the period of study (e.g., gaining seniority) rather than as a result of the treatment. Statistical regression is a general trend for extreme high and low scorers on the dependent variable at Time 1 to score closer to the mean at Time 2, even without treatment. Any maturation or statistical regression effects should be present in the control group as well as the experimental group.

Selection effects occur when the experimental and control groups have different characteristics that differentially affect the dependent variable. There was an effort to select control sites that were similar to the experimental sites in terms of their 
geographical location and demographic characteristics of the workforce. However, participants at the experimental sites may still differ in ways that may affect the results. Therefore, I examined the respondents' demographic characteristics as well as pre-test scores for differences at Time 1 to determine if selection and any interactions involving selection are legitimate threats in this study.

Testing occurs when the act of filling out Time 1 measures affects the scores of Time 2 measures. This threat should be of little concern given that the measures were attitudinal and not performance-oriented. In addition, the questionnaires were given one year apart, making it unlikely that respondents remembered what they answered previously. Diffusion of treatment, compensatory equalization of treatment, compensatory rivalry, and resentful demoralization should also be of little concern for this study, as the control sites were unaware that they were serving as controls. Employees at the control sites were informed that the questionnaires given were part of a yearly assessment of job attitudes.

History effects occur when an unexpected event takes place during the intervention that affects the dependent variable at Time 2. History is a concern in the current study, given that an organizational change event occurred during data collection that was intended to affect participant responses. To address this threat, I created a variable identifying those participants who filled out the Time 1 questionnaires before and after the reorganization, and I used this as a covariate when evaluating the hypotheses of Aim 1. Any threats from instrumentation are limited by employing instruments that contain the same questions from Time 1 to Time 2. 
However, the instruments do differ in that there were additional questions asked at Time 2, most notably those asking about the crew chief program. It may be possible for these additional items to influence participants' responses on the items comprising the dependent variables. However, these additional questions were necessary for evaluating Aim 2 and contained items that were of importance to the USPS and APWU regarding the crew chief program.

Mortality, or attrition, could confound the results of this study. This is apparent in that only 303 out of 661 participants (45.8\%) completed both Time 1 and Time 2 questionnaires. I further examined this potential threat by comparing those who were able to be strongly matched to those who were unmatched for differences in demographic characteristics. There were no differences in education, hours, tenure, age, sex, wave, race, or union membership after controlling for familywise type I error. There was an association of matching and group, $\chi^{2}(1)=14.80, p<.001$, such that participants in the control group were more likely to be matched. Of those participants who were enrolled from the experimental sites, $22.7 \%$ were strongly matched, whereas $37.6 \%$ of participants from the control sites were strongly matched. The effect size of this relationship was $\varphi=.15$ (approximately equal to a Cohen's $d$ of .30 ), indicating that the strength of the relationship between group and match is larger than Cohen's (1987) definition of a small effect size $(d=.20)$. Mortality effects may also be present as a result of unmeasured characteristics, such as job performance (e.g., employees who leave may be more likely to be poor performers, and poor performers have different job attitudes and perceptions than high performers). It is also 
important to note that these tests may not be a direct test of attrition effects because the nature of the matching does not distinguish between unmatched individuals who left the USPS and those who could not be matched.

\section{Analyses}

The analyses were based on data that were originally collected and prepared by Dr. Martin's research team. Before proceeding with the data analysis, I examined the variable distributions for normality by computing means, standard deviations, kurtosis and skewness statistics. Missing data for scale items were handled by requiring data for $80 \%$ of the items before computing a scale for a particular case (Downey \& King, 1998; Schafer \& Graham, 2002). The amount of the remaining missing data was very small (ranged from $0 \%$ to $1.7 \%$ for Aim 1 analyses and 1.2\% for Aim 2 analysis), and I handled any remaining missing data via maximum likelihood approaches embedded within the HLM and structural equation model analyses.

To avoid possible misinterpretation of the results because of pre-existing differences, demographic characteristics were included as control variables in the analyses where appropriate. Employee demographic differences, such as age, tenure, education and gender, may be important because they can affect initial attitudes (Macy, Peterson, \& Norton, 1989). Kahnweiler and Thompson (2000) examined demographic correlates of actual and desired decision making among 826 nonmanagerial employees, and found a nonlinear relationship with age, such that middle aged individuals were more likely to desire involvement than younger or older 
workers and that education was positively related to desired and perceived involvement in decisions. Employees with higher education levels wanted and believed they had more input in decisions than those employees with less education. They did not find gender differences in either desired or actual participation. Therefore, I decided to include education as a covariate and not to include gender as a covariate in the analyses.

Because initial interactions are an important factor in the development of highquality exchange relationships (Bauer \& Green, 1996; Dienesch \& Liden, 1986), it was important to control for tenure. Newer employees may have different attitudes when they first join the organization because they have not worked for their supervisor as long. Newer employees may also have a different perspective if they are entering at a time of better or worse labor relations. Hence, if tenure was not controlled, it could represent a potential alternate explanation for any changes that I might have found. Thus, it was important to control for tenure as well as education in this study. I did not control for age because of its high correlation with tenure, which can create multicollinearity problems in multivariate analyses. I gave priority to tenure because it is, by definition, more commensurate with and thus potentially more relevant to organizational outcomes than age. Although age has been found to have nonlinear effects with perceived participation (Kahnweiler \& Thompson, 2000) and is highly correlated with tenure, only the potential linear effects of tenure were controlled for because previous research has established a linear relationship with tenure and relationship quality (Bauer \& Green, 1996; Dienesch \& Liden, 1986). 
Because a major reorganization took place while Time 1 surveying was in progress, it was possible that these changes may have affected the results. I controlled for this by using a dummy variable created by the original research team dichotomizing the three sites that were surveyed before the reorganization and the second three sites that were surveyed after the reorganization.

\section{Hierarchical Linear Modeling}

I used hierarchical linear modeling (HLM) to test the hypotheses of the first aim, which center on evaluating the effects of the program on job satisfaction, company commitment, union commitment, role ambiguity, role conflict, emotional exhaustion, and mail processor satisfaction with supervision. HLM is well suited for analyzing data with independent variables at multiple levels with dependent variables at the lowest level (Hofmann, Griffin, \& Gavin, 2000). In this study, I considered work unit variables to be at the unit level and mail processor variables to be at the individual level. An important assumption in HLM is that cases at the lower level are nested within mutually exclusive cases at the higher level. In other words, mail processors cannot be nested within more than one work unit. Mail processors did not belong to intact groups, given that the structure of the mail processing teams at many sites allowed for the rotation of employees and/or crew chiefs/supervisors. Thus, I was not able to nest mail processors within supervisors or crew chiefs. However, I formed mutually exclusive groups by aggregating across sites by shift. These site by shift groups can be thought of as intact units because employees within each site by shift 
grouping are likely to have worked with each other and do not rotate across shifts or sites. These site by shift units also are likely to have developed their own climates and thus it is reasonable to assume that mail processors within units are more likely to exhibit similar attitudes versus employees between units.

The next step in the HLM process was to determine whether work-unit effects could explain variance in the dependent variable. It is inappropriate to evaluate research aims with inferential statistics that rely on the assumptions of independence of observations and constant variance when group level effects are present (Bryk \& Raudenbush, 1992). In HLM, the random error variance from the work-unit component is constant for all mail processors in a work-unit. That is, mail processors in the same work-unit share the same random error variance. Another problem with using individual level analyses when work-unit effects are present is that the standard errors of the work-unit variables are underestimated because they are calculated using the number of mail processors instead of the number of work-units. HLM resolves these issues by partitioning the error variance at the mail processor and work-unit levels (Hofmann et al., 2000). The first form of the intraclass correlation (ICC(1)), which is based on the ratio of between-group variance to total variance, can be interpreted as the proportion of the total variance in a variable that can be explained by group membership (Bryk \& Raudenbush, 1992). I computed the ICC(1) for each dependent variable to determine the degree to which work-unit effects were present. This estimate also provided an upper bound estimate for the variance that can be explained by work-unit predictors (Bliese, 2000). Currently, there is no criterion for a 
minimum value of the ICC(1) to reflect significant unit-level effects that I was able to locate. However, in Monte Carlo simulations of nested data, Donner and Klar (1996) found that values of the $\operatorname{ICC}(1)$ as little as .01 can lead to incorrect statistical conclusions if the within-group relationships are not accounted for. Donner and Klar recommend that when dealing with the random assignment of intact clusters, researchers should "inherently assume the existence of intracluster correlation rather than attempt to rule it out using statistical testing procedures" (Donner \& Klar, 1996, p. 437).

Estimates for the between-group and within-group variance were based on the results of a random-coefficient regression model. The random-coefficient regression model is similar to ordinary least squares regression in that only the mail processor independent variables are included at this step, but differs in that the intercepts and slopes are allowed to vary across mail processors. Regression equations at two levels, known as Level 1 and Level 2, are computed simultaneously. Level 1 involves the independent, control, and dependent variables at the mail processor level, whereas Level 2 uses the intercept and slopes from Level 1 as the dependent variables. In this step, I used only an intercept term and a residual term to predict the Level 1 intercept and slope. The results of this model demonstrate whether there is significant variation in the intercepts and slopes across work-units, which is indicated by a significant chisquare in the respective residual variance (Hofmann et al., 2000). The presence of significant variance in the residual term for the intercepts supports continuing to the intercepts-as-outcomes model, whereas the presence of significant variance in the 
residual for slopes indicates the appropriateness for testing a slopes-as-outcomes model.

The intercepts-as-outcomes model is a continuation of the random-coefficient model, with the addition of work-unit variables in Level 2 of the equation to predict the intercept of the Level 1 equation. If the addition of the work-unit variable of interest significantly reduces the residual between-groups variance in intercepts, then the work-unit variable of interest is related to the mail processor level dependent variable after partialling out the variance explained by mail processor predictor variables. Put in another way, the intercept represents the adjusted mean for each work-unit on the dependent variable of interest.

The interpretation of the Level 2 parameters may be difficult if measures do not have a meaningful zero point (Hofmann \& Gavin, 1998; Hofmann et al., 2000). When evaluating hypotheses using the intercepts-as-outcomes models, Hofmann and Gavin (1998) recommend centering variables around the overall or grand mean. With grand mean centering, the variance in the intercept term is equivalent to the between group variance in the dependent variable after controlling for the Level 1 dependent variables (Hofmann \& Gavin, 1998; Hofmann et al., 2000). Another advantage of centering the variables about the grand mean is that it reduces multicollinearity resulting from the correlation between intercept and slope estimates across groups (Hofmann \& Gavin, 1998).

My first research aim was to investigate whether the crew chief program was effective in improving mail processor satisfaction with supervision (Hypothesis 1), job 
satisfaction (Hypothesis 2), company (Hypothesis 3) and union commitment (Hypothesis 4) and in reducing role ambiguity (Hypothesis 8a), role conflict (Hypothesis 8b), and emotional exhaustion (Hypothesis 9) among mail processors. I used HLM to evaluate this aim rather than repeated-measures ANOVA because HLM takes into account that mail processors were nested within groups. I computed change scores for mail processors and crew chiefs by subtracting their score on a particular attitude at Time 1 from Time 2 . The variables in this analysis have a meaningful zero point, which reflects no change, and thus I did not center them to facilitate interpretation of the regression coefficients. Each of the 7 major study variables for mail processors were modeled as a dependent variable with control variables (education and tenure) serving as independent variables in the Level 1 analysis. If there was between group variance to be explained in the slope and/or intercept, then a dichotomous control variable representing time of administration $(0=$ before reorganization, 1 = after reorganization) and a dichotomous variable representing group $(0=$ control, $1=$ experimental $)$ were entered in the Level 2 equation. Thus, $I$ used the HLM equation that follows to predict each of the 7 dependent variables:

Level 1: $\Delta$ outcome $($ Time $2-$ Time 1$)=\beta_{0}+\beta_{1}($ Education $)+\beta_{2}($ Tenure $)+$ $\beta 3($ Outcome at Time 1) $+\mathrm{r}$

Level 2: $\beta_{0}=\gamma_{0}+\gamma_{1}$ (Group) $+\gamma_{2}$ (Time of administration $)+u_{0}$

A hypothesis was supported if the group coefficient was statistically significant and the sign of the coefficient $\left(\gamma_{1}\right)$ was positive, which indicates that the experimental 
sites demonstrated a greater amount of positive change in the outcome. The value of the coefficient would also indicate the difference in experimental and control group means after controlling for tenure, education, and time of administration.

\section{Structural Equation Modeling}

Aim 2 is concerned with testing a form of the SSO model using data from Time 2. The hypotheses that fall under this aim were that perceptions of crew chief support are negatively related to role stressors (Hypothesis 5a and Hypothesis 5b) and emotional exhaustion (Hypothesis 5c) and positively related to job satisfaction (Hypothesis 5d) and both forms of commitment (Hypothesis 5e and Hypothesis 5f). In addition, I hypothesized that perceptions of crew chief support would moderate the relationship between role stressors and emotion exhaustion (Hypothesis 6a and Hypothesis $6 \mathrm{~b}$ ) and the relationship between emotional exhaustion and job satisfaction (Hypothesis 6c). Finally, I hypothesized job satisfaction to be positively related to company (Hypothesis 7a) and union commitment (Hypothesis 7b).

The hypotheses of Aim 2 were evaluated using covariance structure modeling with maximum likelihood estimation from AMOS 5.0 (Arbuckle, 2003). To assess model fit, I examined the chi square statistic, the ratio of chi square to degrees of freedom, the Root Mean Square Error of Approximation (RMSEA), the Comparative Fit Index (CFI), and the Parsimony Comparative Fit Index (PCFI). The RMSEA is the error per degree of freedom of the fit of the covariance matrix implied by the model to the observed covariance matrix. The CFI compares the absolute fit of the specified 
model to the absolute fit of the independence model. The PCFI adjusts the CFI for the ratio of the degrees of freedom in the model to the degrees of freedom in the independence model, with values closer to 1.00 indicating better fit. My criteria for good model fit included a RMSEA of .08 or below (Browne \& Cudeck, 1993; MacCallum, Browne, \& Sugawara, 1996), and a CFI of .95 or above (Hu \& Bentler, 1999). In addition, I considered the model to exhibit good fit when most of the values in the standardized residual matrix were below a value of 1.96 . This corresponds to a $95 \%$ confidence interval around an assumed residual of 0 . A measurement model was not required, as I evaluated the model at the manifest level.

To test for interaction effects in the model, I formed interaction terms by multiplying the moderator variable by the independent variable (Li et al., 1998). For Hypotheses $6 \mathrm{a}, 6 \mathrm{~b}$, and $6 \mathrm{c}$ this resulted in a total of three interaction terms: role ambiguity X mail processor perceptions of crew chief support (Hypothesis 6a), role conflict X mail processor perceptions of crew chief support (Hypothesis $6 \mathrm{~b}$ ), and emotional exhaustion $\mathrm{X}$ mail processor perceptions of crew chief support (Hypothesis 6c). The overall model is depicted in Figure 3. 


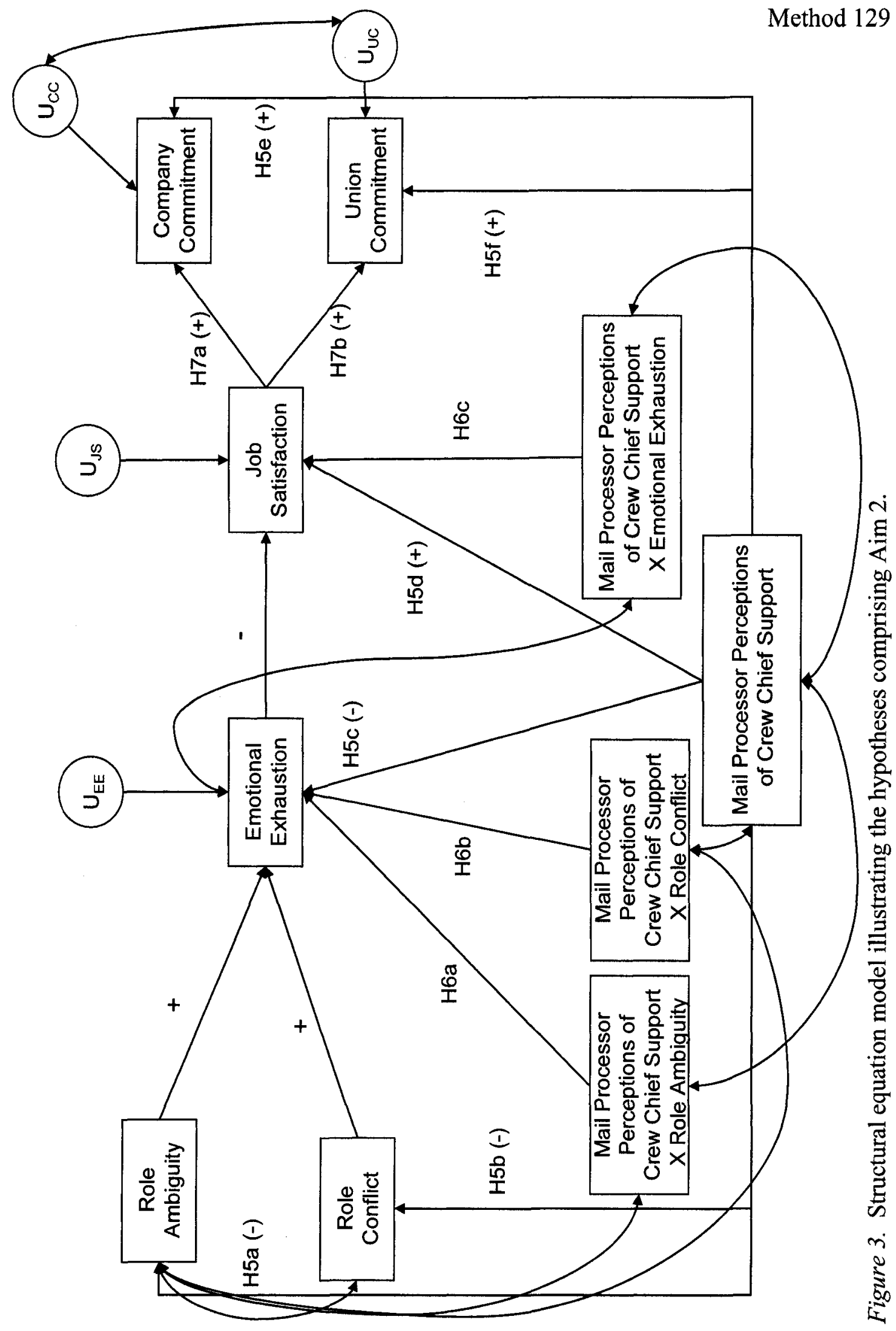


The sample for the covariance structure models consisted of the 538 mail processors from Time 2. Based on a power analysis with 538 cases, an alpha of .05, and 19 degrees of freedom, the structural equation model has $87 \%$ power to reject a model of close fit $(\mathrm{RMSEA}<=.05)$ if the model has truly mediocre fit $(\mathrm{RMSEA}=$ $.08), 85 \%$ power to reject a model of not close fit $(\mathrm{RMSEA}>.05)$ if the model has truly good fit $(\mathrm{RMSEA}=.01)$, and $90 \%$ power to reject a model of exact fit (RMSEA $=.00)$ if the model has truly adequate fit (RMSEA $=.05)$ (MacCallum et al., 1996).

The current study builds on previous research by simultaneously evaluating interaction and main effects in a covariance structure model, rather than testing moderator hypotheses via separate regression analyses for each outcome variable. Testing effects simultaneously is superior in that Type I error inflation is avoided and fit statistics are provided that enhance judging the adequacy of the model as a whole. Including interaction effects in the model is also consistent with a systems perspective in that I did not examine parts of the system in isolation. That is, I examined whether mail processor perceptions of support from their crew chief influenced the relationships between stressor and strain variables and strain and outcome variables. 
Chapter 7. Results

\section{Preliminary Analyses}

An examination of the distributions for each of the study variables revealed that all distributions approached normality. Thus, I did not perform any transformations on the variables. Because of the quasi-experimental nature of the current study, I examined whether there were differences in demographic characteristics at baseline. Comparisons of demographic characteristics at the control and intervention sites are presented in Table 5. I performed Fisher's exact test or chi square tests to determine differences across sites in categorical variables, and independent samples t-tests to investigate differences in continuous variables. None of these tests were significant, suggesting that the distributions of demographic characteristics were similar across the intervention and control sites. This provides some evidence for the equivalency of groups at baseline. 
Table 5

Demographic characteristics by group and for total sample at baseline

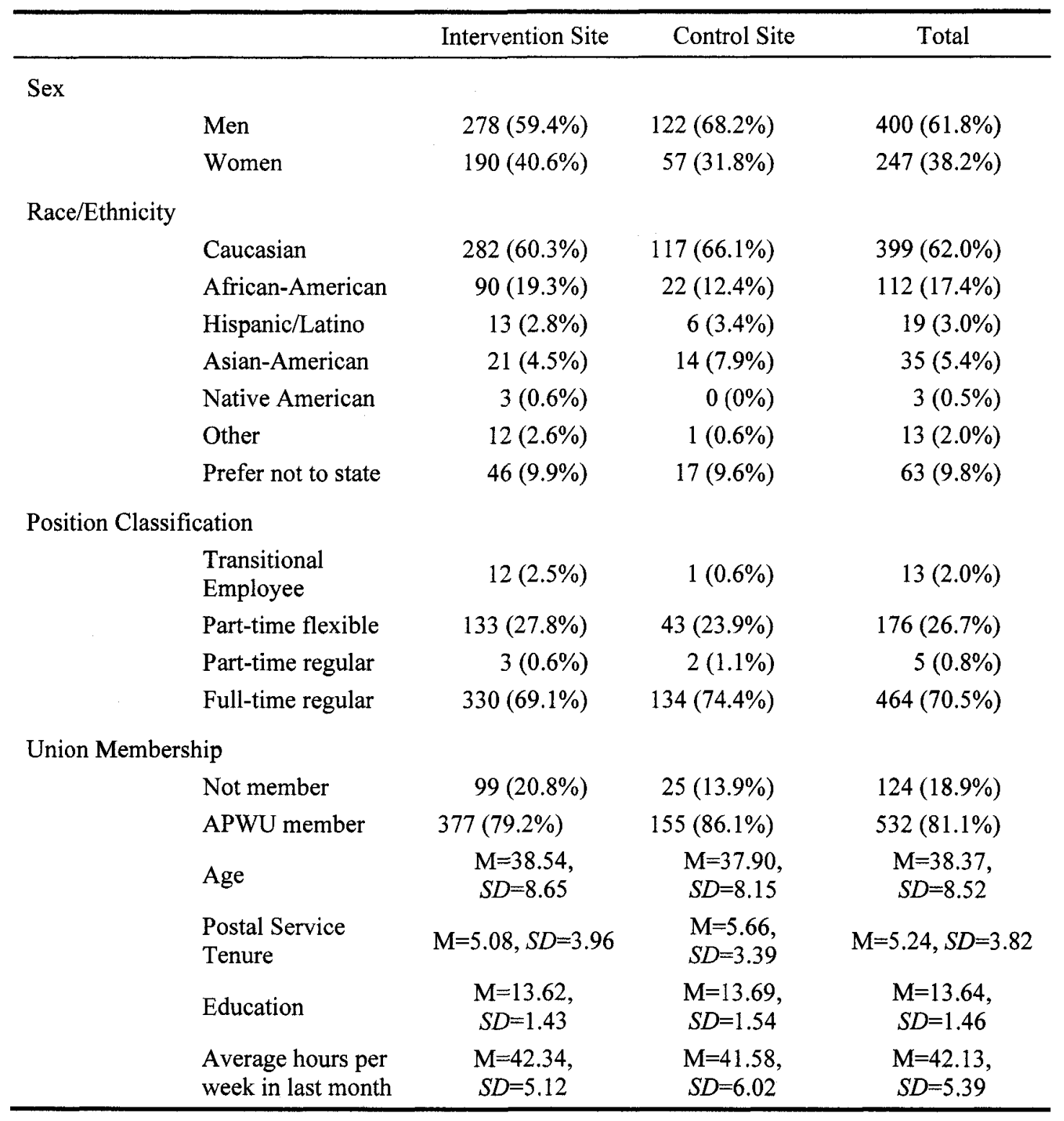


The total sample at baseline consisted of $61.8 \%$ men with a mean age of 38.37 years $(S D=8.52)$ and mean years of education of $13.64(S D=1.46)$. Sixty-two percent of the participants were Caucasian, $17.4 \%$ were African-American, $5.4 \%$ were Asian-American, 3.0\% were Hispanic/Latino, 2.5\% were Native American or other, and $9.8 \%$ of the sample preferred not to state their race/ethnicity. Most of the sample belonged to the APWU union (81.1\%), and had worked for the postal service an average of 5.24 years $(S D=3.82)$. The mean number of hours per week worked in the last month was 42.13 hours $(S D=5.39)$, where $70.5 \%$ of the sample were classified as full-time regular employees, $26.7 \%$ as part-time flexible, and $2.8 \%$ as either transitional or part-time regular.

I provide the means, standard deviations, Cronbach's alpha, and scale intercorrelations for Time 1 and Time 2 in Table 6 and Table 7, respectively. The correlation coefficients among the study variables are very similar from Time 1 to Time 2, with the exception of the relationships of the variables with USPS tenure. At Time 1, the correlations between USPS tenure and the other variables are almost all nonsignificant, whereas the relationships are all significant at Time 2. 


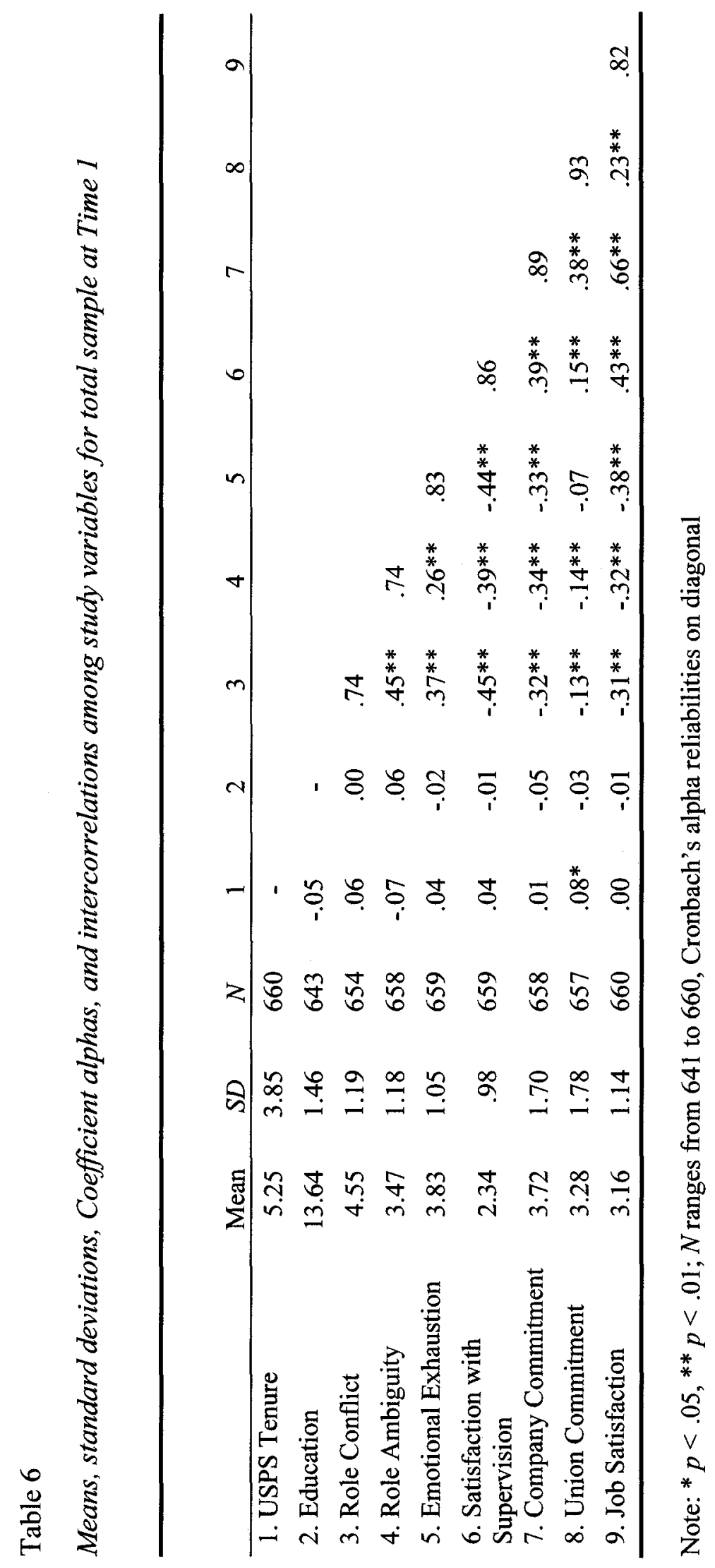

Results 134 


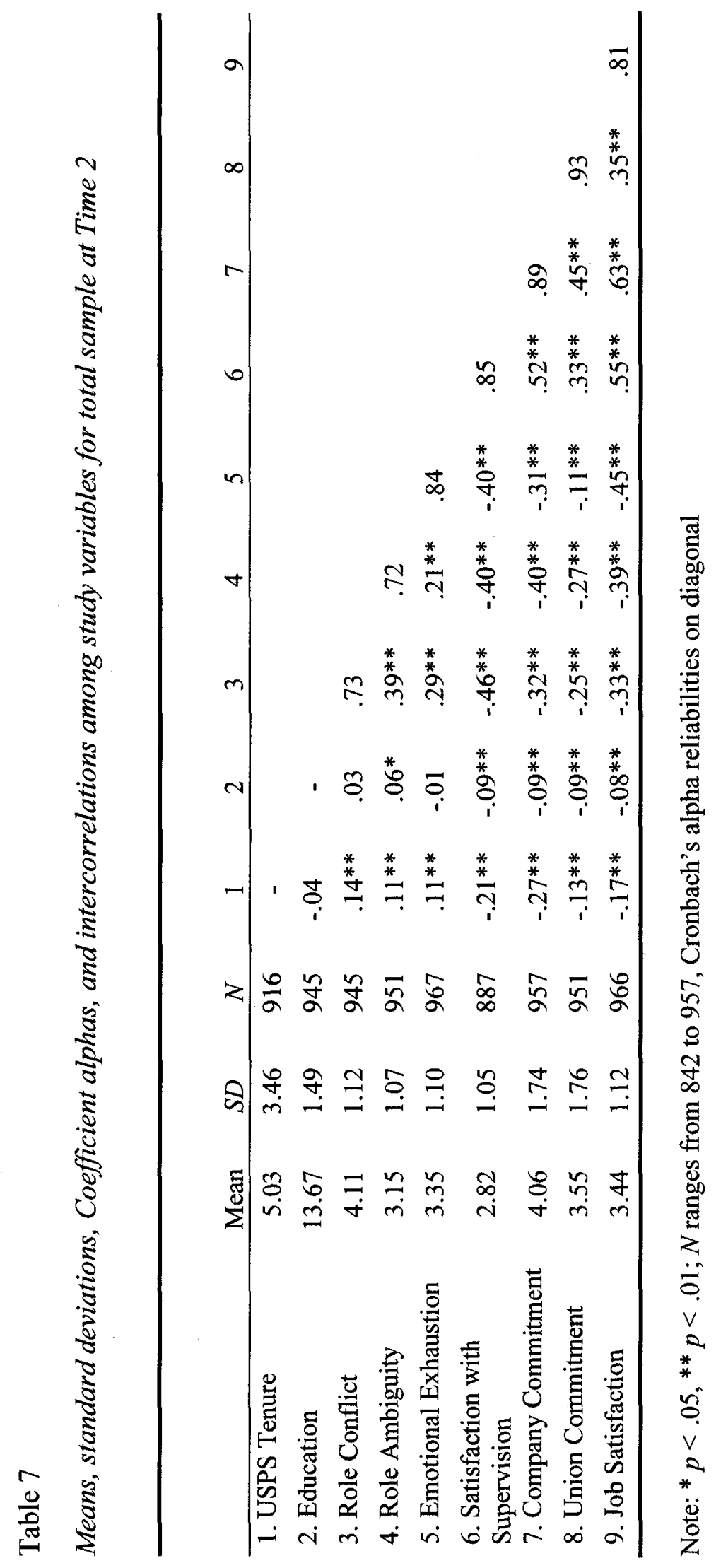

Results 135 
Table 8 presents the intercorrelations among the study variables at Time 1 and Time 2 for the subsample that I used to evaluate the hypotheses of Aim 1. Recall that this subsample contains only those cases that I was able to confidently match across the two timepoints $(n=177)$. In this subsample, the pattern of correlations at Time 1 is very similar to the correlations at Time 2 . Even the relationships between postal service tenure and the study variables were similar across the two time points, unlike the pattern found between the two time points in the full sample.

One possible explanation for this result may be the increase in newly hired employees that were present at Time 2 , as indicated by the smaller mean tenure at Time $2(\mathrm{M}=5.03, S D=3.46)$ compared to Time $1(\mathrm{M}=5.25, S D=3.85)$ and increase in number employees from Time $1(N=660)$ to Time $2(N=916)$. Thus, it seems plausible that the combination of reduced range restriction and increased $N$ at Time 2 influenced the level and significance of the correlations of tenure with the study variables.

I also tested for demographic differences between the intervention and control sites in the Aim 1 subsample. Of the demographic characteristics, I found only one significant difference. Employees at the control sites $(M=7.52, S D=3.62)$ had more tenure at the postal service than the intervention sites $(M=5.61, S D=3.00), t(175)=$ $3.79, p<.01$. However, it is important to note that I controlled for tenure in the Aim 1 analyses, which would mitigate any confounding effects as a result of differences in tenure. 
Results 137

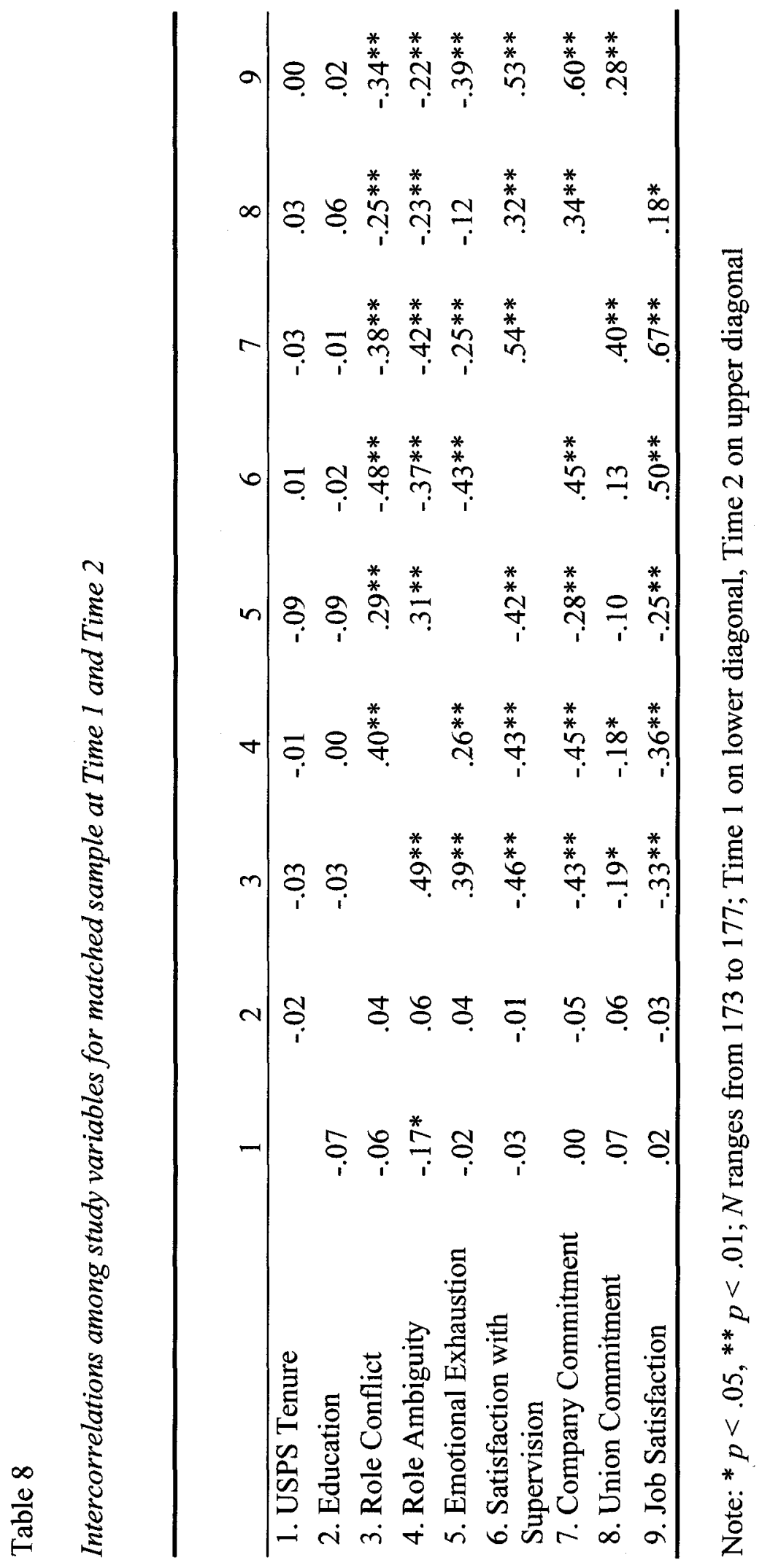


Results 138

Table 9 provides the means and standard deviations for the Aim 1 subsample. For the subsample as a whole, role conflict decreased from Time $1(M=4.58, S D=$ $1.24)$ to Time $2(M=4.37, S D=1.18), t(173)=2.73, p<.01$, and role ambiguity decreased from Time $1(M=3.45, S D=1.13)$ to Time $2(M=3.26, S D=1.07), t(175)$ $=2.33, p=.02$. Emotional exhaustion decreased from Time $1(M=3.82, S D=1.01)$ to Time $2(M=3.66, S D=1.08), t(176)=2.09, p=.04$. Employees also reported more satisfaction with their supervision at Time $2(M=2.53, S D=1.03)$ compared to Time $1(M=2.36, S D=0.97), t(176)=2.30, p=.02$. However, union commitment decreased from Time $1(M=3.33, S D=1.74)$ to Time $2(M=3.02, S D=1.69), t(175)$ $=2.72, p<.01$. There were no differences from Time 1 to Time 2 in job satisfaction and company commitment. It is also important to note that implementing a Bonferronni correction to control for familywise Type I error (.05/7 tests) would result in statistically significant differences only for role conflict and union commitment $(p$ $<.007)$. 
Table 9

Means and standard deviations of study variables for matched sample at Time 1 and Time 2

Time 1

Time 2

\begin{tabular}{lrrrrrc} 
& Mean & $S D$ & $N$ & Mean & $S D$ & $N$ \\
\hline 1. USPS Tenure & 5.28 & 3.26 & 177 & 6.34 & 3.37 & 177 \\
2. Education & 13.75 & 1.57 & 175 & 13.90 & 1.50 & 176 \\
3. Role Conflict & 4.58 & 1.24 & 176 & 4.37 & 1.18 & 174 \\
4. Role Ambiguity & 3.45 & 1.13 & 177 & 3.26 & 1.07 & 176 \\
5. Emotional Exhaustion & 3.82 & 1.01 & 177 & 3.66 & 1.08 & 177 \\
6. Satisfaction with & & & & & & \\
Supervision & 2.36 & 0.97 & 177 & 2.53 & 1.03 & 177 \\
7. Company Commitment & 3.83 & 1.69 & 177 & 3.70 & 1.73 & 176 \\
8. Union Commitment & 3.33 & 1.74 & 177 & 3.02 & 1.69 & 176 \\
9. Job Satisfaction & 3.23 & 1.10 & 177 & 3.15 & 1.14 & 177 \\
\hline
\end{tabular}

\section{Analysis of Aim 1}

I evaluated all of the hypotheses of Aim 1, which centers on the effectiveness of the crew chief program, with HLM. The first step is to establish that there was significant variance available to be explained by group level variables. Therefore, each of the seven difference scores for the outcomes of interest were regressed on the Time 1 score of the corresponding outcome variable, education, and tenure. Table 10 presents the results of the unconditional tests, including the reliabilities of the intercepts (an estimate of how well the observed means $\left(B_{0}\right)$ for each work unit are indicative of the true means), the intraclass correlations (percentage of variance that can be explained by work unit level variables), and the residual variance estimates and 
the associated chi-square tests of those residual variances. To continue to the intercepts-as-outcomes regression model, there must be significant variance present for Level 2 predictors to explain.

Table 10

Overall model results of the unconditional random-coefficients regression models for each outcome variable

\begin{tabular}{lccccc}
\hline \multicolumn{1}{c}{ Outcome } & $\begin{array}{c}\text { Reliability } \\
\text { of } \mathrm{B}_{0}\end{array}$ & $\begin{array}{c}\text { Intraclass } \\
\text { Correlation } \\
\text { (ICC) }\end{array}$ & $\begin{array}{c}\text { Variance } \\
\text { of } \mathrm{U}_{0}\end{array}$ & $\begin{array}{c}\chi^{2} \text { Test of } \\
\mathrm{U}_{0}\end{array}$ & P value of $\chi^{2}$ \\
\hline Role Conflict & .12 & .02 & 0.02 & $31.37(25)$ & .18 \\
$\begin{array}{l}\text { Role Ambiguity } \\
\text { Emotional }\end{array}$ & .06 & .01 & 0.01 & $24.97(25)$ & $>.50$ \\
$\begin{array}{l}\text { Exhaustion } \\
\text { Satisfaction with }\end{array}$ & .00 & .00 & 0.00 & $18.94(25)$ & $>.50$ \\
$\begin{array}{l}\text { Supervision } \\
\text { Company }\end{array}$ & .54 & .17 & 0.13 & $58.34(25)$ & $<.01$ \\
$\begin{array}{l}\text { Commitment } \\
\text { Union Commitment }\end{array}$ & .17 & .03 & 0.05 & $30.82(25)$ & .20 \\
Job Satisfaction & .23 & .04 & 0.07 & $31.89(25)$ & .16 \\
\hline
\end{tabular}

Based on the results of the unconditional tests, it appears that there is not significant variance available to be explained by group-level variables for most of the outcome variables of interest. There was almost no residual variance in $\mathrm{B}_{0}$ for role ambiguity $\left(\mathrm{ICC}=.01 ; \mathrm{U}_{0}=.01, \chi^{2}(25)=24.97, p>.50\right)$ and emotional exhaustion $\left(\mathrm{ICC}=.00 ; \mathrm{U}_{0}=.00, \chi^{2}(25)=18.94, p>.50\right)$. There was no significant residual variance in company commitment $\left(\mathrm{ICC}=.03 ; \mathrm{U}_{0}=.05, \chi^{2}(25)=30.82, p=.20\right)$, role 
conflict $\left(\mathrm{ICC}=.02 ; \mathrm{U}_{0}=.02, \chi^{2}(25)=31.37, p=.18\right)$, or union commitment $(\mathrm{ICC}=$ $\left..04 ; \mathrm{U}_{0}=.07, \chi^{2}(25)=31.89, p=.16\right)$. Thus, there was no support for Hypothesis 3 , Hypothesis 4, Hypothesis 8a, Hypothesis 8b, and Hypothesis 9. After controlling for education and tenure, there was no variance in company or union commitment, role conflict, role ambiguity, or emotional exhaustion at the work unit level to be explained by the intervention. There was marginally significant residual variance in job satisfaction $\left(\mathrm{ICC}=.06 ; \mathrm{U}_{0}=.05, \chi^{2}(25)=35.41, p=.08\right)$. The only outcome to have significant residual variance was satisfaction with supervision $\left(\mathrm{ICC}=.17 ; \mathrm{U}_{0}=.13, \chi^{2}\right.$ $(25)=58.34, p<.01)$. Although the residual variance was only marginally significant for job satisfaction, I proceeded to evaluate the intercepts-as-outcomes model for this variable and satisfaction with supervision to determine whether the intervention accounted for significant variance in the intercept.

Two variables were entered in the Level 2 intercept equation for supervision and job satisfaction, time of administration (covariate) and group (intervention vs. control). Recall that mail processors were nested within site by tour units. I present the results of these analyses in Table 11 and Table 12. For satisfaction with supervision, there was no significant improvement in the model as indicated by the reduction in the deviance statistic of $1.22(2), p>.50$. This indicates that the addition of time of administration and group did not significantly improve fit compared to the unconditional model. Given the non-significant change in fit, it is not surprising that the parameter coefficient for group was also not significant, $(\lambda=.09, p=.65)$. Thus, there were no significant differences in the change scores for satisfaction with 
supervision between the control or crew chief sites. The model did indicate that there is still significant variance left to explain in satisfaction with supervision difference scores, $\mathrm{U}_{0}=.12, \chi^{2}(25)=57.34, p<.01$.

Table 11

Overall model results of the intercepts-as-outcomes random-coefficients regression models for satisfaction with supervision and job satisfaction

\begin{tabular}{lccccc}
\hline \multicolumn{1}{c}{ Outcome } & $\begin{array}{c}\text { Reliability of } \\
\mathrm{B}_{0}\end{array}$ & $\begin{array}{c}\text { Intraclass } \\
\text { Correlation } \\
(\mathrm{ICC})\end{array}$ & $\begin{array}{c}\text { Variance of } \\
\mathrm{U}_{0}\end{array}$ & $\begin{array}{c}\chi^{2} \text { Test of } \\
\mathrm{U}_{0}\end{array}$ & $\begin{array}{c}\text { P value of } \\
\chi^{2}\end{array}$ \\
\hline $\begin{array}{l}\text { Satisfaction with } \\
\text { Supervision }\end{array}$ & .53 & .16 & 0.12 & $57.34(23)$ & $<.01$ \\
Job Satisfaction & .26 & .05 & 0.07 & $35.12(23)$ & .05 \\
\hline
\end{tabular}


Results 143

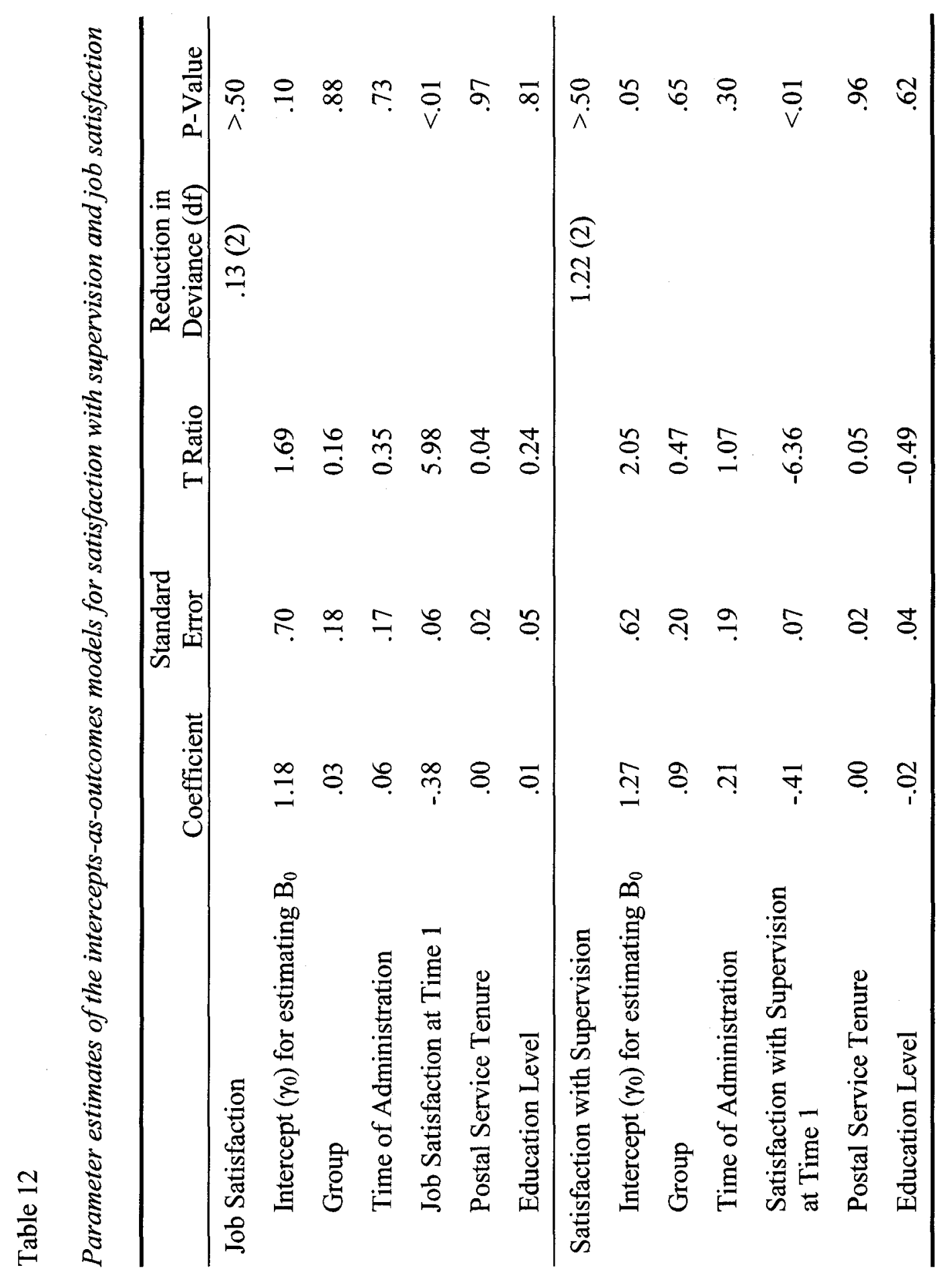


The reduction in the deviance statistic was also non-significant for job satisfaction, deviance $=.13(2), p>.50$, indicating that the addition of the Level 2 predictors did not improve the fit of the model. The parameter coefficient for group was non-significant $(\lambda=.03, p=.73)$, suggesting that the crew chief intervention did not have an effect on job satisfaction. However, there was additional variance left to be explained in job satisfaction difference scores $\left(\mathrm{U}_{0}=.05, \chi^{2}(25)=35.12, p=.05\right)$. In summary, there was no support for any of the hypotheses of Aim 1, suggesting there were no significant differences between the control and crew chief sites in the amount of change in role conflict, role ambiguity, emotional exhaustion, satisfaction with supervision, company commitment, union commitment, and job satisfaction.

\section{Analysis of Aim 2}

The hypotheses of Aim 2 were evaluated on a subsample of the data consisting of participants at the experimental sites at Time $2(N=538)$. The following analyses seek to replicate and extend the stressor-strain-outcome model of stress and to test whether support from crew chiefs moderates the relationships between stressors and strain and strain and outcomes.

The means, standard deviations, and the intercorrelations among the variables of interest are presented in Table 13. Consistent with Hypotheses H5a to H5c, mail processor perceptions of crew chief support were negatively related to role ambiguity $(r=-.29, p<.01)$, role conflict $(r=-.36, p<.01)$, and emotional exhaustion $(r=-.18$, $p<.01)$. Mail processor perceptions of crew chief support were also positively related 
to job satisfaction $(r=.31, p<.01)$, union commitment $(r=.35, p<.01)$, and company commitment $(r=.30, p<.05)$, consistent with hypotheses $5 \mathrm{~d}$ to $5 \mathrm{f}$, respectively. Hypotheses $7 \mathrm{a}$ and $7 \mathrm{~b}$ also have some support, in that job satisfaction is positively related to company commitment $(r=.68, p<.01)$ and union commitment $(r$ $=.33, p<.01)$. 


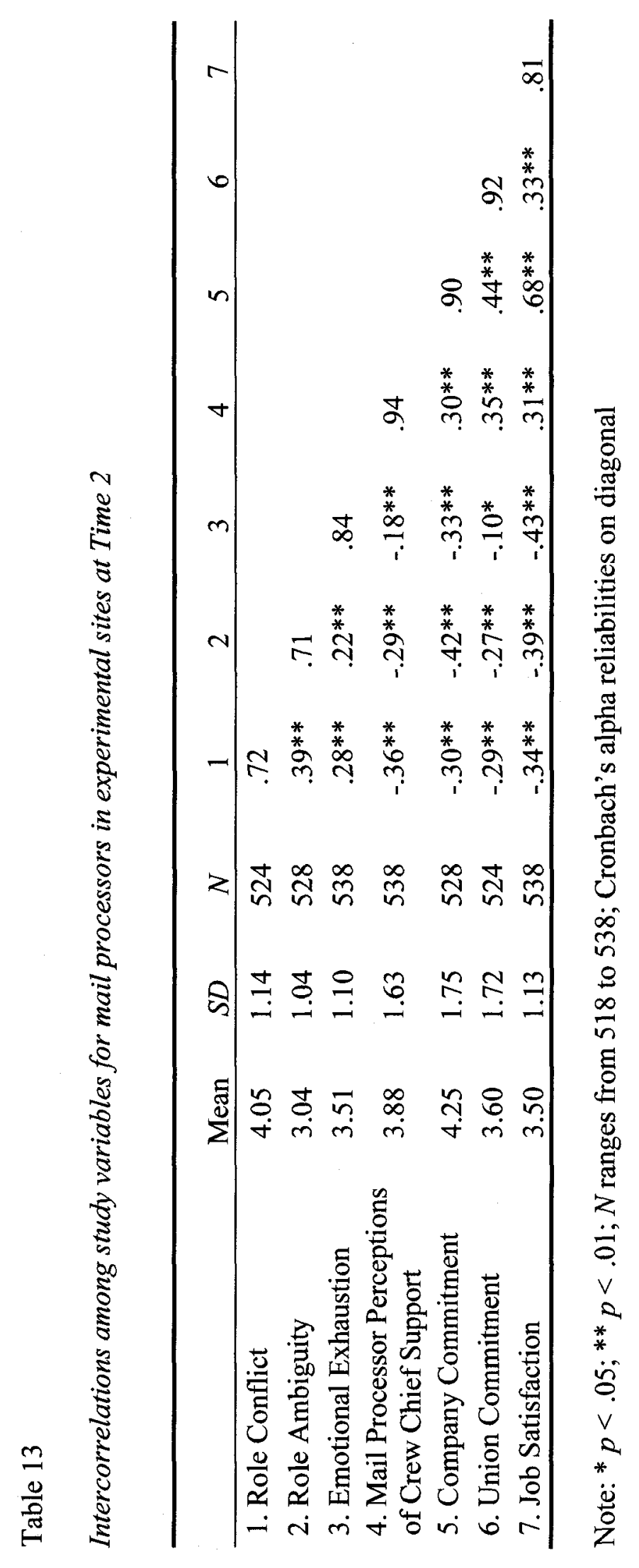

Results 146 
I evaluated the hypotheses of Aim 2 with structural equation modeling, which simultaneously models all of the hypothesized relationships, allows the inclusion of multiple endogenous (dependent) variables, and provides fit statistics for the overall model. I tested an initial model, as outlined in Figure 3 without including the interaction effects, to establish support for the main effect hypotheses (H5 and H7). I present the overall fit statistics for all of the structural equation models in Table 14. The initial model had poor fit, $\chi^{2}(8)=90.39, p<.01, \mathrm{RMSEA}=.14, \mathrm{CFI}=.91, \mathrm{NFI}=$ .91 . The path from crew chief support to emotional exhaustion was non-significant, $\beta$ $=-.05, p=.10$, and was subsequently dropped from the model. An inspection of the modification indices and standardized residuals suggested that adding paths from role ambiguity to job satisfaction, to company commitment, and to union commitment would significantly improve the model. Because of the plausibility of these paths (cf. A. Cohen, 1992; Fullagar \& Barling, 1991; O' Driscoll \& Beehr, 1994; Schaubroeck et al., 1989),, they were included as part of the final model. The final non-interaction model exhibited very good fit $\left(\chi^{2}(6)=19.65, p<.01, \mathrm{RMSEA}=.07, \mathrm{CFI}=.99, \mathrm{NFI}=\right.$ 98). 
Table 14

Overall fit statistics for structural equation models

\begin{tabular}{lcccccc}
\hline & $\chi^{2}$ & $\chi^{2} / \mathrm{df}$ & RMSEA & CFI & PCFI & NFI \\
\hline $\begin{array}{l}\text { Initial Non-Interaction } \\
\text { Model }\end{array}$ & $90.39(8)$ & 11.30 & .14 & .91 & .26 & .91 \\
$\begin{array}{l}\text { Final Non-Interaction } \\
\text { Model }\end{array}$ & $19.65(6)$ & 3.28 & .07 & .99 & .21 & .98 \\
Initial Interaction Model & $32.06(18)$ & 1.78 & .04 & .99 & .32 & .97 \\
\hline
\end{tabular}

The next step was to test the model including the moderator effects. I included three additional variables, representing the interaction of role conflict and crew chief support, role ambiguity and crew chief support, and emotional exhaustion and crew chief support, to the final non-interaction model. I centered all of the variables that were involved in the interaction terms to reduce the inherent multicollinearity of variables that are multiplicative derivatives of other variables in the model. The fit for the initial interaction model was good, $\chi^{2}(18)=32.06$, RMSEA $=.04, \mathrm{CFI}=.99$, NFI $=.97$. However, an inspection of the parameter estimates for the paths involving the interaction terms revealed that these three paths were not significant.

The relationship between the interaction term of crew chief support $\times$ role ambiguity to emotional exhaustion was not significant, $\beta<.01, p=.93$. The interaction term of crew chief support and role conflict was not significantly related to emotional exhaustion, $\beta=-.04, p=.11$. In addition, the path from crew chief support $\times$ emotional exhaustion to job satisfaction was not significant, $\beta=.01, p=.73$. These findings fail to support Hypotheses $6 \mathrm{a}, 6 \mathrm{~b}$, and $6 \mathrm{c}$, that crew chief support moderates 
the relationships between role ambiguity and emotional exhaustion, role conflict and emotional exhaustion, and emotional exhaustion and job satisfaction, respectively. I also tested these interactions in separate models to rule out non-significance as a result of multicollinearity. Even when evaluated separately, the relationships involving these moderator variables remained non-significant. Thus, the final non-interaction model also serves as the final model.

I present the parameter estimates for the final model in Table 15 and Figure 4. In support of Hypothesis 5a, mail processor perceptions of crew chief support were negatively related to mail processor role ambiguity, $\beta=-.28, p<.01$. Increased support from crew chiefs was associated with less role ambiguity for mail processors. Hypothesis $5 \mathrm{~b}$ was also supported, such that mail processor perceptions of crew chief support were negatively related to mail processor role conflict, $\beta=-.36, p<.01$. Higher support from crew chiefs was associated with less role conflict for mail processors. There was also support for Hypothesis $5 \mathrm{~d}$, in that mail processor perceptions of crew chief support were positively related to mail processor job satisfaction, $\beta=.18, p<.01$. More positive perceptions in crew chief support were associated with increased job satisfaction. Hypotheses 5e and $5 f$ were also supported, such that mail processor perceptions of crew chief support were positively related to mail processor company commitment $(\beta=.07, p=.03)$ and union commitment $(\beta=$ $.26, p<.01$ ), respectively. Increased crew chief support was associated with increased company and union commitment. 


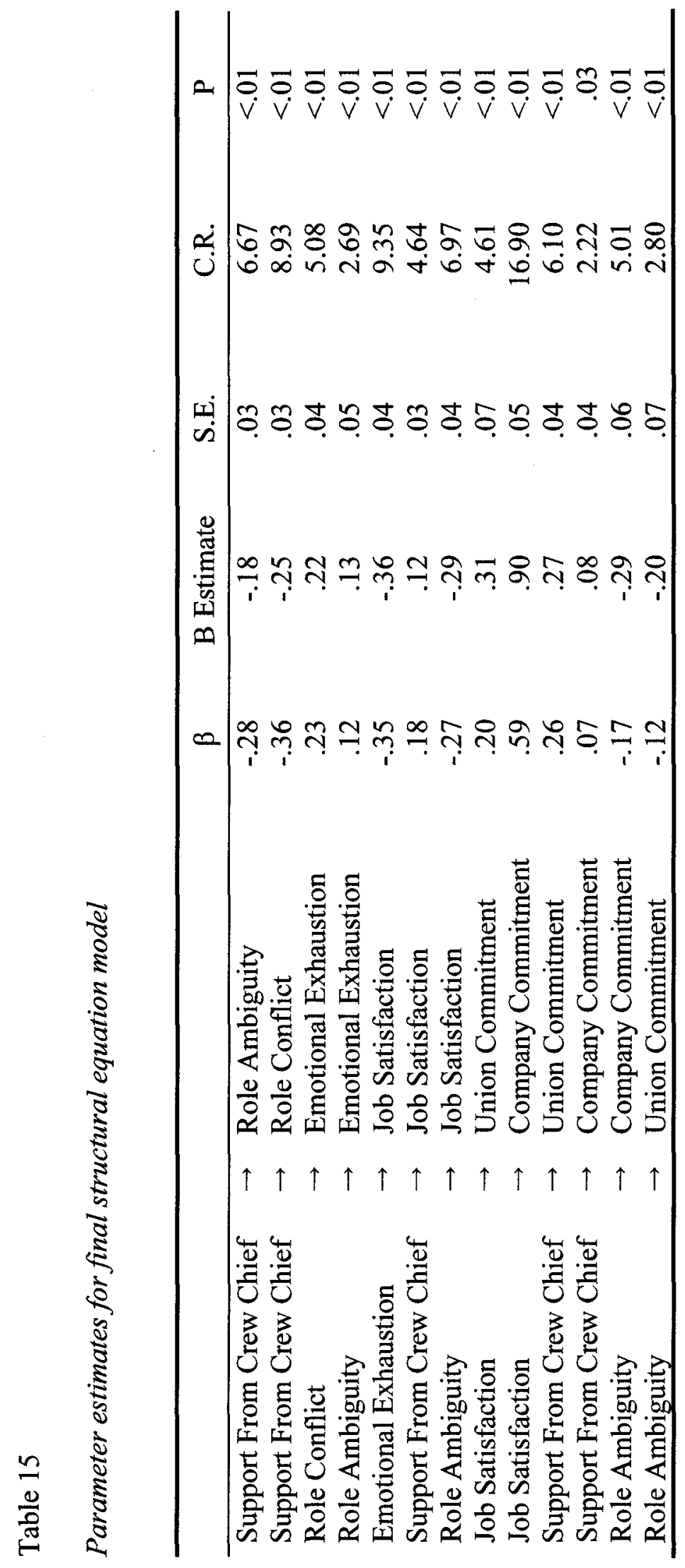

Results 150 


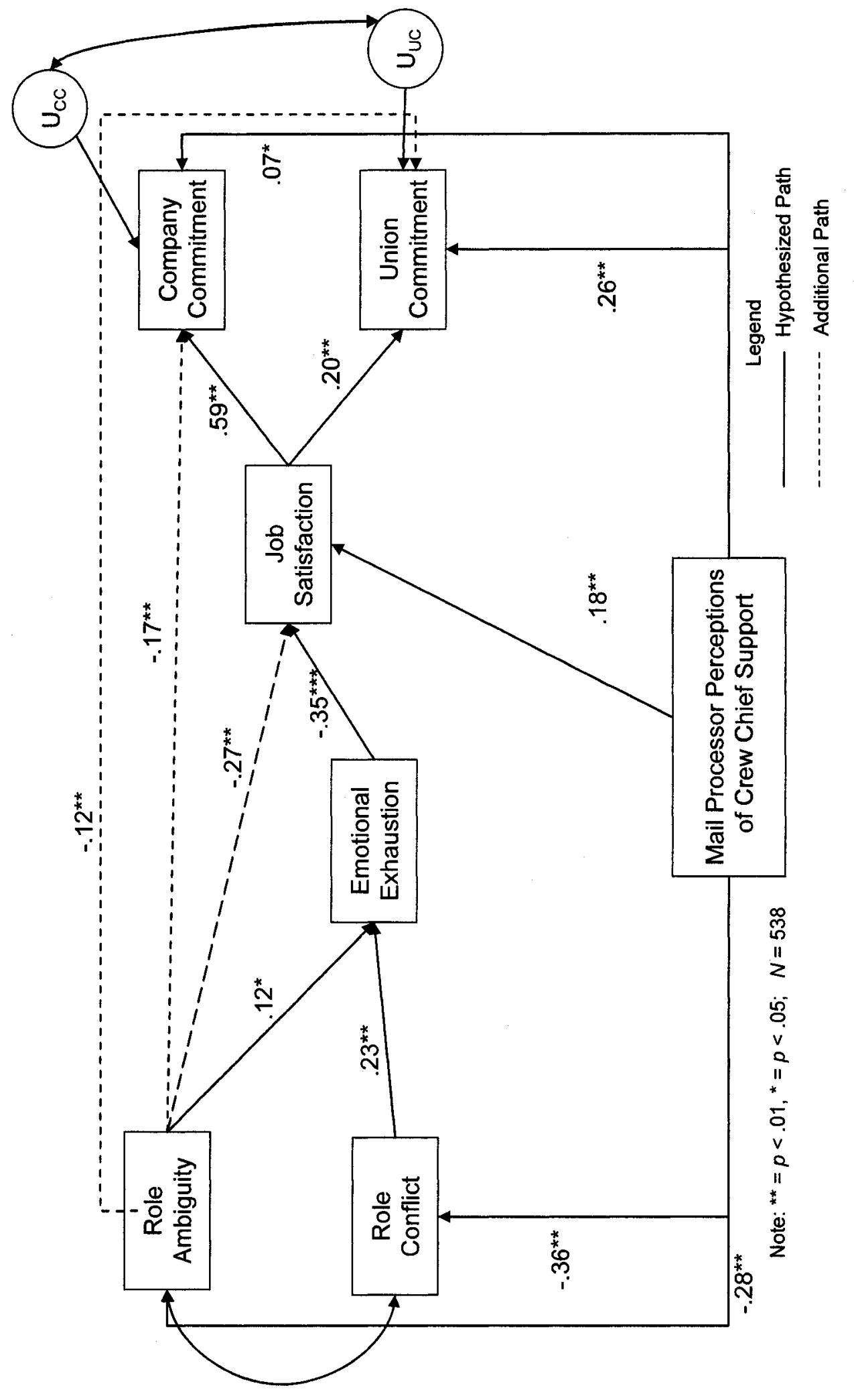

Results 151

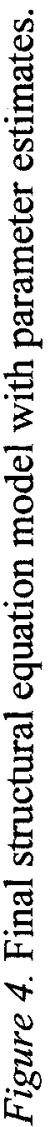


Consistent with the stressor-strain-outcome model, role ambiguity $(\beta=.12, p$ $<.01)$ and role conflict were positively associated with emotional exhaustion $(\beta=.23$, $p<.01)$. Thus, increased role ambiguity and role conflict were associated with more emotional exhaustion. Also consistent with the stressor-strain-outcomes model, the strain-outcomes component was supported with the finding that emotional exhaustion was negatively related to job satisfaction, $\beta=-.35, p<.01$. Higher emotional exhaustion was associated with less job satisfaction.

Job satisfaction was positively related to company commitment, $\beta=.59, p$ $<.01$, which provides support for Hypothesis 7a. Higher levels of job satisfaction were associated with higher levels of company commitment. There was also support for Hypothesis $7 b$, in that job satisfaction was positively related to union commitment, $\beta=$ $.20, p<.01$. Higher levels of job satisfaction were linked to higher levels of union commitment.

Table 16 presents the squared multiple correlations for each of the endogenous variables in the model. The squared multiple correlation represents the proportion of the variance explained in a dependent variable by the other variables in the model. The most variance was explained in company commitment (49\%), followed by job satisfaction (30\%) and union commitment (19\%). The stress and strain variables in the model had similar amounts of variance explained, with $13 \%$ of the variance accounted for in role conflict, $9 \%$ in emotional exhaustion, and $8 \%$ in role ambiguity. 
Table 16

$R$-squared estimates for the endogenous variables in the final structural equation model

\begin{tabular}{ll}
\hline & $\mathrm{R}^{2}$ \\
\hline Role Ambiguity & .08 \\
Role Conflict & .13 \\
Emotional Exhaustion & .09 \\
Job Satisfaction & .30 \\
Company Commitment & .49 \\
Union Commitment & .19 \\
\hline
\end{tabular}

To understand the systemic nature of the relationships involved in this model, one must take into account the indirect as well as the direct effect when attempting to assess the impact of a one unit change in one variable on another variable. Although evaluating the total effects is most valuable when evaluating causal models with the primary purpose of prediction, examining the total effects has utility in cross-sectional designs as it may reveal variables with small direct effects that have large indirect effects.

I present the total standardized and unstandardized effects of each independent variable in the model on each dependent variable in Table 17. This table summarizes the expected change in a dependent variable given a one unit change in the independent variable, taking into account the direct and indirect relationships specified in the model. This view of the results provides a more systems view of association among variables. For example, when examining only the direct effects, one finds that a 1.00 standardized unit increase in role ambiguity is associated with a .17 
standardized unit decrease in company commitment. However, the size of the effect changes if the indirect effects of role ambiguity on company commitment are taken into account. These additional paths include:

Role ambiguity $\rightarrow$ Emotional exhaustion $\rightarrow$ Job satisfaction $\rightarrow$ Company commitment

Role ambiguity $\rightarrow$ Job satisfaction $\rightarrow$ Company commitment Thus, a 1.00 standardized unit increase in role ambiguity (read from the column) is associated with a total decrease of .35 standardized units in company commitment (row), which is $106 \%$ larger than the direct effect alone. 


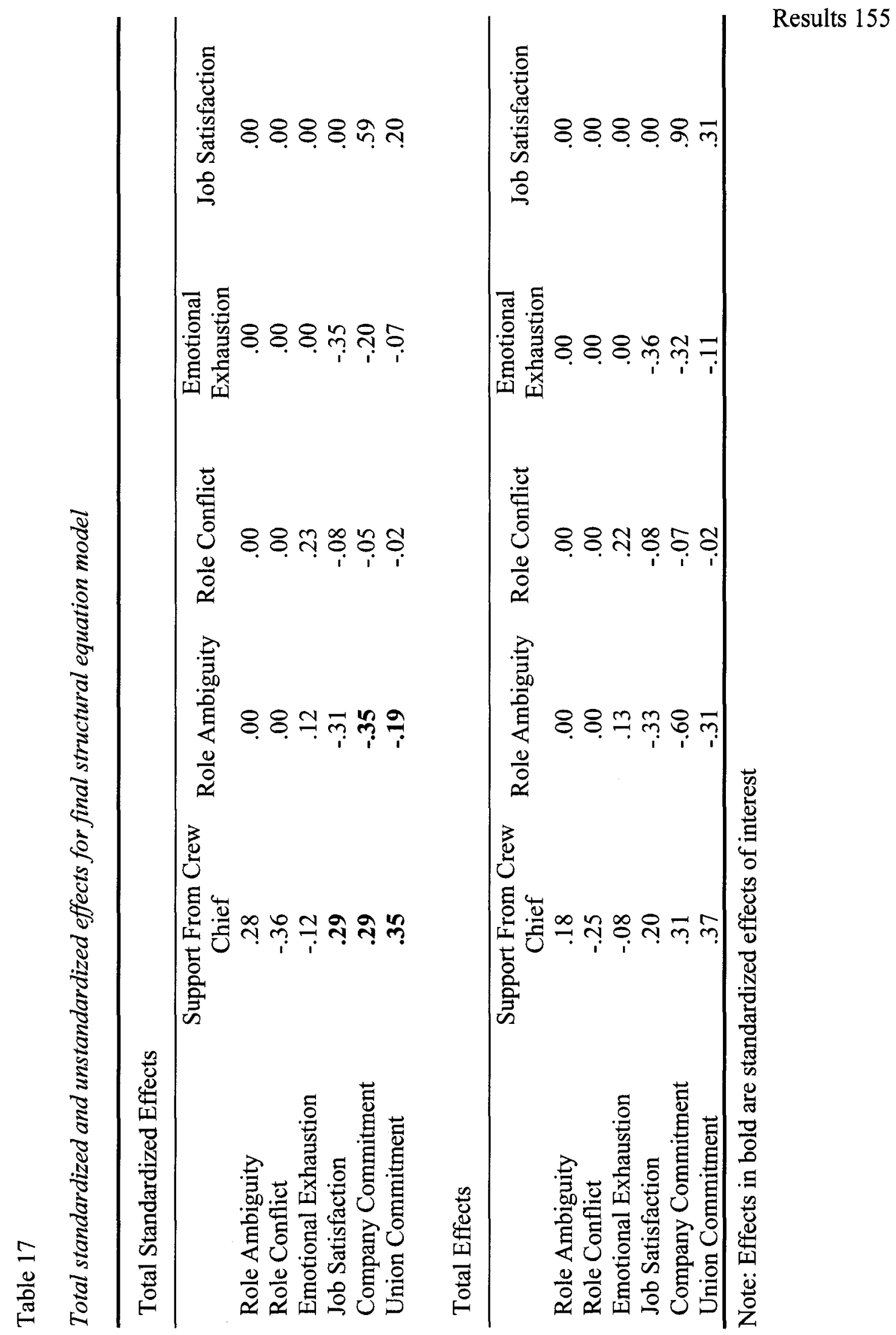


The total effects of most interest are bolded in Table 17, which includes the effects described above. A 1.00 standardized unit increase in role ambiguity is associated with a .19 standardized unit decrease in union commitment, which is $58 \%$ larger than the direct effect alone. The indirect effects for the relationship between crew chief support and union commitment, job satisfaction, and company commitment are also large compared to the direct component. A 1.00 standardized unit increase in crew chief support is linked with a .35 standardized unit increase in union commitment ( $35 \%$ larger than the direct effect alone), a .29 standardized unit increase in job satisfaction ( $61 \%$ larger than the direct effect alone), and a .29 standardized unit increase in company commitment (314\% larger than the direct effect alone). Based on this examination of the total effects, it appears that role ambiguity and crew chief support demonstrate stronger relationships with commitment and job satisfaction than suggested by the examination of the direct effects alone. 
One of the advantages of secondary data analysis is the ability to track what has happened since the pilot testing of the intervention occurred. The last government documents that I were able to obtain that discussed the crew chief program was a report and statement to the Congressional Chairman of the Subcommittee on the Postal Service, which is part of the Committee on Government Reform and Oversight (United States General Accounting Office, 1997a, 1997b). In fact, the title of the report itself, which was a follow-up to the 1994 report, speaks volumes about where the state of labor relations were between management and the union, despite the crew chief and other organizational development initiatives: "Little Progress Made in Addressing Persistent Labor-Management Problems." According to the report, the crew chief trial program, which ended in March of 1994, was "set aside" (p. 40) during contract negotiations between the USPS and the APWU. As of February 1997, Postal and APWU officials were still evaluating the results of the crew chief program. However, one can take this statement, along with the fact that this is three years after completion of the pilot program, as evidence that the crew chief program was probably not implemented on a wider scale.

The 1997 report also reiterated some of the findings of the initial qualitative review by the GAO in the 1994 report. According to the GAO (1997a, 1997b), some of the positive aspects of the crew chief program were that participants at the crew chief sites reported feeling more comfortable taking instructions from and providing 
Implementation Analysis 158

input to crew chiefs rather than supervisors. Five major criticisms of the program were that the program: (1) only directly empowered one individual, the crew chief, (2) did not provide incentives for team performance, (3) did not hold employees or supervisors accountable for poor performance, (4) did not clearly define the roles and responsibilities of the crew chiefs and supervisors, and (5) based selection of crew chiefs on seniority rather than on qualifications. The National Association of Postal Supervisors (NAPS), continued to be opposed to the program, stating that the crew chief was just another layer of supervision and that a true empowerment intervention would take the form of self-managed work teams with one supervisor.

The APWU also cited some of their results stating that morale and job satisfaction improved at all sites with the crew chief program compared to the control sites, and that the differences were more pronounced in retail service installations than in mail processor installations. The APWU considered the crew chief program to be successful enough to be implemented on a wider scale, but claimed the USPS was still resistant to the concept. As a result of the surveying and other assessments, the APWU concluded that the crew chief program was a success, in that the union members wanted it continued. However, the program was suspended as a result of disputes during the 1994 bargaining period.

Patton (1986) states that the lack of positive findings from many interventions may not be necessarily be a result of the failure of the actual interventions, but a failure to actually implement the intervention as it was conceived. Most program evaluations focus on whether or not a program achieved its intended goals, also known 
as outcome evaluation. However, there is strong evidence suggesting that implementation evaluation is just as important, if not more important, than outcome evaluation. One cannot assess the effectiveness of a program in a valid fashion if it has not been properly implemented (Patton, 1986; Scheirer \& Rezmovic, 1983). Solely focusing on outcome measures can lead to errors such as terminating potentially successful programs (Type II errors) and inappropriately expanding programs that are context-specific.

According to Patton (1986), an important function of implementation analysis is to determine the extent to which the program was implemented compared to the original design, which is known as discrepancy evaluation. This can be a difficult step, since programs develop slowly as they need to adapt to unanticipated problems and barriers. Another important element of implementation analysis is process evaluation, which concerns the "internal dynamics and actual operations of a program to understand its strengths and weaknesses (Patton, 1986, p. 139)." Discrepancy and process evaluation are usually best undertaken using qualitative data.

Given the importance of discrepancy and process evaluation to understanding intervention implementation, I examined the qualitative findings from the GAO reports and performed a content analysis on APWU reports and structured interview transcripts of managers and union members who were participants at the crew chief sites. Dr. Martin provided me with the transcripts of these structured interviews conducted in Birmingham, Rochester, Royal Oak, St. Paul, Lehigh Valley, and Louisville sites. The APWU reports/letters are available in Appendix B and the 
questions included as part of the interview, as well as the transcripts of the interviews, are provided in Appendix C. All of the quotes cited in this chapter originate from the transcripts included in Appendix C.

A benefit of the structured interviews was that I was able to capture the opinions on various issues that may have affected the implementation and effectiveness of the crew chief program. A disadvantage of these structured interviews was that there was not much content on anything outside the parameters of the questions asked. However, upon review of the interview questions, I believe that the interview was fairly comprehensive and that the most pertinent issues related to the implementation of the program were captured.

I began the content analysis by first reading the documents and summarizing the relevant themes from each site. After developing this summary, I proceeded to group the themes according to larger categories, and to orient the analysis around these more general themes rather than a site by site summary that I initially developed. For each theme, I also noted those sites that focused on this theme in their interview. Where there was disagreement within a site, I indicated what type of participant (management vs. mail processor) made the comment and/or if comments were directed at different tours within a site. I then organized these themes into four general categories; (1) Overall/Global Impressions, (2) Benefits of the Crew Chief Program, (3) Barriers to Crew Chief Program Success, and (4) Unresolved Issues. The following is a discussion of these four major themes and their subthemes. 


\section{Overall/Global Impressions}

\section{Overall opinion of crew chief program}

Based on APWU reports and interviews with mail processors, crew chiefs and supervisors at St. Paul (American Postal Workers Union, 1993c), Sacramento (American Postal Workers Union, 1993b), Rochester, Birmingham, and Louisville, most interviewees agreed that the crew chief program was positive and worth continuing. All the interviewees at Birmingham gave a rating of at least 7 out of 10 in how supportive they are of the crew chief program as it currently existed and all gave a 10 out of 10 in how supportive they would be if it functioned ideally. The APWU's national business agent, Mike Morris, came to a different conclusion about how the program was operating at Birmingham. Morris, in a letter dated December 6, 1993 to the President of the APWU about interviews he conducted on November $29^{\text {th }}$ and $30^{\text {th }}$, 1993, reported that all three tours at the Birmingham site believed that the majority of mail processors at Birmingham were ambivalent about the crew chief program. Few mail processors were openly hostile about it, but few others were enthusiastic. However, Morris found that mail processors liked crew chiefs better than supervisors, and this sentiment was even shared by those who disliked the crew chief program.

The APWU found that at St. Paul, some mail processors felt "shut out" of the program, and did not even want to discuss the program with the interviewers. At Louisville, everyone seemed to be satisfied with the performance of the crew chiefs on Tour 1, but claimed that there were many problems on the other tours, particularly Tour 3. All but one interviewee at Louisville supported the program as it currently 
existed, but all indicated they would be extremely supportive if it were to function ideally.

According to the interviewees conducted by Dr. Martin's research team at Lehigh Valley, the crew chief "runs" Tour 1, and Tour 3 were ran by supervisors with the crew chief perceived as a "glorified" mail processor. Many believed that Tour 2 exhibited the biggest changes, in that supervisors did not seem to be around as much. In addition, national business agent, Mike Morris, found that the supervisors, crew chiefs, and mail processors from Tour 1 were very supportive of the initiative and it was among the best of the pilot sites, whereas Tour 3 was the worst.

The APWU, in a letter dated 12-29-93 to the Rochester crew chief steering committee (1993a), concluded that the crew chief program at the Rochester site had many problems. The findings from the interviews conducted by Dr. Martin's research team at Rochester were more positive than those reported by the APWU. However, most of the participants interviewed at Rochester by Dr. Martin's team felt the crew chief program had plenty of room left to develop before becoming truly effective. One management interviewee from Rochester commented:

I don't think [the crew chief program is operating] the way I envisioned it. I thought employees would be more empowered. They (mail processors) aren't more committed. The crew chiefs are empowered. 
Implementation Analysis 163

Change in labor-management relations in the past year

Regarding the amount of change that occurred within the last year in labormanagement relations since the crew chief program was implemented, employees of St. Paul and Louisville felt that relations had improved. At Rochester, although most participants believed that the overall relationship between union and management was good, they were mixed on how much change actually occurred over the past year. Another interviewee believed that the crew chief program was not working as intended on Tour 2 because of very poor labor-management relations.

At the Birmingham plant, most participants believed that labor-management relations stayed the same if not improved. However, some stated that labor relations remained poor on Tour 3. Another participant thought that there were poor relations between crew chief and supervisors on Tour 2. On the issue of whether or not the crew chief program was a catalyst for any changes witnessed in the past year, one management interviewee at Birmingham stated:

So much happened in the USPS in '93, it's hard to tell what changes are due to.

Interviewees at Lehigh Valley were mixed on whether relations improved in the past year. All of them indicated that there was either no change or that relations changed for the better; no one believed that relations worsened. One union member commented:

I think it has improved, it is not as adversarial, we have enlightened union representation. Management is more cooperative with workers, the new MDO on Tour 3 has improved relations there. 
And one management member commented:

I think so. I think it is more relaxed, union is able to come to managers now. The reorganization changed things a lot, and improved it.

\section{Benefits of the Crew Chief Program}

\section{Improvement in operations}

At St. Paul, interview participants indicated that operations were better organized, and that crew chiefs were better able to keep machines running continuously. Respondents reported more flexibility in the operations, and believed that mail processors now had more voice. The interviewees also believed that overall communication had improved with the addition of a crew chief. One participant mentioned that another benefit of the crew chief program was that it allowed employees to better understand the supervisors' perspective of operations. The smoothness of operations also seemed improved, with less conflict between employees and supervisors. One union participant remarked that this reduction in conflict was largely the result of less contact between supervisors and mail processors. One management respondent was more optimistic in his/her assessment:

People [mail processors and crew chiefs] have more "stock in product." [The] crew chief has taken away some of the "edge" of supervision control over [the] employee. At this facility, union-management relations are formal, and [the] crew chief fits the way this facility runs. At other facilities, where relations are better (more open), perhaps a crew chief program would not be needed. Here, however, communication was very poor before the crew chief program. There was no formal way (organizationally sanctioned way) for employees to voice opinions, to influence how work is done. [The] key is participation. 
Other benefits that the St. Paul interviewees mentioned were that the program got employees involved and that good crew chiefs set an example for other mail processors to follow.

At Sacramento, the APWU found that crew chiefs enjoyed their new position, and many mail processors indicated that they wanted to apply to become crew chiefs. Like St. Paul, supervisors that were interviewed by the APWU at Sacramento reported smoother operations and mail processors believed that working conditions were more relaxed. Rochester interviewees believed that the crew chief program was responsible for lower grievance rates, smoother operations, and increased productivity because crew chiefs were "closer" to the work than supervisors. One union member commented:

As a result of the program, grievance rates are lower, a positive buffer has been created, and the crew chief serves as a peacemaker.

Interviewees at Royal Oak believed that the crew chief program had resulted in increased safety awareness and behavior by employees. They also stated that the crew chief program had improved communication, and that employees felt they had more input and voice via the crew chief steering committee. These interviewees also claimed that there were fewer grievances filed as a result of the crew chief program. Interviewees from Birmingham also thought that the addition of crew chief improved overall work processes. Union interviewees at Birmingham felt that the crew chief program improved teamwork and job characteristics. Management participants stated that they discovered potential in their employees, and felt that 
teamwork improved. What follows are some of the actual statements from

interviewees.

A couple of union participants said:

Crew chief can use [their] brain and employees can now express themselves.

Cooperation between employees [is] much better. [There is] less disagreement between employees [and] better teamwork.

Some management participants said:

We have identified a lot of potential in employees that didn't know existed before. The project has built teamwork on all three tours.

[The crew chief program] brought out initiative in mail processors - close [enough] to where [they] could function as [a] self-managed unit.

Finally, One union employee from Louisville commented:

The project gave the clerk responsibility to get the mail out. They know and are ready to do it all. Crew chiefs are able to say things that supervisors can't, so it gets people going. Crew chiefs set everything up so that job is clear. The staff knows what to do and can spend most of the time actually doing it. Crew chiefs take responsibility seriously.

\section{Program Flexibility}

At Lehigh Valley, some participants praised the crew chief program for its flexibility in its implementation. They believed that the ability to tailor the program for the local unit was important for taking into consideration idiosyncratic circumstances that would have been ignored with a "one-size fits all" approach. One management participant stated:

[The crew chief program] works well because we have had the opportunity to adapt the program to local conditions. It is essential to be able to have local 
options, to have the program not be a rigid nationwide program with no local flexibility.

This sentiment was also shared by a participant in Louisville, who felt that one of the strongest characteristics of the crew chief program was its flexibility.

We need to have each facility go with what works best for that facility. [We] shouldn't force a general program for everyone, and don't change our plant to conform to everyone else's, because ours works for us. Implement ours because it works! [The] APWU makes it work here, not necessarily management. Tailor the program for each facility, leave flexibility in [the] contract.

\section{More time for supervisors to accomplish other tasks}

According to Louisville and St. Paul interviewees, there was agreement that crew chiefs had benefited supervisors by reducing supervisors' workload and thus providing supervisors with more time to accomplish other tasks. At Lehigh Valley, participants stated that mail processors preferred to receive instructions from crew chiefs rather than supervisors, and were pleased to see their supervisors less frequently. A benefit to supervisors was that they had more time to perform other duties because crew chiefs alleviated the workload of supervisors. The APWU found that supervisors at the St. Paul site liked the program and appreciated the assistance given by the crew chiefs. Also, mail processors felt that crew chiefs were more accessible compared to supervisors. 


\section{Barriers to Crew Chief Program Success}

\section{Initial roll-out}

According to the St. Paul interviews, many did not like the crew chief program when it was first implemented. A major hindrance was the lack of communication about the program when it was initially rolled out. Some interviewees believed that supervisors should not have been responsible for giving out information on the crew chief program, as the interviewees did not believe that the supervisor presented the program in a supportive and enthusiastic manner. However, more employees started to like it as they became more acclimated to the program.

At Birmingham, one interviewee indicated that there were many inconsistencies in implementation across the three tours at the start, but the program "settled" after some time. A union participant at Royal Oak stated that the poor organization at the initial rollout of the program was a major barrier to the successful implementation of the crew chief program:

[There was a] lack of organization from day 1. Change is hard enough to introduce, more so if you aren't organized. [The] reorganization [of the USPS] affected [the] crew chief program negatively because attention went to reorganization instead of the crew chief program. Reorganization was a big thing, [the] crew chief [program] was a little thing.

\section{Lack of support}

According to the Birmingham interviews conducted by Dr. Martin's research team, some participants indicated that the biggest hindrance to the successful implementation of the crew chief program was the lack of support from management. 
Implementation Analysis 169

The crew chief program threatened some supervisors and one participant believed that supervisors were actively undermining the crew chief initiative. According to a couple of the union interviewees:

Supervisors talk to employees and tell them that the [crew chief] program won't work.

[Supervisors] talk against crew chiefs [and] try to get people to deselect crew chiefs.

Morris found at the Sacramento site that there was the impression by some employees that management would never accept the program, and that some members of management might be actively subverting the crew chief program. According to interviews conducted by Morris at Lehigh Valley, Tour 3 supervisors were very opposed to the crew chief pilot and were actively trying to sabotage it. At Rochester, the APWU discovered that some supervisors continued to maintain a floor presence, and sometimes undermined the crew chief in the instructions given to mail processors.

At Louisville, a major obstacle was the perception by supervisors that their job would be in jeopardy with the addition of crew chiefs. Thus, supervisors either responded by abdicating most of their responsibilities to the crew chief or did not fully support the program. At Royal Oak, interviewees believed that problems have arisen because of an ongoing power struggle between some crew chiefs and supervisors.

According to some of the interviewees at St. Paul, some supervisors were resentful of crew chiefs. A problem at this site was that some mail processors were reported receiving conflicting instructions when the supervisor did not communicate through the crew chief. In addition, some supervisors were still stuck in the "old way 
of doing things," and that overall trust levels remained low. One union member commented:

Management fears change - longer tenure equals more fear. [Management] held reins for so long, they were afraid to let go.

\section{Role ambiguity}

According to a majority of those interviewed at Louisville, the foremost hindrances to the effective implementation of the crew chief program was the lack of clarity regarding the crew chief's duties and responsibilities, as well as a clear outline of how the supervisor's job changed as a result of the crew chiefs. At Birmingham, the interviewees mentioned that employees were initially confused regarding the exact role of the crew chief. Many mail processors perceived the crew chief position as replacing the supervisor position.

At Rochester, the APWU found that mail processors were frustrated with trying to understand the role differences between themselves, crew chiefs, and supervisors. In addition, mail processors reported feeling doubly supervised, because they had to report to a crew chief and supervisor. According to the Rochester interviews by Dr. Martin's research team, there appeared to be a lack of clarity defining the role of the crew chief. One union participant stated:

Not enough explication of differences between supervisors and crew chiefs. Crew chief is a liaison and acts as a crew member, but is seen as another layer of management because supervisors were not involved enough (not acting to discipline poor performers). Supervisors should keep role of disciplinarian, but have not. When someone gets disciplined, it is because the "crew chief ratted on me." Short staffing has been a problem as has the pay differential and lack of communication. Also, management avoids confrontation. 
Crew chief perceives self as supervisor

At Lehigh Valley, interviewees believed that some of the worst aspects of the program were not necessarily inherent to the program, but were largely attributable to the behavior of certain crew chiefs. More specifically, crew chiefs who thought of themselves and acted as supervisors were received poorly by the rank and file. At St. Paul, interview participants also indicated that there was a misconception by some crew chiefs that the position was equivalent to that of a supervisor. Some crew chiefs took the job for the wrong reasons, such as for a change of tour and certain days off. The St. Paul APWU report also indicated that some crew chiefs also needed to better articulate their full duties to their crew. Participants at Rochester also remarked that some crew chiefs had allowed the authority to "go to their head." As a result, many mail processors perceived the crew chiefs as lower level management. This was especially the case when mail processors perceived that the crew chiefs were not spending enough time on the machines.

\section{Crew chief not spending enough time on machines}

A recurring issue throughout the interviews regarded the amount of time crew chiefs spent running the machines alongside the mail processors. According to the APWU report on the Rochester site, mail processors viewed the crew chiefs positively when the crew chiefs spent time on the machines. At Lehigh Valley, some interviewees stated that those crew chiefs who did not appear to work enough on 
Implementation Analysis 172 machines were received poorly by the rank and file. These interviewees also noted that crew chiefs on Tour 1 appeared to spend enough time on machines. The APWU found that many of the mail processors at the Sacramento plant complained that crew chiefs did not spend enough time on the machines.

There was a lot of variability in interviewee responses from St. Paul regarding the amount of time crew chiefs spent on the machines. According to the APWU report, crew chiefs were not spending enough time on machines and were performing tasks that should have been delegated to someone else (e.g., bringing in mail for processing). Respondents from Louisville were also mixed on the issue of whether or not crew chiefs spent enough time operating the machines. Some believed crew chiefs spent too little time on the machines; others thought crew chiefs spent an appropriate amount of time. Unlike many of the other sites, all Birmingham interviewees believed that the amount of time crew chiefs spent on the machines was appropriate.

\section{Ineffective Supervisors and/or Crew Chiefs}

Another barrier to the crew chief program was problems with some supervisors and/or crew chiefs. For example, one respondent from Rochester indicated that there had been some cases where a displacement of responsibility occurred when dealing with problem employees. The crew chief expected the supervisors to handle disciplinary actions while the supervisors expected the reverse. Although this could also be classified as a case of role ambiguity, I included this example under this theme 
Implementation Analysis 173

because the context of the interview seemed to suggest that the ambiguity in disciplinary responsibility was a convenient excuse to not have to deal with the issue.

Supervisors from Lehigh Valley appeared to become less motivated and productive as a result of the crew chief program. One management participant remarked:

Supervisors lost a little bit of control, energy, and interest. They don't have hands-on control. [The] crew chief is torn between having to direct people and being a buddy. Discipline has suffered as well as overall work habits. We have more problems now, employees report late, take longer breaks, and are more laxed now.

At Louisville, a couple of management interviewees believed that some supervisors might have become lazy under the program, relying on the crew chief to do most of the work for them.

There were also problems with some crew chiefs. One Lehigh Valley interviewee commented that most Tour 2 crew chiefs spent much of their time "sitting around a desk." Interviewees also believed that some crew chiefs abused the position and used it as an opportunity to do less work. At Louisville, the problems with some crew chiefs took on a different tone. All of the union interviewees had expressed concern that crew chiefs had assumed too many of the roles and duties of supervisors, with some crew chiefs overstepping their boundaries. Thus, crew chiefs acted more like supervisors rather than a liaison between mail processors and management. When asked whether the crew chief program was operating as expected, one union interviewee replied:

No. [I] thought [the] crew chief would be a "working leader" on [the] machines, working, and giving instructions. Instead, they just stand around. 
Implementation Analysis 174

They don't work on the machines when they should. The crew chiefs seem to pick out friends to work with and delegate to. They give their favorites the good work. Crew chiefs use control inappropriately.

\section{Staffing shortages}

Another theme that was consistent among many of the crew chief sites was the problem of inadequate staffing. At Rochester, interviewees reported that inadequate staffing made it difficult to gauge the impact of the crew chief program. Understaffing made it difficult for a crew chief to spend time on machines, which appeared to be critical for a mail processor to respect a crew chief. According to the APWU report for the Rochester site, staffing problems that were present at the beginning of the crew chief program led to a "shaky start." At Royal Oak, interviewees also indicated that understaffing has been an impediment to the success of the crew chief program. At St. Paul, the APWU found that staffing was still a problem, as there were not enough staff to handle the volume their operations were experiencing. This problem was also echoed by those interviewed by Dr. Martin's research team, where interviewees were concerned with staffing shortages, including those at the crew chief position. Finally, the understaffing issue was brought up by one of the participants at Birmingham, in that promoting mail processors to crew chiefs and not replacing those mail processors resulted in the same amount of work that had to be accomplished by less people. 
Implementation Analysis 175

\section{Unresolved Issues}

\section{Training}

A question asked of all interviewees as part of the structured interview regarded the amount and quality of technical and interpersonal training that employees received regarding the crew chief program. At Royal Oak, interviewees agreed that the technical training provided as part of the crew chief pilot was adequate, but that the interpersonal component was lacking. St. Paul participants felt that they received the right amount of technical training. Some indicated that they would liked to have seen more interpersonal training, but others indicated that lack of interpersonal skills were more of a selection problem than a training one.

Morris also believed that better job training was needed for crew chiefs and mail processors for the crew chief program to be successful. However, according to the interviews conducted by Dr. Martin's research team, most participants at Birmingham found the technical training to be adequate. Like Royal Oak and St. Paul, most Birmingham participants found the interpersonal training to be deficient. Most believed that almost all of the current crew chiefs were competent, and that the key to being an effective crew chief was to have great interpersonal skills and good relationships with mail processors.

At Lehigh Valley, most participants agreed that the interpersonal portion of crew chief training could have been better. Like the other sites, technical training was not really a problem. One participant believed that the crew chief program should be 
changed so that mail processors and supervisors receive training related to the crew chief program itself.

Rochester interviewees believed that the initial crew chiefs were better trained than the later crew chiefs, and that interpersonal skills were a problem for some crew chiefs. The interviewees also believed that new supervisors needed more training before they assumed the full-time duty post. At the time, the crew chiefs spent a great deal of time training new supervisors rather than performing their assigned crew chief duties.

Unlike the other sites, most Louisville interviewees believed that both the technical and interpersonal aspects of training were adequate. However, a couple of management participants believed that more interpersonal training should have been provided.

\section{Crew Chief Selection}

The most consistent divide between union and management participants across all sites regarded the issue of what the primary criteria should be for selecting crew chiefs. Management interviewees believed that the most qualified applicants should be selected to become crew chiefs, while union interviewees believed that the most tenured should be selected. At Louisville, a couple of management participants suggested that a "senior best qualified" criterion be used and that a selection process should be employed rather than automatically granting the position to the most senior bidder. 
Implementation Analysis 177

According to the APWU report from Birmingham, union members were unhappy with the joint selection procedure for crew chiefs because three of the five members were members of management, and thus always had the majority in any decision. However, union members were pleased that an un-election procedure for crew chiefs existed, and helped to give some integrity to the crew chief selection process.

The issue of unelection was another issue that union and management interviewees disagreed on. Like Birmingham, union interviewees from Rochester believed that employees should have a right to deselect crew chiefs. Management believed that no unelection process by employees should exist. As one management interviewee put it:

Selection [of crew chiefs] should not be based on seniority. Elections should be held. Unelections are a negative way of getting rid of people. Some groups vote out the crew chief continuously.

\section{Rotation}

Rather than a consistent difference of opinion across management and union lines, the issue of whether to rotate mail processors among crew chiefs differed among the sites. St. Paul rotated its mail processors and the machines they worked on. Interviewees reported that most everyone at the site liked rotation because it provided variety. Crew chiefs were not assigned to regular crews at Rochester. Some participants remarked that mail processors and crew chiefs preferred rotation to ensure that no one gets "stuck" with the majority of the best or worst people. At Lehigh 
Implementation Analysis 178

Valley, most mail processors also rotated crews. However, unlike St. Paul and Rochester, one union member at Lehigh Valley commented that there was not $100 \%$ agreement among the Tours on the issue of whether to rotate.

A very hotly debated issue on each Tour. We left it up to the crew chiefs to decide among themselves. This issue and other issues is where we give them some discretion.

Some mail processors at Louisville rotated machines, and crew chiefs were assigned to specific machines. Other mail processors were assigned to regular crews. Interestingly, according to one union interviewee, most crew chiefs assigned to a regular crew had requested the implementation of rotations. On the contrary, one management interviewee felt that crew chiefs should remain with the same crew, because he or she believed that having a regular crew built dedication and motivation.

At Birmingham, the issue of rotation was decided upon on a tour-by-tour basis. Tour 2 assigned crew chiefs to machines, and mail processors rotated machines. Tour 1 had regular crews (mail processors and crew chief) that rotated machines. One union and one management member believed the program would be better with intact crews, as they believed an intact crew provided the time required of mail processors and crew chiefs to build good rapport and relationships with each other.

Unlike the other sites, Royal Oak employed regular crews throughout each tour, with the exception of those assigned to BCS machines that rotated. Almost all of those interviewed believed that having a regular crew was beneficial. 
Implementation Analysis 179

\section{Suggestions for improvement}

One suggestion for improving the crew chief program was to elevate the crew chief to a higher position and salary grade. One management interviewee from St. Paul believed that elevating the crew chief would create greater commitment to the position. This suggestion was also brought up by a participant in Lehigh Valley.

Two of the union member participants from Lehigh Valley believed that more local union support could have improved the program. There seemed to be a lack of "buy in" by the rank and file that needed to be there for the crew chief program to be truly successful. Some Lehigh Valley participants also indicated that more communication on crew chief duties would have been beneficial, so that mail processors better understood that just because a crew chief was not on a machine did not mean they were not working.

\section{Number of supervisors required}

At Rochester, union participants thought the number of supervisors would be reduced because of the crew chief program. These participants also complained that management was promoting too many crew chiefs to 204B's (temporary supervisors), making them part of management. Related to this issue, union members from Birmingham believed that one of the worst aspects of the program was the apparent similarity between temporary supervisors (204B's) and crew chiefs, and thus felt that the temporary supervisors were redundant. 
Implementation Analysis 180

\section{Additional Questionnaire Findings}

Some of the major themes outlined from these interviews were consistent with the results of the survey used to obtain the data for the current study. In addition to the items that comprised the outcome measures used in this study, questions were asked of mail processors at the trial sites regarding their opinion on various aspects of the crew chief program. A summary of these findings, in the form of frequency distributions, is provided in the following paragraphs.

Equal numbers of mail processors were satisfied and dissatisfied with the crew chief program as it currently existed ( $42 \%$ each), and $16 \%$ were neither satisfied nor dissatisfied. Forty-seven percent slightly or strongly agreed that they felt more comfortable discussing work-related problems with crew chiefs rather than supervisors.

Mail processors were relatively split on whether top management supported the crew chief program, $29 \%$ believed that top management was not helping to make the crew chief program work well and $39 \%$ believed that top management was doing what they could to make the program work well. Thirty-six percent were neutral on this question.

Most mail processors slightly (38\%) or strongly agreed $(27 \%)$ that they understood the role of crew chief. However, most mail processors appeared to view the crew chief as a surrogate for management. For example, $53 \%$ believed that the crew chiefs simply replaced supervisors, $52 \%$ viewed the crew chiefs as part of management, and $60 \%$ agreed that crew chiefs acted just like supervisors. 
Implementation Analysis 181

Fifty two percent of mail processors reported that crew chiefs spent too little $(26 \%)$ or far too little time on the machines $(37 \%), 18 \%$ felt it was about the right amount of time, and a total of $4 \%$ indicated that crew chiefs spent too much time $(2 \%)$ or far too much time $(2 \%)$ on the machines.

The great majority of mail processors either slightly agreed (18\%) or strongly agreed $(66 \%)$ that they should have had the right to vote out ineffective crew chiefs. The majority also slightly (24\%) or strongly agreed (55\%) that the ability of mail processors to vote out crew chiefs made crew chiefs more responsive to the needs of mail processors.

Most mail processors probably did not (23\%) or definitely did not want (39\%) to become crew chiefs in the future, with $22 \%$ uncertain and $17 \%$ indicating that they would probably or definitely want to become a crew chief. However, when asked what should happen with the crew chief program, only $26 \%$ of mail processors believed the crew chief program should be discontinued, with the majority indicating that the program should either remain the same $(15 \%)$ or change slightly $(20 \%)$, moderately $(24 \%)$, or greatly (15\%). $45 \%$ of mail processors slightly or strongly agreed that inadequate staffing hindered the effectiveness of the crew chief program.

\section{Summary}

Taken as a whole, these findings from the implementation analysis seem to suggest that the crew chief program, although not perfect, had the promise to be a successful intervention. Most interviewees were at least somewhat supportive of the 
crew chief program and felt that relations between management and employees remained the same, if not improved. Both management and union interviewees also indicated that they would be totally supportive of the crew chief if it functioned ideally. The majority of the mail processors indicated that the crew chief program should be changed and not discontinued, which can be taken as an indicator that the crew chief program was not implemented to the degree required to achieve its full potential.

The implementation analysis revealed several barriers that could have prevented the crew chief program from achieving its primary outcomes. There were problems with the initial roll-out of the program, such that for several sites it took longer than expected for the crew chief program to get up and running, and thus reduced the effective time the crew chief program was actually in place. Also, making a poor first impression could have made it more difficult for the crew chief program to garner support. Another barrier was the perceived lack of support by management. Many interviewees believed that not only did supervisors not fully support the program, but that supervisors seemed to actively undermine it.

The implementation analysis also revealed that many USPS employees had trouble understanding the actual roles and duties of the crew chief. Related to this issue was a concern that certain crew chiefs perceived themselves as supervisors and thus assumed that role rather than acting as a group leader and liaison for the group. In some cases it appeared that certain supervisors played off this role ambiguity by displacing some of their responsibilities onto the crew chief, such as disciplining 
Implementation Analysis 183

employees. Another barrier was that most mail processors perceived that the crew chief did not spend an adequate portion of their time working on the machines alongside their crew. Finally, staffing shortages were found to be another impediment to the success of the crew chief program.

There were also several themes I developed in the implementation analysis that I grouped under the category "unresolved issues." These themes concerned issues where there was still disagreement between management and union member or between sites. Although many agreed that technical training involved with the crew chief program was adequate, more training should have been provided for interpersonal skills. However, some participants believed that interpersonal skills can only be developed so far and that it should be more emphasized in the selection process.

The issue of crew chief selection was a divisive one between management and union participants. Union participants believed that the primary criterion for crew chief selection should be seniority and that an unelection power by mail processors be retained. Management participants believed that crew chief selection should be based on qualification and were not in favor of an unelection process for crew chiefs.

Another issue that was far from consensus among sites concerned staff rotation. Even within sites there were differences in how rotation was structured depending on tour and/or type of machine. Many of the sites used some form of rotation, and many participants at those sites indicated that they favored rotation over intact teams. Some sites and tours used intact teams, and believed that this was a 
Implementation Analysis 184

critical characteristic for building a good relationship between crew chiefs and mail processors.

Also grouped under this category of unresolved issues were suggestions for improvement made by participants. For example, some participants believed that elevating the crew chief to a higher position and providing an increase in pay would make the position more attractive and engender more commitment to the position. Finally, in a subcategory of its own, some suggested that with the crew chief program should come a reduction in the number of supervisors and the elimination of the temporary supervisor (204B) program.

The other major category derived from this implementation analysis was the perceived benefits of the crew chief program by participants. Many participants believed that the crew chief helped improve the efficiency of operations and communication, and reduced the number of grievances. A characteristic of the crew chief program that received high praise was the ability of the sites to tailor aspects of the program for their specific situation. Finally, some participants believed that the crew chief program allowed supervisors to become more productive by offloading some of their responsibilities to the crew chief. 


\section{Chapter 9. Discussion}

My first aim was to perform a program evaluation of the crew chief initiative at the USPS by examining the effects of the crew chief program on mail processors role stressors, job strain, job satisfaction, and company and union commitment. The quantitative analyses failed to support any of the hypotheses related to Aim 1 . The crew chief intervention implemented at the USPS failed to demonstrate any significant changes after one year in role ambiguity, role conflict, emotional exhaustion, job satisfaction, supervisory satisfaction, union commitment, and organizational commitment. Unit-level climate effects were controlled for by employing an analytic strategy that accounted for the non-independence of observations, namely hierarchical linear modeling. However, the results suggest that after controlling for education and tenure there was hardly any variability at the unit level in the difference between Time 1 and Time 2 role ambiguity (Hypothesis 8a), emotional exhaustion (Hypothesis 9), company commitment (Hypothesis 3), role conflict (Hypothesis 8b), and union commitment (Hypothesis 4) that could be explained by the intervention. There was marginally significant variance at the unit level in the difference between Time 1 and Time 2 job satisfaction (Hypothesis 2) and significant variance in satisfaction with supervision (Hypothesis 1), but the group variable did not explain any significant variance after controlling for tenure, education, and wave.

My second aim was to replicate and extend the stressor-strain-outcome model of stress and to test the proposition that mail processor perceptions of support from 
crew chiefs moderate the relationships between stressors and strain and strain and outcomes. The basic tenets of the model were supported, such that role ambiguity and role conflict (stressors) were positively associated with emotional exhaustion (strain), and emotional exhaustion was negatively related to job satisfaction and negatively indirectly related to company and union commitment (outcomes). I also found that crew chief support was negatively related to mail processor role ambiguity, role conflict and emotional exhaustion (Hypothesis 5a, Hypothesis $5 b$, Hypothesis $5 c$, respectively) and positively related to job satisfaction, company commitment, and union commitment (Hypothesis 5d, Hypothesis 5e, Hypothesis $5 f$, respectively). In addition, consistent with past literature (e.g., Gordon et al., 1980; Schaubroeck et al., 1989; Viswesvaran \& Deshpande, 1993; Williams \& Hazer, 1986), I found job satisfaction to be positively associated with company commitment (Hypothesis 7a) and union commitment (Hypothesis 7b). However, I failed to find support for any buffering effects of crew chief support on the role ambiguity-emotional exhaustion relationship (Hypothesis 6a), on the role conflict-emotional exhaustion relationship (Hypothesis 6b), or on the emotional exhaustion-job satisfaction relationship (Hypothesis 6c). Moreover, the data support direct paths from role ambiguity to each of the outcome variables, such that role ambiguity was negatively related to job satisfaction, company commitment, and union commitment beyond the indirect relationships of role ambiguity via emotional exhaustion and job satisfaction. 


\section{Did the Intervention Work?}

The original study headed by Dr. Martin was an impressive and complex undertaking to evaluate a specific intervention in the context of larger organizational change effort at one of the United States' largest employers, the United States Postal Service. The impetus for this organizational development effort was a string of violent episodes that occurred in the mid 1980's and early 1990's at USPS facilities that gained national media attention. Investigations by the press and the United States Government Accounting Office (1994a, 1994b, 1997c) indicated that the authoritative culture and poor management-labor relations were primary factors in creating a work environment that was susceptible to violence. In addition, the poor work environment created undue stress and dissatisfaction among the employees of the USPS that may not have culminated in violence, but could have contributed to poorer physical and mental health of employees. From the USPS's perspective, such a hostile work environment likely created inefficiencies in the form of decreased productivity and high grievance activity. Thus, public and political pressure led the USPS to adopt a series of interventions to help improve the work environment. One of these initiatives, the crew chief program, was designed to empower employees by allowing one of the mail processors to directly lead the crew rather than the supervisor. The first aim of this study was to evaluate the impact of the crew chief program on employees' stress, strain, job satisfaction, and organizational and union commitment.

Unfortunately, I was unable to find quantitative support for any of the hypotheses related to Aim 1. This makes it difficult to claim that the crew chief 
intervention was successful in improving organization stress, strain, commitment, and satisfaction. In the next section, I discuss some of the potential explanations related to theory, implementation, and design for why my hypotheses about the effectiveness of the crew chief program failed to obtain support.

\section{Theoretical Issues}

Is an empowerment intervention inappropriate for the current context? One possible explanation for why the crew chief program may not have produced the expected change in organizational outcomes is because an empowerment-based team structure may be inappropriate for the type of work performed at USPS mail processing facilities. Elmutti (1997) argued that self managing team structures are not well-suited for organizations that utilize highly automated production technology because only limited intervention is required by employees. In other words, because machines are largely responsible for performing the work, teamwork processes are not only unnecessary, but may be a hindrance to efficient performance. However, I believe this to be an unlikely scenario in the case of the USPS. Although mail processing work is highly automated, other aspects of operations, such as reacting to machine breakdowns and the fact that more than one person is required to operate the USPS machines, would benefit from an empowering team structure. Nevertheless, given that much of the process remains greatly automated, it is reasonable to expect smaller effects of an empowerment intervention in this setting compared to other settings where tasks accomplished as a group are not highly automated. 
Were all employees really empowered? Much of the justification for why I believed the crew chief intervention should have been successful came from the selfmanaged work teams and empowerment literature. Based largely on the tenets of social exchange theory (Blau, 1964), I argued that the empowering of mail processors by the USPS and the APWU would essentially lead to a reciprocation by the mail processors in the form of job and supervisor satisfaction and company and union commitment. I also argued that the empowerment provided by the crew chief program would give mail processors with the control and resources to reduce and cope with stress and strain. Taking a step back into the realm of process evaluation, I must consider whether the intervention was implemented as designed. That is, did the crew chief program empower employees?

According to the literature discussed in Chapter 3, empowerment is inherent in a self-managed team structure. Although the structure of crews under the crew chief program shared some similarities with self-directed work teams, it did not meet the accepted definition of self-directed teams (see Osterman, 1994) for two main reasons. First, the crew members did not supervise their own work or make their own decisions about its pace and flow. Second, not all crews were intact units such that mail processors were assigned to one crew. The following two sections discuss in more detail these important differences.

Did crew members have direct control over their work? Under the crew chief program, only one individual, the crew chief, was formally empowered to make decisions on how the crew would accomplish its work. In fact, this was one of the 
major criticisms of the crew chief program made by the GAO (1997a, 1997b). The National Association of Postal Supervisors (NAPS), a non-bargaining organization representing USPS supervisors, believed that the crew chief essentially represented an additional layer of management and that a true empowerment intervention would require traditional self-managed work teams with one direct report, the supervisor.

I argued that although only the crew chief was formally empowered by the program, mail processors also would be empowered through the influence they would gain in determining how they work. This was expected to be accomplished by having an increased probability of building a high quality leader-member exchange with the crew chief. That is, crew chiefs would be more likely to provide voice and input in decision making to mail processors because mail processors and crew chiefs would be more likely to share values and identify with one another. That is, the crew would be directed by "one of their own" rather than "them" (management).

Unfortunately, this study did not directly measure these intermediate processes required for building trust and thus good leader-member exchange relationships. There was no way to establish in this study whether a high quality leader-member exchange developed between the crew chief and mail processors. However, there was one item that specifically asked mail processors whether crew chiefs are people they could trust. Equal numbers of mail processors (42\%) agreed and disagreed with that statement, with more strongly disagreeing than strongly agreeing. Another interesting set of findings is that the majority of mail processors perceived crew chiefs to be replacements for supervisors, viewed crew chiefs as part of management, and believed 
Discussion 191

crew chiefs acted like traditional supervisors. These findings suggest that the crew chief program was not operating as planned, as it was not the intention of the program for crew chiefs to replace supervisors; rather, the crew chief was expected to act as a liaison between the work crew and the supervisor. In interviews conducted with union members and management at the trial sites, many admitted that there were misunderstandings of the program by mail processors, and much of this was a result of poor communication and training at the initial rollout of the program. Thus, the negative first impression of the program that many mail processors had may have limited the program's ability to achieve its intended goals.

In addition, there were no items included in the questionnaire that inquired directly about employee perceptions of empowerment. Without this information, it is difficult to evaluate whether or not mail processors believed they were empowered by the crew chief program. The results of the interviews with union members and management were also mixed on this issue, although it did appear that more interviewees felt that the crew chief program empowered mail processors.

Are intact work groups critical to building empowerment? The second way USPS crews differed from traditional self-managed work teams was that the crews were not intact teams. Mail processors usually rotated and often did not have the same crew chief from day-to-day. Interestingly, the majority of union members and management interviewed at the trial sites indicated that many employees preferred a rotational structure. According to the interviewees, the rotation introduced fairness by 
ensuring that no one crew had many of the "best" or "worst" employees, and that no mail processor would get "stuck" with an ineffective crew chief.

However, some interviewees believed that using intact teams could have improved the crew chief program. These interviewees believed that maintaining intact teams would provide the necessary time for crew chiefs and mail processors to build rapport and relationships, which would lead to better teamwork. Some research supports this reasoning. For example, Campion et al. (1996) found that teams with members who only belonged to one team and were comprised of mostly permanent members were perceived to have more positive team characteristics and be more effective. Thus, crews at USPS processing plants may have failed to develop a singleteam identity, which could have limited their potential for success.

\section{Implementation Issues}

Lack of support from supervisors. Another possibility for the lackluster results concerns the limited involvement of supervisors in the design and implementation of the program. In fact, as indicated by the GAO reports (1994a, 1994b, 1997a, 1997b) and from the interviews conducted with union employees and management at trial sites, many supervisors viewed the crew chief program as a threat to their job security. These supervisors were opposed to the program and may have even been attempting to undermine it. Although supervisors were not eliminated, they were removed from the mail processing operation and the number of required supervisors would have been reduced if the crew chief program had been made permanent (GAO, 1994). Thus, it 
was not surprising that the National Association of Postal Supervisors formally opposed the crew chief initiative (Goodin, 1992).

Involving supervisors from the outset might have made them more likely to accept the crew chief program. When supervisors are not involved, they may feel that the organization has abandoned them in favor of the newly empowered employees, and therefore they could be motivated to ensure that the initiative does not succeed (Harrison, 1995). It is difficult to imagine how supportive supervisors could possibly have been for a program that may threaten their jobs. Interestingly enough, when mail processors were asked who benefited most from the crew chief program, 79\% indicated that supervisors benefited at least a moderate amount, which is more than any of the other stakeholders (mail processors, APWU local union, customers, and the USPS). Assuming that supervisors themselves do not perceive themselves as the principal beneficiaries, this creates a situation where neither of the major stakeholders who were the primary targets of the crew chief program believed they were the primary beneficiaries!

Were labor-management relations too poor at baseline? The extremely poor labor-relations climate may be another explanation for the lack of support for the hypotheses related to Aim 1. Although a major goal of this initiative was to improve labor-management relations, because the climate was initially faced with tremendous conflict, the crew chief program faced barriers "getting off the ground." This conjecture is consistent with some of the findings from the interviews conducted with employees and management at the crew chief trial sites. Many interviewees brought 
up the problem that the crew chief program did not get as an effective start as it could have. Miscommunication, whether inadvertent or not, is a common symptom of poor labor-management relations, and was cited, along with lack of training, for why the crew chief program had an ineffective rollout. As discussed above, some union employees believed management did not support the program and that management was actively undermining the program. Even if this perception was inaccurate, the evident distrust is a sign of a poor labor management climate that may have made it difficult for employees to accept the program as a genuine attempt to expand employee participation.

\section{Design Issues}

Lack of power. I based the evaluation of the Aim 1 hypotheses on a smaller than anticipated sample size and thus experienced low power for the tests of the hierarchical linear models. Recall that the sample size was reduced from 262 to 177 cases, given the problems uncovered with the matching scheme. Even though the matching problem did not affect the Level 2 sample size, the average group size fell from 10 to 6.8 , which translated to a $32 \%$ reduction at Level 1 . With such small groups, any large deviation of even one member within a group could have had a disproportionately strong influence on the within-subjects variation in the unit, leading to attenuated reliability and intraclass correlations. This is in fact what occurred in this dataset. Only satisfaction with supervision had an intercept reliability of over .30 . This 
lack of power makes it difficult to conclude convincingly that there was indeed no effect of the program on organizational stressors, satisfaction, and commitment.

Did enough time elapse to detect changes in outcomes? When evaluating organizational programs and interventions, one must always be conscious of the time span within which the program exists and when the outcome measures are collected. In the present study, the length of time of when baseline and follow-up measures were given was approximately one year. However, according to the implementation analysis data, many interviewees reported that it took additional time for the crew chief program to be implemented. Moreover, even if the crew chief program was properly implemented immediately after the baseline data was collected, was one year enough time to expect dramatic changes in the culture and attitudes of the organization?

Absence of key mediator. The pivotal component of this program, the empowerment of employees, upon which much of the justification for why I believed the program would improve job satisfaction, company and union commitment, and reduce stress and strain, was not included as a proximal outcome in this study. In the hypothesized temporal sequence, the crew chief program would first have to affect empowerment perceptions, which would then produce change in other organizational attitudes. Hence, mail processor empowerment perceptions were perhaps more likely to change after one year compared to the other outcomes examined in this study. Despite the fact that many interviewees indicated that mail processors believed they were more empowered, it would have been preferable to know the opinions of the 
entire sample via a questionnaire measure of empowerment. Having this data would have allowed for a stronger assessment of the crew chief program.

Were there other (unmeasured) outcomes that the crew chief program may have affected? Another consideration is that there may have been other important outcomes that the crew chief program improved that were not assessed in this study. The most salient outcomes that come to mind are objective indicators such as productivity, efficiency, attendance, and retention. Interestingly, Belanger et al. (2003) found that although efficiency improved as a result of the use of self-directed teams, there was still a lack of commitment to the organization. The authors' explanation for these results is that the initiative might have increased the social distance between management and employees by removing supervisors from the work process. Thus, efficiency may increase and workers may become more satisfied, but this does not necessarily lead to increased commitment to the organization or even improved labormanagement relations. This situation is certainly possible in the current study. Some evidence for this effect comes from the interview transcripts with union employees and management at the trial sites. Some interviewees stated that the crew chief program improved efficiency at the plants. In addition, a few remarked that some mail processors saw the crew chief program as a success by distancing the supervisors from the workroom floor. Mail processors saw this as an "improvement" in labormanagement relations. 


\section{Unsupported Hypotheses of Aim 2}

Crew chief support and emotional exhaustion. Although there was initial support for Hypothesis 5c, such that a higher level of crew chief support was bivariately associated with a lower level of emotional exhaustion, the relationship was not significant when evaluated in the full model. This pattern of results is similar to that reported by Schaubroeck et al. (1989), suggesting that the relationship between crew chief support and emotional exhaustion is completely mediated by role ambiguity and role conflict. Assuming that this finding generalizes to other forms of social support, this would suggest that increased social support leads to a reduction in strain by decreasing the level of perceived role stressors. Thus, this finding, along with the findings reported by Schaubroeck et al. (1989), would suggest that social support does not have a direct relationship with strain, but has an indirect effect such that the mechanism of associated change with strain is through the relationship of social support to stress.

Moderating effects of crew chief support. A major component of Aim 2 was to evaluate the moderating effects of crew chief support on the stressor-strain and strainoutcome relationships. Unfortunately, the data failed to support the moderator Hypotheses 6a, 6b, and 6c. As discussed in Chapter 5, research often fails to detect hypothesized moderator effects of support on employee outcomes of stress and strain. In fact, moderator effects in general are very difficult to support in the social sciences (Aguinis, 1995; Cronbach, 1987; Jaccard, Wan, \& Turrisi, 1990). Two of the more influential methodological reasons for this difficulty include the restriction of range in 
the joint distribution of the moderator and independent variables that is common in field research (Aguinis \& Stone-Romero, 1997; McClelland \& Judd, 1993) and the inherent lower reliability of the interaction term compared to its component parts (Busemeyer \& Jones, 1983; Evans, 1985; Jaccard et al., 1990). I examined the joint distributions of crew chief support with role ambiguity, role conflict, and emotional exhaustion, and found certain combinations of the moderator with the independent variables that were significantly lower than the expected sample size. For example, only $17(3.2 \%)$ participants scored in both the low range of role conflict and crew chief support and $12(2.3 \%)$ scored high on both variables. Hence, the restriction of range in the joint distribution of the moderator and independent variables present in this study adversely affected the power to detect a significant interaction.

In addition to the methodological obstacles common to moderator models, there are also some theoretical explanations for why the moderator effects of crew chief support were not supported. One reason may be the omission of individual differences in the model. For example, mail processors may have different requirements for the type of support they would like to receive (cf. Reynolds \& Perrin, 2004). More independent-minded mail processors may not respond well to a crew chief constantly offering support, maybe interpreting these support-oriented behaviors as "micro-management" or evidence of distrust. Consistent with this proposition, some research had found moderating effects of individual differences on the buffering effect of social support. For example, Cummins (1990), found a three-way interaction among supervisor support, job stress, and relationship orientation, such that supervisor 
support buffers the relationship between job stress and job satisfaction for relationship-oriented individuals, but demonstrated no buffering effect for taskoriented individuals. Given the nature of the mail processor job, it would be appropriate to characterize the position as more task-oriented in nature than relationship-oriented. If individuals are attracted to and tend to remain in jobs that are consistent with their interests and personality type (Holland, 1997; Holland \& Gottfredson, 1976), then it would be reasonable to assume that most mail processors are task-oriented. Thus, the results from Cummins (1990) are consistent with the findings of this study in their lack of evidence for a buffering effect of supervisor support.

Another possible three-way interaction involves the moderating effect of one job stressor on the other. As discussed in Chapter 5, Fried and Tiegs (1993) found that the buffering effect of social support from a union steward was present when both role ambiguity and role conflict were high. Extending this finding to my research, crew chief support may only become salient as a buffer between stress and strain when the mail processor is under high levels of multiple job stressors.

\section{Summary}

In summary, although the quantitative findings of this study failed to support the Aim 1 hypotheses, it is difficult for me to conclude that the intervention did not have an effect. This is not only because it is logically incorrect to interpret a nonsignificant finding as proof that an effect does not exist, but also because there are 
alternative theoretical, implementation-related, and design-related explanations that are more plausible in accounting for the lack of findings than attributing it entirely to the design of the crew chief program. The results of the implementation analysis, discussed in the previous chapter, seem to indicate that the crew chief program was not implemented to the extent necessary to produce the maximum effect on the outcomes of interest. As discussed in Chapter 8, the GAO evaluators, APWU evaluators, and the great majority of interviewees believed the crew chief program was successful and had the potential to be even a greater success. In fact, $74 \%$ of mail processors at the Time 2 crew chief sites believed that the crew chief program should have been continued "as is" or with changes. Given the totality of the evidence, I conclude that even though the findings may have failed to support the effectiveness of the crew chief program on the outcomes included in this study, the results are inconclusive regarding the overall value of the crew chief program as an effective organizational intervention because of the methodological concerns and theoretical issues discussed in this section.

\section{What did Work?}

\section{Implementation Analysis Findings}

The results of the implementation analysis not only provided insight on why I was not able find quantitative changes in the outcomes, but also highlighted the areas in which the crew chief program benefited the USPS and its employees. Most of the participants interviewed had a favorable opinion of the crew chief program and 
Discussion 201

believed that labor-management relations improved after the crew chief program was implemented. The following two sections discuss some of the perceived benefits and positive characteristics of the crew chief program reported by interviewees.

Benefits of the crew chief program. The implementation analysis revealed that many of those interviewed believed that the crew chief program improved operations at the mail processing facilities. According to the participants, crew chiefs helped to organize better operations, improved communication and teamwork, and were better able to keep the mail processing machines operating continuously. Interviewees also believed that crew chiefs helped to increase mail processors' safety awareness and behavior. Lastly, interviewees reported that fewer grievances were filed under the crew chief program.

Thus, it appears that the crew chief program may have had a beneficial impact on productivity-based outcomes. As discussed above, it may be possible for an intervention to impact measures of productivity and not cause change in attitudinal outcomes. Another possibility is that improvements cited by interviewees are more proximal outcomes of the intervention than job attitudes. That is, perhaps more time was required to produce changes in attitudinal outcomes than for more productivitybased indicators. Unfortunately, there was no quantitative data on productivity outcomes available to statistically test whether the experimental sites demonstrated improvement in productivity compared to the control sites.

Another benefit of the crew chief program cited by interviewees was that supervisors had more time to complete administrative tasks because the crew chiefs 
alleviated some of their managerial workload. Some supervisors reported that they appreciated the assistance provided by crew chiefs. However, the majority of mail processor interviewees indicated that the true benefit of the crew chief program was that it limited the amount of time mail processors had to interact with supervisors. Mail processors were clear that they preferred to receive instructions from the crew chief and felt that crew chiefs were more approachable.

Positive characteristics of the crew chief program. One characteristic of the crew chief program lauded by many of the interviewees was the ability to tailor portions of the program to the needs of a particular facility. The interviewees appreciated having "voice" in how to implement the program at their local unit to take into account unique circumstances that would have been ignored with a rigid, standardized program. This provision of "voice" in the implementation of the program is not only favorable to employees, but also may be essential to garnering employee "buy-in" to the program.

An apparently important aspect of the crew chief program, at least from the perspective of the mail processors, was the ability of a crew to vote out a crew chief. According to Kulisch and Banner (1993), having this option available to the team decreases the likelihood of viewing the team leader as a management surrogate, and encourages teams to view them more as a team member. If team members viewed crew chiefs as a management "crony," then team members may be more likely to reject the crew chief program and likely to react negatively as they may have felt that 
management was trying to bamboozle them with a change effort that really was not a change at all.

As discussed previously, most mail processors perceived crew chiefs to be replacements for supervisors and viewed crew chiefs as part of management. Interestingly, of all the items asked of mail processors at the trial sites, the most endorsed opinion items were those regarding the ability to vote out crew chiefs. Mail processors believed that they should have the right to vote out ineffective crew chiefs and that this ability made crew chiefs more responsive to the needs of mail processors. Almost all employees interviewed shared the same beliefs. However, some members of management were not in favor of allowing mail processors to vote out crew chiefs, as they felt that some of the decisions about the deselection of crew chiefs were more political and personal in nature than related to crew chief ineffectiveness.

However, I do believe that the deselection process was an important characteristic of the program, in that it was certainly the most empowering component. It may be true that political and personal considerations may come into play when deciding whether to vote out a crew chief. However, this is an intrinsic characteristic of all participatory and democratic processes. What is interesting though is that this power is what I would deem negatively-oriented rather than positively-oriented. Allowing mail processors to elect their crew chiefs would be more positive in nature, voting a crew chief "in" rather than voting one "out." This might have also generated a stronger feeling of empowerment for mail processors. 


\section{Importance of Crew Chief Support}

Mail processors who reported high levels of crew chief support were more likely to report lower levels of role ambiguity and role conflict, supporting Hypotheses $5 \mathrm{a}$ and $5 \mathrm{~b}$. If these relationships reflect causal effects, then one strategy the USPS can implement to reduce role stressors would be to increase the level of support provided by the crew chief to mail processors. Given that a large component of support is relationally based (e.g., Blau, 1964; S. Cohen \& Wills, 1985; Griffin et al., 2001; LaRocco et al., 1980), the USPS could provide more crew chief training in interpersonal skills and/or add interpersonal competency as a criteria for crew chief selection to increase the pool of available social support. However, this would require the USPS to reimplement the crew chief program, creating the need for an additional intervention study to conclude whether changes in support are associated with changes in role stressors.

The findings did support all of the other hypothesized main effects of crew chief support. Mail processors who reported higher levels of crew chief support were more likely to report higher job satisfaction, company commitment, and union commitment. These results support Hypotheses $5 \mathrm{~d}, 5 \mathrm{e}$, and $5 \mathrm{f}$. Using support as a proxy for the quality of the relationship between the crew chief and mail processor, these findings highlight the critical link between positive relationships and organizational outcomes. That is, these results supporting the contention that employees "generalize" their relationship with their crew chief, who can be considered an agent of the organization, to that of the larger organization itself. This logic also 
Discussion 205

should extend to job satisfaction and company commitment. Employees who receive support will be more content with their job and will reciprocate to the organization with commitment, because the supervisor is a representative/agent of the organization. An additional benefit in the case of the crew chief, as a union member, is that mail processors who receive support from the crew chief are likely to reciprocate in kind to the union with increased commitment.

\section{Prominence of Role Ambiguity}

Although there was much support for the hypothesized relationships in the model, the initial model as a whole did not fit well. This was largely a result of unspecified strong relationships that were not included in the model. In examining the modification indices and standardized residual matrix of the initial model, I discovered that there were significant relationships of role ambiguity with job satisfaction, company commitment, and union commitment. In effect, this suggested that there were significant direct effects of role ambiguity and the outcome variables beyond the indirect effects via emotional exhaustion and job satisfaction. Mail processors who reported high role ambiguity were less likely to have high job satisfaction, high company commitment, and high union commitment beyond any of the implied mediation effects. Because these relationships were entirely plausible (cf. A. Cohen, 1992; Fullagar \& Barling, 1991; O' Driscoll \& Beehr, 1994; Schaubroeck et al., 1989), they were included in the final model, resulting in a significant improvement in overall 
model fit. The other role stressor that was included, role conflict, did not exhibit any additional direct effects.

This pattern of results brings a certain prominence to role ambiguity, at least at the USPS mail processing facilities. There are aspects of role ambiguity that affect job satisfaction beyond that explained by emotional exhaustion. In addition to producing strain, perhaps role ambiguity produces frustration and discontent that is reflected in job satisfaction because clarity in one's work role is an essential expectation. Traditionally, work carried out in unionized organizations is governed by labor contracts that specify the exact duties and tasks expected to be performed by employees.

Also of note is that role ambiguity explained variance in both company and union commitment, surpassing that of which was captured through the negative relationship of role ambiguity to job satisfaction. That is, there are aspects of role ambiguity associated with both company and union commitment that are not explained by role ambiguity's direct and indirect association (via strain) with job satisfaction. One possible explanation for role ambiguity's direct relationship with company commitment is that in addition to not being satisfied with their work, employees may see role ambiguity as a violation of their contract, and may respond by becoming less committed or by failing to develop commitment to the company. In social exchange terms, employees could consider the presence of role ambiguity as a breach of both the social and economic exchange agreement. A possible explanation for role ambiguity's direct connection to union commitment also follows from social exchange theory. 
Employees who attribute the failure for clarity in work roles to the union are less likely to reciprocate with commitment to the union.

\section{Evaluation of Direct and Indirect Effects}

One of the major benefits of evaluating the SSO model with a covariance structure modeling framework is that it allows the evaluation of relationships among variables within the context of other variables and their relationships that are present in a particular model. Although structural equation modeling is less capable than system dynamic models in incorporating system-based principles, it goes beyond most general linear model-based analyses in enabling researchers to consider a larger set of direct and indirect relationships among the variables in a model. One of the tenets of systems science is that small changes in one variable can effect larger changes in other variables throughout the system (e.g., Levine, Van Sell, \& Rubin, 1992; Senge, 1990; Sterman, 2000). In the case of covariance structural modeling, it is possible for a variable to have small direct effect, but have large indirect effects. Hence, focusing strictly on the direct effects could lead one to underestimate the total magnitudes of the relationships present among variables included in a particular model.

In the case of the current model, role ambiguity had a total effect on company commitment and union commitment that was much larger than the direct effect alone. In addition, crew chief support exhibited significant larger total effects than direct effects alone, especially for company commitment, where the total effect was $314 \%$ larger than the direct effect itself. From the examination of the total effects, the 
Discussion 208

strongest predictors of job satisfaction were emotional exhaustion, role ambiguity, and crew chief support. For company commitment, the strongest effects were from job satisfaction, role ambiguity, and crew chief support. Finally, for union commitment, the strongest effect was from crew chief support, followed by job satisfaction and role ambiguity.

\section{SSO Model}

Aim 2, which was concerned with replicating and extending the stressor-strainoutcome model, received more support than Aim 1. Rather than focusing on the effects of the crew chief intervention per se, the central goal of Aim 2 was to confirm the expected relationships among the central outcomes of the intervention after the implementation of the crew chief program. Another key variable was perceptions of crew chief support, which I hypothesized would have direct effects on all of the outcome variables and to moderate the stressor-strain and strain-outcome relationships.

The relationships among the central variables posited by the SSO model received support. Mail processors who reported more role conflict and role ambiguity also indicated higher levels of emotional exhaustion than those who reported less role conflict and role ambiguity. These results confirm the expected relationship between stressors and strain. Mail processors who reported high levels of emotional exhaustion were less likely to have high job satisfaction. This finding replicates previous research showing that strain is negatively associated with positive organizational outcomes. 
Discussion 209

Thus, this study, along with previous research (cf. Cartwright et al., 1995; Mack et al., 1998; Quick et al., 1997; Sauter et al., 1990), highlights why organizations should be concerned with employee stress. Besides an ethical concern organizations should have for their employees, employees who experience less strain should have higher job satisfaction. Job satisfaction is significant to organizations because it has been linked to outcomes of value, such as company commitment (established in this study as well as Deery et al., 1994; Mathieu \& Zajac, 1990; Schaubroeck et al., 1989; Tett \& Meyer, 1993), job performance (Iaffaldano \& Muchinsky, 1985; Judge et al., 2001), absenteeism (Scott \& Taylor, 1985), and turnover intentions (Mobley et al., 1978; Tett \& Meyer, 1993).

\section{Job Satisfaction and Company and Union Commitment}

Mail processors who were more satisfied with their job reported higher levels of both company commitment and union commitment. These findings lend support to Hypotheses $7 \mathrm{a}$ and $7 \mathrm{~b}$. The positive relationship of job satisfaction and company commitment is a replication of several previous studies (Elangovan, 2001; Farkas \& Tetrick, 1989; Schaubroeck et al., 1989; Williams \& Hazer, 1986). However, even though I modeled the effect as a directional effect from job satisfaction to company commitment, the current findings do not necessarily confirm this ordering given the cross-sectional nature of the study design. As discussed in Chapter 5, it may be the case that company commitment affects job satisfaction (Bateman \& Strasser, 1984), or that a reciprocal relationship exists between these attitudes (Farkas \& Tetrick, 1989). 
Previous research on the relationship between job satisfaction and union commitment has been less clear (e.g., 1998; Bamberger et al., 1999; Fullagar \& Barling, 1989; Gordon et al., 1980; Viswesvaran \& Deshpande, 1993). An argument can be made that when employees are less satisfied with their job, they are likely to respond with more commitment to the union because the union is an instrument by which employees can improve their job situation. For example, if employees are dissatisfied with their pay and benefits, they can ask the union to negotiate these desires on their behalf, and in turn, reciprocate to the union with their commitment. This increase in commitment could arguably occur regardless of whether the union was successful in achieving employees' desires. However, if the union is successful in improving working conditions for the employees, then a dynamic phenomenon occurs where job satisfaction and union commitment both improve, and the increase in job satisfaction reinforces the commitment to the union. This pattern would suggest a positive relationship between job satisfaction and union commitment.

In the current study, I argued that the crew chief program, as an initiative proposed by the union, would improve employee job satisfaction and employees would reciprocate with increased commitment to the union because they would attribute the program to the union. Although I was not able to demonstrate that job satisfaction or union commitment increased more in crew chief sites than in control sites, I did establish a positive link between the two. Moreover, the correlation between job satisfaction and union commitment increased from Time 1 (total sample $r$ $=.23$, matched sample $r=.18)$, to Time 2 (total sample $r=.35$, matched sample $r=$ 
.28 ), whereas the relationship between job satisfaction and company commitment remained relatively stable from Time 1 to Time 2 (total sample $r=.66$, matched sample $r=.67$; total sample $r=.65$, matched sample $r=.60$, respectively). Obviously, an examination of correlations alone is not enough to validate the dynamic nature of the relationship between job satisfaction and union commitment, but the pattern of results as well as the mixed findings in the literature are consistent with this idea.

\section{Improving the Crew Chief Program}

The GAO (1994a, 1994b) believed there were four major shortcomings of the crew chief program, which I concur would strengthen the crew chief program if they were addressed. First, the GAO agreed with management that selecting crew chiefs based more on seniority than on qualifications is problematic. The GAO felt that the number of ineffective crew chiefs could be reduced by shifting the emphasis to qualification from seniority. It is not entirely apparent to me based on the quantitative and qualitative data on whether there were a significant number of ineffective crew chiefs, but from a performance standpoint, it makes sense that incorporating qualification-based criteria would improve the quality of the crew chiefs chosen. As discussed in Chapter 8, union and management interviewees disagreed about how crew chiefs should be selected. The GAO suggested a two-part system for the selection of crew chiefs. The GAO recommended that the steering committee at each location be responsible for screening applicants and allow mail processors to select the crew chiefs from that pool. 
Discussion 212

Second, the GAO noted that the USPS did not provide incentives for team performance. The literature on compensation and performance management discusses the importance of matching the compensation system to the nature of the work (Baker \& Salas, 1997; Dickinson \& McIntyre, 1997; Reilly \& McGourty, 1998; Sahl, 1998; Simonds Jr \& Bell, 1997; Tesluk, Mathieu, Zaccaro, \& Marks, 1997; Zigon, 1997). For example, a commission based system works well for salesperson performance and a salaried system works well for management employees. In team-based organizations, team performance should be evaluated and rewarded in addition to individual performance (Reilly \& McGourty, 1998; Sahl, 1998; Simonds Jr \& Bell, 1997; Tesluk et al., 1997; Zigon, 1997). Hence, to maintain the proper motivation for work crews, future implementations of the crew chief program need to connect with the performance management and compensation system directly and clearly.

The third problem highlighted by the GAO was that the USPS did not do a good job of holding employees or supervisors accountable for poor performance. Several employee interviewees brought up the issue of poor accountability. Some respondents felt neither crew chiefs nor supervisors wanted to be involved with disciplinary matters and simply "passed the buck" back and forth to each other. Mail processors who performed poorly created a burden to the crew, as other members needed to work harder to pick up their "slack." Hence, clearly outlining and enforcing policies for performance accountability would not only likely improve the functioning of the crew chief program, but overall individual and team performance as well. 
Discussion 213

The fourth major problem highlighted by the GAO concerned the ambiguity perceived by employees involved in the crew chief program regarding the roles and responsibilities of the crew chiefs and supervisors. The results of the implementation analysis reinforced this finding, where many interviewees felt there was some confusion regarding the exact role of the crew chief among supervisors and the rank and file. Any future implementation of this type of program needs to delineate very clearly what the exact roles and duties of the crew chiefs are, and how the introduction of crew chiefs impacts other positions. Training on the program should not only be given to crew chiefs, but to all employees involved. Further, the information should be communicated with newsletters, presentations, paycheck inserts, town hall meetings, and any other communications medium available to the organization. This information barrage should also be backed with an audit as part of the process evaluation to ensure that employees are receiving and understanding the information. A sound understanding of the crew chief program could have a profound impact on its success.

\section{How Does the Current Study Differs from Previous Published Research Using} this Data?

Although Martin (2001) based his research findings on the same dataset that I used in this study, the aims, focal variables, and analytical strategies between our studies differ. One goal of Martin's research was to determine whether workgroup and supervisor climate at baseline, perceived support of the crew chief program by management, and view of the role of the crew chief predicted acceptance of the crew chief program by mail processors and crew chiefs. To test the hypotheses based on this 
Discussion 214

aim, Martin used hierarchical multiple regression analysis and examined regression results separately for mail processors and crew chiefs. The other goal of Martin's research was to determine whether mail processors and crew chiefs differed on the variables used in the regression analysis. Martin examined these differences using a MANOVA followed by univariate t-tests.

Martin (2001) found that crew chiefs had higher levels of acceptance of the crew chief program compared to mail processors. Of the climate variables measured at baseline that Martin examined, he found that the crew chiefs' perception of the workgroup group climate was positively related to crew chief program acceptance whereas crew chiefs' assessment of the supervisory climate and satisfaction with advancement opportunities were negatively related to program acceptance. Martin explains the latter findings by suggesting that mail processors became crew chiefs as a means to improve their work situation. Consistent with this reasoning is Martin's finding that crew chiefs reported more negative perceptions of supervisory climate compared to mail processors at Time 1. Similarly, one of the aims of my research was to determine whether the crew chief program improved the work environment as defined by stressors, strain, job and supervisory satisfaction, and company and union commitment. Improving the work environment for all mail processors, not just crew chiefs, was one of the major objectives of the program. However, in my study, it was only appropriate for me to examine mail processors as there was not enough of a sample size to provide adequate tests on attitude changes in crew chiefs. In sum, this set of findings from Martin's studies provides evidence for why mail processors may 
have become crew chiefs, whereas my study was more of a direct test on whether change occurred on various organizational outcomes in mail processors.

In Martin's (2001) study, the climate variables that were statistically significant for the crew chiefs were not found to be significant to crew chief program acceptance for the mail processors. However, Martin found that union loyalty was positively related to acceptance and postal service loyalty was negatively related to program acceptance (note that Martin included these variables as indicators of workplace climate in his study). Mail processors who were more committed to the union and less committed to the USPS were more likely to accept the crew chief program. Martin viewed this finding as evidence that mail processors perceived the crew chief program as a union initiative rather than a USPS initiative. This is an interesting finding in that both types of commitment were found to be positively related to each other in this sample, yet they had opposite effects with crew chief acceptance in Martin's study.

In my study, I found perceptions of crew chief support by mail processors to be positively related to both union and company commitment, albeit the strength of the relationship was greater for union commitment. Using an exchange framework, I explained these findings by suggesting that mail processors reward both the union and the USPS with commitment as reciprocation for the crew chief support provided. This implies that mail processors viewed the initiative as sponsored by both the union and USPS. Hence, the justifications Martin (2001) and I provide for the findings involving commitment, each of which are based on an exchange framework, are contradictory. 
Discussion 216

However, it is important to note that crew chief support and program acceptance are very different variables, and that the hypothesized causal ordering differs for each. In Martin's study, loyalty at Time 1 was used to predict acceptance at Time 2 . In my study, I positioned crew chief support as an antecedent to both types of commitment. Perhaps baseline climate perceptions are important in determining acceptance, but it is possible that mail processors shift their perceptions over time and come to perceive the USPS as a partner in the initiative. It is also important to note that the subsamples used in establishing these relationships were different in our two studies. The subsample in my study for this analysis consisted of all mail processors at Time 2, whereas in Martin's study included only mail processors who were able to be matched from Time 1 to Time 2 .

Martin (2001) also found that mail processors had more acceptance of the crew chief program when they viewed the crew chief position as a promotion and did not perceive the crew chief as a member of management. The latter finding was one of the major themes from the implementation analysis, and is consistent with Martin's study in that mail processors had negative attitudes toward the program when crew chiefs were viewed as a member of management. This is also consistent with one of the arguments I made in Chapter 3 for why the crew chief program would improve labor relations. The promotion of "one of their own (mail processor)" as in charge of the workgroup rather than "one of them (management)" should lead to better leadermember relations. 
Also, the only variable to be related to program acceptance for both mail processors and crew chiefs was perceived support of the crew chief program by management. In both groups, the more supportive upper management was viewed to be of the crew chief program, the more likely crew chiefs and mail processors would accept the crew chief program. As discussed previously and in Martin (2001), this finding is not surprising given prior findings in the literature on the importance of management support for successful organizational interventions. According to the survey results on this item, $36 \%$ of mail processors either strongly agreed or slightly agreed that top management was helping the crew chief program work well, and another $36 \%$ were neutral. Moreover, $48 \%$ of crew chiefs either strongly agreed or slightly agreed that top management was helping the crew chief program work well, and $22 \%$ were neutral. Martin reported this as a significant difference between these groups. It would have been interesting to have had a measure of support given to upper management to be able to compare their level of perceived support to mail processors and crew chiefs. I would imagine that the percentage of top management who supported the program would be even higher. According to the implementation analysis, although many respondents believed that supervisors did not support the crew chief program, it did appear that upper management respondents were more supportive of the program. Perhaps the level of disparity among the ratings could be taken as an indicator of "disconnect" among the levels of the organization.

Other attitudes in which crew chiefs had more positive attitudes than mail processors include perceptions of supervisor support, having adequate staffing, 
Discussion 218

viewing the crew chief position as a promotion, knowing the crew chief role, and not viewing the crew chief as a part of management. Drawing on exchange theory, Martin (2001) expected these differences because crew chiefs derived more of the benefits of the program. Hence, they were more likely to have more positive attitudes relating to the crew chief program. However, given the results of the implementation analysis in this study, it is surprising to see that crew chiefs reported a mean level of supervisor support that was above 4 (neutral) on a seven-point scale, given that they are likely to be directed affected by lack of supervisor support. The mean of mail processor ratings on perceived supervisor support of crew chiefs was below 4, indicating a slight disagreement with the item, which is consistent with the implementation analysis (note that crew chiefs were not interviewed as part of the implementation analysis.

In summary, Martin (2001) focused on predicting crew chief acceptance and describing differences between mail processors and crew chiefs on various organizational attitudes, whereas my research was a program evaluation to determine whether the crew chief program produced change in organizational stressors, strain, supervisory and job satisfaction, and company and union commitment. Additionally, my study differs in that I also examined the relationships between stressors, strain, support from the crew chief, job satisfaction, and union and company commitment.

\section{Limitations}

One possible problem with the dataset that I used to evaluate Aim 1 was the possibility that selection bias was present in the sample. Although I established that 
Discussion 219

those who were included in the analysis did not significantly differ from those who were not included on numerous variables, there still exists the possibility of response bias related to "third" variables that I was unable to evaluate but that could distinguish the groups. An example of a third variable likely to create a response bias in the current study would be turnover. Mail processors who were not present at Time 2 because they quit were obviously not included as part of the sample. Those mail processors who quit during the intervention period were likely to have different job attitudes from mail processors included in the sample at Time 1, and may have quit as a result of high stress and/or low satisfaction and commitment. Another limitation, discussed in more detail in the Design Issues section of this chapter, concerns the unexpected reduction in sample size resulting in inadequate power.

In the present study, the length of time between the baseline and follow-up measures was approximately one year. However, according to the implementation analysis data, many interviewees reported that it took additional time for the crew chief program to be implemented. Hence, not all sites had the crew chief program in place for one full year. Moreover, even if the crew chief program was properly implemented immediately after the baseline data were collected, there is the issue of whether one year was enough time to expect statistically significant changes in the job attitudes of interest.

The use of a self-report questionnaire to gather data creates a susceptibility to various biases, such as social desirability and common method variance, which could have influenced my findings. There are at least four reasons why these biases may 
Discussion 220

have had minimal effects in the present study. First, the outcomes of interest assessed in this study are attitudinal in nature, and therefore are most suitably measured by selfreport. Second, the survey data were collected from mail processors anonymously and thus should have minimized any motivation for socially desirable responding. Third, the correlation matrices across the sample subsets among the measures showed no signs of general positive manifold (i.e., large numbers of positive correlations), which suggests that a common method factor is unlikely to explain all of the estimated statistical relationships among the variables. Finally, some empirical research suggests that method variance accounts for a small proportion of the observed covariation among variables (Doty \& Glick, 1998). Therefore, while method biases may have been present, it does not seem likely that my findings are purely attributable to the assessment instruments.

Lastly, the use of a cross-sectional design in Aim 2 limits the strength of the causal inferences one can draw from the data. For example, job satisfaction and company commitment could exert reciprocal effects on each other such that higher job satisfaction leads to greater company commitment, and this increased commitment leads to greater job satisfaction. Therefore, I limited the use of causal language with regard to the Aim 2 hypotheses and I suggest that future research expand these findings using more dynamic and longitudinal methodologies. 
Discussion 221

One of the strengths of the design of this study was the explicit modeling of the inherent nested nature of the data. That is, employees who work within crews and are more likely to share common work experiences and attitudes with other members of their crew than with members of other crews. Given that most of the mail processors rotated crews within a particular tour at a particular site, the intervention was based at the tour level for each site. The proper evaluation of organizational interventions must take nesting into account, otherwise one risks violating a key assumption of the statistics one uses to assess these evaluations.

Although this study did not demonstrate quantitatively improvement in stressors, strain, job satisfaction, and company and union commitment, the implementation analysis from the qualitative data suggested there was a large potential for the crew chief program to succeed. Without the qualitative data, I would have been much less optimistic in my conclusions about the crew chief program. I believe one of the strengths of this dissertation is to serve as another example of how and why employing mixed methods in research endeavors provide better data upon which to answer research questions about organizations. Hence, organizational research, especially research concerned with evaluating interventions, should employ both methods of inquiry whenever possible. A more detailed discussion of combining quantitative and qualitative methods can be found in writings by Hammersley (1992), Morgan (1998), and Ponterotto and Greiger (1999).

A major challenge for organizational research, especially with settings where the state of labor-management relations is poor, is to guarantee convincingly to 
participants that their responses to questionnaires and/or interviews will remain anonymous or confidential. Obviously, an anonymous design is more secure from a privacy standpoint than a confidential one, as there is no way to trace back who answered a particular questionnaire. The only exception would be a unique combination of demographic characteristics or knowledge of a respondent's handwriting. Hence, guaranteeing anonymity is more likely to encourage a higher participation rate and engender more honest responses than confidentiality. However, anonymity can make it difficult to match data from multiple sources. This can be data from the same point in time, such as performance ratings, or respondent data from other points in time. Some form of identification is required to link the data from various sources, and therefore the best one can do to maintain privacy is guarantee the confidentiality of the data.

Unfortunately, as discussed in the limitations section, the current study employed a longitudinal design with anonymous data. Given the hostile work climate at the USPS at the time, those involved in the data collection at the time had to make a decision on the tradeoff between participation and data quality versus the ability to link data from one timepoint to another. The research team chose to keep the surveys anonymous, and decided that data could be linked by matching demographic characteristics and handwriting across the two timepoints. That employees were extremely concerned about their privacy is evident in the reports from the research team that some participants distorted their demographic characteristics to prevent anyone from being able to link a particular questionnaire to them. However, 
guaranteeing anonymity in a longitudinal design inevitably reduces the available power of any analyses, and introduces a possible selection bias for those who were matched and unmatched.

The question for future research and practice is then: How can researchers best manage the balance between guaranteeing privacy, both objectively and from the respondents' perspective, and needing to link data from different sources from respondents? Although the most logical solution to date is to guarantee confidentiality and credibly emphasize to employees that any identifying information will never be revealed to anyone outside a particular research team, this may be too difficult a "sell" in some organizations and lead to smaller response rates and lower quality data. Future research on innovative strategies on this matter is needed, as this is a pervasive issue that faces many organizational researchers and practitioners.

Future research should also consider examining organizational support as a possible buffer of the stress-strain-outcomes relationships. Given that organizational support is a higher level construct than the similar concept of social support, it may also be the case that organizational support will have a greater buffering effect for stressors, strains, and outcomes at the group level. Evidence for main effects of organizational support on stress comes from a study by Cropanzano et al (1997) that found organizational support to be negatively related to job tension, somatic tension, general fatigue, and burnout. 
One benefit of the crew chief program that arose out of the qualitative data from the implementation analysis is that there seemed to be less grievances filed by employees. As discussed in Chapter 2, there were an extraordinarily high number of grievances by employees at the USPS compared to other unionized work settings, and this was expensive for the USPS and likely reinforced poor labor relations with the union and its members. It would also have been interesting to know whether the crew chief program had an impact on other objective measures such as productivity and attendance. Employing both objective and attitudinal measures would have better captured the "program effectiveness" domain. Although this is not a novel idea, the current study should serve as a reminder that researchers need to use objective and subjective measures of the criterion domain whenever possible.

One of the innovative aspects of the current research was the significant involvement of the union in the design and implementation of the crew chief program. A meta-analysis by Macy and Izumi (1993) of 131 North American field studies of such workplace transformations found that only nine percent fully involved a union. In this study, the APWU was not only involved as a full partner, but also was the party that initially proposed the program. It is doubtful that the crew chief intervention would have had any chance of being successfully implemented if not for the support of the union. Practitioners should strive for a fully committed union as well as management to any organizational intervention in unionized work settings. In fact, this cooperation in itself could be an important first step in improving labor management relations. 
In addition, it is important to recall that the entire USPS was undergoing organizational changes at the time the crew chief program was implemented, and I found a significant reduction in stressors, strain, and union commitment, and an improvement in satisfaction with supervision across all sites. With the exception of the finding concerning union commitment, it is tempting to suggest that the other forms of organizational development the USPS was experiencing at that time contributed to these changes. Although this reasoning is entirely plausible, experimental threats to validity, such as maturation and statistical regression, are impossible to rule out with the current dataset.

Regardless of the true cause of these changes, the most important lesson to impart to organizational researchers and practitioners is to always remember that interventions, or field research for that matter, do not exist in a vacuum. That is, one must always consider the context in which the intervention and/or research is being conducted. Hence, although it is possible to evaluate whether there were differential changes in outcomes by comparing sites undergoing the same organizational changes, with the only major difference between the sites being whether the crew chief program was implemented, it may not be possible for the crew chief program by itself to affect those changes. Perhaps it is inappropriate to evaluate the crew chief program, or any single intervention program for that matter, in isolation from other changes that may be taking place. This is essentially a systems perspective, in that any intervention component needs to be considered along with its other components. This would also 
suggest that if other necessary components are not present, then any intervention without the right "ingredients" might be doomed for failure.

To highlight this reasoning with the crew chief program, recall in the previous section that GAO believed that the performance management system was not commensurate with the intervention. More specifically, one cannot expect team performance to improve if the team as a whole is not rewarded for its accomplishments. Therefore, future research and practice with an integrated and multifaceted intervention needs to be well developed and implemented to produce the desired changes throughout the organization. Moreover, as with all systems, there are always unforeseen challenges and behavior that may result from an intervention, and hence reinforces the importance of including a process evaluation in any study assessing organizational interventions.

In addition, none of the interviewees and only approximately a quarter of the mail processors believed that the crew chief program was not worth continuing. The GAO (1994a, 1994b, 1997c, 1997d) also recommended that the crew chief program be continued and expanded as one approach to implementing self-managed work units. The premature termination of the crew chief program could potentially damage labor relations by continuing the perception that the USPS is not serious about changing. Thus, it behooves practitioners to convince organizations that follow-through is a critical element of organizational change. In other words, organizational interventions are only worth implementing when the organization is fully committed by providing the necessary time and opportunity for improvement. 


\section{Conclusion}

The current study builds on research concerning self-managed work teams by examining the impact of a specific approach, a crew chief program, had on role stressors, strain, satisfaction with supervision and the job, and company and union commitment. The USPS, the nation's second largest employer, implemented the crew chief intervention at six mail processing plants across the United States and selected an additional three plants to serve as control sites. The analysis of the data also took into account the nested propertied of the data where employees are nested within shifts across sites. The quantitative results did not demonstrate that the crew chief program had more improvement in stressors, strain, satisfaction, and commitment than the control sites. However, based on the implementation analysis based on government and union reports and interview data, I concluded that the crew chief program was probably not fully implemented as designed and that the program was performing well enough to warrant at least an extension for further evaluation.

Unfortunately, after the pilot testing period expired, the program was not formally renewed. It seems that political influences within the organization were a major determinant on the ultimate fate of the crew chief program, as there was strong opposition to the program by many supervisors and the organization that represents their interest, the National Association of Postal Supervisors. It is a shame that in many situations, as this is not unique to the USPS, political interest overshadows an objective assessment of determining the effectiveness of programs and interventions. 
This is a reality that practitioners and researchers must always keep in mind when proposing, designing, and implementing organizational change interventions.

Another major goal of the present research was to replicate and extend the stressor-strain-outcome model that is popular in the organizational stress literature. The extension that this research provided was to examine how perceived support from a crew chief is related to role ambiguity, role conflict, emotional exhaustion, job satisfaction, company commitment, and union commitment. The data strongly supported the main effects outlined in the model, but there was no support for any of the proposed interaction effects. Also of note, modifications to the model in which role ambiguity had direct relationships with job satisfaction and union commitment dramatically improved the fit of the model. This suggests that role ambiguity may have effects on organizational attitudes that are beyond which are explained by role ambiguity's relationship with strain. For organizations, role ambiguity and support from one's immediate supervisor may be key levers that organizations should place more focus on reducing and improving, respectively, in order to catalyze other positive changes throughout the organization. 


\section{References}

Agars, M. D., Unckless, A. L., \& Tesluk, P. E. (1998). A cross-level examination of factors influencing union commitment and participation. Paper presented the Conference of the Society for Industrial and Organizational Psychology, Dallas, TX.

Aguinis, H. (1995). Statistical power problems with moderated multiple regression in management research. Journal of Management, 21(6), 1141.

Aguinis, H., \& Stone-Romero, E. F. (1997). Methodological artifacts in moderated multiple regression and their effects on statistical power. Journal of Applied Psychology, 82(1), 192.

Allen, N. J., \& Meyer, J. P. (1990). The measurement and antecedents of affective, continuance and normative commitment to the organization. Journal of Occupational Psychology, 63, 1-18.

Alutto, J. A., \& Acito, F. (1974). Decisional participation and sources of job satisfaction: A study of manufacturing personnel. Academy of Management Journal, 17, 160-167.

American Postal Workers Union. (1993a). Report of follow-up visit to rochester on december 6, 1993 to rochester, ny crew chief local steering committee.

American Postal Workers Union. (1993b). Report of follow-up visit to sacramento on august 10 and 11, 1993 to sacramento, ca crew chief local steering committee.

American Postal Workers Union. (1993c). Report of follow-up visit to st paul on august 12 and 13, 1993 to st paul, mn crew chief local steering committee.

Anonymous. (1993). Postal service promises new management style. Occupational Hazards, 55, 32. 
Anthes, G. H. (1993, Oct 4). Postal service sorts through automation. Computerworld, $27,26$.

Arbuckle, J. L. (2003). Amos 5.0 [computer software]. Chicago, IL: SmallWaters.

Arthur, J. B., \& Dworkin, J. B. (1991). Current topics in industrial and labor relations research and practice. Journal of Management, 17, 515-551.

Bachman, R. (1994). Violence and theft in the workplace. Washington: U.S. Department of Justice, Bureau of Justice Statistics.

Baker, D. P., \& Salas, E. (1997). Principles for measuring teamwork: A summary and look toward the future. In M. T. Brannick, E. Salas \& C. Prince (Eds.), Team performance assessment and measurement: Theory, methods, and applications (pp. 331-355). Mahwah, NJ: Erlbaum.

Bamberger, P. A., Kluger, A. N., \& Suchard, R. (1999). The antecedents and consequences of union commitment: A meta-analysis. Academy of Management Journal, 42, 304-317.

Bateman, T. S., \& Strasser, S. (1984). A longitudinal analysis of the antecedents of organizational commitment. Academy of Management Journal, 27, 95-112.

Bauer, T. N., \& Green, S. G. (1996). Development of leader-member exchange: A longitudinal test. Academy of Management Journal, 39, 1538-1567.

Bedeian, A. G., \& Armenakis, A. A. (1981). A path-analytical study of the consequences of role conflict and ambiguity. Academy of Management Journal, $24,417-424$.

Belanger, J., Edwards, P. K., \& Wright, M. (2003). Commitment at work and independence from management: A study of advanced teamwork. Work and Occupations, 30, 234-252. 
Bishop, J. W., \& Scott, K. D. (2000). An examination of organizational and team commitment in a self-directed team environment. Journal of Applied Psychology, 85, 439-450.

Blau, P. M. (1964). Exchange and power in social life. New York: Wiley.

Bliese, P. D. (2000). Within-group agreement, non-independence, and reliability: Implications for data aggregation and analysis. In K. J. Klein \& S. W. Kozlowski (Eds.), Multilevel theory, research, and methods in organizations: Foundations, extensions, and new directions (pp. 349-381). San Francisco, CA: Jossey-Bass.

Block, P. (1987). The empowered manager: Positive political skills at work (1st ed.). San Francisco, CA: Jossey-Bass.

Boulding, K. E. (1956). General systems theory: The skeleton of science. General Systems, 1, 1-17.

Brooks, B. R. (2001, Jun 22). Mail disorder: Blizzard of grievances joins a sack of woes at u.S. Postal service. Wall Street Journal, p. A1.

Brower, H. H., Schoorman, F. D., \& Tan, H. H. (2000). A model of relational leadership: The integration of trust and leader-member exchange. Leadership Quarterly, 11, 227-250.

Browne, M., \& Cudeck, R. (1993). Alternative ways of assessing model fit. In K. A. Bollen \& S. Long (Eds.), Testing structural equation models (pp. 136-162). Beverly Hills, CA: Sage.

Bryk, A. S., \& Raudenbush, S. W. (1992). Hierarchical linear models: Applications and data analysis methods. Thousand Oaks, CA: Sage Publications, Inc.

Burns, T., \& Stalker, G. M. (1994). The management of innovation (Rev. ed.). Oxford, England: Oxford Univ Press. 
Busemeyer, J. R., \& Jones, L. E. (1983). Analysis of multiplicative combination rules when the causal variables are measured with error. Psychological Bulletin, 93(3), 549-562.

Butler, J. K., Cantrell, R. S., \& Flick, R. J. (1999). Transformation leadership behaviors, upward trust, and satisfaction in self-managed work teams. Organization Development Journal, 17, 13-28.

Cammann, C., Fichman, M., Jenkins, G. D., Jr., \& Klesh, J. R. (1983). Assessing the attitudes and perceptions of organizational members. In S. E. Seashore, E. E. Lawler, III, P. H. Mirvis \& C. Cammann (Eds.), Assessing organizational change: A guide to methods, measures, and practices (pp. 71-138). New York, NY: John Wiley \& Sons.

Campion, M. A., Papper, E. M., \& Medsker, G. J. (1996). Relations between work team characteristics and effectiveness: A replication and extension. Personnel Psychology, 49, 429.

Cappelli, P., \& Chauvin, K. (1991). A test of an efficiency model of grievance activity. Industrial \& Labor Relations Review, 45, 3-14.

Cartwright, S., Cooper, C. L., \& Murphy, L. R. (1995). Diagnosing a healthy organization: A proactive approach to stress in the workplace. In L. R. Murphy, J. J. Hurrell, Jr., S. L. Sauter \& G. Keita (Eds.), Job stress interventions (pp. 217-233). Washington, DC: American Psychological Association.

Cohen, A. (1992). Antecedents of organizational commitment across occupational groups: A meta-analysis. Journal of Organizational Behavior, 13, 539-558.

Cohen, A. (1993). An empirical assessment of the multidimensionality of union participation. Journal of Management, 19, 749-773.

Cohen, J. (1987). Statistical power analysis for the behavioral sciences (Rev. ed.). Hillsdale, NJ, England: Lawrence Erlbaum Associates, Inc.

Cohen, S., \& Wills, T. A. (1985). Stress, social support, and the buffering hypothesis. Psychological Bulletin, 98, 310-357. 
Cohen, S. G., \& Ledford, G. E., Jr. (1994). The effectiveness of self-managing teams: A quasi-experiment. Human Relations, 47, 13-44.

Conger, J. A., \& Kanungo, R. N. (1988). The empowerment process: Integrating theory and practice. Academy of Management Review, 13, 471-482.

Cook, T. D., Campbell, D. T., \& Peracchio, L. (1992). Quasi experimentaion. In M. D. Dunnette \& L. M. Hough (Eds.), Handbook of industrial and organizational psychology (2nd ed., Vol. 1, pp. 491-576).

Cooke, W. N. (1990). Factors influencing the effect of joint union-management programs on employee-supervisor relations. Industrial \& Labor Relations Review, 43, 587-603.

Cordery, J. L., Mueller, W. S., \& Smith, L. M. (1991). Attitudinal and behavioral effects of autonomous group working: A longitudinal field study. Academy of Management Journal, 34, 464-476.

Cotton, J. L., Vollrath, D. A., Froggatt, K. L., Lengnick-Hall, M. L., \& Jennings, K. R. (1988). Employee participation: Diverse forms and different outcomes. Academy of Management Review, 13, 8-22.

Cronbach, L. J. (1987). Statistical tests for moderator variables: Flaws in analyses recently proposed. Psychological Bulletin, 102(3), 414-417.

Curry, J. P., Wakefield, D. S., Price, J. L., \& Mueller, C. W. (1986). On the causal ordering of job satisfaction and organizational commitment. Academy of Management Journal, 29, 847-858.

Dansereau, F., Jr., Cashman, J., \& Graen, G. (1973). Instrumentality theory and equity theory as complementary approaches in predicting the relationship of leadership and turnover among managers. Organizational Behavior \& Human Performance, 10, 184-200.

Dansereau, F., Jr., Graen, G., \& Haga, W. J. (1975). A vertical dyad linkage approach to leadership within formal organizations. Organizational Behavior \& Human Performance, 13, 46-78. 
Davis, C. E., \& West, J. P. (1979). Attitudinal differences among supervisors in the public sector. Industrial \& Labor Relations Review, 32, 496-505.

Dean, L. R. (1954). Union activity and dual loyalty. Industrial \& Labor Relations Review, 7, 526-536.

Deci, E. L., Connell, J. P., \& Ryan, R. M. (1989). Self-determination in a work organization. Journal of Applied Psychology, 74, 580-590.

Deery, S. J., Iverson, R. D., \& Erwin, P. J. (1994). Predicting organizational and union commitment: The effect of industrial relations climate. British Journal of Industrial Relations, 32, 581-597.

Deluga, R. J. (1994). Supervisor trust building, leader-member exchange and organizational citizenship behaviour. Journal of Occupational and Organizational Psychology, 67, 315-326.

Dessler, G. (1999). How to earn your employees' commitment. Academy of Management Executive, 13, 58-67.

Dickinson, T. L., \& McIntyre, R. M. (1997). A conceptual framework for teamwork measurement. In M. T. Brannick, E. Salas \& C. Prince (Eds.), Team performance assessment and measurement: Theory, methods, and applications (pp. 19-43). Mahwah, NJ: Erlbaum.

Dienesch, R. M., \& Liden, R. C. (1986). Leader-member exchange model of leadership: A critique and further development. The Academy of Management Review, 11, 618-634.

Dirks, K. T., \& Ferrin, D. L. (2002). Trust in leadership: Meta-analytic findings and implications for research and practice. Journal of Applied Psychology, 87, 611628.

Donaldson, L., \& Hilmer, F. G. (1998). Management redeemed: The case against fads that harm management. Organizational Dynamics, 26, 7-20. 
Donner, A., \& Klar, N. (1996). Statistical considerations in the design and analysis of community intervention trials. Journal of Clinical Epidemiology, 49(4), 435439.

Doty, D. H., \& Glick, W. H. (1998). Common method bias: Does common methods variance really bias the results? Organizational Research Methods, 1, 374-406.

Downey, R. G., \& King, C. V. (1998). Missing data in likert ratings: A comparison of replacement methods. Journal of General Psychology, 125, 175-191.

Dunham, R. B., Smith, F. J., \& Blackburn, R. S. (1977). Validation of the index of organizational reactions with the jdi, the msq, and faces scales. Academy of Management Journal, 20, 420-432.

Eaton, A. E. (1994). The survival of employee participation programs in unionized settings. Industrial \& Labor Relations Review, 47(3), 371.

Eaton, A. E., \& Voos, P. B. (1989). The ability of unions to adapt to innovative workplace arrangements. American Economic Review, 79, 172-176.

Edwards, K. J., Hershberger, P. J., Russell, R. K., \& Markert, R. J. (2001). Stress, negative social exchange, and health symptoms in university students. Journal of American College Health, 50, 75-79.

Eisenberger, R., Armeli, S., Rexwinkel, B., Lynch, P. D., \& Rhoades, L. (2001). Reciprocation of perceived organizational support. Journal of Applied Psychology, 86, 42-51.

Eisenberger, R., \& Fasolo, P. (1990). Perceived organizational support and employee diligence, commitment, and innovation. Journal of Applied Psychology, 75, 51.

Eisenberger, R., Huntington, R., Hutchison, S., \& Sowa, D. (1986). Perceived organizational support. Journal of Applied Psychology, 71, 500-507. 
Eisenberger, R., Stinglhamber, F., Vandenberghe, C., Sucharski, I. L., \& Rhoades, L. (2002). Perceived supervisor support: Contributions to perceived organizational support and employee retention. Journal of Applied Psychology, 87, 565-573.

Elangovan, A. R. (2001). Causal ordering of stress, satisfaction and commitment, and intention to quit: A structural equations analysis. Leadership \& Organization Development Journal, 22, 159-165.

Elmuti, D. (1997). Self-managed work teams approach: Creative management tool or a fad? Management Decision, 35, 233-239.

Emery, C. R., \& Summers, T. P. (1996). The role of organizational climate in the implementation of total quality management. Journal of Managerial Issues, 8 , 484-496.

Evans, M. G. (1985). A monte carlo study of the effects of correlated method variance in moderated multiple regression. Organizational Behavior \& Human Decision Processes, 36(3), 305.

Farkas, A. J., \& Tetrick, L. E. (1989). A three-wave longitudinal analysis of the causal ordering of satisfaction and commitment on turnover decisions. Journal of Applied Psychology, 74, 855-868.

Fenwick, R., \& Olson, J. (1986). Support for worker participation: Attitudes among union and non-union workers. American Sociological Review, 51, 505-522.

Fields, M. W., \& Thacker, J. W. (1992). Influence of quality of work life on company and union commitment. Academy of Management Journal, 35, 439-450.

Fisher, C. D. (1985). Social support and adjustment to work: A longitudinal study. Journal of Management, 11(3), 39-53.

Fried, Y., \& Ferris, G. R. (1987). The validity of the job characteristics model: A review and meta-analysis. Personnel Psychology, 40, 287-322. 
Fried, Y., \& Tiegs, R. B. (1993). The main effect model versus buffering model of shop steward social support: A study of rank-and-file auto workers in the u.S.A. Journal of Organizational Behavior, 14, 481-493.

Frone, M. R., Russell, M., \& Cooper, M. L. (1995). Job stressors, job involvement and employee health: A test of identity theory. Journal of Occupational and Organizational Psychology, 68, 1-11.

Fullagar, C., \& Barling, J. (1989). A longitudinal test of a model of the antecedents and consequences of union loyalty. Journal of Applied Psychology, 74, 213-227.

Fullagar, C., \& Barling, J. (1991). Predictors and outcomes of different patterns of organizational and union loyalty. Journal of Occupational Psychology, 64, 129143.

Fullagar, C., Gallagher, D. G., Gordon, M. E., \& Clark, P. F. (1995). Impact of early socialization on union commitment and participation: A longitudinal study. Journal of Applied Psychology, 80, 147-157.

Ganster, D. C., Fusilier, M. R., \& Mayes, B. T. (1986). Role of social support in the experience of stress at work. Journal of Applied Psychology, 71, 102-110.

Gerstner, C. R., \& Day, D. V. (1997). Meta-analytic review of leader-member exchange theory: Correlates and construct issues. Journal of Applied Psychology, 82, 827844.

Goffin, R. D., \& Jackson, D. N. (1988). The structure validity of the index of organizational reactions. Multivariate Behavioral Research, 23, 327.

Gomez, C., \& Rosen, B. (2001). The leader-member exchange as a link between managerial trust and employee empowerment. Group \& Organization Management, 26, 53-70.

Goodin, M. (1992). Postal workforce is in transition. Crain's Detroit Business, 8(8), 14. 
Gordon, M. E., Philpot, J. W., Burt, R. E., Thompson, C. A., \& Spiller, W. E. (1980). Commitment to the union: Development of a measure and an examination of its correlates. Journal of Applied Psychology, 65, 479-499.

Graham, J. W., \& Verma, A. (1991). Predictors and moderators of employee response to employee participation programs. Human Relations, 44, 551-568.

Greengard, S. (1999). Zero tolerance: Making it work. Workforce, 78(5), 28-34.

Griffin, M. A., Patterson, M. G., \& West, M. A. (2001). Job satisfaction and teamwork: The role of supervisor support. Journal of Organizational Behavior, 22, 537550.

Guzzo, R. A., \& Dickson, M. W. (1996). Teams in organizations: Recent research on performance and effectiveness. Annual Review of Psychology, 47, 307-338.

Hackman, J., \& Oldham, G. R. (1976). Motivation through the design of work: Test of a theory. Organizational Behavior \& Human Decision Processes, 16, 250-279.

Hammersley, M. (1992). Deconstructing the qualitative quantitative divide. In J. Brannen (Ed.), Mixing methods: Qualitative and quanitative research (pp. 3956). Brookfield, VT: Ashgate Publishing.

Harris, T. E. (1992). Toward effective employee involvement: An analysis of parallel and self-managing teams. Journal of Applied Business Research, 9, 25-33.

Harrison, E. L. (1995). The case for supervisor involvement. Human Resource Management International Digest, 3(2), 12-14.

Hart, K. M., Capps, H. R., Cangemi, J. P., \& Caillouet, L. M. (1986). Exploring organizational trust and its multiple dimensions: A case study of general motors. Organizational Development Journal, 4, 31-39.

Heaney, C. A., Israel, B. A., Schurman, S. J., Baker, E. A., House, J. S., \& Hugentobler, M. (1993). Industrial relations, worksite stress reduction, and employee well- 
being: A participatory action research investigation. Journal of Organizational Behavior, 14, 495-510.

Highhouse, S., \& Becker, A. S. (1993). Facet measures and global job satisfaction. Journal of Business \& Psychology, 8, 117-127.

Hobfoll, S. E. (1989). Conservation of resources: A new attempt at conceptualizing stress. American Psychologist, 44, 513-524.

Hofmann, D. A., \& Gavin, M. B. (1998). Centering decisions in hierarchical linear models: Implications for research in organizations. Journal of Management, 24, 623-641.

Hofmann, D. A., Griffin, M. A., \& Gavin, M. B. (2000). The application of hierarchical linear modeling to organizational research. In K. J. Klein \& S. W. Kozlowski (Eds.), Multilevel theory, research, and methods in organizations: Foundations, extensions, and new directions (pp. 467-553). San Francisco, CA: Jossey-Bass.

Holland, J. L. (1997). Making vocational choices: A theory of vocational personalities and work environments (3rd ed.). Odessa, FL: Psychological Assessment Resources.

Holland, J. L., \& Gottfredson, G. D. (1976). Using a typology of persons and environments to explain careers: Some extensions and clarifications. Counseling Psychologist, 6(3), 20-29.

Hu, L., \& Bentler, P. M. (1999). Cutoff criteria for fit indexes in covariance structure analysis: Conventional criteria versus new alternatives. Structural Equation Modeling, 6(1), 1-55.

Hutchison, S., Sowa, D., Eisenberger, R., \& Huntington, R. (1986). Perceived organizational support. Journal of Applied Psychology, 71, 500-507.

Iaffaldano, M. T., \& Muchinsky, P. M. (1985). Job satisfaction and job performance: A meta-analysis. Psychological Bulletin, 97, 251-273. 
Ironson, G. H., Smith, P. C., Brannick, M. T., Gibson, W. M., \& Paul, K. B. (1989). Construction of a job in general scale: A comparison of global, composite, and specific measures. Journal of Applied Psychology, 74, 193-200.

Iverson, R. D., \& Kuruvilla, S. (1995). Antecedents of union loyalty: The influence of individual dispositions and organizational context. Journal of Organizational Behavior, 16, 557-582.

Jaccard, J., Wan, C. K., \& Turrisi, R. (1990). The detection and interpretation of interaction effects between continuous variables in multiple regression. Multivariate Behavioral Research, 25(4), 467.

Jackson, S. E. (1983). Participation in decision making as a strategy for reducing jobrelated strain. Journal of Applied Psychology, 68, 3-19.

Jaros, S. J. (1995). An assessment of meyer and allen's (1991) three-component model of organizational commitment and turnover intentions. Academy of Management Journal, 38, 317-321.

Johnson, P. R., \& Indvik, J. (1996). Stress and workplace violence: It takes two to tango. Journal of Managerial Psychology, 11(6), 18-27.

Judge, T. A., Parker, S. K., Colbert, A. E., Heller, D., \& Ilies, R. (2002). Job satisfaction: A cross-cultural review. In N. Anderson, D. S. Ones \& e. al. (Eds.), Handbook of industrial, work and organizational psychology (Vol. 2, pp. 2552). Thousand Oaks, CA: Sage Publications, Inc.

Judge, T. A., Thoresen, C. J., Bono, J. E., \& Patton, G. K. (2001). The job satisfactionjob performance relationship: A qualitative and quantitative review. Psychological Bulletin, 127, 376-407.

Kahn, R. L., \& Byosiere, P. (1992). Stress in organizations. In M. D. Dunnette \& L. M. Hough (Eds.), Handbook of industrial and organizational psychology (2nd ed., Vol. 3, pp. 571-650). Palo Alto,CA: Consulting Psychologists Press.

Kahn, R. L., Wolfe, D. M., Quinn, R. P., Snoek, J. D., \& Rosenthal, R. A. (1964). Organizational stress: Studies in role conflict and ambiguity. New York: Wiley. 
Kahnweiler, W. M., \& Thompson, M. A. (2000). Levels of desired, actual, and perceived control of employee involvement in decision making: An empirical investigation. Journal of Business and Psychology, 14, 407-427.

Katz, H. C., Kochan, T. A., \& Weber, M. A. (1985). Assessing the effects of industrial relations systems and efforts to improve the quality of working life on organizational effectiveness. Academy of Management Journal, 28, 509-526.

Kelloway, E. K., \& Barling, J. (1991). Job characteristics, role stress and mental health. Journal of Occupational Psychology, 64, 291-304.

Kelloway, E. K., Barling, J., \& Shah, A. (1993). Industrial relations stress and job satisfaction: Concurrent effects and mediation. Journal of Organizational Behavior, 14, 447-457.

Kemery, E. R., Bedeian, A. G., Mossholder, K. W., \& Touliatos, J. (1985). Outcomes of role stress: A multisample constructive replication. Academy of Management Journal, 28, 363-375.

Kerr, S., Hill, K. D., \& Broedling, L. (1986). The first-line supervisor: Phasing out or here to stay? Academy of Management Review, 11, 103-117.

Kirkman, B. L., \& Shapiro, D. L. (2001). The impact of cultural values on job satisfaction and organizational commitment in self-managing work teams: The mediating role of employee resistance. Academy of Management Journal, 44, 557-569.

Klaas, B. S. (1989). Determinants of grievance activity and the grievance system. The Academy of Management Review, 14, 445-458.

Klaas, B. S., Heneman, H. G., III, \& Olson, C. A. (1991). Effects of grievance activity on absenteeism. Journal of Applied Psychology, 76, 818-824.

Klein, J. A. (1984). Why supervisors resist employee involvement. Harvard Business Review, 62(5), 87-95. 
Ko, J.-W., Price, J. L., \& Mueller, C. W. (1997). Assessment of meyer and allen's threecomponent model of organizational commitment in south korea. Journal of Applied Psychology, 82, 961-973.

Kochan, T. A., Katz, H. C., \& Mower, N. R. (1984). Worker participation and american unions: Threat or opportunity? Kalamazoo, MI: W. E. Upjohn Institute for Employment Research.

Koeske, G. F., \& Koeske, R. D. (1989). Construct validity of the maslach burnout inventory: A critical review and reconceptualization. Journal of Applied Behavioral Science, 25, 131-144.

Koeske, G. F., \& Koeske, R. D. (1993). A preliminary test of a stress-strain-outcome model for reconceptualizing the burnout phenomenon. Journal of Social Service Research, 17, 107-135.

Kozlowski, S. W., \& Doherty, M. L. (1989). Integration of climate and leadership: Examination of a neglected issue. Journal of Applied Psychology, 74, 546-553.

Kozlowski, S. W., \& Klein, K. J. (2000). A multilevel approach to theory and research in organizations: Contextual, temporal, and emergent processes. In K. J. Klein \& S. W. Kozlowski (Eds.), Multilevel theory, research, and methods in organizations: Foundations, extensions, and new directions (pp. 3-90). San Francisco, CA: Jossey-Bass.

Kulisch, T., \& Banner, D. K. (1993). Self-managed work teams: An update. Leadership \& Organization Development Journal, 14(2), 25-29.

LaRocco, J. M., House, J. S., \& French, J. R. (1980). Social support, occupational stress, and health. Journal of Health \& Social Behavior, 21, 202-218.

Laschinger, H. K. S., Finegan, J., \& Shamian, J. (2001). The impact of workplace empowerment, organizational trust on staff nurses' work satisfaction and organizational commitment. Health Care Management Review, 26(3), 7-23.

Lawler, E. E., III, \& Mohrman, S. A. (1987). Quality circles: After the honeymoon. Organizational Dynamics, 15(4), 42-55. 
Leana, C. R., Ahlbrandt, R. S., \& Murrell, A. J. (1992). The effects of employee involvement programs on unionized workers' attitudes, perceptions, and preferences in decision making. Academy of Management Journal, 35, 861-873.

Lee, R. T., \& Ashforth, B. E. (1996). A meta-analytic examination of the correlates of the three dimensions of job burnout. Journal of Applied Psychology, 81, 123133.

Leiter, M. P., \& Maslach, C. (1988). The impact of interpersonal environment on burnout and organizational commitment. Journal of Organizational Behavior, 9, 297-308.

Levine, R. L., Van Sell, M., \& Rubin, B. (1992). System dynamics and the analysis of feedback processes in social and behavioral systems. In R. Levine \& $\mathrm{H}$. Fitzgerald (Eds.), Analysis of dynamic psychological systems: Methods and applications (Vol. 1, pp. 145-287). New York: Plenum Press.

Li, F., Harmer, P., Duncan, T. E., Duncan, S. C., Acock, A., \& Boles, S. (1998). Approaches to testing interaction effects using structural equation modeling methodology. Multivariate Behavioral Research, 33, 1-39.

Liden, R. C., Wayne, S. J., \& Sparrowe, R. T. (2000). An examination of the mediating role of psychological empowerment on the relations between the job, interpersonal relationships, and work outcomes. Journal of Applied Psychology, $85,407-416$.

Liou, K.-T., \& Nyhan, R. C. (1994). Dimensions of organizational commitment in the public sector: An empirical assessment. Public Administration Quarterly, 18, 99-118.

Locke, E. A. (1976). The nature and causes of job satisfaction. In M. D. Dunnette (Ed.), Handbook of industrial and organizational psychology (pp. 1297-1343). Chicago: Randall McNally.

MacCallum, R. C., Browne, M. W., \& Sugawara, H. M. (1996). Power analysis and determination of sample size for covariance structure modeling. Psychological Methods, 1, 130-149. 
Mack, D. A., Shannon, C., Quick, J. D., \& Quick, J. C. (1998). Stress and the preventative management of workplace violence. In R. W. Griffin \& A. O'Leary-Kelly (Eds.), Dysfunctional behavior in organizations: Violent and deviant behavior (pp. 119-141). Greenwich, CT: JAI Press.

Macy, B. A., Peterson, M. F., \& Norton, L. W. (1989). A test of participation theory in a work re-design field setting: Degree of participation and comparison site contrasts. Human Relations, 42, 1095-1165.

Magenau, J. M., Martin, J. E., \& Peterson, M. M. (1988). Dual and unilateral commitment among stewards and rank-and-file union members. Academy of Management Journal, 31, 359-376.

Martin, J. E. (2001). Employee acceptance of the crew chief program in the postal service: An analysis with pre and post data. Advances in Industrial and Labor Relations, 10, 51-73.

Martin, J. E., Magenau, J. M., \& Peterson, M. F. (1986). Variables related to patterns of union stewards' commitment. Journal of Labor Research, 7, 323-336.

Martin, J. E., \& Peterson, M. M. (1987). Two-tier wage structures: Implications for equity theory. Academy of Management Journal, 30, 297-315.

Maslach, C., Jackson, S. E., \& Leiter, M. P. (1996). The maslach burnout inventory (3rd.Ed). Palo Alto, CA: Consulting Psychologists Press.

Maslach, C., Jackson, S. E., \& Leiter, M. P. (1997). Maslach burnout inventory. In C. P. Zalaquett \& R. J. Wood (Eds.), Evaluating stress: $A$ book of resources (3rd ed., pp. 191-218). London, England: The Scarecrow Press, Inc.

Mathieu, J. E., \& Farr, J. L. (1991). Further evidence for the discriminant validity of measures of organizational commitment, job involvement, and job satisfaction. Journal of Applied Psychology, 76, 127-133.

Mathieu, J. E., \& Zajac, D. M. (1990). A review and meta-analysis of the antecedents, correlates, and consequences of organizational commitment. Psychological Bulletin, 108, 171-194. 
McClelland, G. H., \& Judd, C. M. (1993). Statistical difficulties of detecting interactions and moderator effects. Psychological Bulletin, 114(2), 376.

McDermott, K., Laschinger, H. K. S., \& Shamian, J. (1996). Work empowerment and organizational commitment. Nursing Management, 27(5), 44-47.

Meyer, J. P., \& Allen, N. J. (1997). Commitment in the workplace: Theory, research, and application. Thousand Oaks, CA: Sage.

Meyer, J. P., Stanley, D. J., Herscovitch, L., \& Topolnytsky, L. (2002). Affective, continuance, and normative commitment to the organization: A meta-analysis of antecedents, correlates, and consequences. Journal of Vocational Behavior, 61, $20-52$.

Miller, K. I., \& Monge, P. R. (1986). Participation, satisfaction, and productivity: A meta-analytic review. Academy of Management Journal, 29, 727-753.

Mintzberg, H. (1979). The structuring of organizations: A synthesis of the research. Englewood Cliffs, NJ: Prentice-Hall.

Mobley, W. H., Horner, S. O., \& Hollingsworth, A. (1978). An evaluation of precursors of hospital employee turnover. Journal of Applied Psychology, 63, 408-414.

Morgan, D. L. (1998). Practical strategies for combining qualitative and quantitative methods: Applications to health research. Qualitative Health Research, 8(3), 362-376.

Moses, T. P., \& Stahelski, A. J. (1999). A productivity evaluation of teamwork at an aluminum manufacturing plant. Group \& Organization Management, 24, 391412 .

Mowday, R., Steers, R., \& Porter, L. (1979). The measurement of organizational commitment. Journal of Vocational Behavior, 14, 224-227.

Norquist, G. G. (2003, June 9). Just how big is the united states postal service? Postal Newsletter, 1. 
Nyhan, R. C. (1999). Increasing affective organizational commitment in public organizations. Review of Public Personnel Administration, 19, 58-70.

O' Driscoll, M. P., \& Beehr, T. A. (1994). Supervisor behaviors, role stressors and uncertainty as predictors of personal outcomes for subordinates. Journal of Organizational Behavior, 15, 141-155.

Osterman, P. (1994). How common is workplace transformation and who adopts it? Industrial \& Labor Relations Review, 47, 173-188.

Patton, M. Q. (1986). Utilization-focused evaluation (2nd ed.). Thousand Oaks, CA: Sage.

Payne, R. L., Wall, T. D., Borrill, C., \& Carter, A. (1999). Strain as a moderator of the relationship between work characteristics and work attitudes. Journal of Occupational Health Psychology, 4, 3-14.

Peoples, J. E. (1998). Automating the u.S. Postal service's mail processing system. Inform, 12(7), 31-34.

Perry, J. L., \& Wise, L. R. (1990). The motivational bases of public service. Public Administration Review, 50, 367-373.

Ponterotto, J. G., \& Grieger, I. (1999). Meging qualitative and quantitative perspectives. In M. Kopola \& L. A. Suzuki (Eds.), Using qualitative methods in psychology (pp. 49-62). Thousand Oaks, CA: Sage.

Porras, J. I., \& Berg, P. O. (1978). The impact of organization development. Academy of Management Review, 3, 249-266.

Porras, J. I., \& Robertson, P. J. (1992). Organizational development: Theory, practice, and research. In Dunnette, marvin d (ed); hough, leaetta $m$ (ed) (1992) handbook of industrial and organizational psychology, vol 3 (2nd ed) (pp 719 822) xxiii, 1095pp.

Postal reorganization act of 1970,39 U.S.C. $\S 101$ et seq. 
Pun, K. F., Chin, K. S., \& Gill, R. (2001). Determinants of employee involvement practices in manufacturing enterprises. Total Quality Management, 12, 95-109.

Putti, J. M., Aryee, S., \& Phua, J. (1990). Communication relationship satisfaction and organizational commitment. Group \& Organization Studies, 15, 44-52.

Quick, J. C., Quick, J. D., Nelson, D. L., \& Hurrell, J. J., Jr. (1997). Preventive stress management in organizations. Washington, DC: American Psychologial Association.

Randall, D. M. (1990). The consequences of organizational commitment: Methodological investigation. Journal of Organizational Behavior, 11, 361-378.

Randolph, W. (2000). Re-thinking empowerment: Why is it so hard to achieve? Organizational Dynamics, 29, 94-107.

Reilly, R. R., \& McGourty, J. (1998). Performance appraisal in team settings. In J. W. Smither (Ed.), Performance appraisal: State of the art in practice (pp. 244-277). San Francisco, CA: Jossey Bass.

Reshef, Y., Kizilos, M., Ledford, G. E., Jr., \& Cohen, S. G. (1999). Employee involvement programs: Should unions get involved? Journal of Labor Research, 20, 557-569.

Reynolds, J. S., \& Perrin, N. A. (2004). Mismatches in social support and psychosocial adjustment to breast cancer. Health Psychology Vol 23(4) Jul 2004, 425-430.

Rhoades, L., Eisenberger, R., \& Armeli, S. (2001). Affective commitment to the organization: The contribution of perceived organizational support. Journal of Applied Psychology, 86, 825-836.

Riketta, M. (2002). Attitudinal organizational commitment and job performance: A meta-analysis. Journal of Organizational Behavior, 23, 257-266.

Rizzo, J. R., House, R. J., \& Lirtzman, S. I. (1970). Role conflict and ambiguity in complex organizations. Administrative Science Quarterly, 15, 150-163. 
Romzek, B. S. (1990). Employee investment and commitment: The ties that bind. Public Administration Review, 50, 374-382.

Rotter, J. B. (1966). Generalized expectancies fo internal versus external control of reinforcement. Psychological Monographs, 80, (1, Whole No 609).

Sahl, R. J. (1998). 'good teams' or good performance? Issues in developing team-based measurements. Journal of Compensation \& Benefits, 13(4), 28.

Sandelands, E. (1994). Managing without supervisors. Management Decision, 32, 5051.

Sauter, S. L., Murphy, L. R., \& Hurrell, J. J. (1990). Prevention of work-related psychological disorders: A national strategy proposed by the national institute for occupational safety and health (niosh). American Psychologist, 45, 11461158 .

Schafer, J. L., \& Graham, J. W. (2002). Missing data: Our view of the state of the art. Psychological Methods, 7, 147-177.

Schaubroeck, J., Cotton, J. L., \& Jennings, K. R. (1989). Antecedents and consequences of role stress: A covariance structure analysis. Journal of Organizational Behavior, 10, 35-58.

Scheirer, M. A., \& Rezmovic, E. L. (1983). Measuring the degree of program implementation: A methodological review. Evaluation Review, 7, 599-633.

Schilder, J. (1992). Work teams boost productivity. Personnel Journal, 71(2), 67-72.

Schriesheim, C. A., Castro, S. L., \& Cogliser, C. C. (1999). Leader-member exchange $(\operatorname{lmx})$ research: A comprehensive review of theory, measurement, and dataanalytic practices. Leadership Quarterly, 10, 63-113.

Scott, K., \& Taylor, G. (1985). An examination of conflicting findings on the relationship between job satisfaction and absenteeism: A meta-analysis. Academy of Management Journal, 28, 599-612. 
Senge, P. M. (1990). The fifth discipline: The art and practice of the learning organization. New York: Doubleday.

Settoon, R. P., Bennett, N., \& Liden, R. C. (1996). Social exchange in organizations: Perceived organizational support, leader-member exchange, and employee reciprocity. Journal of Applied Psychology, 81, 219-227.

Shadur, M. A., Kienzle, R., \& Rodwell, J. J. (1999). The relationship between organizational climate and employee perceptions of involvement. Group \& Organization Management, 24, 479-503.

Shore, L. M., Tetrick, L. E., Sinclair, R. R., \& Newton, L. A. (1994). Validation of a measure of perceived union support. Journal of Applied Psychology, 79, 971977.

Simonds Jr, J. G., \& Bell, R. C. (1997). Creating individual and team performance measurements. Employment Relations Today, 23(4), 27-35.

Simons, J., \& Blackmon, D. A. (1998, Dec 30, 1998). Online shopping lifts delivery concerns' volume. Wall Street Journal, p. 1.

Sinclair, R. R., \& Tetrick, L. E. (1995). Social exchange and union commitment: A comparison of union instrumentality and union support perceptions. Journal of Organizational Behavior, 16, 669-680.

Skarlicki, D. P., \& Folger, R. (1997). Retaliation in the workplace: The roles of distributive, procedural, and interactional justice. Journal of Applied Psychology, 82, 434-443.

Smith, A. (2001). Perceptions of stress at work. Human Resource Management Journal, $11,74-86$.

Smith, F. J. (1976). Index of organizational reactions (ior). Catalog of Selected Documents in Psychology, 6 5, p4-55. 
Spreitzer, G. M., \& Kizilos, M. A. (1997). A dimensional analysis of the relationship between psychological empowerment and effectiveness, satisfaction, and strain. Journal of Management, 23, 679-704.

Stamps, D. (1996). Going nowhere: Culture change at the postal service fizzles. Training, 33(7), 26-34.

Steers, R. M. (1977). Antecedents and outcomes of organizational commitment. Administrative Science Quarterly, 22, 46-56.

Sterman, J. D. (2000). Business dynamics: Systems thinking and modeling for a complex world. Boston, MA: McGraw Hill.

Suliman, A. M. T. (2002). Is it really a mediating construct? The mediating role of organizational commitment in work climate-performance relationship. The Journal of Management Development, 21, 170-183.

Tan, H. H., \& Aryee, S. (2002). Antecedents and outcomes of union loyalty: A constructive replication and an extension. Journal of Applied Psychology, 87, 715-722.

Tansky, J. W., \& Cohen, D. J. (2001). The relationship between organizational support, employee development, and organizational commitment: An empirical study. Human Resource Development Quarterly, 12, 285.

Tesluk, P. E., Mathieu, J. E., Zaccaro, S. J., \& Marks, M. (1997). Task and aggregation issues in the analysis and assessment of team performance. In M. T. Brannick, E. Salas \& C. Prince (Eds.), Team performance assessment and measurement: Theory, methods, and applications (pp. 197-224). Mahwah, NJ: Erlbaum.

Tesluk, P. E., Vance, R. J., \& Mathieu, J. E. (1999). Examining employee involvement in the context of participative work environments. Group \& Organization Management, 24, 271-299.

Tetrick, L. E., \& Fried, Y. (1993). Industrial relations: Stress induction or stress reduction? Journal of Organizational Behavior, 14, 511-514. 
Tetrick, L. E., Slack, K. J., Da Silva, N., \& Sinclair, R. R. (2000). A comparison of the stress-strain process for business owners and nonowners: Differences in job demands, emotional exhaustion, satisfaction, and social support. Journal of Occupational Health Psychology, 5, 464-476.

Tett, R. P., \& Meyer, J. P. (1993). Job satisfaction, organizational commitment, turnover intention, and turnover: Path analyses based on meta-analytic findings. Personnel Psychology, 46, 259-293.

Thacker, J. W., \& Fields, M. W. (1986). Personal communication.

Thacker, J. W., Fields, M. W., \& Barclay, L. A. (1990). Union commitment: An examination of antecedent and outcome factors. Journal of Occupational Psychology, 63, 33-48.

The President's Commission on Postal Organization. (1968). Towards postal excellence (the kappel commission report). Washington, DC: Government Printing Office.

Tierney, P. (1999). Work relations as a precursor to a psychological climate for change the role of work group supervisors and peers. Journal of Organizational Change Management, 12, 120-133.

Torres, C. (2004, February 24, 2004). Internet purchases rise four times faster than total retail sales growth. Chicago Sun-Times, p. 57.

Townsend, J., Phillips, J. S., \& Elkins, T. J. (2000). Employee retaliation: The neglected consequence of poor leader-member exchange relations. Journal of Occupational Health Psychology, 5, 457-463.

Turban, D. B., \& Jones, A. P. (1988). Supervisor-subordinate similarity: Types, effects, and mechanisms. Journal of Applied Psychology, 73, 228-234.

United States Department of Health and Human Services. (1999). Healthy people 2000 review, 1998-99. Hyattsville, Maryland: U. S. Department of Health and Human Services Centers for Disease Control and Prevention National Center for Health Statistics. 
United States General Accounting Office. (1994a). U.S. Postal service labormanagement problems persist on the workroom floor: Report to congressional requesters vol $i$ (No. GAO/GGD-94-201A). Washington, D.C.: Government Printing Office.

United States General Accounting Office. (1994b). U.S. Postal service labormanagement problems persist on the workroom floor: Report to congressional requesters vol ii (No. GAO/GGD-94-201B). Washington, D.C.: Government Printing Office.

United States General Accounting Office. (1994c). U.S. Postal service: The state of labor-management relations; statement of michael e. Motley, associate director, government business operations issues to the u.S. Senate subcomittee on federal services, post office, and civil service (No. GAO/T-GGD-95-46). Washington, DC: Author.

United States General Accounting Office. (1997a). U.S. Postal service little progress made in addressing persistent labor-management problems: Report to the chairman, subcommittee on the postal service, committee on government reform and oversight, house of representatives (No. GAO/GGD-98-1). Washington, DC: Author.

United States General Accounting Office. (1997b). U.S. Postal service little progress made in addressing persistent labor-management problems: Statement of bernard l. Ungar, director, government business operations issues, [general government division], before the subcommittee on the postal service, house committee on government reform and oversight (No. GAO/T-GGD-98-7). Washington, DC: Author.

United States General Accounting Office. (1997c). U.S. Postal service little progress made in addressing persistent labor-management problems: Report to the chairman, subcommittee on the postal service, committee on government reform and oversight, house of representatives (No. No. GAO/GGD-98-1). Washington, DC: Author.

United States General Accounting Office. (1997d). U.S. Postal service little progress made in addressing persistent labor-management problems: Statement of bernard l. Ungar, director, government business operations issues, [general government division], before the subcommittee on the postal service, house 
committee on government reform and oversight (No. No. GAO/T-GGD-98-7). Washington, DC: Author.

Vallas, S. P. (2003). Why teamwork fails: Obstacles to workplace change in four manufacturing plants. American Sociological Review, 68, 223-250.

van der Klink, J. J. L., Blonk, R. W. B., Schene, A. H., \& Dijk, F. J. H. v. (2001). The benefits of interventions for work-related stress. American Journal of Public Health, 91, 270-276.

Verma, A. (1989). Joint participation programs: Self-help or suicide for labor? Industrial Relations, 28, 401-410.

Verma, A., \& McKersie, R. B. (1987). Employee involvement: The implications of noninvolvement by unions. Industrial \& Labor Relations Review, 40, 556-568.

Viswesvaran, C., \& Deshpande, S. P. (1993). Are conclusions of union commitment robust to empirical techniques employed? Relations Industrielles, 48, 539-556.

Vroom, V. H. (1964). Work and motivation. New York: Wiley.

Wagner, J. A., III. (1994). Participation's effects on performance and satisfaction: A reconsideration of research evidence. Academy of Management Review, 19, 312330 .

Wagner, J. A., III, \& Gooding, R. Z. (1987). Shared influence and organizational behavior: A meta-analysis of situational variables expected to moderate participation-outcome relationships. Academy of Management Journal, 30, 524541.

Wall, T. D., Kemp, N. J., Jackson, P. R., \& Clegg, C. W. (1986). Outcome of autonomous workgroups: A long-term field experiment. Academy of Management Journal, 29, 280-304. 
Wayne, S. J., Shore, L. M., \& Liden, R. C. (1997). Perceived organizational support and leader-member exchange: A social exchange perspective. Academy of Management Journal, 40, 82-111.

Weber, P. S., \& Weber, J. E. (2001). Changes in employee perceptions during organizational change. Leadership \& Organization Development Journal, 22, 291-300.

Wellins, R. (1995). Texas instruments gets from here to there. Training \& Development, $49,40-41$.

Williams, L. J., \& Hazer, J. T. (1986). Antecedents and consequences of satisfaction and commitment in turnover models: A reanalysis using latent variable structural equation methods. Journal of Applied Psychology, 71, 219-231.

Wright, T. A., \& Cropanzano, R. (1998). Emotional exhaustion as a predictor of job performance and voluntary turnover. Journal of Applied Psychology, 83, 486493.

Young, B. S., Worchel, S., \& Woehr, D. J. (1998). Organizational commitment among public service employees. Public Personnel Management, 27, 339-348.

Zammuto, R. F., \& O'Connor, E. J. (1992). Gaining advanced manufacturing technologies' benefits: The roles of organization design and culture. Academy of Management Review, 17, 701-729.

Zigon, J. (1997). Team performance measurement: A process for creating team performance standards. Compensation \& Benefits Review, 29(1), 38. 
Appendix A. Survey Results for Time 1 and Time 2 Across All Intervention and Control Sites for Mail Processors and Crew Chiefs

\section{OCDPCS EMPLOYE SURVEY RESULTS FROM ALL, 9 CrTES (GG SURVEYS)}

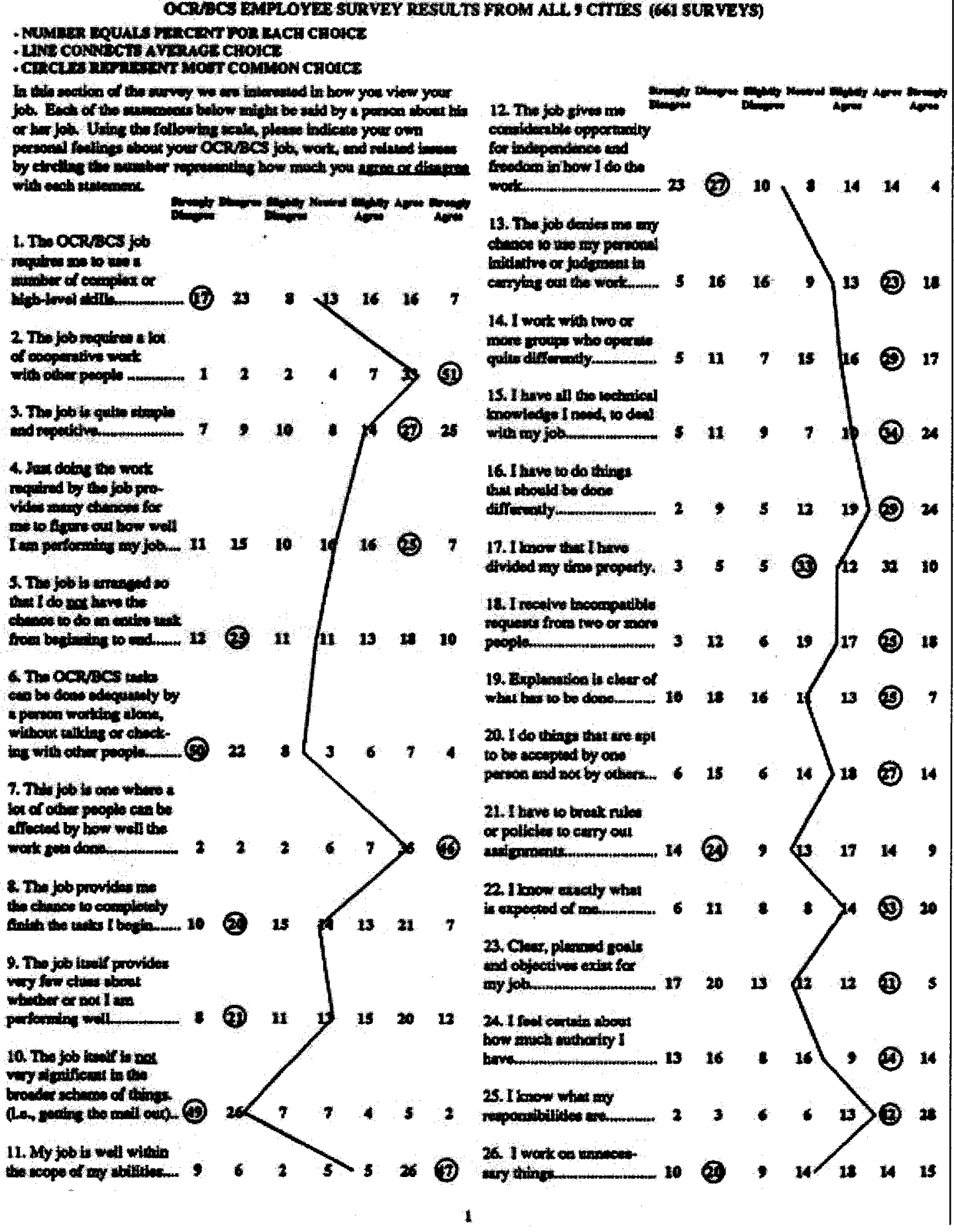




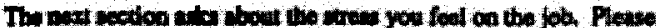

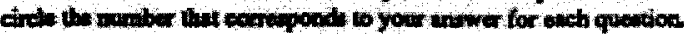

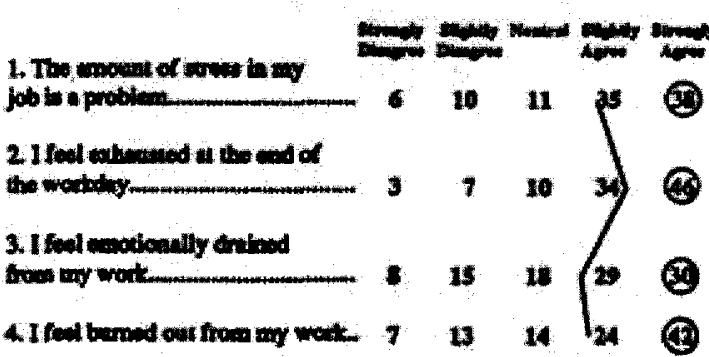

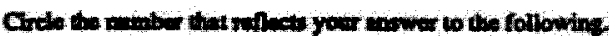

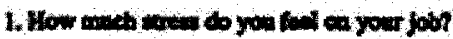

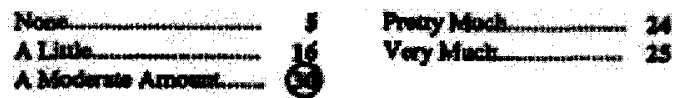

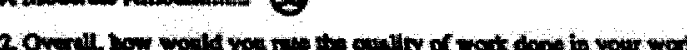
powe?

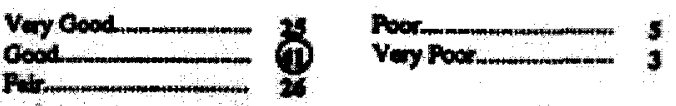

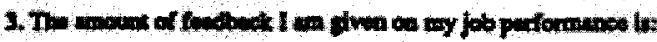

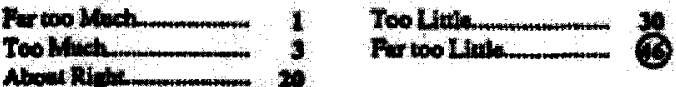

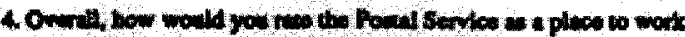

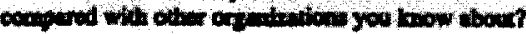

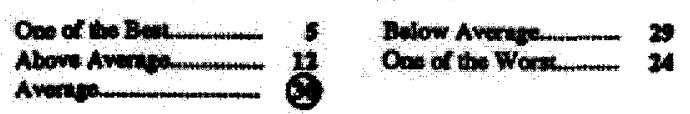

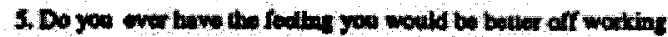

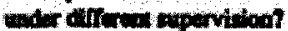

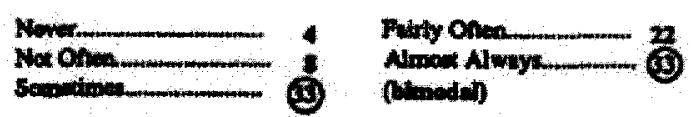

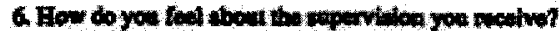

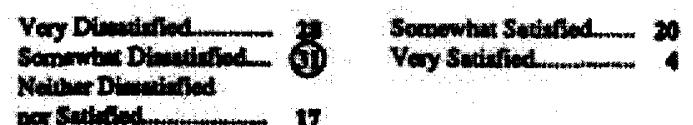

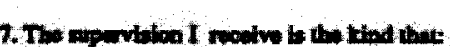

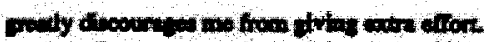

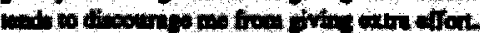

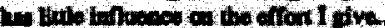

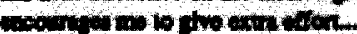

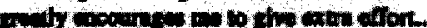

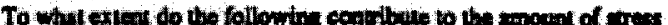
yow fod ow do gost

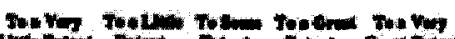
1. Confta bohmona ne

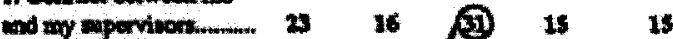

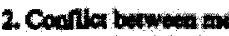

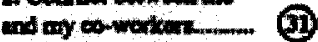

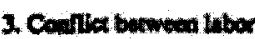

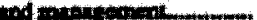

4. Lint of hwohnesen in mither wath whed

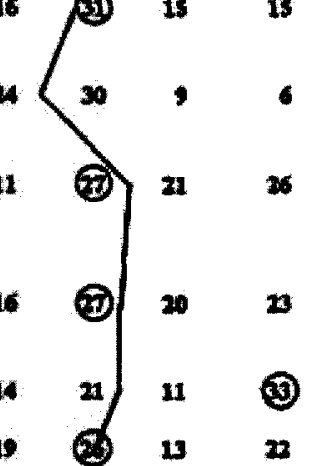

5. Uedotingle work allowlon

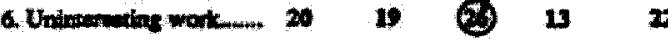

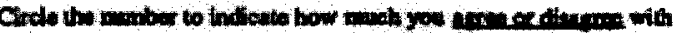
ead ataver.

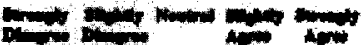

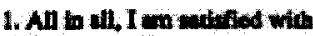
ang bol

16

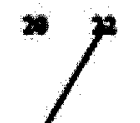

(2)

13

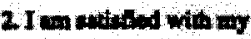

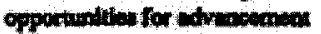
whe Podul serrias.

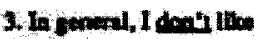
math (3)

4. Inowil Itwe wathe bure

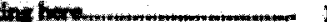
4

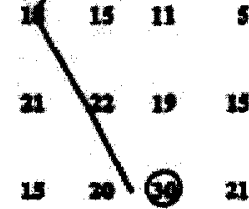

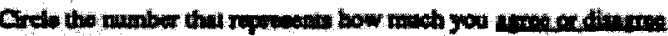

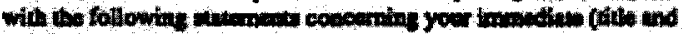

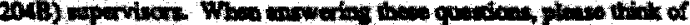

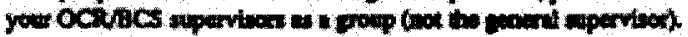

Iin pawnd, iny

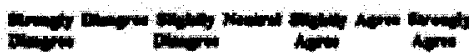

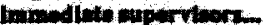

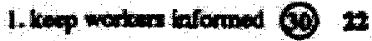

2 cantrowad betre enticived:

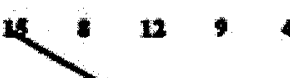

1. deal whin wotere will.

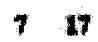
(2)

Ludto ply

5. low for an otwo Wheme when thins ofo wore

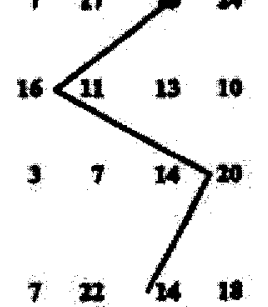

1) 9 


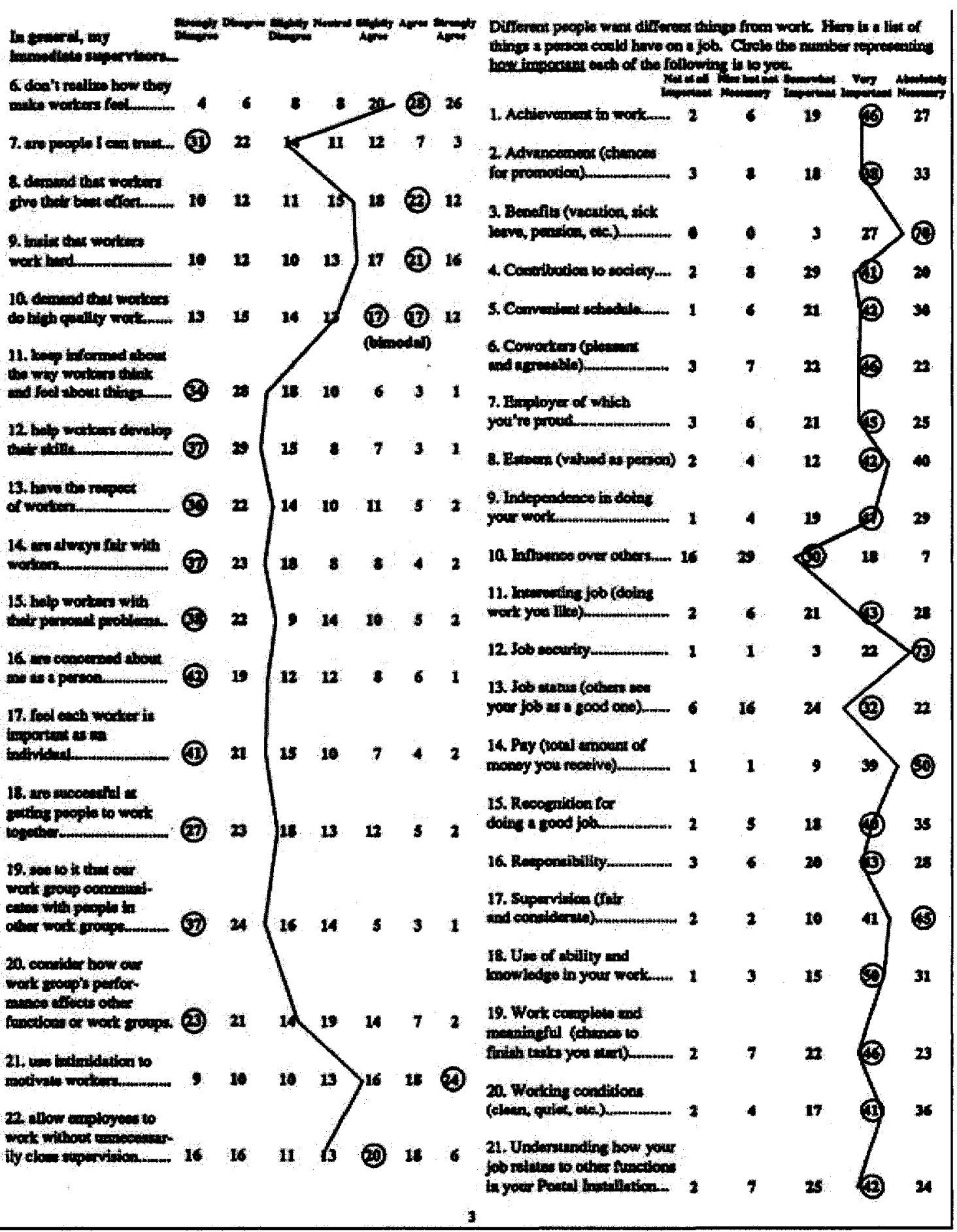




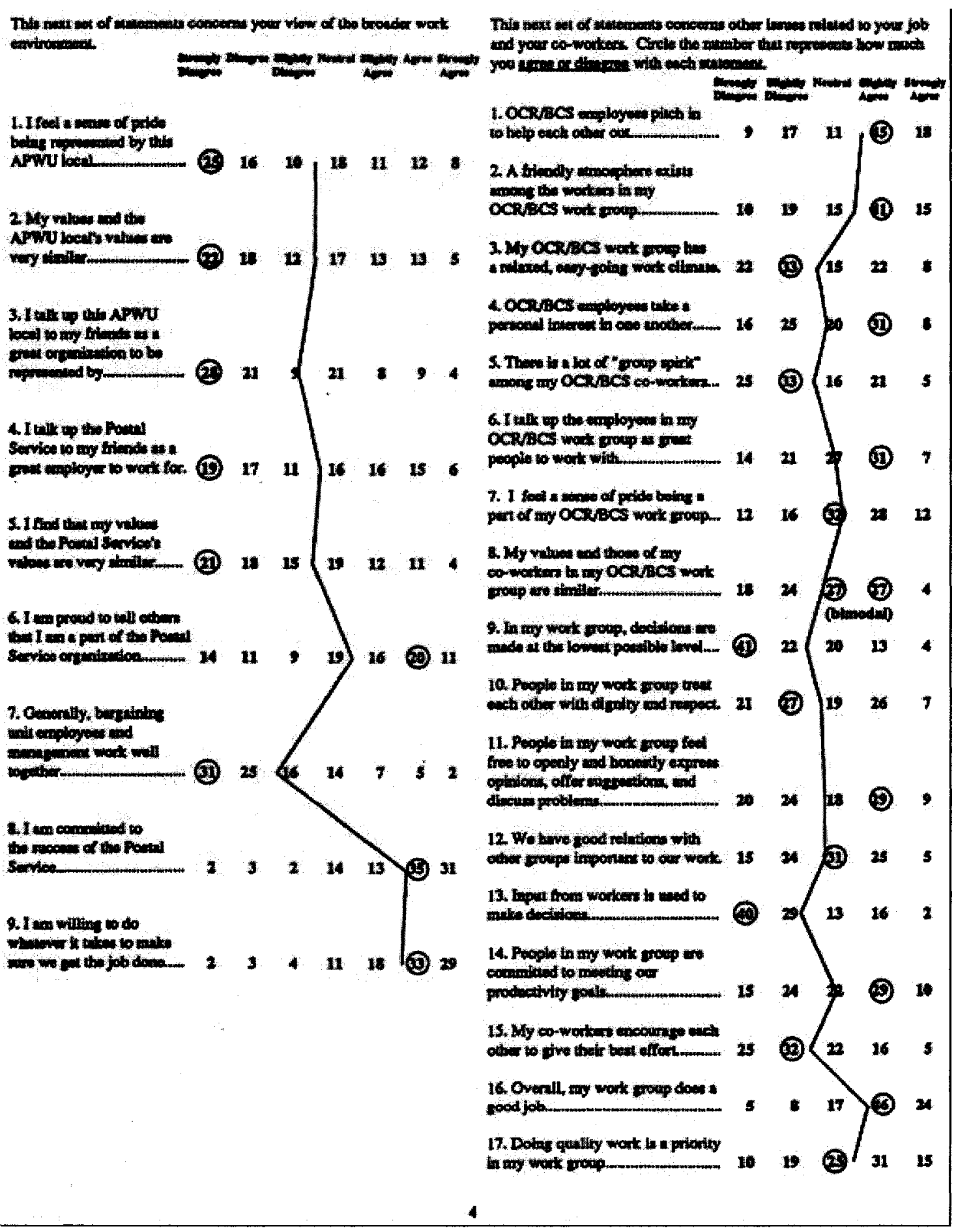




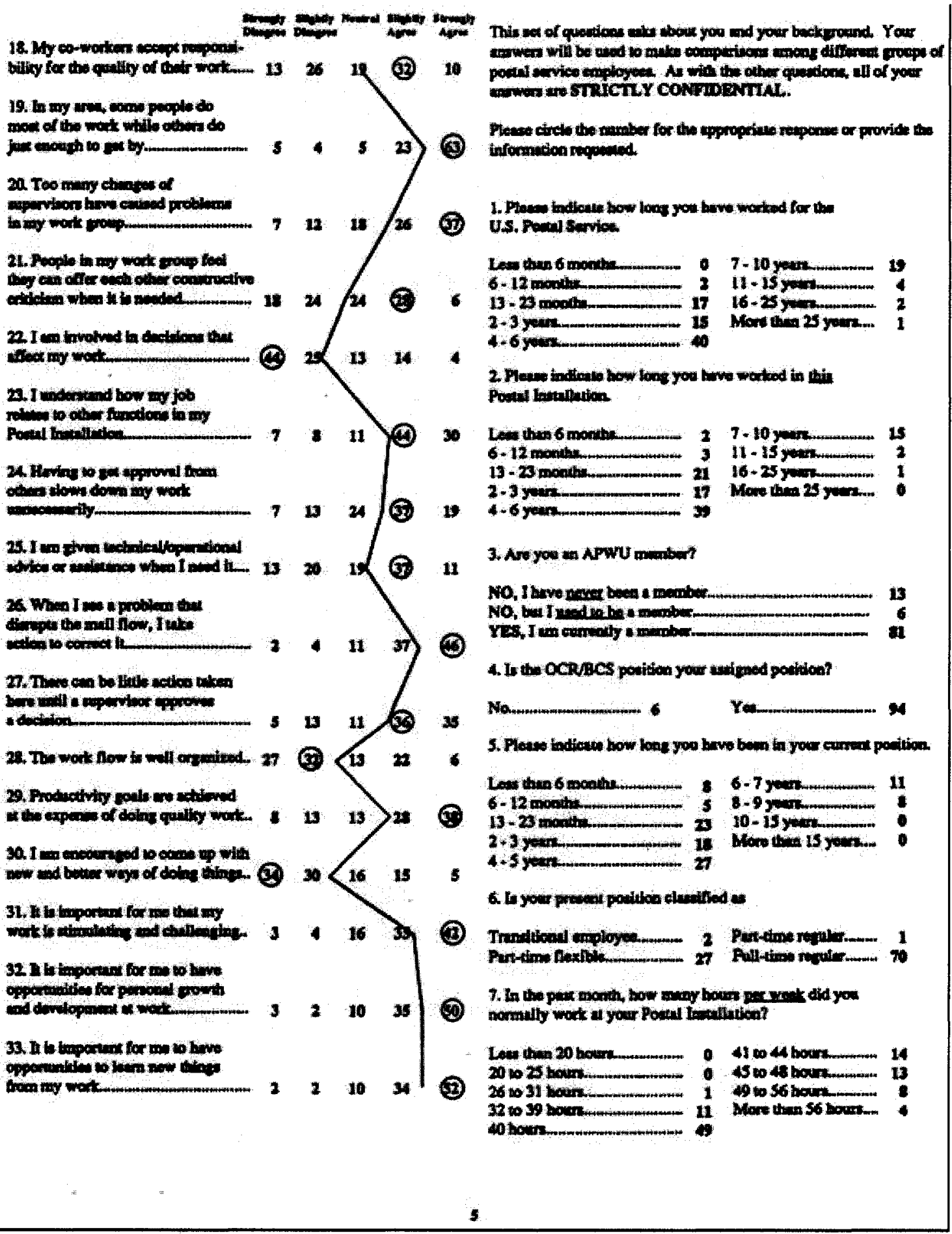




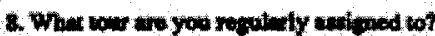

Tow 1

Tour 2

4

17

Rom 3 .

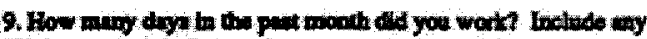

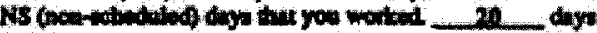

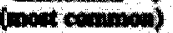

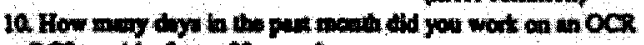

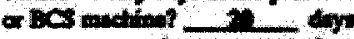
(mintering)

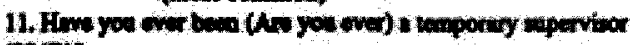
Qunstr

Wo,

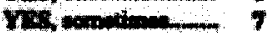

Yes, finfy oflem

Hom olman

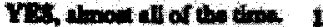

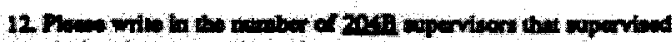

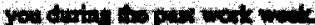

$$
\text { (mentosia) }
$$

aprotses 2 (whrin)

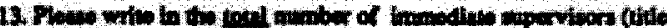

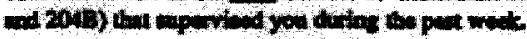

$$
3 \text { (netcominas) }
$$

aprines 8 (morns)
14. What is you and? a

Fengen 3

15. Whis ts your ach?

Lav 120

20 is 24 yen

$2502 \mathrm{gam}$

30 to 34 you

35 wo 39 youm.

Cow to yeen

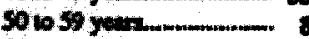

Coor wore yeen

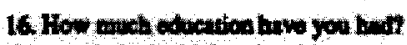

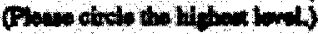

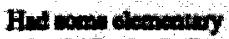

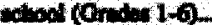

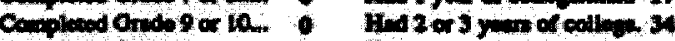
C.uphesond II

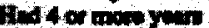

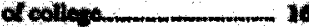

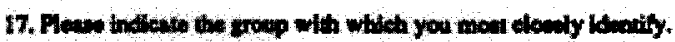

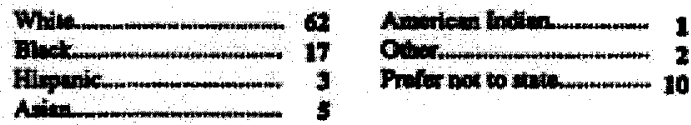

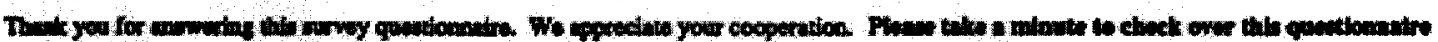

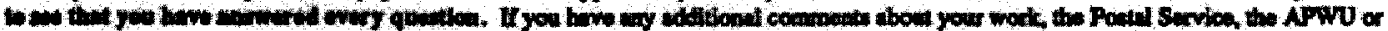

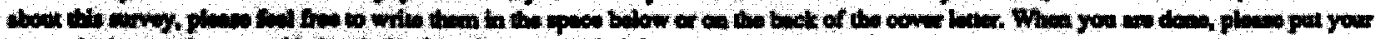

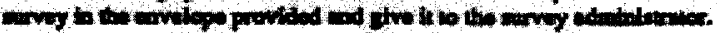

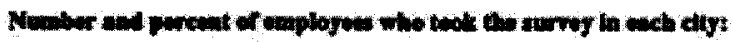

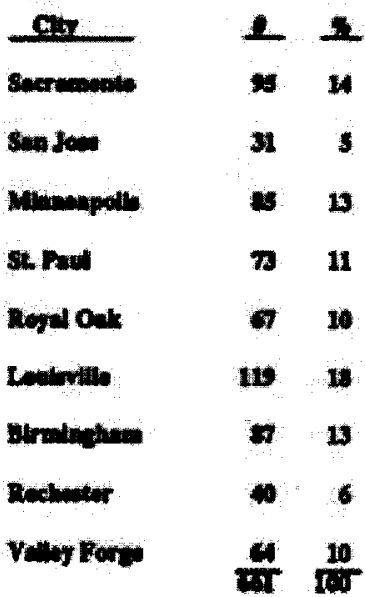




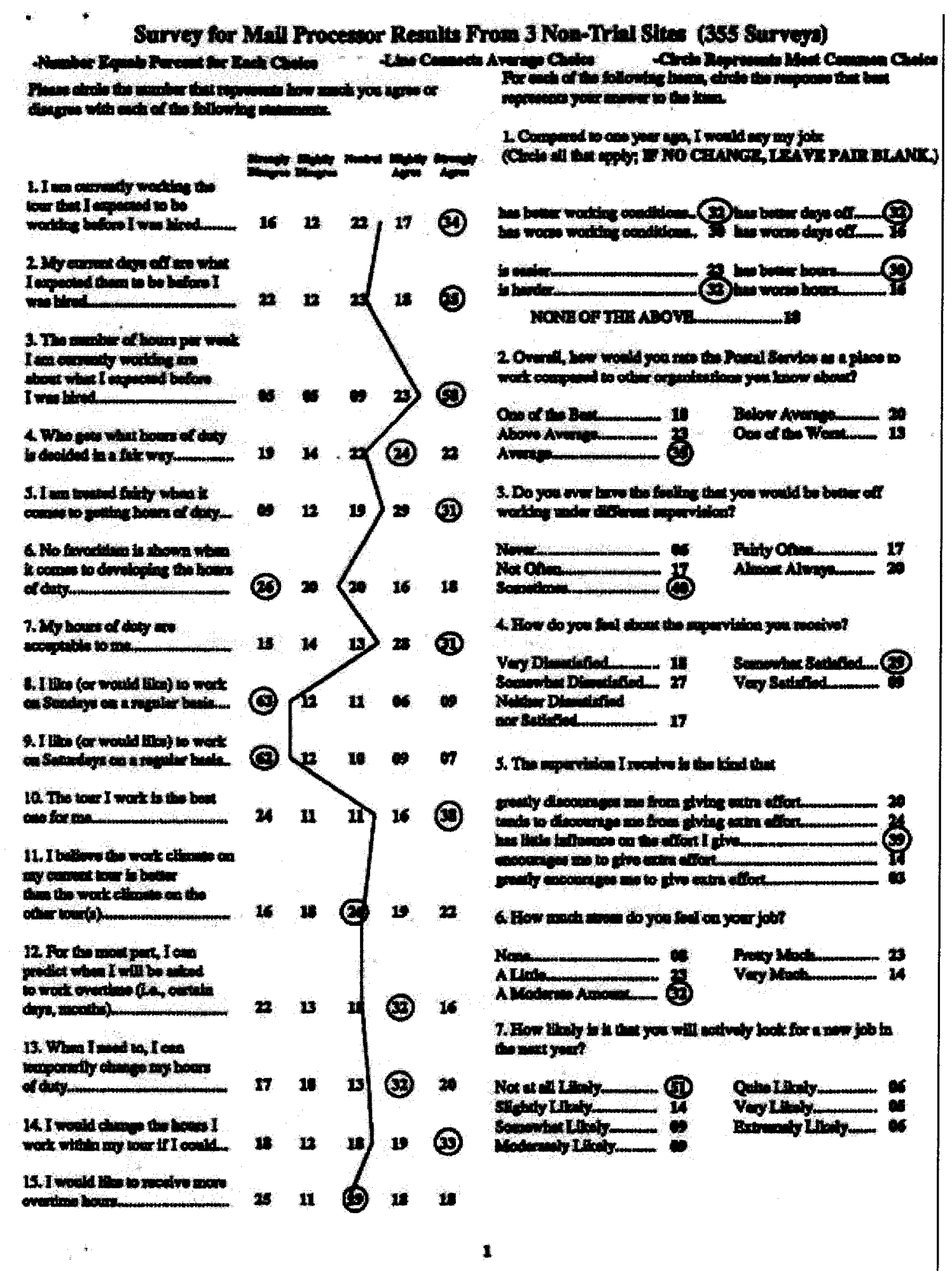




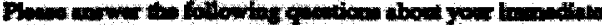

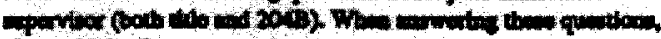

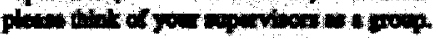

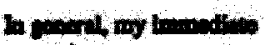

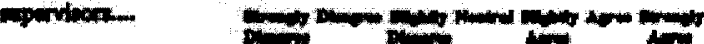

1. Movoratariata

watum

(3) 19 is is $10 \mathrm{~m}$

2 bow toromid bout be

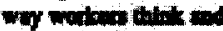

tal bow obing

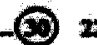

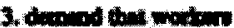

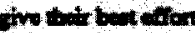

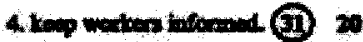

Shwo tormpoed rotken

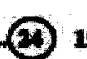

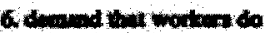

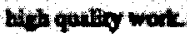

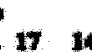

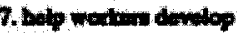

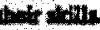
(a) 1

2 bintintwe wom bor 10 15

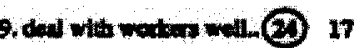

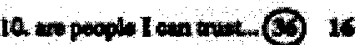

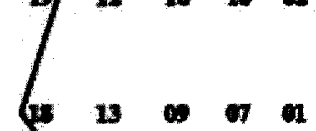
11801615

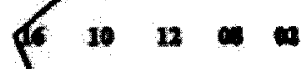

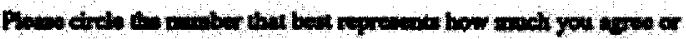

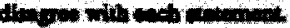

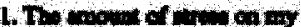

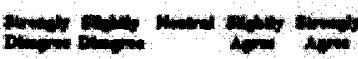
Holpoworim

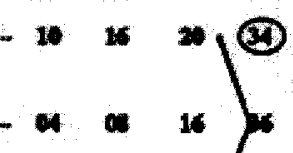

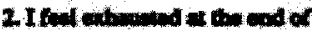
tast

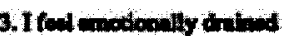
Gow tart

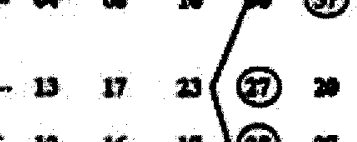

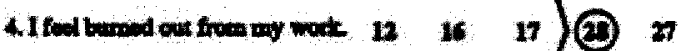

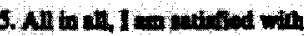
notob

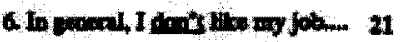

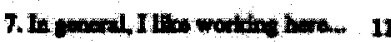

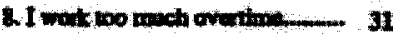

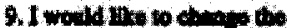

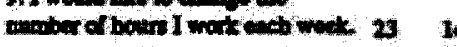

(1)

thenethentish.

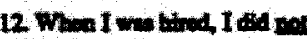

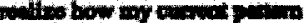

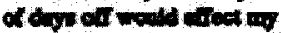
parsatilyo

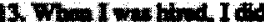

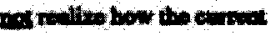
bom of my bor wols wed

(2) 2

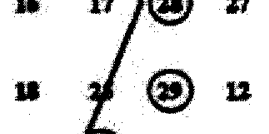

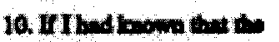

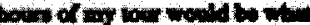
Ho rewom, I mald athwo

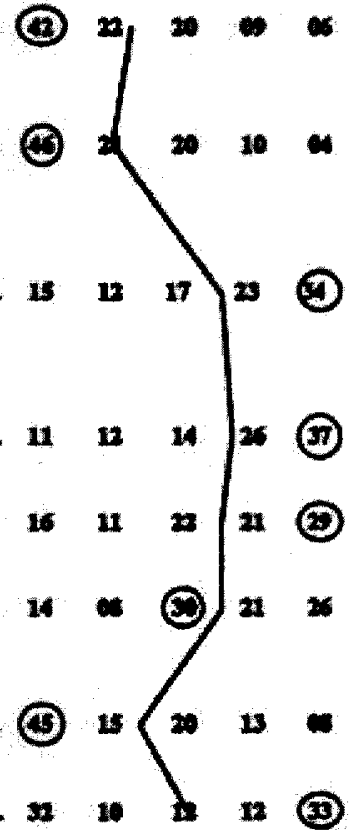

4.M fawily dow nos tho wromectory

15. H thodrowert mingened dury

161 monetion od with wa

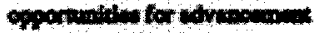

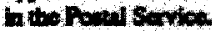

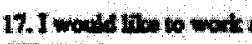
Anowion

31 in 1

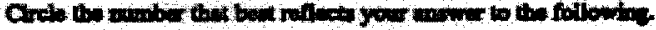

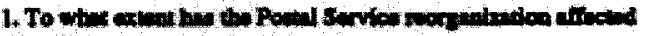
your fow

Nere

(6) AComberiblenow 16

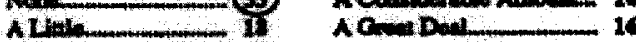

NMandimat 17

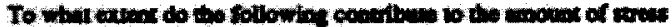
rented on the jos?

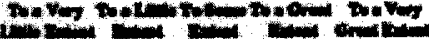

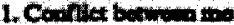

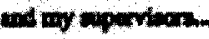

2 Condien berwen wa woremedim

(3) 2010

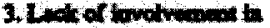

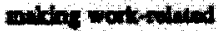
Antidin 20 a (a) is 1

18

(Q) 1

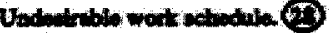

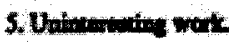

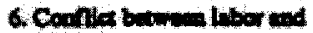
nonoment 1

(6) $1 * \infty$

$19 \quad 13 \quad 17$

$17 \quad 2 \quad 13 \quad 17$

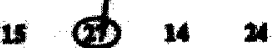




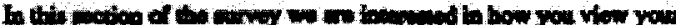

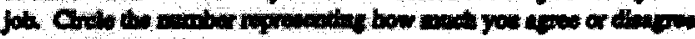

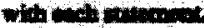

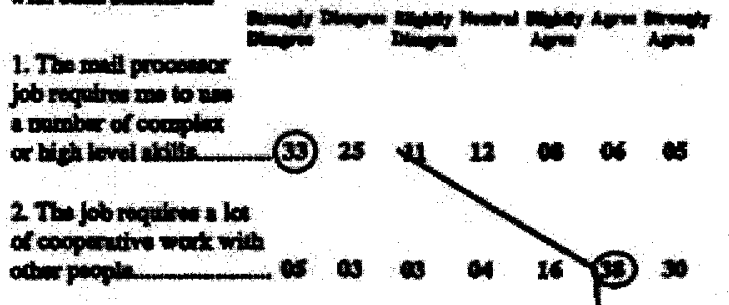

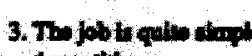
ard repictive a in

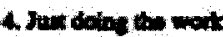

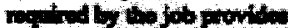

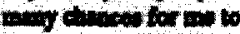

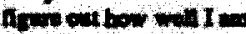

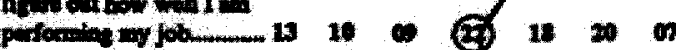

5. To joh te enenged to Din Ibores bue the

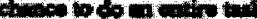
trombetang wed is is if (C) 13.15 is

6. The will proesenor thito

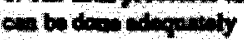

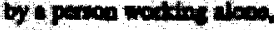
witrot tell the or chim the with ot repopie
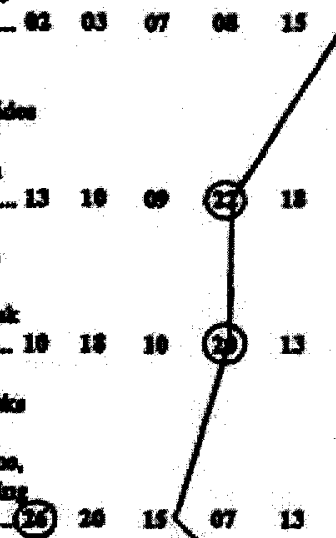

(9)

7. nin pob been whes:

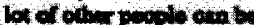
whend by bor wedl to wat rowidon $-\infty$ 4
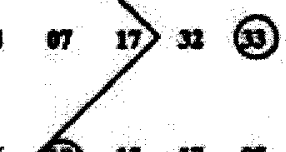

17ne job providen wo be

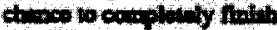

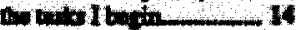
12. 16 4

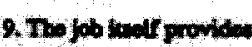
way tow chan wove whether oo II en partoris well $\infty$
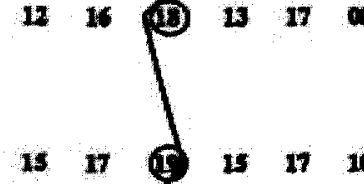

10. no job thertis as very defievent to th trouder actions of thon

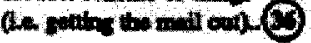

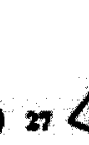

11. Wh bot in will within the enopo of uy abilita. 6
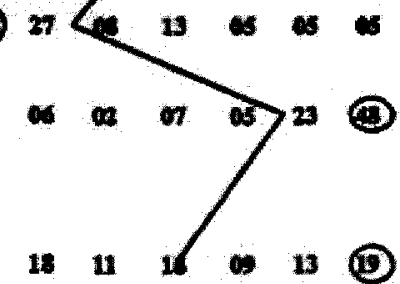

(nomition postion

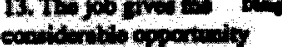

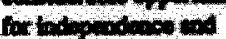
formbralos

thents 17

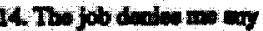

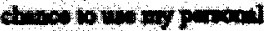

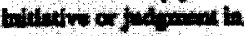

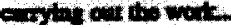

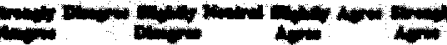
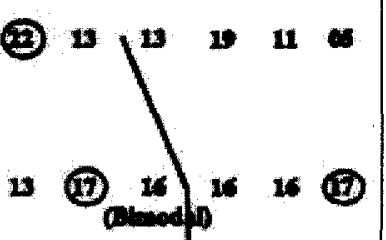

15. I wod with now worowe wbo operas

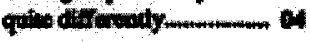
a. 1

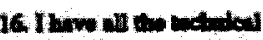

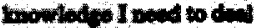

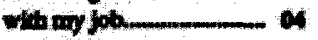

17. Wrow wo do thing the

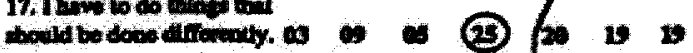

18) Inow than

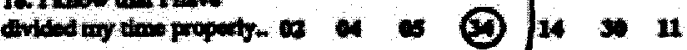

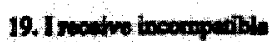
nowat bovetwo or ware purple

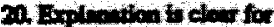
whing bosion wollo es

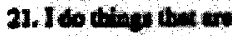

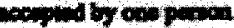
adrot byotine

2. Drow wowlowio

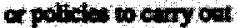

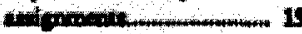

2. It wow enesty wha berped of on of o 10

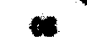

(9) 1

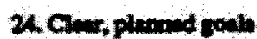

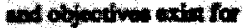
ing 14

16 in

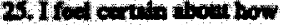

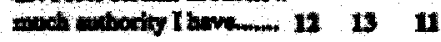

26. Inow what my reperilbitlien

27. Ineted monowathos 1

2. I bollowl wh work

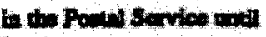
Intive 
Appendix A 264

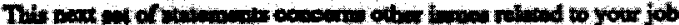

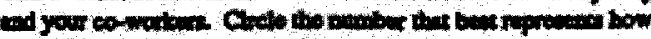

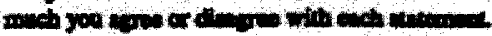

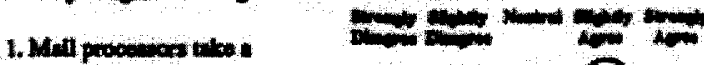

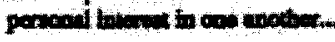

20wath wy wat powetow soad got

15. 17

(3) 1

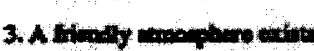
arese the wathat in way and

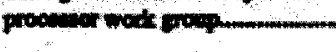

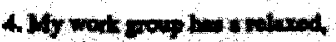

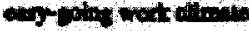

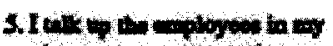

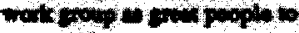

wodr dit

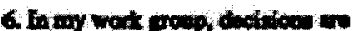

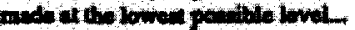

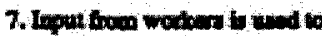
mitedolumen

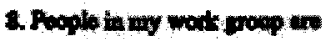

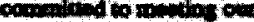

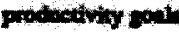

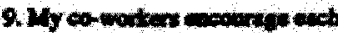

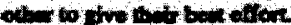

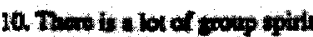

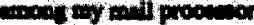
concidate

15. Doine gualty wett toe priporly th eng woik soop

12 My ob-utwo weon nepertitity for the gailly orefroul

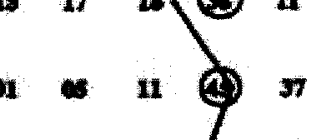

a a 11 )

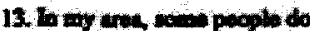
wov of the wod wre ollow do furat nowato ot by

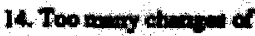

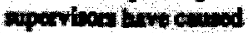

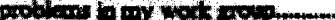

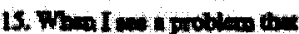

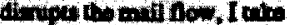
cotoromat .

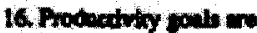

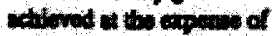

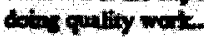

$26020 \%$

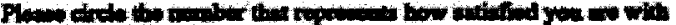
and or tar bellowing

inim.

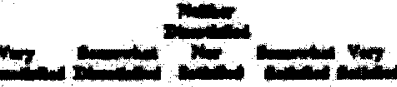

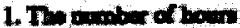

vou wats owd weat.

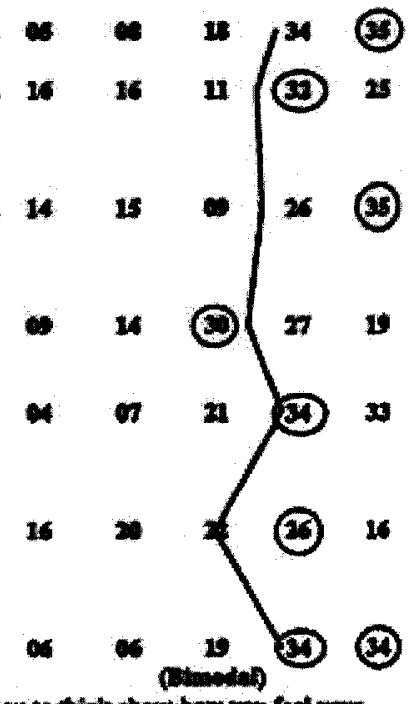

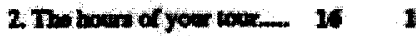

3. Tredyoyan an

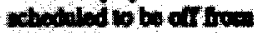

cis

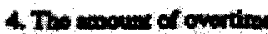

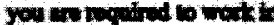

wownerowith

S. The wribly ef the dry

of he weraty woit.

Q Thenth whes

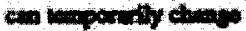

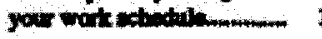

7. The alliny of two

waid at wans you waik

and wis

atronila

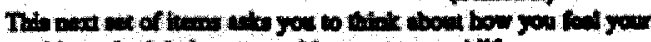

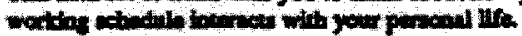

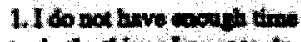

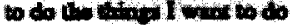

oreidie of twet.

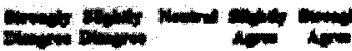

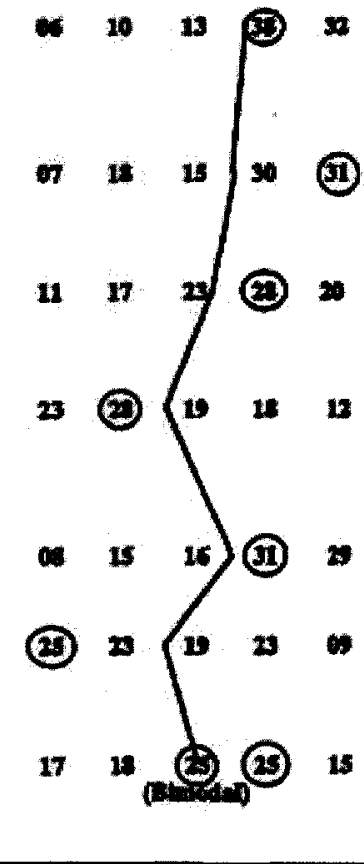

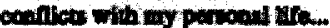

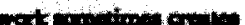

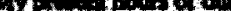

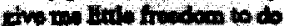

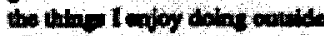

15

1

$\infty$

14

et 0

13

(1) 1

610

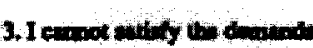

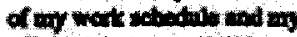

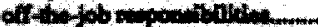

4 Mypum aben orduy

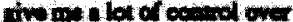

trypumb

S Besw of an wod

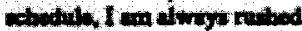

wotketine Irwo wo

catem on 6

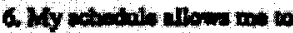
mint to sed of my hodly-

$7, \mathrm{~W}$, wom of tritime I 


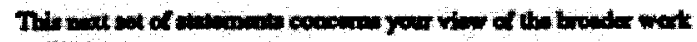
antrounes

rand $\rightarrow$

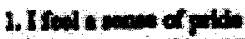

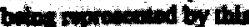

Arive lowil

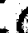

(6) 1

2Mr viluen wede Aprulowilu whe wer vey toller

3. Iwatequarus

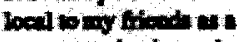
peocengutantion to be nipriminad by

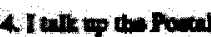
Sirviow of ug thend as pres exploge to wather
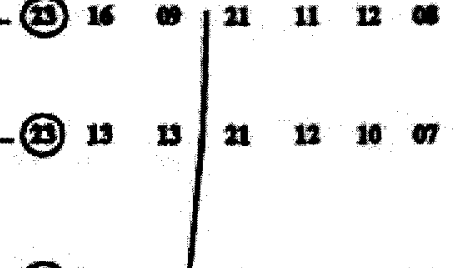

S. If ind thet wo valum

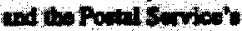

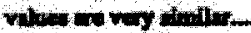

QI Im proid on wiol otwathal Impirt of

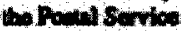
expaldiming

7. Omenthy beryinles

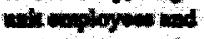
wherwent wat wal nontin.

\section{9}

14

17

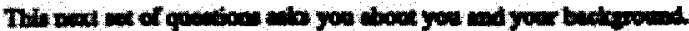

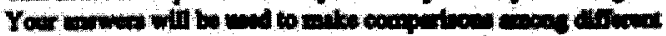

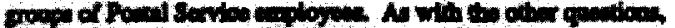

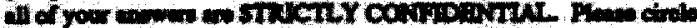

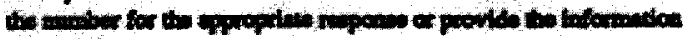
noginged.

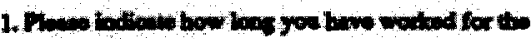
UA Powad senim.

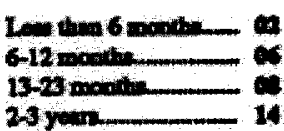

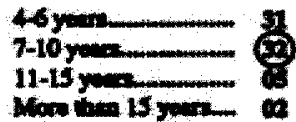

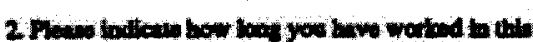
Powl huvilides:

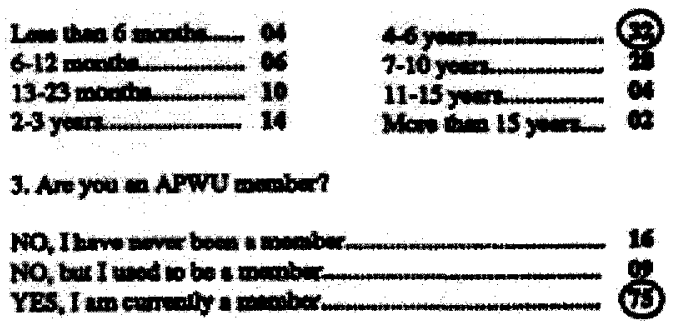

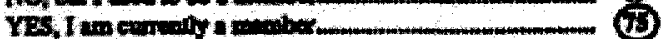

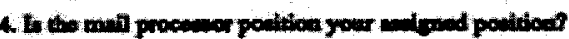

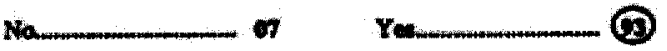

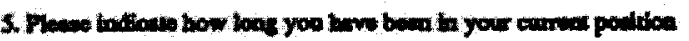

Len thas 6 morth 1

612 man -11

$67 \times$ m 15

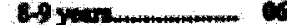

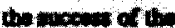

D.tits.

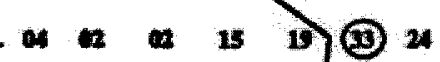

$2310 \mathrm{~m}$

Nowtan $10 \mathrm{y}$ min a

9. I wow withes to whimenction both

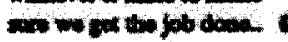

10. I chantist thos niting

11. I will pwoty lock

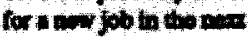
yera

$121 w+6=w$ bow

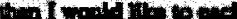
(⿻一,

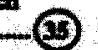

13. I whatilinesw

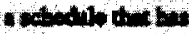

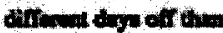

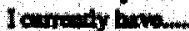

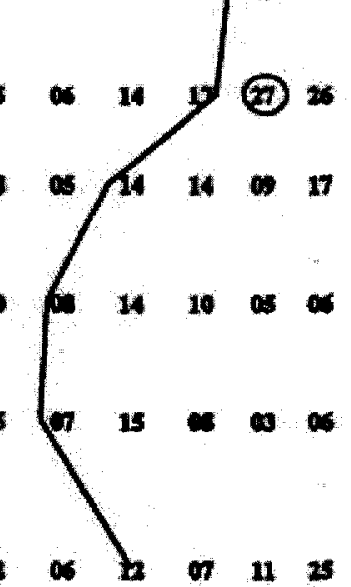

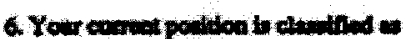

Trattond woplosw- 1

Prom

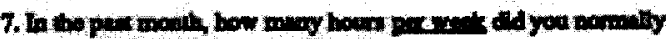

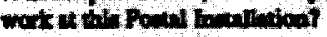

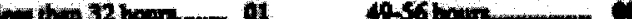

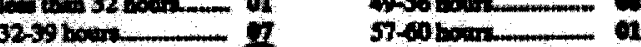

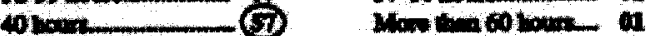

$41,1 \ldots$

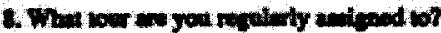

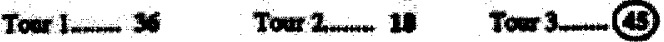

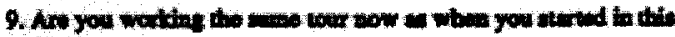
inathe

Nom-12 4 


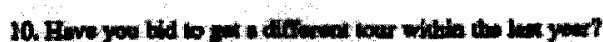
No

$\mathbf{Y}$

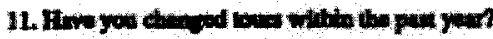

W

Ye.......

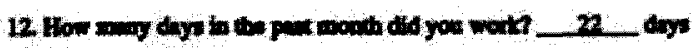

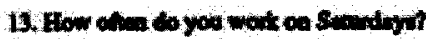

$n_{i n+1}$

19thas

1 thenenow

\section{3 then monthm} Alumer low

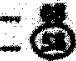

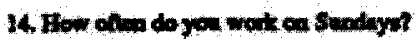

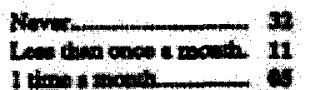

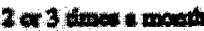
Anowat ohwor.

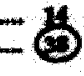

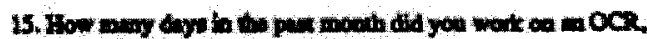

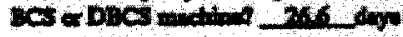

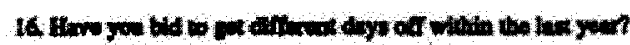

ro.

$x$ 4

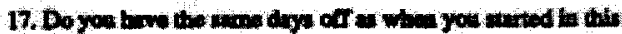
fintint

No:

ra.

13

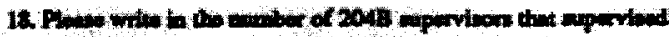

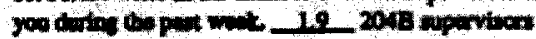

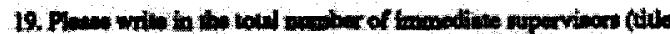

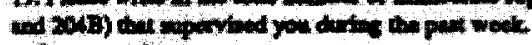
$3.20 m$ man

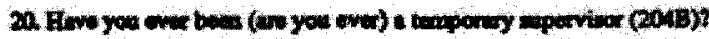

Nor wowe

Yas. nom

Xas fith atem

Yase oin.
21. What byerent

Mista.

0

Wimita

3

2. $w+1 / y+4$

Iact then 20

2047 rimin.

6

$6-35$ - 13

353 min

(A) 5

cosoniming

6oromy

6

30347 r 2

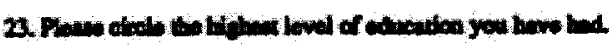

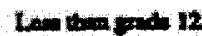

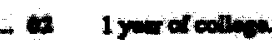

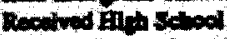

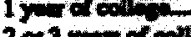

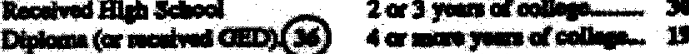

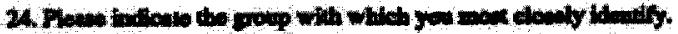

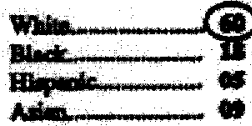

Wethin Anima

an

8*

(1)

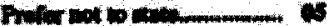

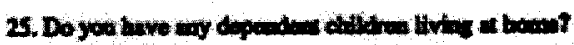

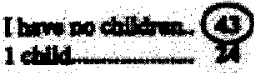

Selowa

4ellitha

Serwoodinter.

in

2 ebliting

2

it

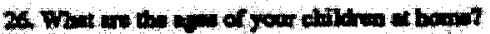
(Cind in thing

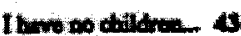

12w 28 rawa dit

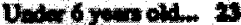

oner It romest

6ollyould 77

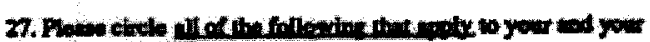

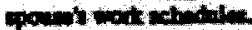

Imontmon

4

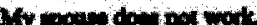

Wy powe wotes thet tion

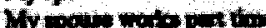

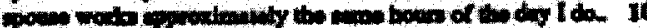

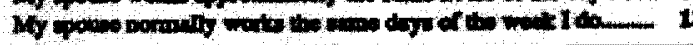

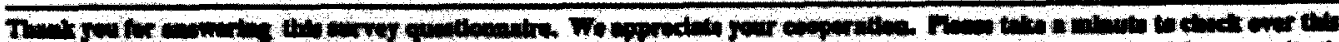

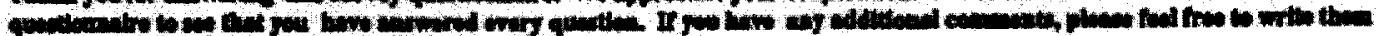

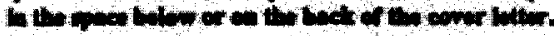

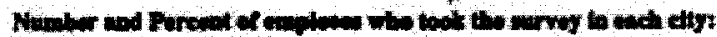

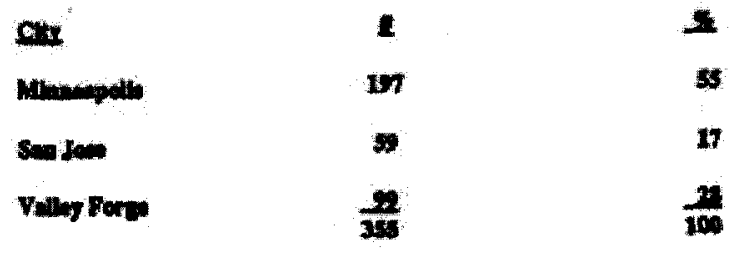




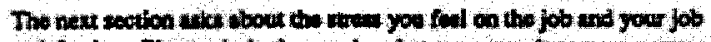

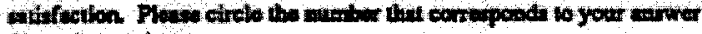
for ench quirsion.

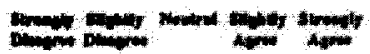
1. The umoun of wewa th my jow he protion

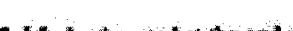
the workdy 1219,00

3. as

3. ICol amodiandy drain iroming wats

1. Tout bout $11 \int_{3} 170$

5 All in all $t$ wan antiaed with my $i x$

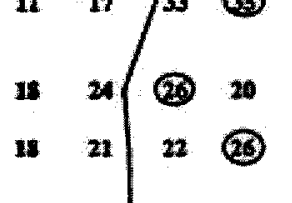

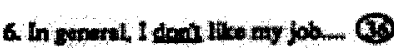

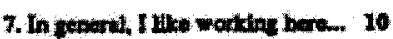

10

8. I wod too nueb oneraw 6s

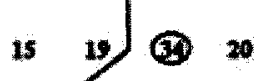
$2 x<13 \quad 10$ $10 \quad 13>26$

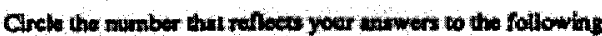

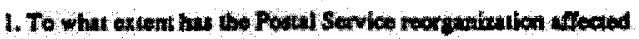
pour jobl

How.

A Inito<smiles>[C+]1[C+]C=C1</smiles>

2)

A Comitertble Amorint. 18

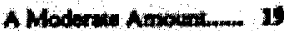

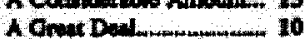

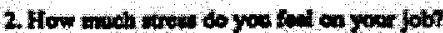

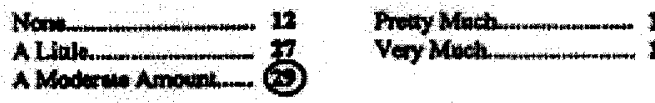

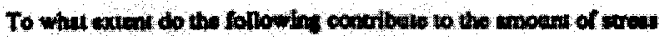
you bed en the job?

1. Contliet betwion ime

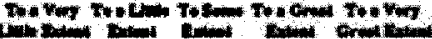

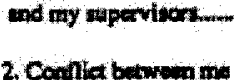

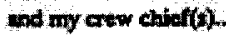

3. Conlia bowean owem

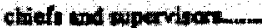

4. Leck of inwolventa In miekins woot-rallated

dow tolon (1)

16

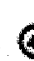
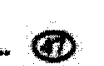

16

10

or

(2)

5. Underindule wort ectuodute

6. Unintereatins work (i)

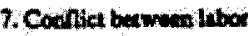
and mangement.

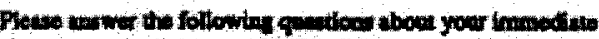

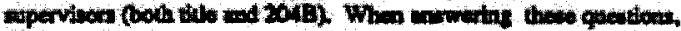

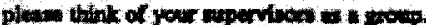

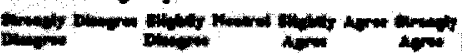

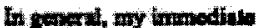

superisan.

1 work will with the

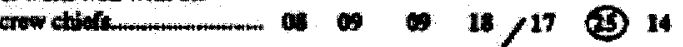

2. wo dwaye tit wid worken:

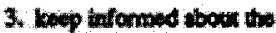
wey worthere thint

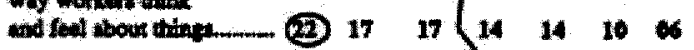

4 demund bis watien the dwist bes efior.

S. exppen the erew did

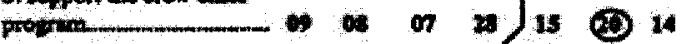

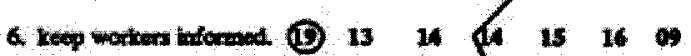

7. wodersond the role of

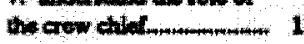
11011211011

Stowe the nempat of

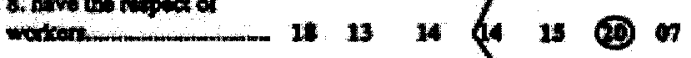

9.0 modith wothen

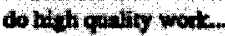
13

10. 00 throwet the crow cufot ta leplenwain:

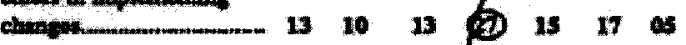

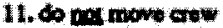

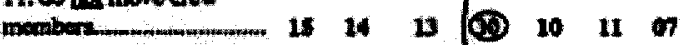

12. Wint thoy do not now

13. do not contrudtict the cow chisto * $1 4 \quad 1 3 \longdiv { 3 } 1 0$ 12

14. betp worken dovelop thetr thilk

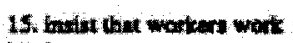
huxd.

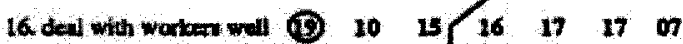

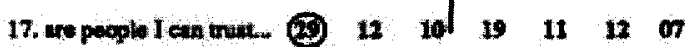




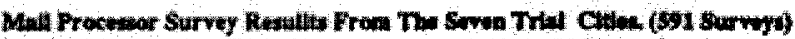

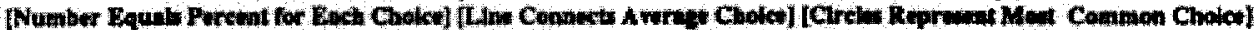

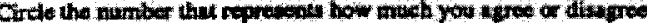

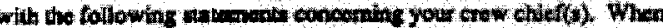

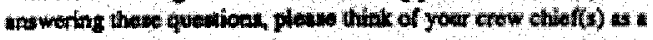
Xatip.

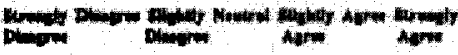

In general, my crew chief $(\mathrm{s})$

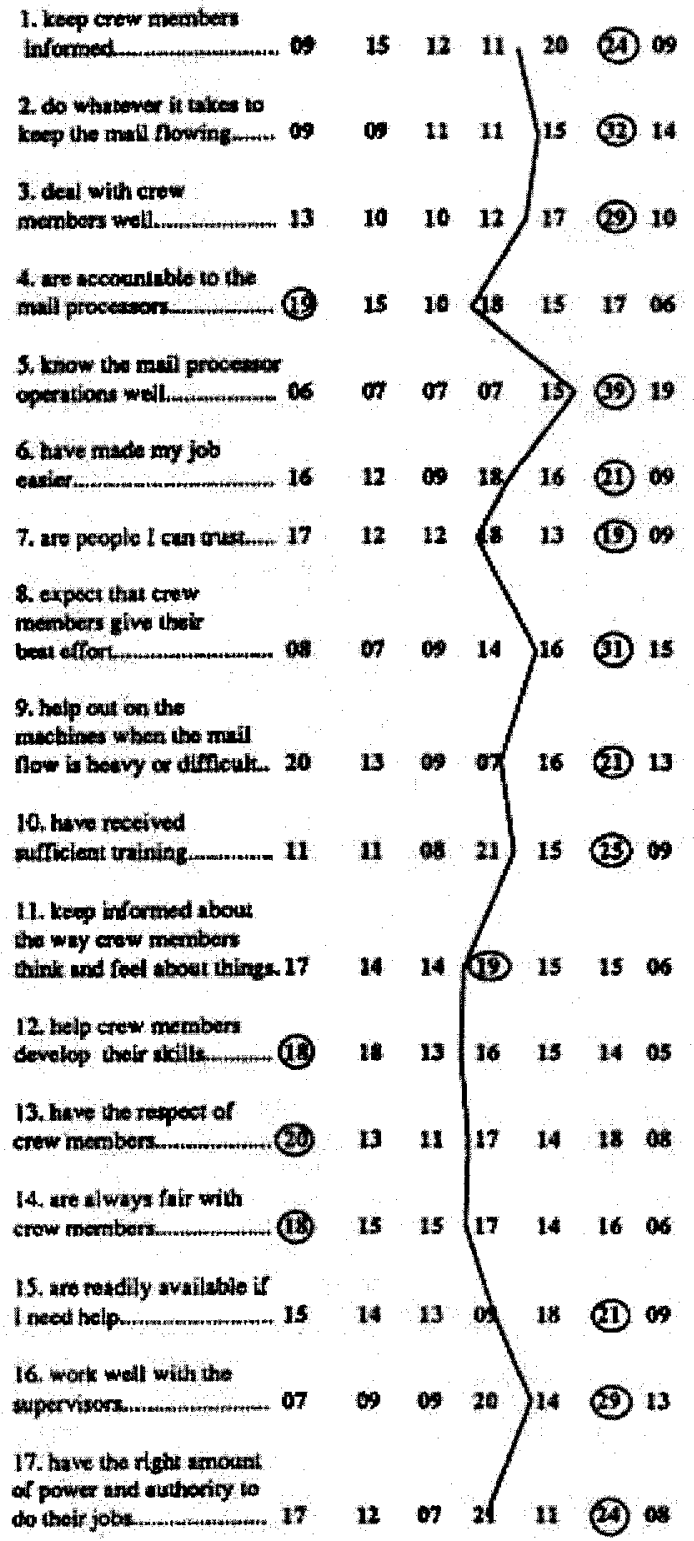

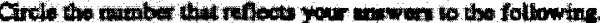

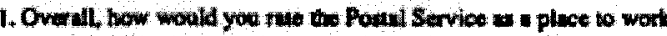
cempend with odher orgatizilana you bow bout?

\begin{tabular}{|c|c|}
\hline 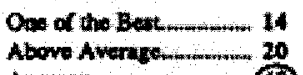 & 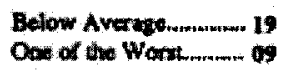 \\
\hline
\end{tabular}

2. Do you ever buve the feeling you woald be betuer off worting

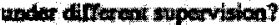

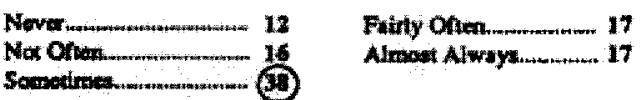

3. How do you fod bous ube suparvitsion you recerve?

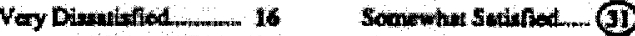

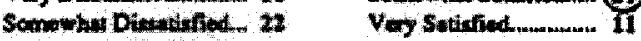
Neliber Divadiefed

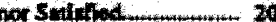

4. The eupervitutes I roceive be the lind thut

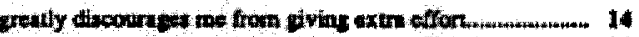

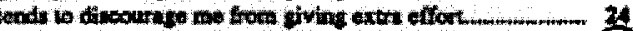

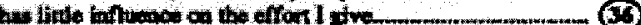

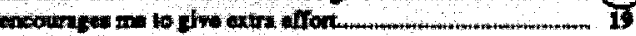

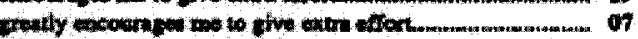

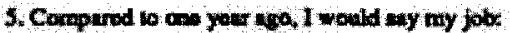
(Crcle wil the ipply, B No chaNGE, LEAVE PAB BLAKK.

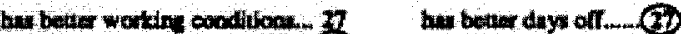

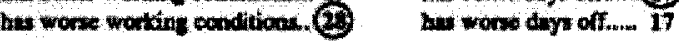

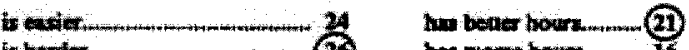

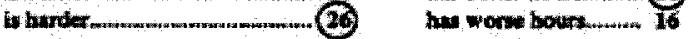
NONE OF TIE ABOVE z)

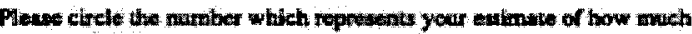

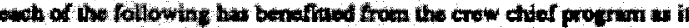
currenily operates in your Poutal burullistion. Nin

1. Superviluan: a) 14 16 30

2. Mril Proces: 2.

3. The ARWU Loed Union.

4. Oenting the Mtel Ow

5. Cratomen

6. The USPS

2) 20210 (3) 230 is (3) $19<20$ is 10 (2) $21 \quad 1_{20} \quad 21 \quad 13$ 


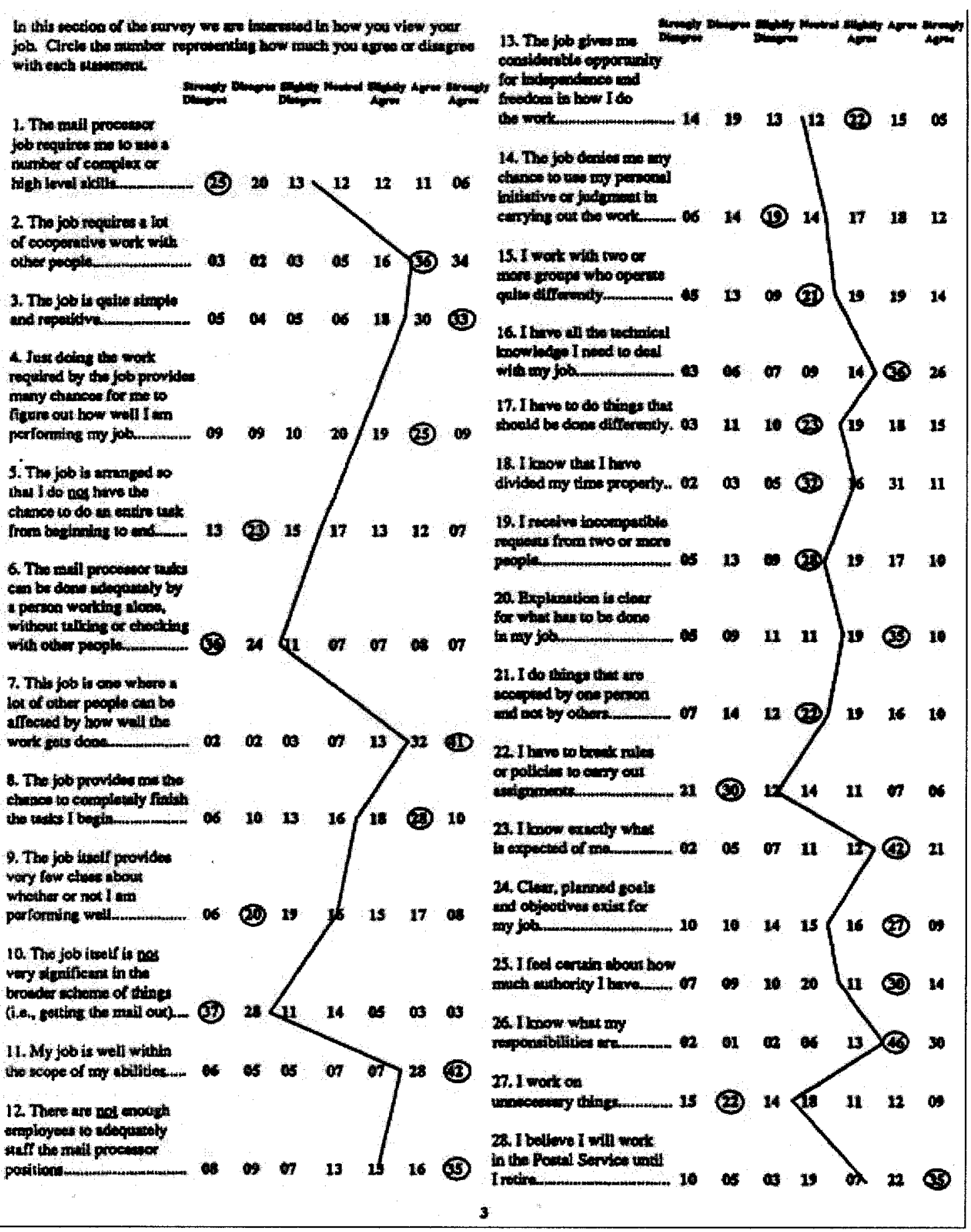




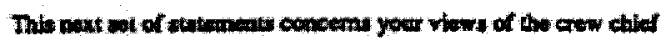
Darnax.

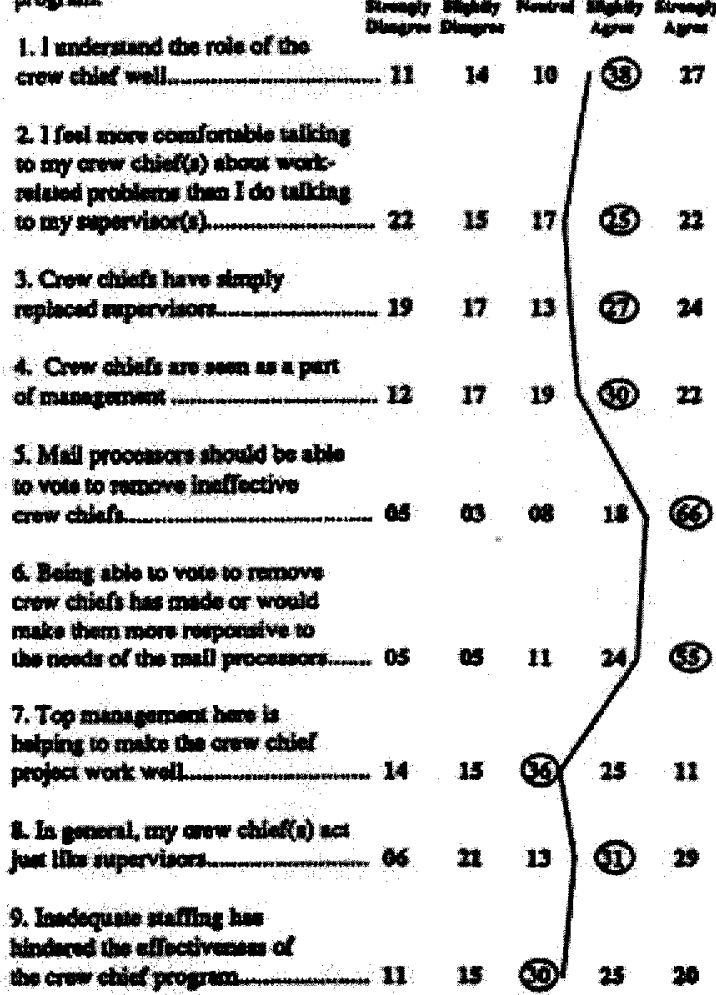

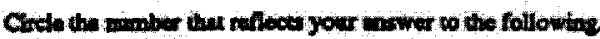

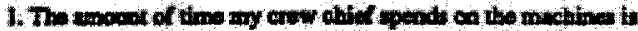

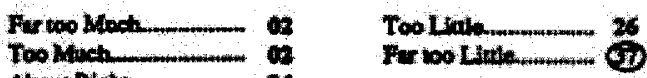

Arow Atho

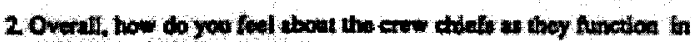

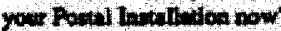

Vog Deathrat in

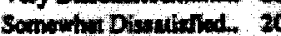
Nolu- Dbalietrod nas sutura Sompwhismaned, (1) Vay Sutinled.

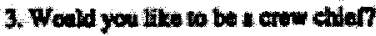

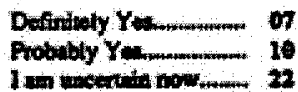

Pobiblyor

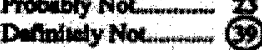

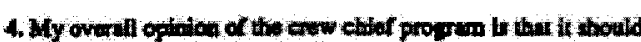

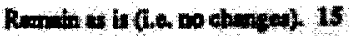

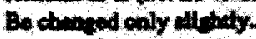

Dechon d anoderiaty

Be draned pridy-1s

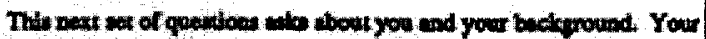

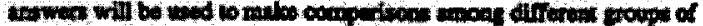

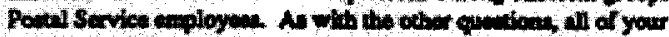

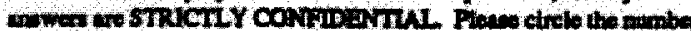

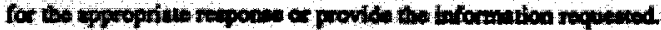

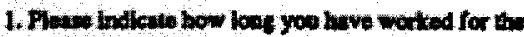
1. Powal Sanve

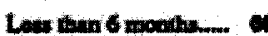
$6-12$ andh

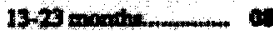

46 youm

$7010 \mathrm{yman}$

$1.15 \mathrm{ran}=\mathrm{a}$

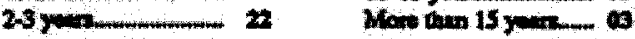

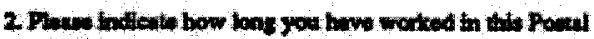
Indellubor.

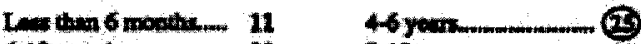

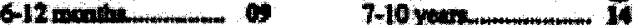

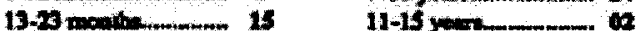

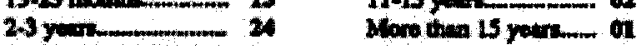

1. Axyod to APWU wamber?

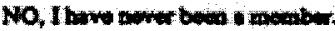

No, bia I wed w be andon

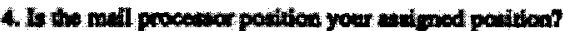

How $10 \quad \mathrm{Y}$

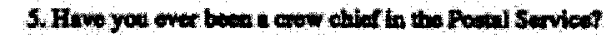

No, $D$ mas.

Yes, entime enw dite

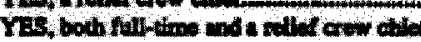

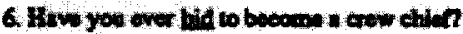

No wowe

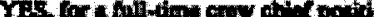

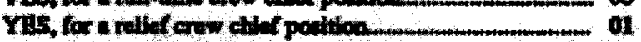

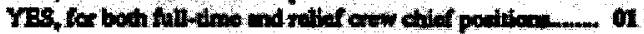

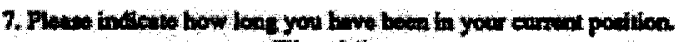

(Elinodit)

Ant. 6

612 manthatum 1

13-75 amomand 1

89 y

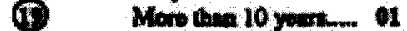

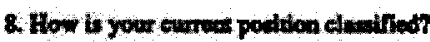

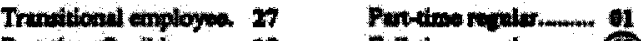

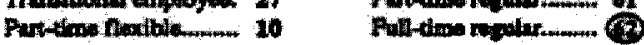

PENSE CONTMUUE ON THE NEXT PAOK 


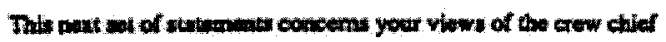
progume. 1. I whicuand the role of the

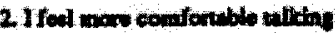

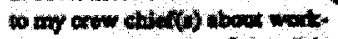

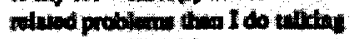

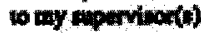

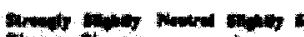
then tom

3. Cow dids how taraly

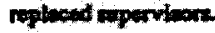
$\mathbf{I}$

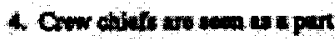

$\alpha$ monowinat.

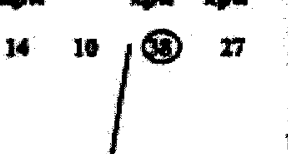

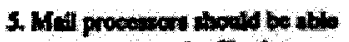

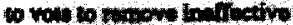
armenteris.

28

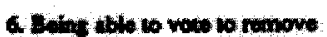
crow chitor he node of woit

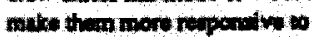

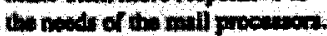

7. Top mancepmen bus to

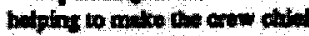

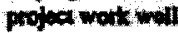

\section{Aint}

A Is furtis supervitos

Q. Indwawe traing bis

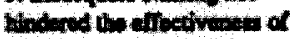

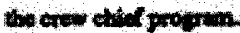

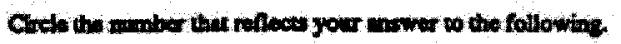

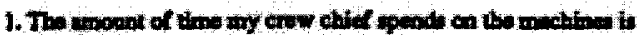

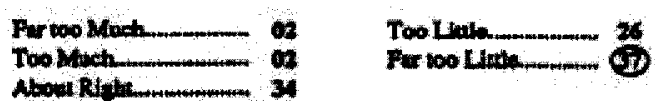

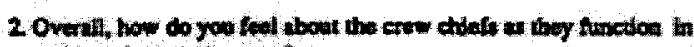
yow Rordil lawnithon nown

Verg Dowinod.... Somowh Derutertad 20 Nolom Dratiefted nat stited Sourohessuditat (T) Ver satidat; II

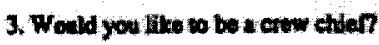

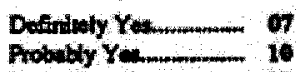
Poble Yen 1

Frobubly Now Difinilityok 3

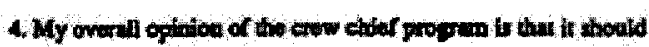

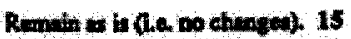
Be oboupd enly dit hely

Bewhinumading

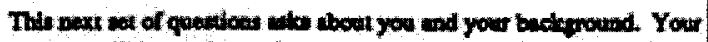

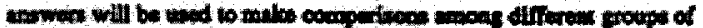

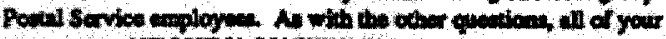

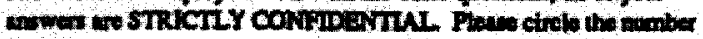

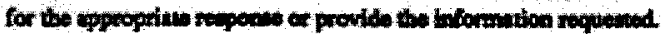

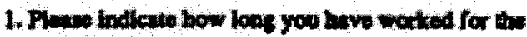
Us. Povill Sarita.

Leas than 6 woothe.

1200han of

1328 enondar -

23 Ywan-

4 your:

$710 \mathrm{yen}$

M-15 yenam a

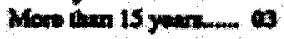

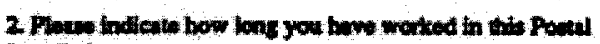
indintes.

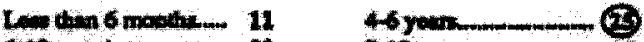

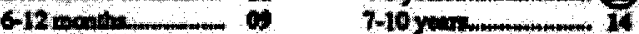

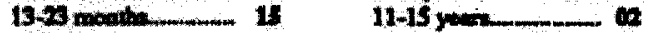

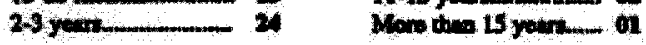

\section{An you en APril mowber}

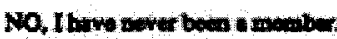

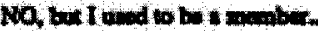

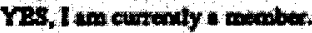

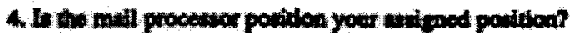

Na to $Y=$

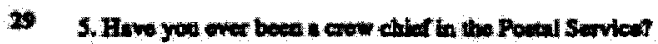

Ho,

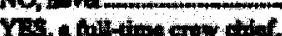

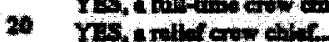

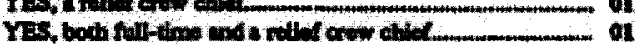

is

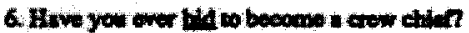

No, enere

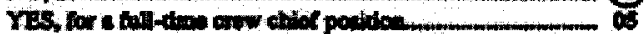

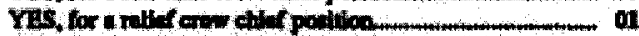

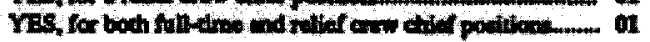

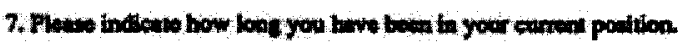

Athodity

$6-12$ monthe 1

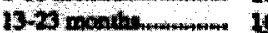

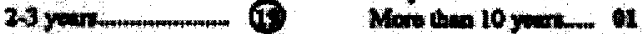

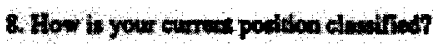

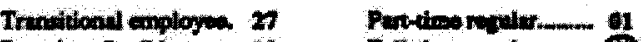

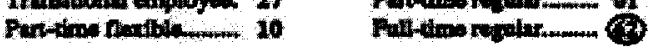

\section{PLENE conTunE ON TrE MEXT PAOE}




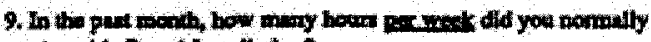

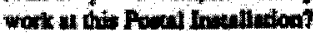

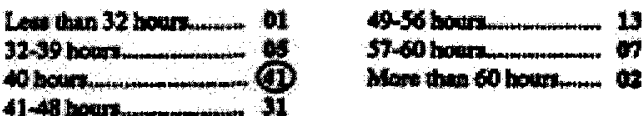

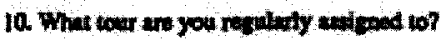

Tour 1

$$
\text { G) Dour } 2
$$

13

$\operatorname{Tom} 3$

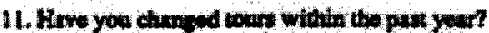

Ma. (b)

Yes: 31

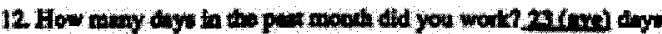

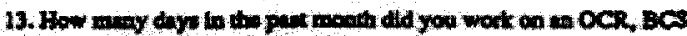

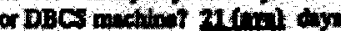

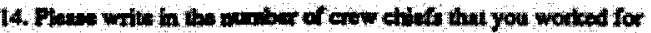

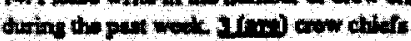

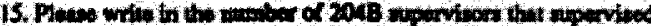

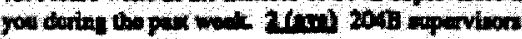

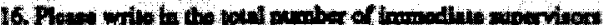

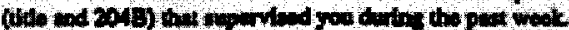

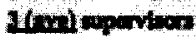

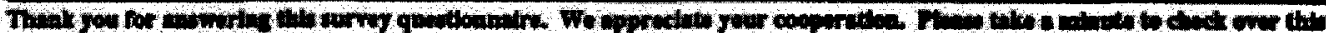

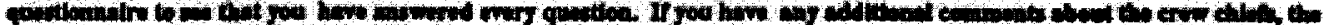

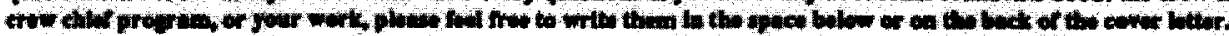

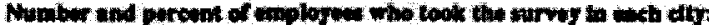

Aly

$$
1
$$

Loulunilo 12

Armingane $s$

Rochwor 40 of

Curat Valley of o

gerrenatle of 14

Stin pal 12

Rogul oul $\frac{14}{10}$

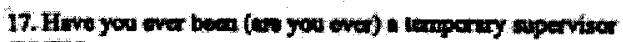
oush

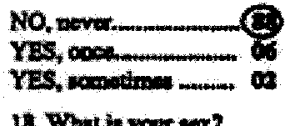

YRs, filly elon of $\mathrm{TBs}$ chen

Yes, thing th of the time of

18. What b your wax?

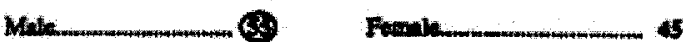

19. What te you ap?

Vemonen 20 marm-

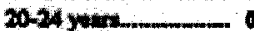

2009 yen.

$30-34$ vaer.mon 2

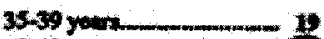

44-19 yetr-mo

900 ram

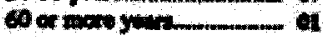

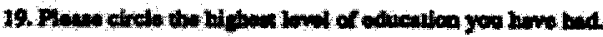

Lew than an 12

a) Iyeredin.

203 tanat of collingen

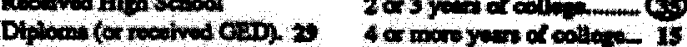

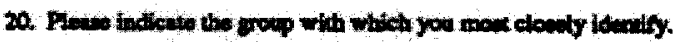

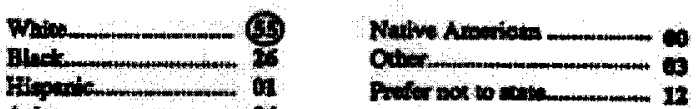

(a)

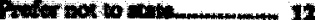

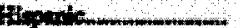

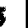

$$
3
$$$$
\text { 1. }
$$ 
Surrey For Crew Chiefs Results (Full Tine and Relien)

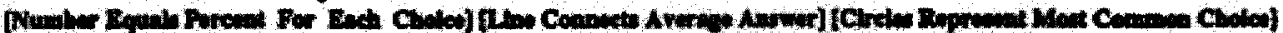

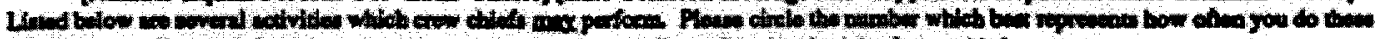

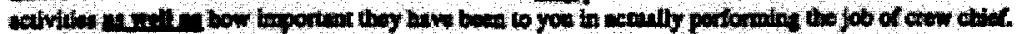

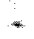

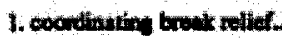

2domleping dily wotp ples:

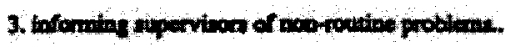

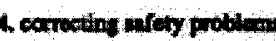

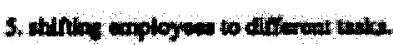

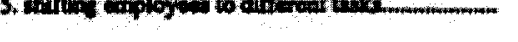

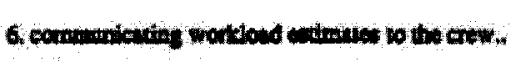

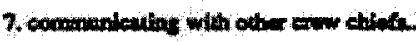

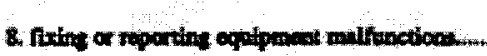

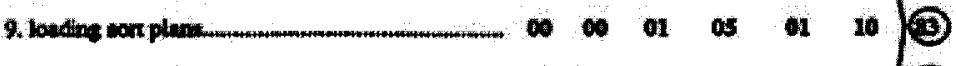

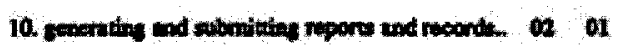

$$
\text { 1owas }
$$$$
\text { on }
$$

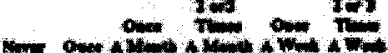

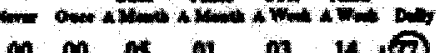

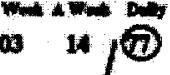

of os o a os

a o$$
\text { a. }
$$

a)

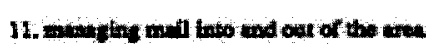

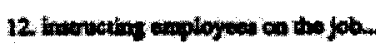

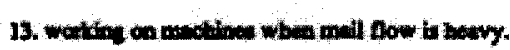

14. winteraployes.

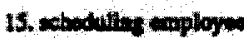

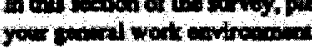

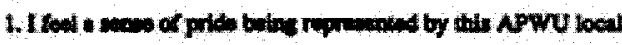

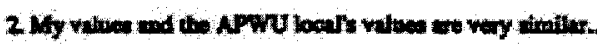

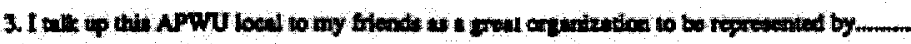

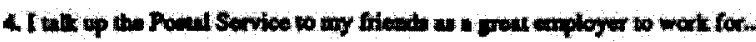

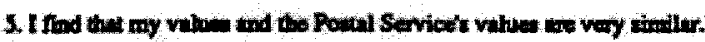

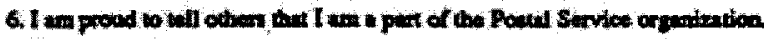

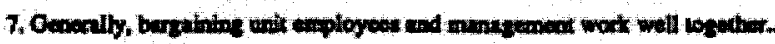

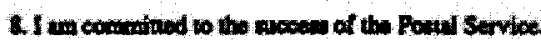

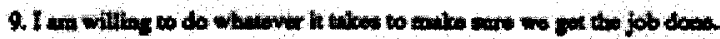

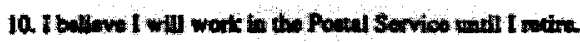

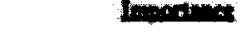

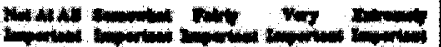

$$
\begin{aligned}
& \text { a } 1 \text { or } 4 \text { (1) } \\
& \text { e. } 01 \\
& 40 \\
& \text { a } n \\
& \text { a } 101 \\
& \text { a. } 05 \\
& \text { a a } 0 \\
& \text { a. or a } \\
& \text { a. } 13 \\
& \omega \\
& \text { a) or } \\
& \text { a) } 15 \\
& \text { a) } 11 \\
& \text { a } \infty \\
& \text { 11 } 6
\end{aligned}
$$

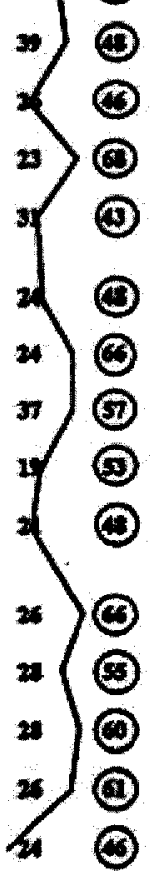




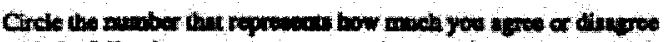

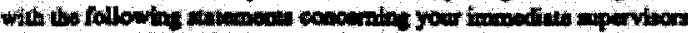

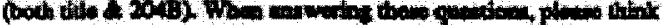

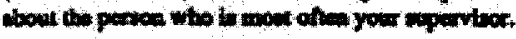

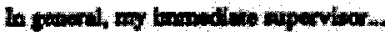

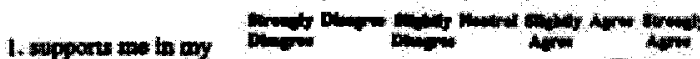

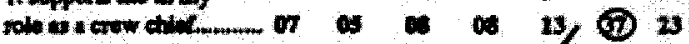

2 ho the noma

owouk r. 10. 10 )

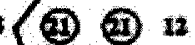

3. becks me when bur ine problem

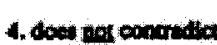

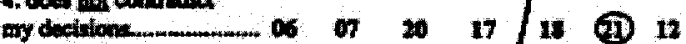

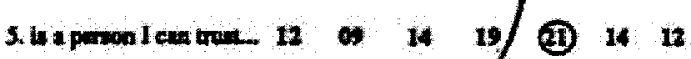

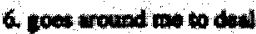
Whithe vorberm a 14

7. nuppest the crow ellit

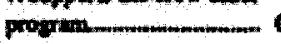
6. 10 os .

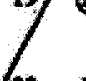
(2),

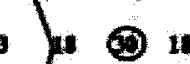

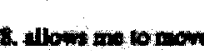
werbersonic. $-1$
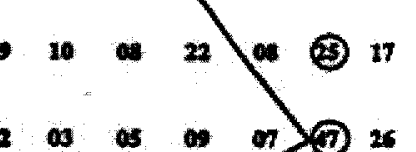

Q bhow on when thito

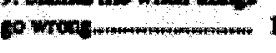

10. thing be the ones an nend now thits
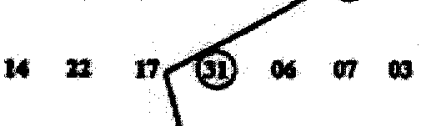

11. wote with mo in

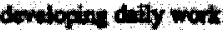
Plin: 29 21 or 12 o it:

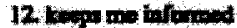
dowa workndited dhing .

.

13. undmotentin no note

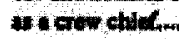
20

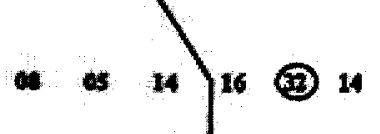

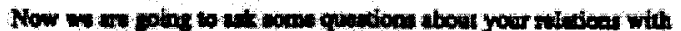

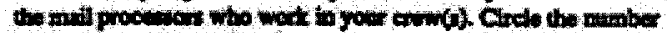

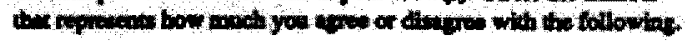

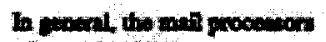
Woo wot wh wo.

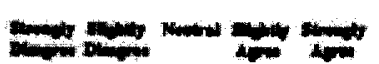

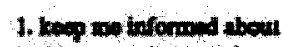

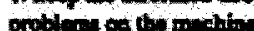

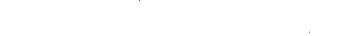

2 whomend my relo ws crivetel. $\left.\begin{array}{lll}4 & 0 & 0\end{array}\right)$

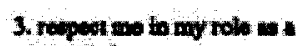
owow oblet:

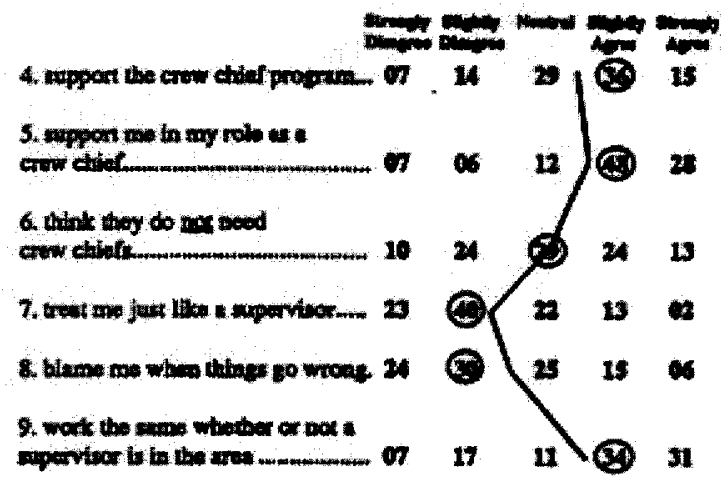

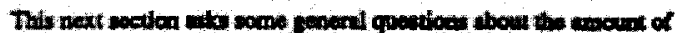

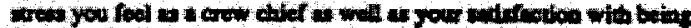

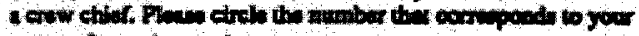
enowar for acto quaction.

1. The monat of whe to any

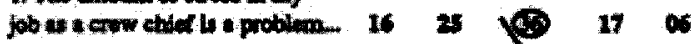

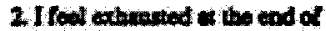
trimenter

3. It ted enotionilly drulned foun ay wot.

4 Itod barned on tow any woth.

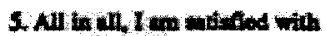
ay enow obitifot

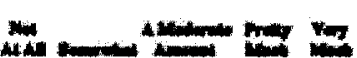

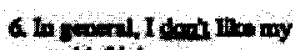
ervetherlot

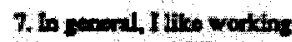

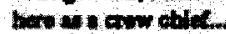

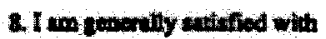

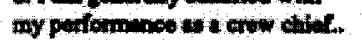

9ifol the wit procenes bo axy arow 60 owenlly

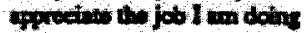
wacion atid

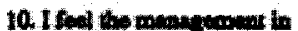

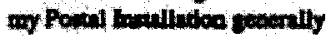

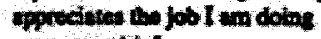

trowotel

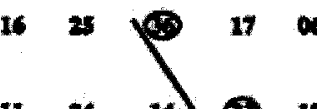

11. I m atenes with ay

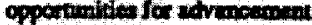
in the Potill Serve:

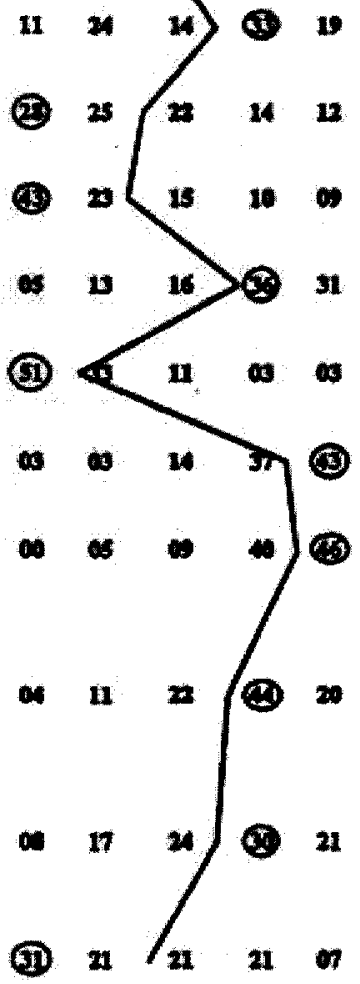




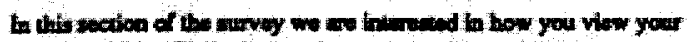

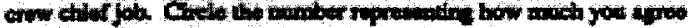

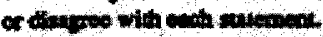

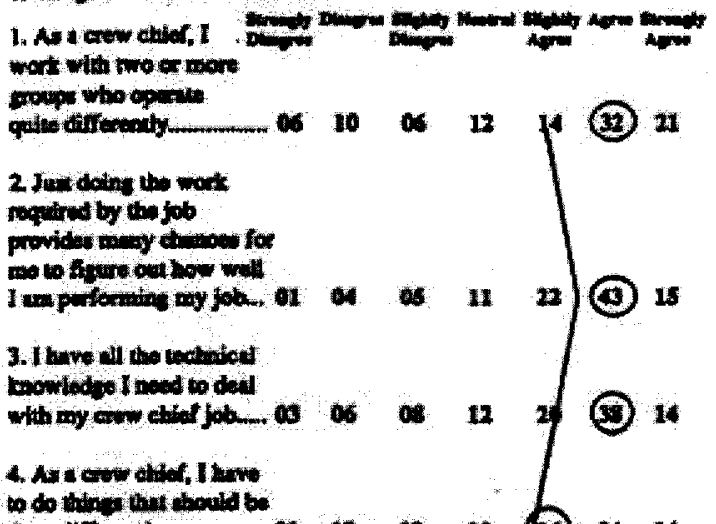

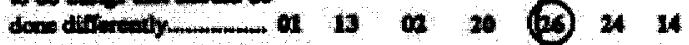

3. Whes potomenting to

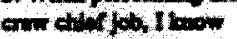

chat I trove divilud wy

ime popdy__- o o o o 2 (3) is

6 As a dow entiof, I

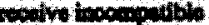

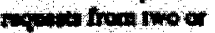

menepople

7. Exwhenton thelow

lor what be to bo doos

un orem dile
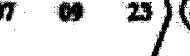

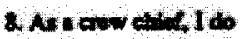

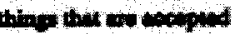

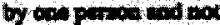

of odtor

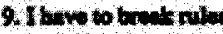

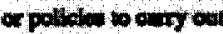
ctanemona

cropeltat $-11$

101 tamm wath whet bexpend of mo th

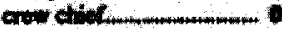
es

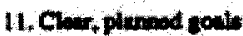
nd obturation witut for divenow diat fats.

12. A s tow ental I rod

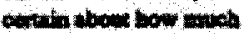
0 (1)

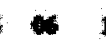

1
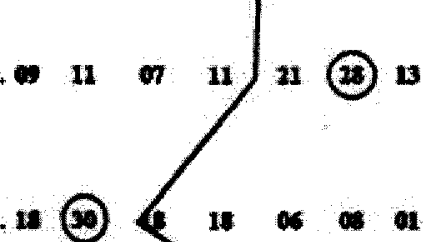

13. Nowow whel a

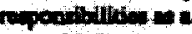
arew diter ares

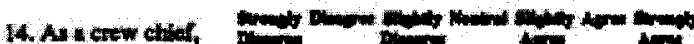

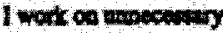
Qings: 1

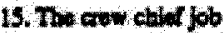
awd with the roop

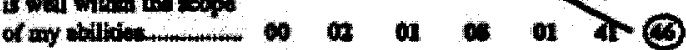

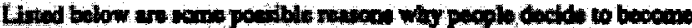

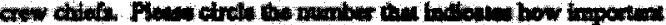

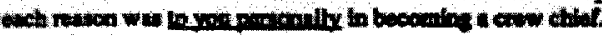

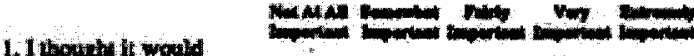

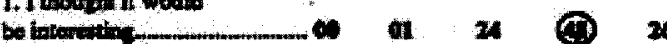

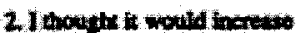

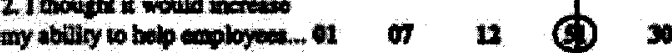

3. Inoudt h wodd dwe w more eny biv to wy thape

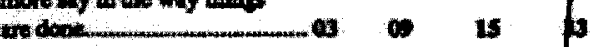

4 I wantod bo luow mane

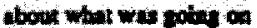

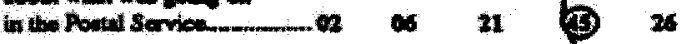

5. Thoaght 1 could thowow

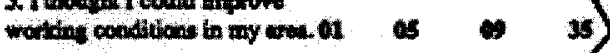

Q Tonnedepostites ormponditutity.

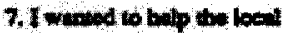
union.

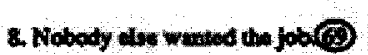

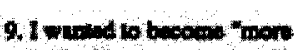

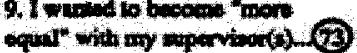

10. 1 wowod 10 exceps to bow of ary 6

11. I taridur I waid oin the repect of m folow weployim

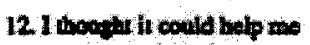

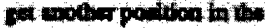
Pootis Surva (7)

13. I wandod to wotk wh Almomaspoph

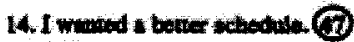

15.t wated wowe anorof mimen- 9

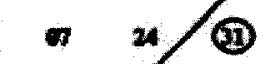

2

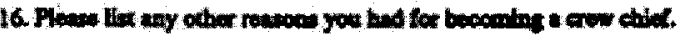




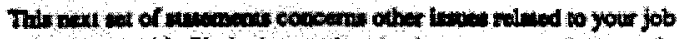

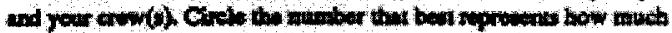

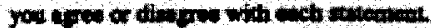

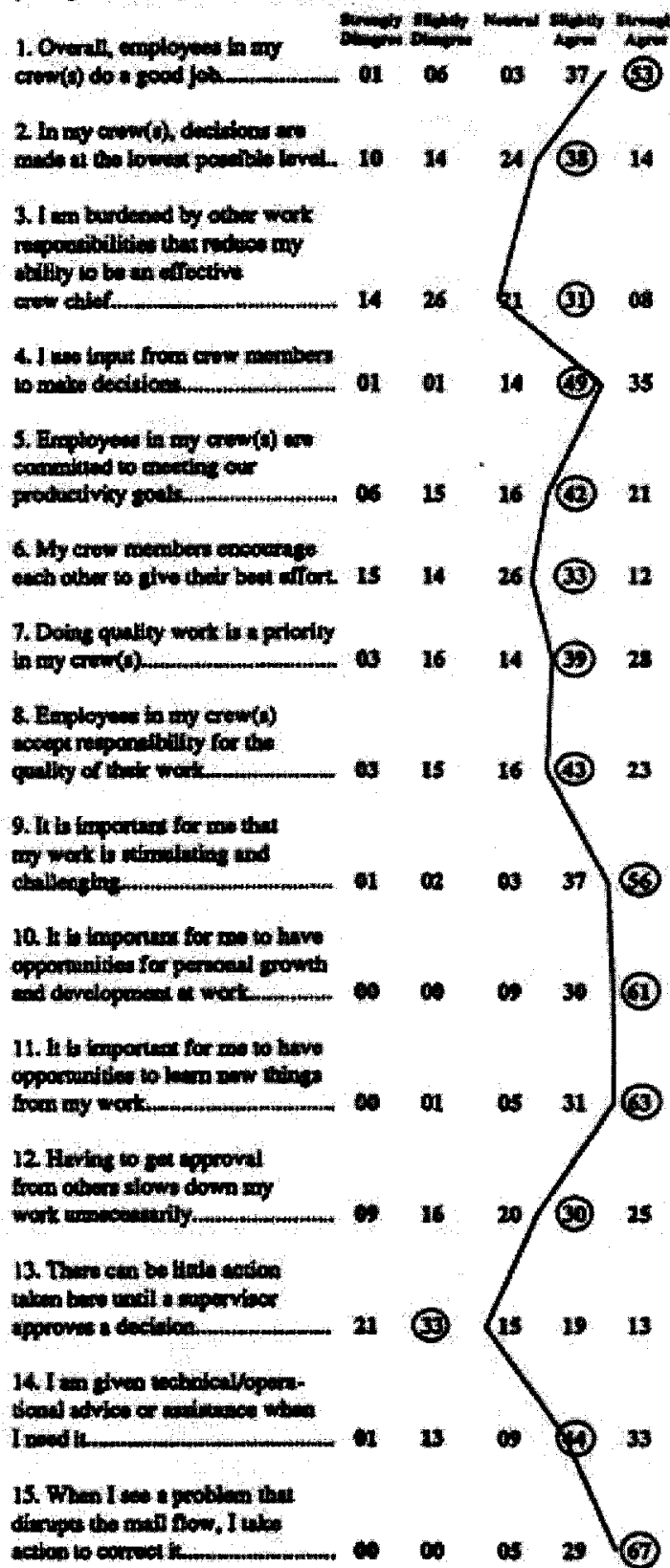

16. Productivity poelli ure

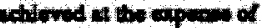

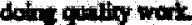

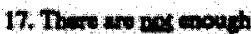

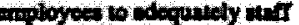

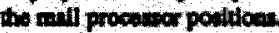

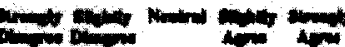
6. is 14 (6) 30

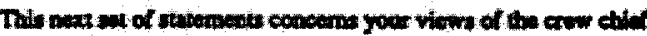
proprum in gevent

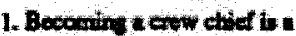

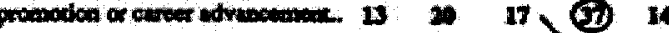

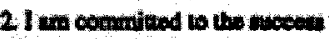

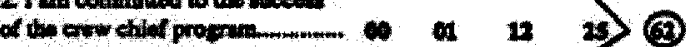

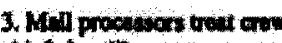

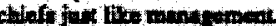

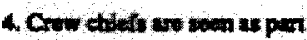

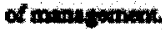

S. Mell prowase thowd be th

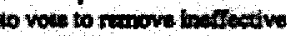
cow clith.

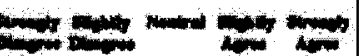

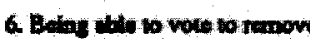
cow chistar mede co would

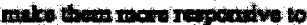

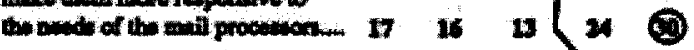

7. I wert wall with othe crov cing

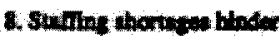

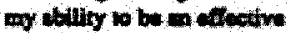
cow dalat.

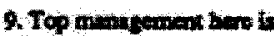

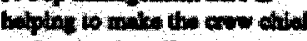
protuet wot well

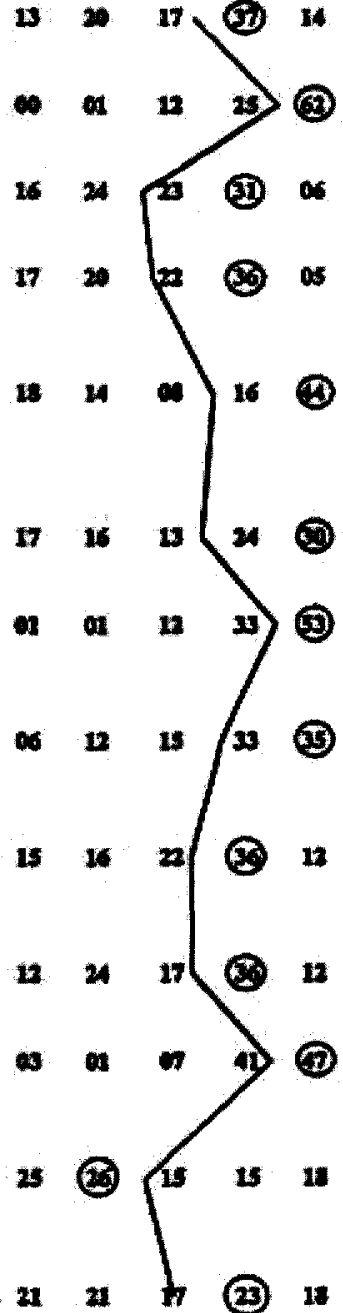

10. Crew obief hne thotith weonat ol power ead wathorly wodote fot

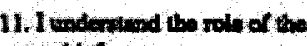
arow dist

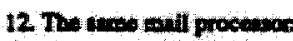

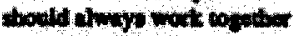
w wenw.

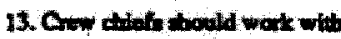

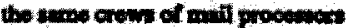
wothrity.

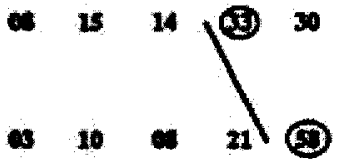




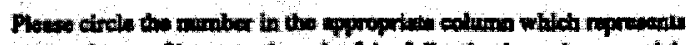

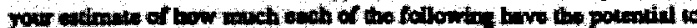

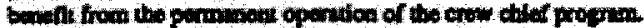

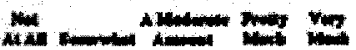

1. Stepanturat

a)

2 Ment Proserar a)

3. The NewV Lom Udom

Aonis bo Whou.

5. Orimomat

6. Thas

7. Cris owe bovand.

L Yos Rimoanlly.

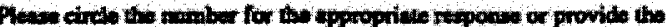

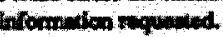

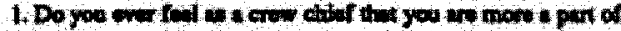

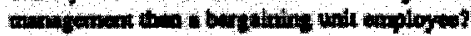

Nera. 3 20

Findrow

Alewat Alway 08

Notom (3)

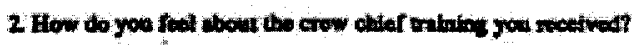

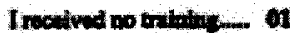

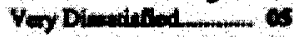

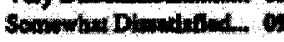

Mother Diandingd

morbteimat 4

Sowmedsidad- 7

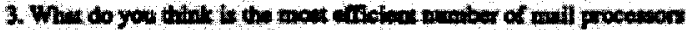

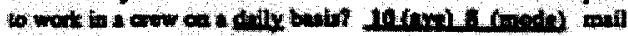
poovers

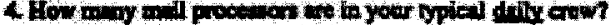

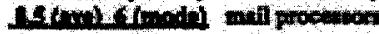

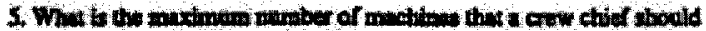

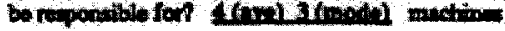

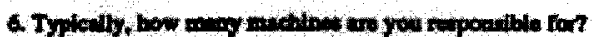

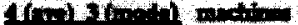

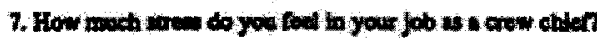

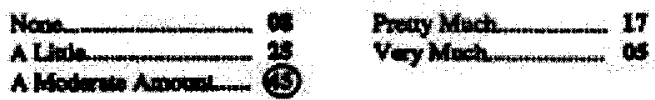

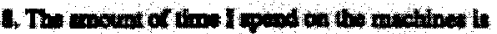

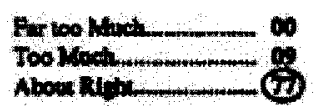

Toolute: 13 About ath _ $-(a)$

(a)

(2)

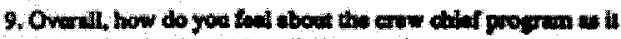

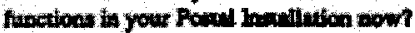

Ver Dimentions.

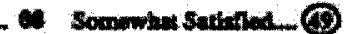

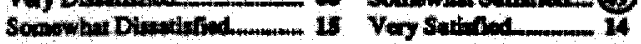

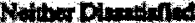
nor Stitfied.

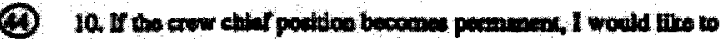
cantinge ou enow dive

Deinolidy Yox

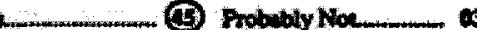

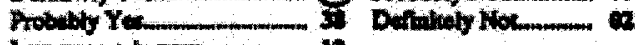

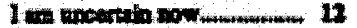

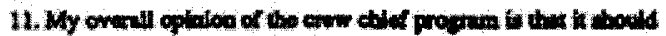

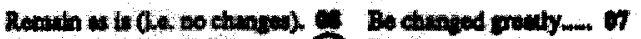

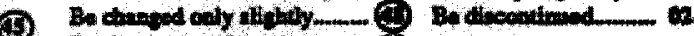

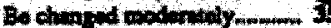

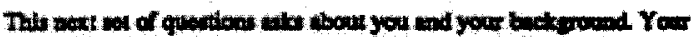

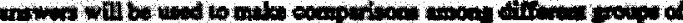

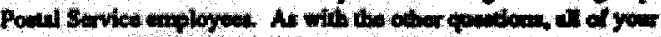

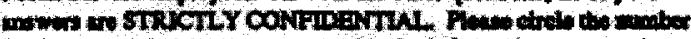

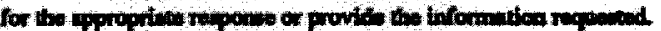

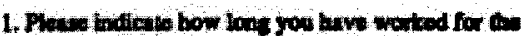
Us, nowals swle

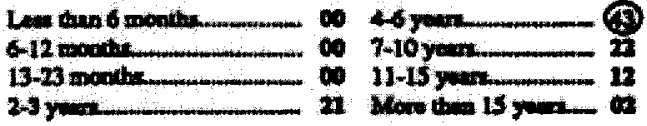

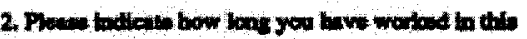
Powd leaviliotion
Lat hen 6 mowith
O12 mondte.
6. $46 y=$
710 yman
1015 yin

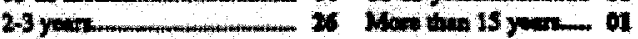

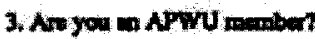

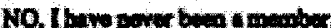
110, bat I waind of be o nember 6 Y 8 , 1 m on mo m

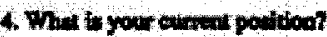

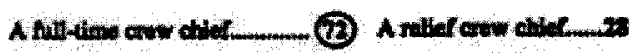

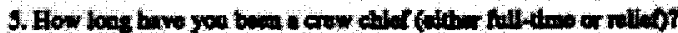

Les $\lim 1$ wath.

a) $700+2$

(9)

203 maita.

13 otomit

$46 \mathrm{mon}$

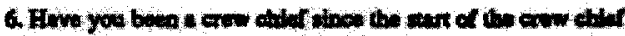
proven u your Pould Inillintinat 


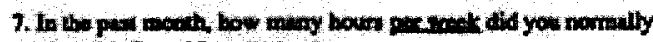

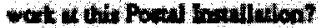

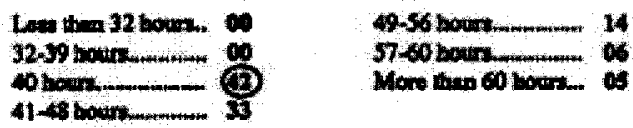

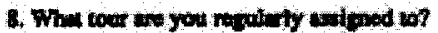

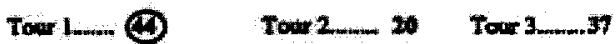

9. How you changed loan whitio owe past you?

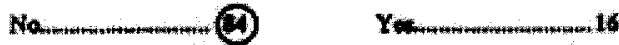

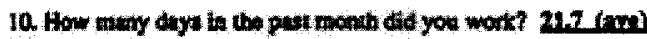
4he

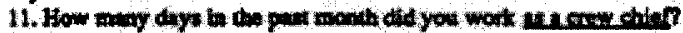

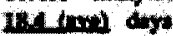

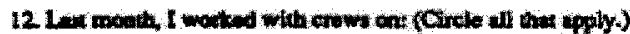

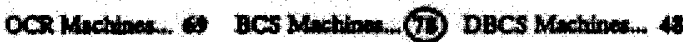

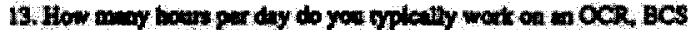

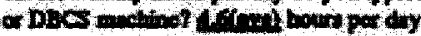

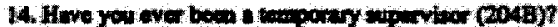

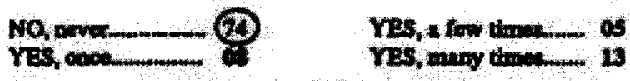

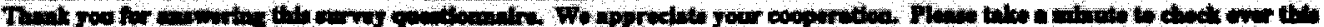

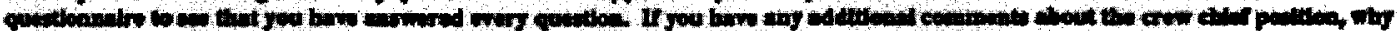

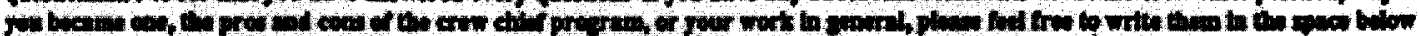

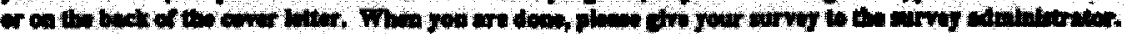

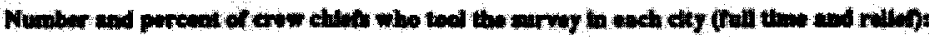

aiv 1

Loxhalis 21

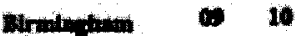

Novinar $\rightarrow 10$

Whately 1416

Exerenowo II 13

at $\mathrm{Bad}$ is

Pogalow in 14

10

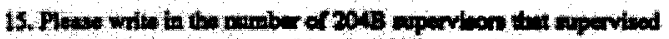

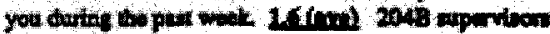

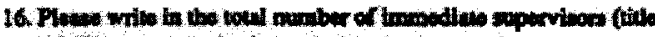

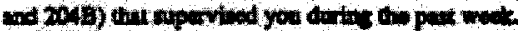

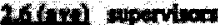

17. What byour wex

Nato

Find 3

10. Mhas L your ingl

Lea does 20

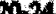

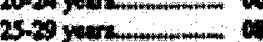

0.34 yetris

$35-39 \mathrm{yman}$

$40-49$ yours.

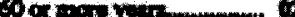

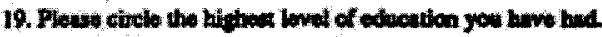

Lene then wat 12

of 1 reer of oollow

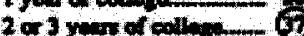

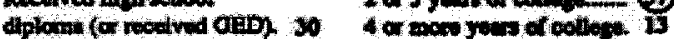

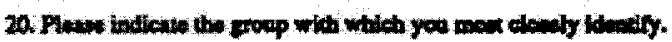

Whos

Nivels.

Anprai

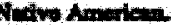

alhe

.

Poffer aco botwo 6 a

10


Appendix B. American Postal Workers Union Reports

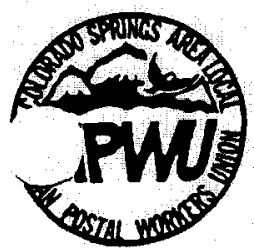

COLORADO SPAINGS AREA LOCAL

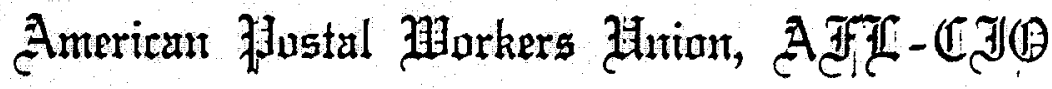

P.O. BOX 2001 - COLORADO SPRINGS, COLORADO 80901

August 25, 1993

Sacramento Crew Chief Local Steering Committee

Please accept this as the report of our follow-up visit to Sacramento on August 10 and $11,1993$.

We're sorry that your schedules did not permit an exit meeting upon completion of our interviews. We know you all have many other duties in addition to the Crew Chief Program. Considering this, we appreciate the time you have spent working to ensure a good test.

We also appreciate the openness of those interviewed in discussing benefits and problems with the program.

Briefly, we made the following observations during our discussions with mail processors, crew chiefs, and supervisors.

- It is apparent that time has made a big difference in employee reaction. Response was almost unanimously favorable to the idea of crew chiefs and the program.

-Every crew chief we talked with enjoyed their job, and most mail processors who were asked, responded that they would want to be a crew chief.

-Supervisors report that operations are running better .

-Mail processors report more relaxed working conditions.

- Training crew chiefs on the passer system has had positive results.

Some areas in need of attention are:

-A few mail processors complained of some crew chiefs not spending enough time on the machines. (This is a common complaint in test sites and seems to be one of the critical tests of a crew chief. Crew Chiefs should make it a point to work the machines when possible. This might mean delegating some other duty such as running for mail in order to have time to be on the machine.) 
-There is still an impression among certain employees that management will never accept the program, and may be undermining it.

- Supervisor turnover has hurt in that new supervisors have never been trained in the program and don't immediately understand what crew chiefs do.

-Complaints of lack of information from the Local Steering Committee to the crew chiefs. Some feel abondoned, locally.

-The crew chief vacancies filled on a long term basis by reliefs, or not filled at all has caused some dissension. Vacancies should be posted and filled.

In addition, we have taken suggestions on the following issues which are more our responsibility than the local committee's.

-There were a number of discussions about the selection process, with no real consensus as to which method would be the best. We understand the importance of having a selection process with integrity.

-Developing a method of assessing the crew chief after placement.

Once again, thanks for all your hard work and committment to the program. We will be on site again in about three months. If you have any questions or problems in the meantime please let us know.

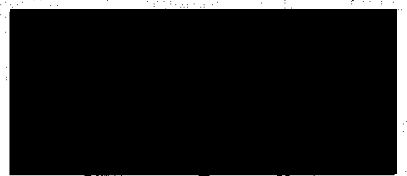

Peter Sgrou

Labor Relations Specialist

U.S. Postal Service

475 L'Enfant Plaza, Room 9300

Washington, D.C. 20260

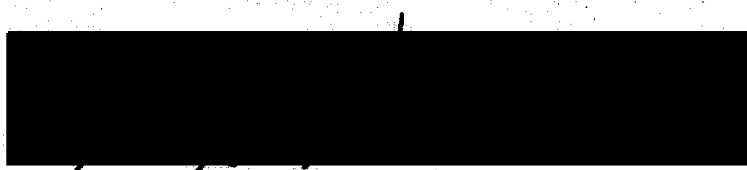

Jon Numair

Industrial Relations Director

Colorado Springs Area Local

American Postal Workers Union

P.O. Box 2001

Colorado Springs, Co. 80901

co: Robert Tunstall

Anthony Vegliante 
COLORADO SPRINGS AREA LOCAL

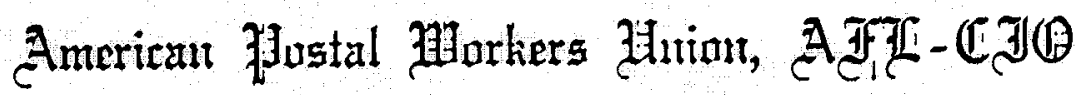

P.O. BOX 2001 - COLORADO SPRINGS. COLORADO 80901

August 25, 1993

St. Paul Crew Chief Local Steering Committee.

Please accept this as the report of our follow-up visit to St. Paul on August 12 and $13,1993$.

As we stated in our exit meeting with you, it appears that good progress has been made in adapting to the Crew Chief program since our last visit. This program takes time to find it's niche because it is such departure from the existing means of performing work and assigning responsibility. We appreciate all your efforts in working to ensure a good test and persevering under some tough circumstances.

We also appreciate the openness of those interviewed in discussing benefits and problems with the program.

Briefly, we made the following observations during our discussions with mail processors, crew chiefs, supervisors, and managers.

- Crew chiefs seem to understand their role very well.

- There is almost unanimous agreement that the program is positive and worth continuing.

- We received reports of reduced tension among mail processors and a more relaxed workplace.

-Most crew chiefs like their jobs, and most mail processors would be interested in becoming a crew chief.

-Supervisors like the program and appreciate the assistance.

- Mail processors feel crew chiefs are more accessible than supervisors.

-Operations are reported to be better organized, with crew chiefs able to keep the machines running more continuously. 
Some areas in need of some attention are:

-Some mail processors complained of some crew chiefs not spending enough time on the machines. (This is a common complaint in test sites and seems to be one of the critical tests of a crew chief. Crew Chiefs should make it a point to work the machines when possible. This might mean delegating some other duty such as running for mail in order to have the time to be on the machine. Or the crew chief could keep theircrew informed of what it is they are doing beside working the machine.)

-Mail processors don't know the full duties of the crew chief. This could possible be an explanation to the resentment found in the "not working the machine" complaint.

-Staffing has been, and continues to be a problem.

-Frustration over management not acting on suggestions or even giving feedback as to why a suggestion was not implemented.

-Mail processors receiving conflicting instructions (supervisor not working through crew chief).

-Mail Processors seem to feel shut out of the program. Many mail processors didn't want to talk with us. We would suggest finding ways of opening a dialogue with mail processors to get them involved. Solicit their input, questions and suggestions. The program should be more for them then anyone else.

In addition, we have taken suggestions on the following issues which are more our responsibility than the local committee's.

-Develop a total training program that includes mail processors and supervisors.

-There were numerous discussions about the selection process, with no real consensus as to which method would be the best. We understand the importance of having a selection process with integrity.

- Have a method of assessing the crew chief after placement.

-Clear up some of the vagueness in the job description. 
II is our understanding that the vacant tour 3 crew chief duty assignment, as well as new "bridge" jobs and tour 1 positions will be posted soon. In response to your request to have members of the National Task Force conduct the training, once you are ready to train the new crew chiefs, let us know, and we will do the training if possible.

Once again thanks for all your hard work and committment to the program. We will be on site again in about three months. If you have any questions or problems in the meantime please let us know.

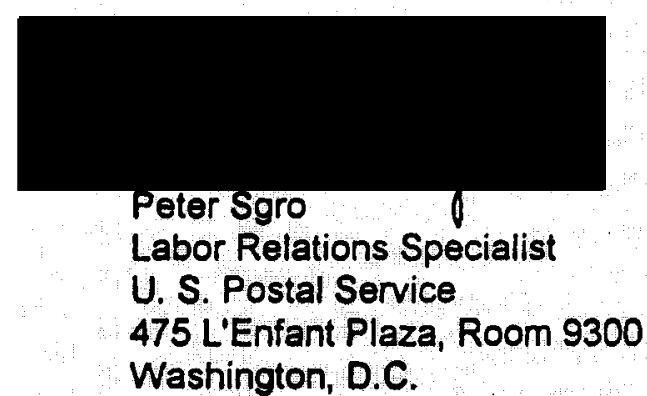

Washington, D.C.

cc: Robert Tunstall

Anthony Vegliante

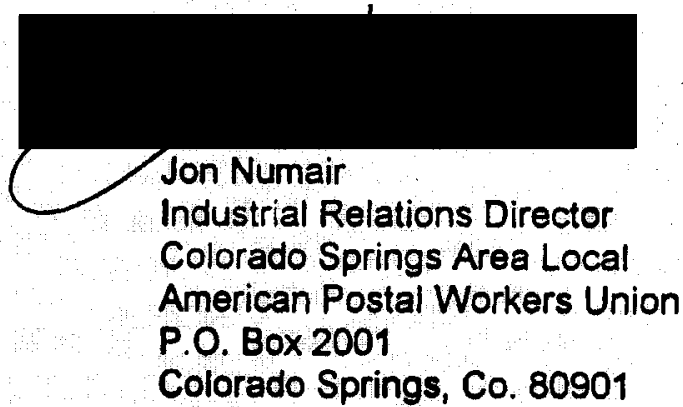

Colorado Springs, Co. 80901 


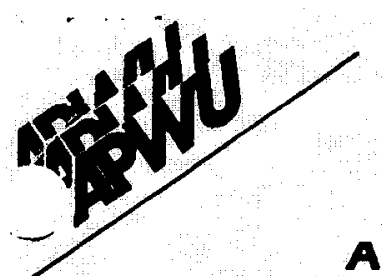

American Postal Workers Union, AFL-CIO

$1300 \mathrm{~L}$ Street, MW, Washington, DC 20005

Ron Nesmith

National Business Agent Moe B111 er, President

Suite 204, French Colonial Bidg. American Postal Workerg Union

2718 south $20 \mathrm{kn}$ stret. 1300 L. Street, N.W.

Birmingham, Ala. 35209 Washington, D.C. 20005

, w

December 6,1993

Notione Excovitive Bame

Mos evile

Willion Rurus

Douglas C. Holbove

Trmaver

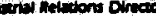

L. Tuncien Onvion

Fnes w uneren

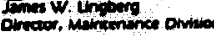

Dervide a nosis.

coorgen N Mexaction

Roglenew cooridnaton

James e willoms

Mhipe C Nomming dt.

Esecem Region

Elusoom zur" rowail

Norrineas encion.

Arctue salesoury

Whatein nowere
Dear Moe,

I conducted follow-up interviews in the Birmingham, AL crew chief test site for automation on all three tours on November 29 and $30,1993$.

Bollowing are my observations and some general comments.

Birmingham used the joint union/management selection system with the un-election procedure. The selection process has been completely taken over by management. Several senior bidders were not chosen based solely on their attendance with no opportunity to explain their attendance. Their 3972 was a disqualifier. When I confronted the union steering comittee person on this, he said they protested but there was nothing they could do because management had them outnumbered 3 to 2 on the committee.

This is an example of the inability of a weak union to maintain integrity in the joint selection process. While it has worked well in Louisville, KY, it is an abysmal failure in Birmingham. It has become a "best qualified" process and as a result the members have lost confidence in the process. Their only input is to un-elect, which they have done.

This serves to demonstrate why foint selection is not a viable option for the APWU if this pilot is accepted. We could not ensure fundamental taimess for all members. 
Moe BIIIer

December 6, 1993

Page Two

This follow-up has also demonstrated the need to better prepare the mail processors for the program. The crew chiefs and some supervisors seem to genuinely like the program. The majority of mail processors are ambivalent at best. While only a few were openly hostile, few were enthusiastic either. Even the ones who dislike the program prefer crew chiefs to supervisors when asked that pointed question.

I believe this site has settled down since the last visit. I credit the un-election which took place in August with giving some integrity to what is viewed as a best qualified selection procedure.

We must do a better job training the crew chiefs and the mail processors but I remain convinced of the value of the program. I believe it has the added potential of eliminating the 204-B program. It is being discontinued in this office early next year. I believe this pilot deserves some of the credit for that.

If you have questions, feel free to call.

Yours in Solidarity,

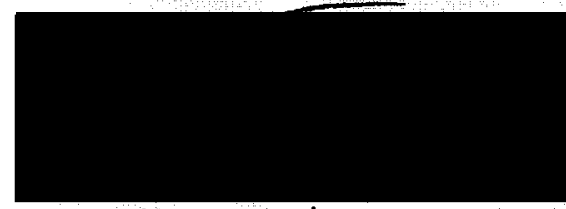

Mike Morris

National Business Agent

American Postal Workers Union

$\mathrm{MFM} / \mathrm{bal}$

opieu\#2

afl-cio

cc: B. TunstalI

J. Numair 


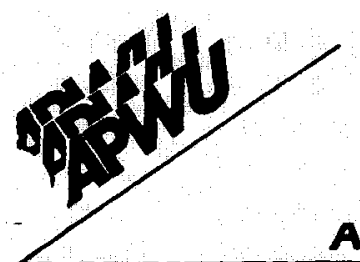

American Postal Workers Union, AFL-CIO

$1300 \mathrm{~L}$ stree NW, Washingion oC 20005

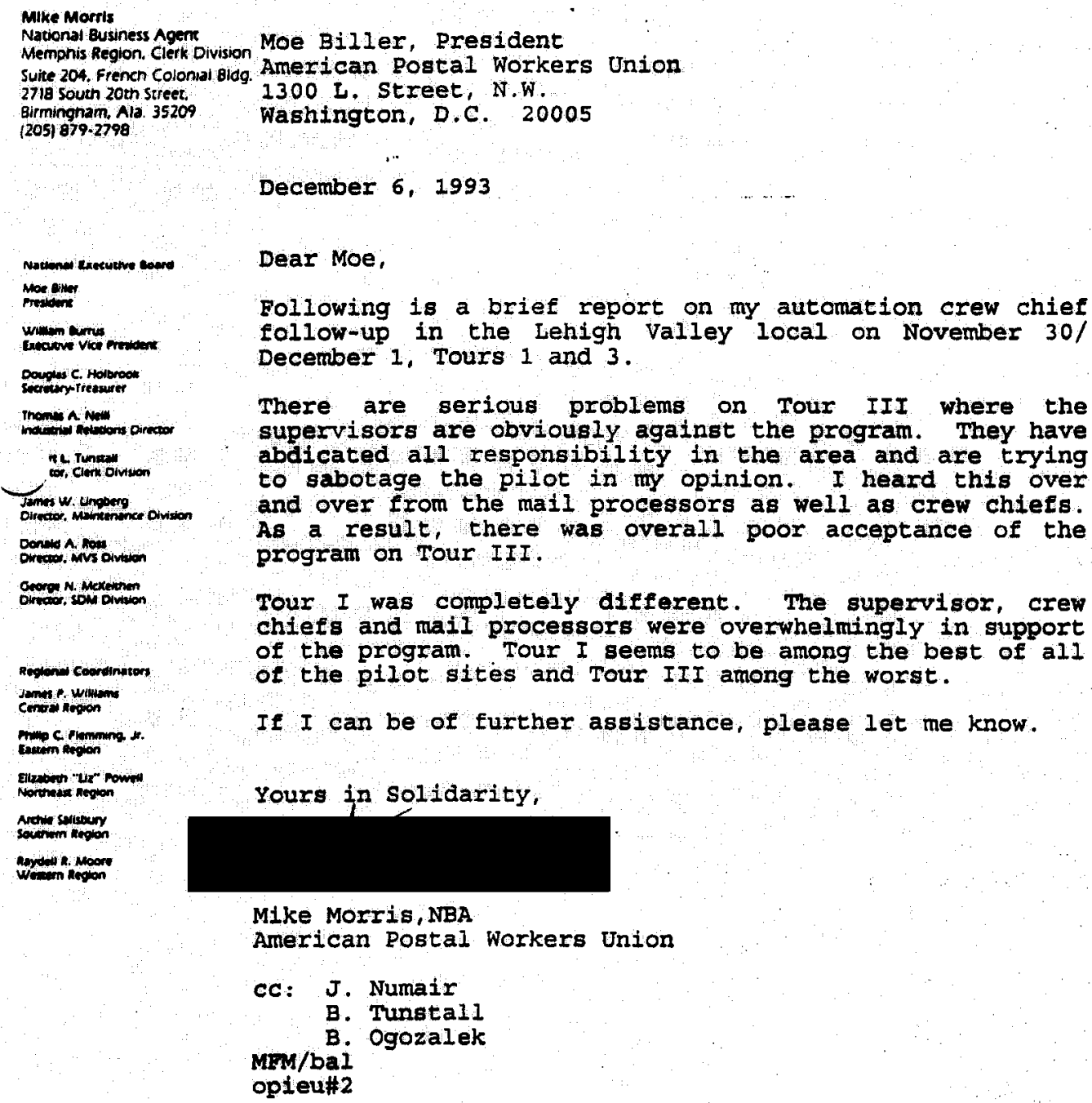

Tour I was completely different. The supervisor, crew chiefs and mail processors were overwhelmingly in support of the program. Tour I seems to be among the best of all of the pilot sites and Tour III among the worst.

If I can be of further assistance, please let me know.

Yours in Solidarity,

Mike Morris, NBA

American Postal Workers Union

cc: J. Numair

B. Tunstall

MEM/bal

B. Ogozalek

opieu\#2 


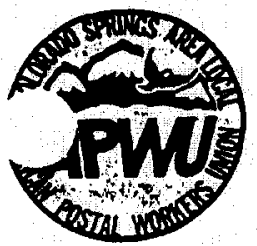

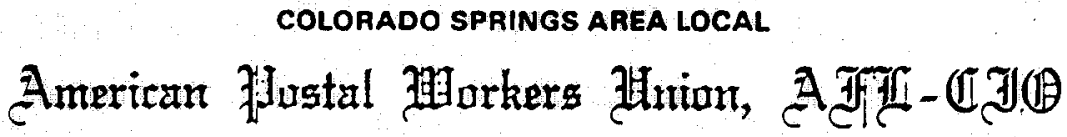

P.O. BOX 2001 - COLORADO SPAINGS. COLORADO 80901

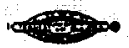

December 29, 1993

Rochester N.Y. Automation Crew Chief Local Steering Committee

Please accept this as the report of our follow-up visit to Rochester on December 6, 1993.

Due to time restraints we regret we did not have an opportunity to talk with your committee, as a whole, upon completion of our follow-up. However, we did talk with most of you individually. We appreciate the time you have spent working to ensure a good test, as well as your input and concern regarding the project.

We also appreciate the openness of those interviewed in discussing the benefits and problems with the program.

Briefly, we made the following general observations during our discussions with mail processors, crew chiefs, and supervisors.

-Due to staffing problems many people felt the test had a very shaky start.

-Crew chiefs were noted to be assisting mail processors by keeping them supplied with mail, and keeping the machines running. We were told they know the operations better than a supervisor, which helps.

- Mail processors expressed frustration over understanding the role differences between mail processors, crew chiefs, and supervisors.

-When the crew chief helps out with the core duties of feeding and sweeping the machine, mail processors view the job positively. When the crew chief is predominantly engaged in other duties they view it negatively.

-With the introduction of crew chiefs, mail processors felt oversupervised. Supervisors maintain a floor presence, sometimes undermining the crew chief. Mail processors now see twice as many people giving them instructions. 
-Pay was viewed as inadequate.

Some of the issues raised in our interviews are common to all the test sites and will be addressed by the National Task Force.

We feel the following suggestions might help you address some of those things you can work on locally.

- Have your Local Steering Committee communicate the role of the crew chief to mail processors and answer questions they might have regarding the distinction between supervisor and crew chief.

- Encourage crew chiefs to spend time feeding and sweeping the machines. Delegate allied work, when possible, to members of the crew.

- Encourage dialogue between crew chiefs, and between crew chiefs and crew members, particularly over problems that have surfaced. Allow the time to talk them through.

- Give guidance to supervisors regarding their changed role. They should be managing the operation, not supervising around the crew chief.

We will be following up again in approximately three months. Please feel free to contact us for any assistance you may need in the meantime. Once again, thank you for your time and efforts in support of the test program.

Nancy Laic

Customer Sorvice Support Programs Analyst

U.S. Postal Service

475 L'Enfant Plaza, Room 4347-E

Washington, D.C. 20260

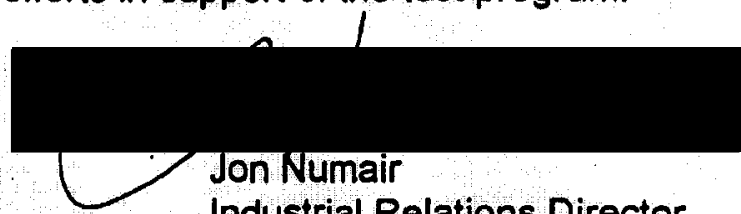

Industrial Relations Director

Colorado Springs Area Local

American Postal Workers Union

P.O. Box 2001

Colorado Springs, Co. 80901

cc: Robert Tunstall

Anthony Vegliante 


\section{Appendix C. Interview Form and Transcripts}

$\overline{\text { CITY }} \overline{\text { TIME }} \overline{\text { DATE }} \overline{\text { NAME }} \overline{\text { WSU INTERVIEWER }}$
SEMI-STRUCTURED INTERVIEW FOR THE CREW CHIEF PROJECT

1. What are your positions in the USPS (and APWU)? (Title?) Note if person is on local crew chief steering committee.

2. How has the union-management relationship changed since last year?

3. What has changed in automation because of the crew chief program?

4. Is the crew chief program functioning the way you thought it would?

5. What do you think has hindered effective implementation of the crew chief program in this site? (General question first, then probe for specific answers)

6. What would you say is the best thing about the crew ehief project? The worst thing?

7. Do you think the crew chiefs in your facllity were adequately trained to perform their new function, both technically and interpersonally?

8. Overall, what proportlon of the current crew chiefs do you think are competent to perform the orew chief job? (Probe for differences between effective and ineffective crew chiefs).

9. Do the crew chiefs in your facility spend time on the machines? (open-ended Eirst, then probe, HOW MUCH AND FOR WHAT REASONS?)

PROBE Do they spend an appropriate amount of time on the machines? (too much/too little)

10. For each meeting below, find out frequency, formalness, purpose, and what is discussed/accomplished?

A. Do the crew chiefs have meetings among themselves?

B. Do the crew chiefs have meetings with the supervisors?

C. Do the crew chiefs meet with the local steering committee?

D. Do the crew chiefs have meetings with their crew members?

E. Are their any other meetings in relation to the crew chief program?

11 Are chiefs assigned to a regular crew or do they have different crew members each day? (RROBE, HOW SHOULD THEY BE ORGANIZED?)

12. Do the same people work together regularly in the oCR/BCS/DBCS unit? All three tours? Describe how they are organized.

13. How are crew chiefs organized to cover the 7 day a week operation? (Probe, how has that worked out?; what would you recommend?)

14. If the crew chief program is made permanent, what changes would you suggest?

15. On a 10-point scale (with 10 being extremely supportive), how supportive of the crew chief project are you:

A. As it currently exists?; B. As it could function ideally? 
SEMI-STRUCTURED INTERVIEW FOR THE CREW CHIEF PROJECT CITY: BIRMINGHAM

\begin{abstract}
1. What are your positions in the OSPS (and APWO)? (TItle?) Note if person is on local crew chlef steering committee.

Union was president, steward and clerk craft director.
committee members and one selection committee member.
\end{abstract}

Management consisted of a plant manager and two MDOs. All three were local steering comittee members.

\title{
2. How has the union-management relationship changed since last year?
}

U1: Has changed; more cooperative relations. Ex: Employee suggests things and management agrees. More employee's needs are addressed. Why? Trying to raise moral nationwide. In terms of the grievance procedure, there is less arbitration at lowest level; mgt will sit and talk rather than argue.

U2: On this tour not a great deal; is positive and has stayed positive. If problem occurs, I can talk to supervisors and work things out. Tour 3 is chaotic; union and management don't work well together. (Yet U2 is not on that tour.)

U3: No big change, operations same as last year. CCs not given full job responsibilities as it was set up; CCs are there, but management is still in tact as if they're not there, therefore, no change. Supervisor percentage hasn't changed - still the same supervisor - too much authority with CCs and supervisors.

M1: Relationship has changed with union president. The leadership atmosphere has changed; problems can be worked out together and things can get solved. There is a better attitude toward getting things solved.

M2: The relationship is more professional now. There were many changes in leadership in APWU and we had to start from scratch at start of the pilot test. Union leadership was different (turnover with APWU occurred approx. mid Apri1, 1993). Relations improved due to change in leadership.

M3: The relationship has improved. Until last year, an adversarial relationship existed due to union president turnover. Over the last year or so, there is more stable union leadership. Restructuring probably improved things, as it eliminated some layers.

\section{What has changed in automation because of the crew chlef program?}

U1: Employees have better feel for what they are doing (the work itself). Communication is better; the employees can express themselves about their work. With the CC being a bargaining unit employee, the communication and 
employee moral is better.

U2: Saw this as another tier of management and that was expressed to the union. I think it is working, as expeditor things can get confused.

U3: The number of people, i.e. - had 5 people and made one a $\mathrm{CC}$, but never replaced that person - the amount of work stayed the same, but now have fewer people. Added more machines, more holdouts on machines, but people don't have help - didn't add personnel to match machines or makeup for one person they lost.

M1: A little more cooperation among mail processors. CC helps get a little more mail out of facility. (Insuring labeling, getting out dispatches.)

M2: Added a lot of equipment. Managed to avoid adding supervisor positions. Didn't remove any, but didn't add any. For example, run 14 pieces with only 2 supervisors per tour. Couldn't do that without cCs.

M3: On Tour 1, there has been more input by $\mathrm{CCs}$ and other employees re: operating procedures, problem identification and correction. Also, greater involvement by employees and increased teamwork.

4. Is the crew chief program functioning the way you thought it would?

U1: On $\mathrm{T} 1$ and $\mathrm{T} 3$ yes, $\mathrm{T} 2 \mathrm{I}$ am disappointed. (Management is less cooperative as well as mall processors and CCs - personality clashes between $\mathrm{CC}$ and supervisors. Deselection process got rid of the problem. T2 did not understand the program.

Employees comments on the internal survey were negative:

a) The T2 wanted $\mathrm{T} 2$ employees as CC

b) Days off were a problem.

c) Selection committee process was a problem for T2 employees.

U2: Yes, pretty much. When CC came on line I thought supervisors would be done away with. Supervisors were still in tact and it was confusing and frustrating.

U3: No. Thought $C C$ would act as an extension of supervisor; maybe one CC under supervisor, and supervisor would direct CC and $C C$ would see that the work would get done - thought would make management presence/role less, BUT still have same number of managers in program. Don't trust people to get mail out - say we know you can do it, but we' re not going to let you alone - the "cover your butt" attitude. Supervisors don't necessarily want program to work (some people think this); supervisors undermining the program.

M1: Yes and No. Yes; assisting as program was intended in terms of helping get the mail out (cooperative crew chiefs). No; some complications with some CCs. Some CCs think they should do all of supervisor's job. They should do everything on their own and do more than is required with supervisors. 
M2: Pretty much. We have settled into a consistent program. There were many inconsistencies between the three tours at start, now there are not as many. So much happened in the USPS in '93, tt's hard to tell what changes are due to. Now pretty accepted here. The deselection process has been a strong 1ssue There were 4 of $14 \mathrm{CCs}$ deselected and 10 reselected. The votes re: deselection and reselection are positive especially regarding reselection. The system is functioning pretty much as expected.

M3: Functions better on this tour; for example, here have generally same staffing rat to as before, but now CCs $f i l l$ in when have supervisors are out unexpectedly. (CCs fill in the gaps.) Initially there were problems re: relations between craft employees; some jealousies, but we don't see much of that now. Some MPs thought that CCs were doing supervisors jobs and they resented the perception of supervisors by a CC.

5. What do you think has hindered effective implementation of the crew chlef program in this alte? (General question firat, then probe for apecific answers)

U1: Yes, management not willing to pull 204B off shift (mgt trainees) out of operation/project. (204Bs need to be pulled off the operation - 204Bs and CCs are redundant and their functions clash). 204B felt threatened and wanted to destroy.

$204 \mathrm{~B}$ was another level of management and CC couldn't function with $204 \mathrm{~B}$.

U2: At start mgt saw this program as a threat and mgt didn't want it to work and it was undermined (Tour 3). Tour 1 had minimal problems - all CCs were reselected (reelected).

U3: Re: Selection - mgt went by attendance 95\% of the time - not a good criterion - should have gone by knowledge, skill - so they didn't get the best person available

M1: The biggest thing is (but shouldn't have been) that some shop stewards thought that there were misgivings as to what CC should be doing. (Ex: one thought that $C C$ should replace supervisor and said that supervisors weren't needed. Some confusion as to job descriptions and what the duties are for both stewards and mgt)

M2: Locally there are hindrances. For example, there wasn't enough time spent educating MPs at the beginning to make people understand all details. During deselection, tried to fix this problem by reinforming. Things have stabilized since voting.

Also, turnover in APWU leadership det back the steering committee for a while, resulting in no effective steering committee. (This turnover in APWU occurred somewhere around April 1993.)

(They conducted a survey around $8 / 93$ re: employee perceptions about CCs. Found that employees thought $\mathrm{CCs}$ are just another form of supervision because MPs didn't understand what CCs were supposed to do. Thought "just added another layer of management" but this was most obvious on Tour 2 - the only tour where $2 \mathrm{CCs}$ were deselected. (that weren't originally on that tour). He thinks it was all political.) 
M3. It's very effective at this site. But, there are problems regarding the selection process - rules changed every time we do it. People go into process without knowing what rules are. On this tour, there is one long term vacant position; if we could fill it maybe we would be stronger.

6. What would you ay is the best thing about the crew chief profect? The warst thing?

BEST

U1: BEST - Given employees something to do other than move mail; they can use their mind; $C C$ can use brain and employees can now express themselves.

U2: - Turn it loose and let it go." People would like it well.

U3: - Cooperation between employees is much better; less disagreement between employees; better teamwork; now they don't have hanging over them that must report to boss.

M1 : BEST - Mail processors direct each other, they are thus more comfortable with task, yet one or two don't like taking orders. Motivation of employee comes from within rather than from supervisor.

M2: existed before. We have discovered very talented people; before there was no outlet for discovery. The project has built teamwork on all 3 tours. The discovery and development of talent has occurred - development is key here.

M3 : Dor - On Tour 1 it has brought out employee commitment, especially in CCs, but also potential future CCs; people just jump right in now without having to be told. It also brought out initiative in MPs - close to where could function as self-managed unit.

WorSF

U1: $204 \mathrm{~B}$ and $\mathrm{CC}$ resemble each other. (CC give instructions and employees see that they are mgt and switches - Mgt has created this impression.)

U2: WORST - Some 204Bs will try to do both CC and 204B job when CC is slck or not there. Some not satisfied; CC taking away annual leave opportunity. But this is just their perception not reality.

U3: WORST - Supervisor talking to employees and telling them that the program won't work - talk against CCs if supervisor doesn't like it - supervisor try to get people to deselect CCs.

M1: WORST - Miscommunication between CC and supervisors. (Ex: sometimes CC feels like things should go consistently day by day but supervisors know that changes occur via mail flow, i.e. supervisors and CCs see a different picture.)

M2 : WorsI - We still have problems from early lack of education of MPs; still have those misconception problems. Would have seen it accepted better and a lot more quickly probably if there was early education. Would have had no deselection if had early education. Also there is a lack of good, clear information regarding the program up front. 
M3: Can't think of a worst thing; no major negatives re: the project.

7. Do you think the crew chlefs in your facility were adequately trained to perform their new function, both technically and interpersonally (IP)?

U1: YES, in both areas. Yet on T2, the two CCs that were unselected would have been successful on another tour. Employees did not like the CCs.

U2: Yes; there was training for a week. (Didn't see training program.) some personality conflicts. Some unselected CCs were not liked because they were not from the day tour.

U3: Technically, yes, But IP, no. There was no instruction given on how to approach people, how to get cooperation, how to motivate people.

M1: Some had interpersonal problems in dealing with people. In the first selection we didn't dig in enough to adequately evaluate CCs. (No interviews) This selection we did interview. More hands on experience given this time. More clear layout of CC program, staffing, scheduling, procedures related to that.

M2: Technically, yes. IP - no. The initial theory was that training looked good, but we lost 2 people on tour 3, not because of technical problems, but because couldn't relate to employees. The initial selection process gave no indication regarding interpersonal skills. Recommends more emphas is on IP initially, with extra regularly scheduled training for IP skills once a month, with different topics, i.e. - nonverbal communication, cooperation.

M3: On Tour 1 - both technically and interpersonally it appears adequate, given their performance, but he didn't sit through training and doubts that training provided knowledge, they probably get that more so from experience and hands on activity. Interpersonally - Haven't performed any worse than supervisors, even better than some - can't really say if adequate because he didn't go to it - he thinks this is a more personal thing (ability) than a training one.

8. Overall, what proportion of the current crew chiefs do you think are competent to perform the crew chlef Job? (Probe for diffexences between effective and ineffective crow chiefs).

U1: ALI. In estimation:

Ineffective - poor communication. Not performing functions of CC.

Effective - Must communicate.

Effectiveness is strongly related to communication and the CC communication. Respect of employees is needed prior to assignment.

U2: All of them. Reviewed them well before selection.

Ineffective - Personality conflicts and it inhibits performance because of the friction, personality conflicts. 
Effective - know the mail flow and be able to coordinate with the expeditor.

U3: Approx. $90 \%$

Effective - IP relationship with fellow co-workers; how fellow co-workers perceive them; is person a good CC/mgr (more than just technical skills)

Ineffective - Person didn't have a high position, so wanted to get into higher level without doing the work; motivation is to do less work and to get higher up, and not for the job itself.

M1: All are capable. Basic factor is interpersonal skills in dealing with other people. Give better direction and promote more loyalty.

M2. All of them are capable so far, haven't had any who weren't. Some MPs have had perception problems, but actually CCs were competent. Ineffective poor communicating; ability to work with others. Effective - can motivate; deal with guestions and concerns; win support of MPs, teamwork. IP skills is the key discriminator - now, they interview CC candidates.

M3: On Tour 1 - 100\%. There's no one most effective CC; they're all really good.

Ineffective - attitude not as positive as all of the other CCs, but its hard to keep positive attitude when there are so many sudden changes without any input.

9. Do the crew chiefs in your faclilty spend time on the machines? (openended first, then probe, HOW MUCH AND FOR WHAT REASONS?)

Ul: Yes, breaks, lunch relief, sick relief, heavy mail days:

9A PROBE Do they spend an appropriate amount of time on the machines? (too much/too little)

UI Is appropriate. Not used as a "flip-flop" person. CC was a rotating relief person and couldn't perform CC duties.

U2: Yes, Breaks and fill-in; help with overflow.

PROBE Do they spend an appropriate amount of time on the machines? (too much/too little)

U3: YES - breaks; lunches; people shortages; heavy volume.

Suggestion: Could alleviate problem by bringing casuals, TEs with flexible schedules - could do this easily and not necessarily use overtime - would allow CC to do his job - they don't use this option, but they should.

PROBI DO they spend an approprlate amount of time on the machines? (too much/too little) 
TOO MUCH (see above comment and suggestion)

MI: Yes, during breaks and on light days the mall processors are taken off machines to let CCs operate machines so that I can avoid overtime. Also, CC will serve to help during light volume (on machine) but go back to CC when volume is heavy.

PROBE Do they spend an approprlate amount of time on the machinea? (too much/too jittle)

Yes, appropriate.

M2: Yes - breaks, lunches, or when there aren't a lot of CC - type

issues/problems and they have the time, high mail volume (Tour 1 and 2 are both short of help/have a lot of vacant positions. Not having CCs help has been a big MP issue they want to see them working/helping.

PROBS Do they spend an appropriate amount of time on the machines? (too much/too little)

Haven't heard any concerns raised recently, so it appears that an appropriate amount of time is spent on machines. He has no observations or feedback that says they' re not. (He did have this type of feedback in the past, but not now)

M3 : Yes, breaks, Iunches and other shortages but not for heavy volume.

PROBE Do they spend an appropriate amount of time on the machines? (too much/too little)

About right amount of time. If required to spend more time, they wouldn't be as effective, but should spend some time. He thinks this is where Tour 2 has an advantage, other tours may require CCs to spend more time on machines, therefore, prevented from reaching full effective potential.

10. For each meeting below, find out frequency, formalness, purpose, and what is discussed/accomplished?

\section{A. Do the crew chlef: have meetings among themselves?}

U1: No.

U2:

U3: No.

MI: No

M2: Nothing formal to his knowledge. Maybe on Tour 1 they get together nightly to coordinate the use of resources and to make sure they work well together in terms of the workload.

M3: Have had some, but not routinely/regularly.

B. Do the crew chlefs have meetings with the supervisors?

01: Yes, every day before shift to lay out plans for the day (Informal). Also as needed throughout the day.

02:

03: He's asked that it take place, so once it did, because had 
misunderstandings and unhappy supervisor. The meeting was with tour superintendent and CCs to work out the problem and to clearly define for them and supervisor what they should do to deal with problens between $\mathrm{CCs}$ and supervisor (occurred approximately two weeks ago)

M1. Meet with them on a regular basis. They meet day-to-day three times a week and then as needed.

M2: Not formally. Each automation supervisor relies on CC for information so probably informaliy there's much interaction.

M3: Supervisors have meetings with all MPs (including CCs). Supervisors act informally with CCs, but don't meet informally/regularly. He feels like if you talk to your staff every day, informally, then you don't need a formal meeting.

C. Do the crow chlefs meet with the local steering committee?

DI, No, no need.

ర2:

03: No.

M1: No, not during my period. Each tour supervisor and mo met with their own CCs.

M2: No, except at voting sessions (once).

M3: No.

D. Do the crew chlefs have neetings with thelr crew nembers?

01, No, as needed on tour.

02 .

03: No, but they should - need to have service meetings - used to have them for employees and their respective supervisors - need meetings between CCs and employees just like these to discuss quality, customer service and generally how to do the job better.

MI: They did, I think, they should have to get ideas and talk about things.

M2. Not sure. Possibly on Tour 1, but each Tour is different.

M3, Yes, informally, as needed to discuss work.

1. Are their any other meetings in relation to the crew chlef program?

01: Safety meeting - supervisor gives this.

02,

03. No.

M1:

M2: Initially, had meetings on each tour, but since voting, have discussed follow-ups, but steering committee hasn't done it yet.

43: The local steering committee met on very a infrequent basis (last one approx. 4 months agol, initially to discuss guidelines for selection. Not very successful. Selection committees have met to select cCs (first for the initial selections, once later for replacement selections.)

11. Are chlefs assigned to a regular crew or do they have different crew

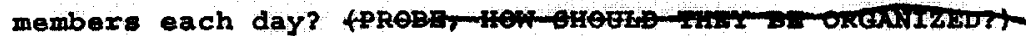

U1: Day-to-day assignment. T1 and T2 assign CCs to a machine and people who work machines will rotate on machines. May hamper the $\mathrm{CC}$ in not letting a rapport build between CC and employees (May have been a problem with unselected CC) But she thinks otherwise. 
U2:

U3: Rotate crews weekly. CCs are assigned to machines. Will rotate machines with people, therefore, CCs get to work with different people.

Suggestion - They should let CCs stay with one specific crew - espectally if the crew works well together. Don't rotate crews.

\section{M1: Rotate}

M2: Different crew members each day. MPs assigned to equipment, and they rotate machines, and CCs stay put. This isn't the same for each tour. The big issue regards organization. He thinks that if there were stable groups (same MPs with $1 \mathrm{CC}$ ), then they could overcome perception problems. But, he also realizes that this limits the ability to determine how effective $C C$ really is, because $C C$ wouldn't have to deal with everything and everyone, but instead with only 1 group. If didn't rotate, then the program would appear to be successful, but wouldn't be able to develop potential.

M3: On Tour 1 there is a regular crew. The entire crew rotates machines two times a week (used to be only once a week but recently changed). They recently changed the makeup of teams as well to provide regular staffing (There were staffing irregularities e.g. days off) Now it is more evenly spread in terms of of days This seems to be working.

12. Do the same people work togethex regularly in the ocR/BCs/DBCs unit? all three tours? Describe how they are organized.

U1: Rotate either weekly or per night. Employee works with same person on a week or just a day. But rotation is oriented on the machines rather than the people. Reason - some machines have less desirable work and no one gets stuck on one machine.

U2:

U3: Yes on all three tours. Rotation.

M1: Rotate

M2: Yes, they pretty much stay together on all 3 tours. People work with people they are familiar with.

M3: On Tour 1, yes. They are organized into four teams, each with the same $C C$ all the time - don't rotate CCs.

13. How are crew chiefs organized to cover the 7 day a week operation? fPxobe, how has that worked out?, what- would you recowmentst

V1: Relief on Tour 1 and 3; each day has a CC and one is there for a sick CC. $T 3$ and TI have two reliefs (Never a time with no CCs.) T2 has 2 CCs and no rellefs. (Absence of $\mathrm{CC}$ is scheduledon low volume days.) 
U2:

U3: Tour 3 - have relief CC to take place of CC who's off - works out well keep it.

M1: Rotate

M2: Have 2 (per Tour 1 and Tour 3 each) relief positions that cover days off. On all 3 tours, on lower volume days, operate with fewer $\mathrm{CCs}$. On Tour 2, have only $2 \mathrm{CCs}$ so there are times when there are no CCs on, but this coincides with low mail volume.

M3: Supposed to be set up so there is full coverage on weekdays and half coverage on weekends, but it's not perfect because there's only one vacancy. There's always one CC on. This works out well.

14. If the crew chtef program is made permanent, what changes would you suggest?

U1: a) Senfority for CC selection

b) Al1 204Bs be removed from operation

Don't change Deselection process, process must be kept. Can stick employees with a CC.

U2: Select CC by seniority. Look at sick leave and seniority generally and interview and then choose.

U3 : Find a better way of selecting CC. The process should be more standardized and not based only on attendance - experience in service should be considered.

M1: Clear and precise job descriptions, and everyone is made aware of what they are.

M2: 1. Make sure is a "Best Qualified" applicant process, Including

interview, to identify IP skills as a key factor to success

2. More training for IP skilis once selected

3. Don't retain voting aspect

4. Need formal means of feedback from crew members, but not for deselecting only for developmental not administrative purposes.

M3: There needs to be better criteria for the selection process, such as seniortty, best qualified, attendance. (Need clear statement of criteria,)

15. On a 10-point scale (with 10 belng extremely gupportive), how supportive of the crew chief project are you: 
A. As it currently exists?; B. As it could function idealiy?
U1: $A$ : 10
B: 10
U2: $A$ : 9
B: 10
U3: A: 7
B: 10
M1: A: $7-8$
B : 10
M2: A: 8
B: 10
M3: A: $9-10$
B: 10

U3: General suggestion: Should reinstate service meetings between CC and crew (like they used to have with employees and supervisors) 


\section{SEMI-STRUCTURED INTERVIEW FOR THE CREW CHIEF PROJECT CITY: LEHIGH VALLEY}

1. What are your positions in the U8P8 (and APWA)? (ritle?) Note if person is on local orew ohief steering committee.

Union consisted of 3 steering committee members, a former clerk craft director, an Industrial Relations Director, a former union president, a former local union executive committee member:

Management consisted of three MDOs, three steering committee members, a former Tour superintendent, and a plant manager.

2. How has the union-management relationship changed since last year?

U1: The reorganization changed local management, it changed the players, took away people that we used to get along with well.

U2: No change

U3: I think it has improved, it is not as adversarial, we have enlightened union representation. Management is more cooperative with workers, the new MDO on tour 3 has improved relations there.

M1: I think so. I think it is more relaxed, union is able to come to the managers now. The reorganization changed things a lot, and improved it.

M2: For tour 3, not much, we never had an adversarial relationship since I became $\mathrm{MDO}$.

M3: I think it has improved. We have low grievance activity. Very low number of level 3 grievances. We don't have tracking for grievance in automation. We have technology changes, mail mix changes and other things.

M4: No.

\section{What has changed in automation because of the crew oblef program?}

U1: CC program arrived when staffing went down. Don't know that there have been major changes. Tour 2 has had the biggest change (the supervisors are not around much.) CC on Tour 1 runs the Tour. Tour 3 is a hands-on operation, with supervisor running the show. CCs are glorified workers.

U2: Tour 1 has no supervisor. (They do not show up on the floor, but are there.) The cCs handle everything. CC runs 
for the mail, not much time on the machines. Tour 3 oK as much. Supervisor works with $\mathrm{CC}$ well. CCs did not have any hands-on experience dealing with people. Tour $2 \mathrm{CCs}$ don't work on the machines, often sit around at the desk.

U3: Based on interviews with MP, I don't really know. We are getting new, more senior person as MP. This may affect things.

M1: Good, allow supervisor freedom to do administrative work and cover more areas. I see some resentment between supervisors and $\mathrm{CC}$ and between $\mathrm{CC}$ and crew members. The crew members think $C C$ is not a team member.

M2: Supervisor lost a little bit of control, energy and interest. They don't have hands-on control. cc torn between having to direct people and being a buddy. Discipline has suffered as well as overall work habits. It is harder for supervisor, they have $C C$ as another. We have more problems now, employees report late, take longer breaks, are more lax now.

M3: The week of training for $C C$ was a very positive experience for the CC. I wish we could have done that for everybody. I touch base with president and director of clerk craft and other steering committee members. It is bound to have an impact on our quality. It is an expensive program. Under the guidelines, CCs are supposed to work a maximum of 20 percent on the machines and the rest of the time as a cc. Pieces of mail processed per hour has declined.

M4: We got cut supervisors, that has helped the program. I have had more flexibility in the staffing of supervisors. I have cut from 3 supervisors to one in automation. It has helped in terms of planning, we can institute things like the DBCSs easily now. They are gung-ho, they know what they are doing.

\section{Is the crew chief program functioning the way you thought it would?}

U1: I have mixed opinions of it. National union in training gave us one view, after national union left management tried to get in the cracks. Training might have been better with national people. Tour 1 MDo is the most in favor of CC program. He is most supportive of the program.

U2: Yes. I thought it was to replace supervisors, and that is what has happened.

U3: Tour 1 is a model, Tour 3 not so good. cCs are not comfortable in their roles. Tour 3 has many non-members. 
M1: It is not going as well as I thought it would. I see CC standing off, not part of team, causes resentment with MP.

M2: Yes, the way I thought it would. Our operation on Tour 3 was ok before, thus there were not major changes. On other Tours there may have been changes.

M3: In an overall sense, it has. I had no preconceptions. I was concerned about the strict adherence about how much ccs work on the machines. I think informally it has worked here about the amount of time spent on the machines. We are very open here and that has helped.

\section{M4: Yes.}

5. What do you think has hindered effective implomentation (or more effective implementation) of the crew ohief progran in this site?

U1: I think it is how employees think of it. Our new PTFs view it differently. They don not know much about it. Tour 1 went well except for PTF problem. Tour 3 has a lot of non-members. I am not sure what we have been doing as a steering committee. The steering committee could have been more involved. We have not evaluated the program as frequently as we could have. The union members on the committee were too involved with other activities.

U2: Lack of participation by the local union.. If we were more involved, we could have handled the issues better.

U3: Rank and file cooperation. Management and supervisor may have supported it. Rank and file have not supported it. We were a little lax in getting guidance to cc from steering committee.

M1: Probably the employees we actually have as ccs. I think they became CCs for the wrong reasons, to get out of work.

M2: The selection method of CC. You have people who want a higher level, we don't have right people in the $\mathrm{CC}$ position. Tour 3 had no $204 \mathrm{Bs}$, it has hindered the program. They had no experience. Some don't know what to do.

M3: I suppose that if I and the others had spent more time on it, it would have been better. Nobody is disappointed about it. It works well because we have had the opportunity to adapt the program to local conditions. It is essential to be able to have local options, to have the program not be a rigid nationwide program with no local flexibility.

M4: Attitudes. The biggest thing is trust. Employees are sure they will be empowered. The majority of employees have 
accepted the program. One employee has not and is fighting the program.

6. What would you say 18 the best thing about the orow chief project $?$ The woret thing?

\section{BE8T \&}

U1: Crew members like taking instructions from crew chiefs, at least on Tour 1 and 2 , where bosses aren't around.

U2: Elimination of supervisor. We don't hear any harassment or favoritism complaints. CCs are handling things better. They pull crew members off and coordinate more.

U3: Getting rank and file involved in decision making process.

M1: It makes it easier for supervisors now because of the reorganization and the lower amount of staffing.

M2: I have been freed up on supervision. I have more flexibility with management personnel. It has not improved the operation, it has only affected my management flexibility.

M3: The training that the cC got along with union support for the program. The union got support and credit for the program. our union believes that they were prime movers in getting it here. They take credit for the jointness.

44: I have good people. I don't have to worry about it.

\section{nOR8T:}

U1: Biggest complaint is that CC think they are bosses, think Iike bosses. On Tour 1 and 2 CC works the machine only 30 minutes a night; this is not enough.

U2: CCs don't work on the machines. The way they behave suggests that some are just a 204B. Tour 1 CC does too much with mail, but not on machines.

U3: It has not lived up to the expectation that we had hoped. On Tour 3, they are not involved in the decision making process. CC could have been involved in delegating things to the members.

M1: The resentment that it causes.

M2: Lack of discipline in unit. Wrong people in cc position are not on top of it. Supervisor has to get involved to get things done. 
M3: The tendency of the USPS and the union to bypass the supervisors. Supervisors feel that it takes jobs from them. The supervisors got the attitudes that they were bypassed.

M4: Communications. The biggest problem is between 4 and 6 a.m. in terms of dispatching mail. CCs get too focused on task and don't tell next person.

7. Do you think the crew chiefs in your faollity were adequately trained to perform their new function, both technicaliy and interpersonally? (IP)?

U1: I wasn't there for all of it, I belleve they were properly trained except for reservations I expressed above. supervisor should be in the training program throughout.

U2: Tour 1 had 204B experience; it is OK. Tour 3 , no. on all Tours reliefs probably didn't get enough hands-on training. IP, training was weak. The CCs are more knowledgeable about operations than supervisors.

03: Yes, training was excellent. In Tour 3 , the supervisors spent quality time with the $c c$ ib helping them. It is difficult to see someone who worked with you work in a different capacity.

\section{M1: Yes.}

M2: Tour 3, no. Training sessions for people with no management experience. None ever had managerial experience. No $204 \mathrm{~B}$ experience on other Tours. $204 \mathrm{Bs}$ helped out on the other Tours. Technically, training was oR. Technical stuff is easy.

M3: They received technical training and 1 1/2 days on group human relations training. What they got was very positive, but not sure if it was adequate. We took people with no background in this, and now have them do it." Some CCs may feel uncomfortable about it.

M4: Yes. Technically they could have received a little bit more. IP, they have some problems with particular individuals. They are afraid they will not be accepted back in the group when the program is terminated.

8. Overal1, what proportion the current crew chiers do you think are competent to do the job? (Brobe for difference between effective and ineffective crew chiefs.)

U1: Al1 but 4. Less effective ones come off "snippety". They make assignments, not being sensitive to the needs of crew members. 
U2: Eighty percent of ours are. Tour 3 is a little weaker. Tour 1 and 2, 100 percent. Ineffective: lack of communication skilis with MP. CCs on Tour 3 say there is a lack of communication with supervisor and $\mathrm{CC}$. We wanted certain types of people in CC position. We let them have people who had been 204Bs in exchange.

U3: Tour 3 forty percent. The difference in effectiveness is IP skills, being able to handle the position and being able to delegate effectively.

M1: On Tour 2 all three are competent. The CCs did serve as $204 \mathrm{~B}$, it made them more knowledgeable. If they think like a 204B, they won't work on the machines. This is the down side to having been a 204B previously, thinking like a supervisor.

M2: Two out of five. CCs who are effective take control of the operation, concentrate on meeting the objective, have a sense of urgency about getting the mail out.

M3: Not all of them, you should see the union about this. We have had conflict between $\mathrm{CC}$ and mail handlers.

M4: All of them. The most effective ones have a sense of urgency in getting things done.

\section{Do the crew chiefs in your facility spend time on the machines?}

U1: Very little to none. They are there for heavy mail, sweeping the mail.

U2: Some yes and some no. Tour 2, no; Tour 1, yes. On Tour 3 , OK. On Tour 3 it is personality differences, on Tour 2 , we have a supervisor who is negative. He sees his job as being hindered.

U3: Yes. The steering committee spends a lot of time on this issue. The rank and file members felt $\mathrm{CC}$ was abusing the position. Sometimes they actually were abusing it, sometimes they were doing $C C$ functions but the members did not know.

M1: Very little. I have never seen them on the machines. I see them standing at the desk. I never see them doing work. I see on Tour 1 that the CCs have a problem in sending unneeded MPs to other areas.

M2: Yes, time varies depending on situation and/or CC. To just help out. Some might want to help out too much.

M3: It depends on the Tour. Some spend more time, some only for breaks. 
M4: For relief, for breaks, for dispatches.

Probe. Do they spend an appropriate amount of time in the machines? (too much/too littie)

U1: No. They hang out and act like a supervisor. When they have nothing to do, they do not think about helping out with the machines. It is just something they do not think of.

U2: Tour 1, yes. Tour 2, no. Tour 3, OK.

U3: OK.

M1:

M2: Some do, some don't. More often than not, they don't help enough.

M3: I haven't dealt with that. since program is working well, we may be OK on this. I don't get complaints about this.

M4: It is not enough time. They spend too much time retrieving mail that MPs could get.

10. For each meeting below, find out frequenoy, formalness, purpose, and what is discussed/accomplishes?

A. Do crew chiefs have meetings among themselves?

U1: Not normally.

U2: on their own, informally on the floor. We changed schedules to overlap with the next Tour.

U3: Yes, depending on Tour. Tour 1 was very good. More formally, every other month.

M1: Yes, they discuss problems in their area. They overlap with CC from other Tours.

M2: No formal meetings. Between the Tours, they discuss what is going on.

M3: They are supposed to. They have Tour change meetings. Things are now worked out.

M4: Every night they get together before the rour to talk about the game plan. I also wanted them to meet every hour, but they do not.

B. Do the crow chiefs have meetings with the supervisors? 
U1: Some with supervisors and MDO.

U2: Not that I know of.

U3: Yes. Varies by Tour, particularly by Tour 1.

M1: Yes, the supervisor tells them what to do.

M2: They have had formal meetings with supervisor. Probably should have done more of that.

M3: They have had.

M4: They are supposed to, but we haven't had one for a while.

c. Do the crew chiefs meet with the local steering committee?

U1: No.

U2: No.

U3: The local steering committee meets by proxy, resulted in reports that the steering committee put out.

M1: Yes. A committee member goes out on the Tour and issues from particular CCs back to the committee.

M2: Not very often. Twice representatives met with CCs.

M3: No, we have talked about this. With things going well, we haven't implemented this.

M4: They did.

D. Do the crew chiefs have meetings with their crew members? U1: No.

U2: They talk to them on the floor.

U3: Bi-monthly with $C C$ and members, but members did not raise issues. They may have thought that everything got tried out, so it was useless to raise it.

M1: OK

M2: No, The supervisors should include CC in the safety meeting. They probably do not do that.

M3: They aren't calling people off the floor for meetings.

M4: No. 


\section{E. Are there any other meetings in relation to the crew chicf program?}

U1: steering committee.

U2: We set up weekly meetings where one MDO and one union steering committee member would poll MPs weekly. Every other week meet with crew chiefs. These two meetings were set up about a month ago. It has not happened yet. We have not implemented them yet.

U3: We have a mechanism for anyone to get feedback from local steering committee by submitting questions.

M1:

M2: steering committee.

M3: The Tours are autonomous. I don't know.

M4: No.

11. Are chiefs assigned to a regular crew or do they have different crew members each day? (Probe. How should they be organiged?)

U1: They have a rotating crew on Tour 2 . On Tour 3 , jobs are assigned by seniority. I like the idea of a rotating crew, that way they can be with different people, they can avoid being stuck with a crew chief that they do not like.

U2: Tour 1 rotate. Tour 2 rotate, depending. Tour 3, OK.

U3: A very hotly debated issue on each Tour. We left it up to the CCs to decide among themselves. This issue and other issues is where we give them some discretion.

M1: They rotate.

M2: This is a regular crew for the regular full-time cc.

M3: They have some differences due to days off. We are trying to keep them together. Each Tour is different.

M4: DBCS is regular, the rest rotate so that once a week they each get a different cc.

12. Do the same people work together regularly in the OCR/BCs/DBCs unit? All three tours? Describe how they are organised.

U1: Tour 2 and 3 allow teaming, they stick together. on Tour 1 they rotate, except for DBCS. 
U2: Tour 1 rotate. Tour 2 , the crew of two moves together. Tour 3, OK.

U3: Tour 3 they do by seniority. On Tour 1 they do not.

M1: Same two people work together.

M2: Yes.

M3: Overall, yes.

M4: They do work together, they rotate together.

13. How are crew chiefs organized to cover the 7 day a weok operation? (Probe. How has that worked out? What would You recommend?)

U1: I worked up schedule, backed up with reliefs. Sometimes we don't have cc coverage on weekends. We had a problem with holiday. We had the junior person work as a relief on a holiday. The reliefs wanted time off in stead of the work.

U2: Posted jobs with days off. Reliefs, Tour 1 covers days off. The one relief is full time. Reliefs on other Tours cover unscheduled days off and weekends.

U3: Reliefs selected on rotating basis, plus cover days off. There was a problem with one relief.

M1: Different days off. One has Sat-Sun, other has Sun-Mon. Relief covers on sunday or holiday and on vacation.

M2: Monday - Friday is OK. sunday could be a problem with the relief $\mathrm{Cc}$.

M3 : OK.

M4: There are $5 \mathrm{ccs}$, only two for saturday night-sunday morning. There are 4 for the rest of the week.

14. If the crew chief progran is made permenent, what changes would you suggeat?

01: The biggest change would be to have everybody get a 2 to 3 hour training session on the program. The crew members should have been trained and learned about the program up front.

U2: OR. I would like some mechanism to have the CCs work on machine. They probably have too much work. They could mandate meetings among CCs, with crew and with management. 
U3: Change pay rate. Set procedure for getting the CC position and removing CCs.

M1: To try to get cCs more involved with crew. Get handson, get on machines.

M2: Higher level job, like level 6 . Better IP training. Selection process should be best qualified. Need to have cc have more control over operation.

M3: I can't think of anything. I would like to see that supervisors are included, not just top management. I would like to see a refocusing of that. The other thing would be something to allow CCs to work on the machines.

M4: Give them a higher level. We have been working fairly well. The selection was fine, the way we have recruited them was $f$ ine.

15. On a 10-point scale (with 10 being extrenely supportive), how supportive of the crew chlef program are you:

A. As it currently exists:

B. As it coula function laeally?

U1: $6 ; 9$

U2: $10 ; 10$

U3: 8 ( 5 for Tour III); 10

M1: $8 ; 10$

M2: $4 ; 8$ Note: It gives me more flexibility to move management personnel around. It could empower employee if you had the right person in the job.

M3: 8 ; 9

K4: $10 ; 10$ 
Appendix C 312

SEMI-STRUCTURED INTERVIEW FOR THE CREW CHIEF PROJECT

CITY : LOUISVILIE 1. What are your positions in the USPS (and APWO)? (Title?) Note if person is
on local crew chief steering committee.

Union consisted of 3 interviewees, each of whom was a mail processor, union steward and member of the steering committee.

Management consisted of four interviewees: 3 MDOs, 2 steering committee members, and one USPS supervisor.

2. How has the union-management relationship changed since last year?

U1: Cooperation has improved although some supervisors don't want to cooperate

(We have to go around them) overall, however the relationship is better.

U2: The relationship on some tours and with certain supervisors is better. But on the others, there is still an adversarial relationship. Reorganization made sense to some and they work with it. Violence ir. the workplace scared people and made them less vocal and forceful. Now they "tell" rather than "yell".

U3: Tour 1 gets along pretty well. There is good rapport, good communication. This behavior has not been seen before. Communication is the key here. Due to the conflict resolution class, we got out the anger and built trust. It also changed the minds of supervisors and workers. The class got hostilities out and created honesty. Stewards now work hard as stewards and as clerks. The Union works well with management because management knows they'll be honest and do their jobs as stewards. The CC program is good on Tour 1.

M1: On this tour the relationship has improved. There are less confrontations. (Last year there were adversarial relationships.) Now, the is more willingness to work things out. After restructuring, things were unstable but the relationship has improved.

M2: The general relationship is more open and trusting. There is less "backstabbing". There have been some individual cases of problems but overall it's positive. (He wasn't in a position when CC program was started.)

M3: Step 2 grievance has improved climate. Overtime is handled as per "article 8 " of the national agreement. (Steering committee?) atmosphere has improved. Some cases of "union perfectionism" have resulted in disciplinary action toward CCs. Adamant regarding taking individuals out of the program. In general, the atmosphere has improved.

M4: There is a pretty good relationship between them. It has gotten better in the past one and one half years due to a change in hierarchy and not a result of the CC project. Steering committee brings better communication to the two sides.

\section{What has changed in automation because of the crew chief program?}

U1: Teamwork has improved. Morale has improved somewhat. There are a few 
discrepancies between CCs and supervisors. The CCs may have overstepped boundaries in some cases but nothing major. CCs have had to be tactful. Some CCs have been allowed over the line; had to be straightened out.

U2: I don't see much change. There are more headaches now. People don't know what you're going to do. Decision making is difficult because there are $3-4$ bosses rather than one. Production has decreased from 31,000 to 18,000 on his tour. Now you can't find supervisors when you need them. The project gave supervisors an easy break, which they take too often. When the CC tries to handle things that the supervisor should handle, the supervisor steps in and raises hell. CCs think they're boss when they're not.

U3: The CC program appears to be good on tour 1. On other Tours, there appear to be problems; tour 3 seems to have the most problems. The CCs are working members of the crew and know what they're doing. They know the sort plans, mail is ready and one seldom has to look for things because CC takes care of it. Dispatches are where they shoula be. Communication is good, everyone knows what to do, all is on time. Supervisors therefore are left open to do what they're supposed to do. The program works well here. The major problem is getting the CCs to take less supervisory roles and duties.

M1: The program is beneficial to supervisors. It frees their time to do administrative tasks. CCs are similar to expeditors. CCs can set up breaks and lunches, Managers can watch from a step back. CCs on this tour have been above average for the most part.

M2: In the reorganization, we lost supervisors. The CC program helped take workload off supervisor and enabled supervisor to expand coverage. It is a better operation with CCs.

M3: Supervisors have become lazy. The CC does the work for them. The CC is not acting as bridge. Supervisors are doing other administrative things and are present less.

M4: More people. Productivity is better. There are some great CCs and some not so great. There are also some employees with bad attitudes toward the CCs. They think the CCs don't do anything. Supervisors can now take a break and leave the floor occasionally and rely on CCs to take care of the floor when necessary. Perhaps program has made some supervisors lazy because they have the CCs to do the work for the. For the most part, supervisors cooperate with the program.

\section{Is the crew chlef program functioning the way you thought it would? \\ U1: Most aspects have worked better than anticipated. There were some problems in the first few months with $\mathrm{T} 1$ and $\mathrm{T} 3$. T2 works well.}

U2: No. Thought CC would be a "working leader" on machines, working, and giving instructions, But, instead, they just stand around. They don't work on the machines when they should. The CCs seem to pick out friends to work with and delegate to. The give their favorites the good work. CCs use control inappropriately.

U3: A lot of people had reservations. They thought the $C C$ would be a 
glorified 204B. But so far the program exceeds expectations. The steering committee works well with 12 people. We take the project seriously.

M1: Yes, but supervisors still think their jobs are threatened. CC can handle job training. Some problems because CCs thought they d be supervisors.

M2. M2 came in late and had to catch up with the program. He doesn't deal with CC directly. He gets most information from committee meetings. The supervisors have slacked off (didn't go through training). There have been some problems in terms of over/under aggressive CCs. The program is functioning properly but he's riot sure where it's going. (He's been in automation since January and on the steering committee since June.;

M3: Not totally. CC timid at first. Now covering more of supervisors job. Supervisors "griling" in a positive way. There is a bridge between craft and supervisors, a sense of responsibility. CCs overstepping bounds - sincere concern about getting mail out, "chiding" people.

M4: 75 percent. Thought we would be able to keep everything running at all times, but there's no specific guidelines. There are too many gray areas. It's hard to get CCs to understand and follow your procedures. There needs to be more specific guidelines to measure the job and work by. CCs need to set and example and with gray areas they can't do that.

5. What do you think has hindered effective implementation of the crew chief program in this site? (General question first, then probe for speciflc answers)

U1: No distinctive guidelines as to what CCs responsibilities are. There is a lack of total management participation. A few supervisors don't want the program. Some supervisors have given up too much control or not enough.

U2: Management's understanding of the program has hindered tt. There is no clear outline regarding CCs responsibilities and duties. The program is not utilized with $\mathrm{CC}$ as a working member of the crew. Management doesn't see to it that the program functions as it should. The CCs are not "working leaders" as they should be.

U3: The program is effective here. There are no ground rules, so it's all trial and error and it works well for us. Most everyone gets along; supervisors, stewards, processors/clerks. There are a few problems with some supervisors. The program is effectively implemented. The steering committee does what's fair and decent for everyone. The only problem is that some supervisors abuse it. Communication from Tour to Tour is still a problem.

M1: In the restructuring four 4 supervisors were lost. There are 17 managers who are still concerned about jobs. Managers are not behind program $100 \%$. some managers have given up all responsibilities.

M2: The supervisor's job is now unclear. Responsibilities are also unclear for CCs. Supervisors don't know if they'd lose their jobs to the crew chiefs.

M3: Not enough senior people (mail processors) becoming involved. They were afraid to get involved because it is new, unknown. 
M4: on tour I there are not enough CCs. We started out with 11 CCa. Now there's a great shortage and that's hindered the program. Again, need more specific guidelines of the program and how it should work. Need to be clear on the role of the CC. Conflict of interest between 204B and CCs.

\section{What would you say is the best thing about the crev chlef profect? The} worst thing?

BEST:

U1: The best thing has been the talent exhibited by CCs. They display initiative by making decisions when the supervisor is not present that accomplish supervisor's goals.

U2: cCs think the this grade levels are the best thing. I think that if implemented correctly, employees can govern themselves. This happens some on my tour, but not on most.

U3: The project give the clerk responsibility to get the mail out. They know and are ready to do it all. CCs are able to say things that supervisors can't, so it gets people going. CCs set everything up so that job is clear. The staff knows wha -o do and can spend most of the time actually doing it. CCs take responsib $y$ seriously. CCs do prep work and let the staff do its job. CCs take lt seriously.

MI: Alleviates manager from doing daily regular chores. Now there is someone to assist in running operation. Managers have time to plan/organize.

M2: Operators are able to get a better understanding of their job. The tasks are clarified for that day. This generates better relationship.

M3: Mail is flowing better because of CC.

M4: Communication. People actually get work done now instead of running around trying to figure out what to do. Some units are more critical than others. Time is more critical in some. Need very dependable CCs in critical areas.

WORST:

U1: The worst thing is the lack of supervisor when some managers use CCs to do their job. Giving up too many responsibilities.

U2: The program is not used the way it should be.

U3: There are no rules or set patterns, so the procedure is trial and error. However, we have set guidelines up as we go along and we have worked out the negatives. The biggest problem is that the supervisors get slack because the CCs are doing a lot of the work and then the supervisors come down on the CCs if a bad choice is made. Another problem is that the supervisors are not consistently accessible. The supervisors often disappear while the CCs take on the responsibilities. The supervisor should always be on the floor, not in the lounge. 
MI: CC thinking they are supervisor.

M2: People look for CC to make decisions. They think Cs is supposed to make decisions. Not sure what they are there for.

M3: Supervisors could do just as good a job. They perceive that the CCs are there to take their position.

M4: From a steering committee perspective: CCs want to be bosses and supervisors allow it, instead of actually being a working member of the crew. From the perspective of a supervisor: The CCs are not able to communicate with all employees.

7. Do you think the crew chiefs in your facility ware adequately trained to perform their new function, both technically and interpersoneliy?

U1: CCs were given adequate training both in terms of technical and IP skills.

U2: Training was adequate. Some had motivations of upward mobility. These people don't use training anyway. Their motivation keeps them from functioning purely with the job. Instead, they concentrate on moving up to the next level. Management doesn't encourage individuality and nonconforming to management expectations.

U3: Overall, we've met the challenge. Most of the employees know generally about the operation, but management doesn't teach everyone about the mail. specifically the employees are not trained well enough in automation. We tried to train them, but sometimes you have to remind them. We need better training on the "whats and whys" of automation. Need more years to learn the "ins and outs" of mail. This should be management's responsibility. The employees don't have a complete picture; only the basics. Remember, it's a pilot program, so there are no guidelines. We tried to train as best we could, but there are many things that had to be addressed as they came up. Interpersonally, most CCs are good, but a few are overzealous and militarylike.

MI: Initially yes, for a new program. Technically and IP both adequate. Interpersonal - more emphasis put on that they are not supervisors

M2: Generally yes. Technically, they know the jobs well. Interpersonally: there are some retired military people are taking a military perspective. They might benefit from interpersonal training to improve skills. Some specific individuals have personal problems which interfere with their CC position.

M3: Technically, yes. Need more experience. IP, yes to get them started/focused.

M4; IP - not enough training. Technically - Training is good here; learn more via application.

8. Overall, what proportion of the current crew chiefs do you think are 
competent to perform the crew chief job? (Probe for differences between effective and ineffective crew chiefs).

U1: At least 80 percent. They have the ability to effectively carry out supervisor's work plan for the day. They move people around as required. There is an effective use of staff. Some CCs are "cocky", For example, some veterans exercise too much authority and have a "militant" attitude.

U2: A very small number, raybe $10 \%$. An effective aspect is the CCs communicate with employees. Their mannerism is good. They work with the unit, they don't just bulldoze in and command people. The good ones come on and take time to talk with the crew. They are more team-oriented. An ineffective aspect is when the CCs yell at people. Some have mannerisms when speaking with employees. Some spread gossip, don't fulfill their duties or pass their responsibilities to others.

U3: All of them. Some take $t$ overboard. Some have to be watched. But overall, all know what they should do and are capable. The CCs on Four 1 seem to work well together and are all good and effective. One suggestion would be to emphasize communication between people, tours, levels. Everyone should be one, not separate. An ineffective aspect is not talking to crew member, not knowing exactly what's going on, making your crew come to you and not going to them. It would be more effective to know exactly what they are doing, stay on top of potential problems.

M1: Tour 1 oniy $90 \%$. $(8 / 11)$ Factors: One CC not following supervisor expectations. Failing to follow instructions of supervisor.

M2: M2 only works with T2 directly. All CCs on T2 are good

The CCs differ in their communtcation skills, specifically, as far as knowing what needs to be done and being able to communicate it to the crew.

M3: Could move easily, $5 / 9$ on tour. 3 top notch. IP skills are distinguishing factor.

M4: 90 percent. Effective: care about what they are doing; want to be informed, want to meet goals. Responsible, conscientious, try to motivate crew. Ineffective: took job for personal motivations, like having days off, authority. Regarding hearing impaired CCs doesn't always want to listen. Need to have complete ability to communicate, both orally and written or it holds things up.

\section{Do the crew chlefs in your facility apend time on the machines? (open- ended first, then probe, HOW MUCH AND FOR WEAT RBAsONS?)}

U1: As required for lunch, break relief, restroom, etc. They spend a maximum of 2 hours per day. On tour 2 they spend "ich less time because there is sufficient staff.

U2: The CCs spend little time on the machines; only for relief or breaks but not for high mail volume. They spend maybe 5 percent of the time $(5-15$ minutes maximum.) They don't "bust their bones". The CCs will call a relief worker in before they will get on machines themselves. 
J3: Yes, approximately 1 to 2 hours for breaks, reliefs, lunches, emergencies. The CCs can also be brought in on overtime as clerks, but if they're on as CC, then that's what they are. They don't fill in for high volume.

M1: Most spend an appropriate time. Some spend too lictle; some too much. Time - an hour or more to relieve on breaks.

M2: Not enough time. For lunch reliefs and to cover breaks only They spend about $25 \%$ of the time.

M3: Over 50 percent. Cover breaks. Shortage of personnel sits.

M4: Yes, Iunches (2), breaks (3), restroom, nurse, but not for high volume. Approximately one hour and 45 minutes - keeps them part of the team.

PROBE Do they spend an appropriate amount of time on the machines? (too much/too little)

U1: Want to see more time to stay "in practice", stay competent on machines. Capability stays, may become rusty.

U2: No, too little. 5 percent is not enough.

U3: Yes, most of them. Some are too "gung ho" (too much time), but most are on an appropriate amount of time.

M1: Mostly appropriate.

M2: Too little time on machines from the reports he's getting. CCs are outside in alley sometimes.

M3: Yes.

M4: On tour 1, yes. It keeps them part of the team. Overall, they spend too little. The CCs spend too much time observing and not actively involved or close to the work. (Although his group is good, not all are.)

10. For each meeting below, find out frequency, formalness, purpose, and what is discussed/accomplished?

\section{A. Do the crew chiefs have meetings among themselves?}

U1: Informal talking about operation. No formal meetings. only 3 CCs on T2.

U2: No.

U3: Yes, every week on tour 1 to discuss and problems on the floor. They take minutes, but it's informal. Surveys/evaluations have been done on the CCs. The meetings also regard communication, problems with supervisors, solutions. They also meet to keep themselves informed.

MI: Meet once a month. Initially once a week to work out challenges. Informal meeting. 
M2: Informal only.

M3: No.

M4: Yes, every two weeks. Somewhat formal. Meet for problem solving, share information.

\section{B. Do the crew chiefs have meetings with the supervisors?}

U1: Cnly one supervisor on tour. Most communication is informal because the tour is small.

U2: They have, but very rarely. They usually only have them when there are problems. In the case that there is a meeting, there must be a member of the steering committee at the meeting. Not all do this, even though they are supposed to, (At some meetings between CCs and the supervisor, there wasn't a nember of the steering committee there, even though the rules dictate that at any such meeting there should be.l

U3: Steering committee must be there, 1 APWU rep, one management rep. Formal meeting. Informal meetings are not allowed (mentioned reps must attend). They all talk, but don't have formal meetings unless there's a problem. (Not) many problems though) During these meetings, fear of retaliation from the supervisor is the biggest obstacle.

M1: At times, if something comes up, i.e. for specific purpose. Manager, steward, employee, CC sit down together to resolve specific problems.

M2: The CC meets with the supervisor to go over inefficiencies. Not to plan the day. Formal meeting.

M3: Informal. Dealing with problems. After joint steering committee they meet with tour.

M4: Only when necessary, for example, if there are specific changes occurring. Usually supervisors only will meet and then pass along information to their respective CCs.

\section{Do the erew chiefs meet with the local steering committee?}

U1: Only when a problem occurs to hear their side. Meet with tour steering committee.

U2: They've asked to meet, but only when there's a problem. Not on a formal basis.

U3: Yes, if they request a meeting the door is always open. A meeting will also be held if a suggestion is dropped in the box.

M1: There aren't as many meetings as when the program began. Initially they did. Some talked with whole committee. The topics were about some cCs not fulfilling responsibility or about conflicts with the supervisor.

M2: There is a suggestion box. Areas of controversy are discussed round table 
style. If a problem is found we try to solve it. We usually reach a consensus. (Problem area or problem supervisor- problem supervisors - working with MDO \& supervisor on each tour????

M3 :

M4: No, only if they request it.

D. Do the crew chiefs have meetings with their crow members?

U1: Informal rotation. No separation of pay locations. CC and supervisor for just CC) decide what will be done.

U2: No.

U3: The clerks talk to the CCs but not in formal meetings. The purpose of talks is to deal with work or daliy stuff.

M1: Usually during service or safety talks but nothing formal.

M2: No.

M3: No.

M4: Yes, at least once a week including the supervisor. Meet just to get people involved and keep them informed. Also to handle changes and hold open discussions.

\section{E. Are their any other meetings in relation to the crew chief program?}

U1: No.

U2: No.

U3: Periodically, meet with $204 \mathrm{Bs}$ and supervisors but not anymore. If there's a problem, a meeting can be set up, but most problems at this point are small and infrequent. The steering committee meets once a month, but will set up a special meeting if problems occur. In these meetings, we meet as 12 members, not as union and management.

M1: No.

M2: No. T2 supervisor meets with employees regarding safety talk and job talk.

M3: T3 met once. Everyone in automation met to discuss the role of a crew chief.

M4: Just steering committee members.

11. Are chtefs assigned to a regular crew or do they have different craw members each daY? (PROBE, HOW SHOULD THEY BE ORGANIZED?)

U1: The CCs rotate with other crew members so that they are assigned to 
different people. The CCs rotate with the work load. The CC needs to be rotated.

U2: They don't really have crews. They have 3 machines per $\mathrm{CC}$, and on any Iiven day, maybe there's $1-2$ people. on the machines. So, the cCs are assigned to regular machines, but not regular crews. They don't rotate machines, unless they want to, but management doesn't want to rotate. (He thinks they should be rotated, but management won't do it.) 'The crew member's assignment to machines changes every day, and this is determined by a CC or supervisor. Unfortunately, some CCs split up teams that work well together, and as a result productivity is lost. It's bad to split up people that work well together just for the CCs own personal reasons. This is a bad attitude on the CCs part.

U3: CCs bid to a regular crew and lccation and that's what you run. Most want to rotate, but that's not set up yet. Reliefs rotate as scheduled. They know where they'll be every night. Perhaps rotation will be the next step because many have requested it.

MI: Usually the same, 12 employees per pay location within pay location. OK this way, keeps consistency.

M2: Pretty much regular crew. Should know all jobs, should remain with one crew. This builds dedication and a motivated crew.

M3: Mostly assigned to a set of machines. Sometimes rotated through OCRs. Rotation is good.

M4: Set to specific machines and crew members rotate between the different machines. This trains everyone in all aspects. There's no specific order. Everyone goes on all machines in a 20 day cycle.

12. Do the same people work together regularly in the OCR/BCs/DBCS unit? All three tours? Describe how they are organized.

U1: Overall, yes. T2 is different because of size. On T1 and T3 the pay locations form the basis for organization.

U2: Yes on all 3 tours. It's usually not really organized, fust depends on who likes who and who works well with who.

U3: On tour 1 , yes. Perhaps on tour 2 they switch around because they have fewer people. Tour 1 always works with the same people, therefore better matches are found between people. It's organized via pay location.

M1: Normally. Organized by supervisors to some extent. CC decides who works with who. Specific decisions.

M2: Same across tours. Organization: The $\mathrm{CC}$ is given machines and told what to run. The CC is left to accomplish task by assigning people and making decisions.

M3: Same people at different ??? 
M4: Not regularly, but occasionally. Would help if could find people who are totally compatible and could work together all the time. Rotation sets up who works with whom. The process is random and done by machines not people.

13. How are crew chiefs organized to cover the 7 day a week operation? (Probe, how has that worked out?, what would you recommend?)

U1: CC positions 5 of 7 days a week. Relief CC assumes off day schedules, alternate does relief position if needed; worked out pretty well. Make sure that there's and alternate for each $\mathrm{CC}$ and at sest one alternate for every 2 CCs.

U2: The CCs have schedules they follow, just like any bidded job. It was done by senior biddex. It works, keep it.

U3: They're scheduled. When jobs were up for bid, it was made sure that all 7 days were covered in schedule. Would like to keep it this way. They need to know when they' 11 work and when they're off - ilke a bid job.

M1: Regular - 8. Alternate - 1, Relief - 3.

Need more alternates to cover shift. Should always have $2-3$ on hand to cover emergencies, sick leave, etc. Had 4 alternates originally - 2 bid, 1 left.

M2: Alternate CC used only as needed for sick leave, annual leave. M2 hasn't heard problems. Losing alternates is a problem. Training new ones is difficult. Need to train alternates every three months in duties, responsibilities and expectations.

M3: Relief cover non-scheduled days. Worked fairly well. Need more alternates in background waiting in wings.

M4: Just reliefs and alternates. This works well. A few times there's no CC but not regularly and not often.

14. If the crew chlef program is made permanent, what changes would you suggest?

U1: Program as laid out by steering committee works well. Define the cCs responsibilities more clearly.

U2: Grade level needs to be 1 grade higher. Don't recommend CC program prefer Senior Mail Processor positions instead, with junior mail processors at a lesser grade level. If the program is kept, the CC needs more activity. They actually need to be a "working leader" and the supervisors need to regain their resporsibilities.

U3: She likes it a lot. We need to have each faclilty go with what works best for that facility. Shouldn't force a general program for everyone, and don't change our plan to conform to everyone else's, because ours works for us. Implement ours because it works! Have trial and error for all sites to determine what works. APWU makes it work here, not necessarily management. Tailor the program for each facility, leave flexibility in contract.

MI: Problem with senior qualified, should be senior best qualified. Now one 
Appendix C 323

SC per 3 machines. Flexibility about how many machines they cover. Working fairly well right now.

M2: Need a better definition of the job. Supervisors may see CC as a competitor. The CC is there to assist not replace. CC Can't be 2043, CC may be most qualified to replace supervisors.

M3: Need more training similar to EIQWL training. Realize that they are the bridge between craft and supervisor. Phase out steering committee.

M4: There needs to be specific guidelines regarding the program (no gray areas). Accountability on CCs part. Now, supervisor is responsible for dispatches but the CC is there to be responsible for dispatches, so supervisor san do other duties, but who's accountable if dispatch doesn't get out in time? Now, CC not accountable and it all falls on supervisor - it's not even. Need clear guldeline and definitions in this area. Regarding the selection process, need to know how lt will be up for posting or bidding. If goes to senior bidder, then need very clear guidelines so that performance is the key not just seniority. Should have an application process instead of just letting it go to the senior bidder. CCs should be accountable to the rules. Capabilities of oral and written communication must be attended to, especially with the hearing impaired. They're excellent workers, but communication is off/weak. How can this be dealt with fairly?

15. On a 10-point scale (with 10 being extremely supportive), how supportive of the crew chlef project are you:

A. As it currently exists?; B. As it could function ideally?

U1: $A: 10 B: 10$
U2: $A: 2 B: 10$

Only problem is that it doesn't function as it ideally should or could-- he supports the ideal, but doesn't like the way it actually is working.

03: A: $10 \mathrm{~B}$ : Can't answer because we don't live in an ideal world.

M1: A: 9

M2: A: 8 B: 9

M3: A: 8 B: 8 (given supervisor is still there)

M4: A: 7

B: 7; because don't really know what Ho has in mind. If ideal means less supervisors, then not totally supportive. If it's actually to be used as a link between management and employees, then very supportive. But, if it is to be used as a cost-effective means (to get rid of supervisors) then not supportive.

Other:

$Q$ : Is the program cost-effective?

A: At this point, no. Last year were at 99 percent operating efficiency. 
SEMI-STRUCTURED INTERVIEW FOR THE CREW CHIEF PROJECT

CITY: ROCHESTER

1. What are your positions in the USPS (and APWO)? (Title?) Note if person is on local crew chlef steering committee.

The union interviewees consisted of a Mail Processor ISM Clerk, PS distribution/window mark-up clerk, a Crew Chief, and the APWU President. Three were steering committee members.

Management interviewees consisted of a plant manager, a SDO, a Quality Improvement specialist, and a manager of In-Plant support. Three were members of the steering committee.

\section{How has the union-management relationship changed since last year?}

घ1: The relationship has stayed the same. The relationship is considered pretty good. Problems with CC cause strains; i.e. using CC as 204B's. Now $90 \%$ of grievances are settled locally and discipline is way down.

U2: The restructuring has caused many changes in management. New supervisors have no knowledge of automation. For the most part, there are no problems. Had CC training sessions with new employees training newer employees. This caused some disorganization. It took time to develop a repoire with new supervisors.

03: Things are good and are improving. Emphasis on newer style of management getting better, even though it takes time.

04: Has not changed much. Still good relationships overall. There are some in management that will always see relations as adversarial. That won't change, but they work around it.

MI: Has gotten better. There is more stability amongst management. People know where management is coming from. Some new union stewards are around. They are impressionable.

M2: Still pretty much communication about the CC program. There needs to be better communication about what the CC program is. There is a lot of room for improvement. Original supervisors have left area or tour. Relationship is still pretty much the same.

M3: No real changes. Union-management relationship on my level (Pres. \& Chief stewards) is very good.

M4: Agreement - discipline would not be part of agreement if CC is integrated. Has not changed - people get along pretty well.

\section{What has changed in automation because of the crew chief program?}

प1: As a result of the program, grievance rates are lower, a positive buffer has been created, and $C C$ serves as a peacemaker. Can't get straight answers or productivity figures from management. CC is blamed when mail doesn't go out right.

02: As a result of the program, there are less grievances and fewer problems with individuals. The union has put forth much effort. MPs and CCs have learned about each other and have realized that $C C$ is not an easy job. Seems to be less mail processed wrong. 
5. What do you think has hindered effective implementation of the crew chlef program in this site?

U1: Initial short staffing, keeping the same number of supervisors, and promoting CC to 204B's has hindered effective implementation. Also, one CC has become a supervisor.

U2: There is poor communication among management. The management side of the steering committee is not providing information to the first-line supervisors in a timely manner. Assignment of newer supervisors is a problem. Newer supervisors don't understand the program. There should be one member of each side of the steering committee on each tour - they do have this now. More emphasis should be placed on the philosophy and intent of the program. Training should be more formalized. Allowing CCs to become $204 \mathrm{Bs}$.

03: More meetings are needed, only one or two among mail processors. Also, not enough explication of differences between supervisors and CCs. CC is a liaison and acts as a crew member, but is seen as another layer of management because supervisors were not involved enough (not acting to discipline poor performers). Supervisors should keep role as disciplinarian, but has not. When someone gets disclplined, it is because "the CC ratted on me". Short staffing has been a problem as has the pay differential and lack of communication. Also, management avoids confrontation.

04: Didn't hire people specifically for automation. Moved people around and they weren't trained specifically for what they did on the job - i.e. LSM people on automation inappropriately, Makes CC end up training people. Full fledged mail processors see CC program as not too beneficial; not what CC program should be. This resulted in discouraging the CCs because they had co work with improperly trained people.

M1. Local management should be aware before the union employees know. Extended to $3 / 31 / 93$ - I did not even know. Need a little more leadership skills training.

42. Some CCs are being used as 204Bs. One CC has been promoted from $204 \mathrm{~B}$ to management, How do you tell a person that they can't promote to a $204 \mathrm{~B}$ or management because they are a CC? They should be able to backfill. The program causes instability. Staffing is a problem. CCs are not able to do training. CCs are doing too many supervisory functions.

M3: New unskilled, untested supervisors. Staff is brand new (MPs).

M4: Proper staffing has been a hinderance. If there had been proper staffing, it would have been a better test. We did not backfill to compensate for CCs being taken of machines, which aggravated the shortage of people.

\section{What would you say is the begt thing about the crew chlef project? The worst thing?}

BEST

01: The reduction in discipline and recurring $\mathrm{gr}$ - vances.

02: Empowering the APW employees. They get better knowledge of how a supervisory type job functions (CC). Results in more efficient business decisions.

U3: CCs can make things happen. They can get into management layers and get listened to. Crews like CCS. The benefit of the unelection process is to reinforce people who are doing a good job, but are not certain. 
03: Productivity is up - two pass everything twice now (technical term for how many times mail is run through machines). More machines and more machines coming. CCs get mail which keeps operators running machines.

U4: Runs smoother because $C C$ is closer to work than supervisors were. CCs share in the work and have a better understanding of it. People like the program for the most part and have a good view of it. Staffing is still not quite adequate. people are put on machines in a haphazard fashion and inconsistently. That puts a load on the CC in that the CC has to instruct people who were just put on the machine. There is a "put the bodies over there" attitude on the part of the supervisors.

M1: Initially a rough start - NO STAFFING. Clerks can now handle technical details with a better staffing.

M2: CCs have workload shifted to them. CCs not given non-CC responsibilities by supervisors - when to add or bring down a machine should be more of a joint decision, Supervisors not assisting CCs the way they should.

M3: Supervisors are not taking as much of an interest. Have given CCs too much decision making. Allows supervisors to go and do something else. There are no increases in productivity or through-put. Post offices in the area are not happy with $P \& D$ performance - worse than last year. This is not related to CCs.

M4: Not much has changed. Were short staffed initially - not a good test yet. Hard to judge program when plant is running with fewer people.

\section{Is the crew chlef program functioning the way you thought it would?}

ס1: No, I thought that the $C C$ would have more authority. Also, I thought it would reduce the number of supervisors by $50 \%$, however, we still have the same number of supervisors in the area. Management promotes CC to $204 \mathrm{~B}^{\prime} \mathrm{s}$.

02: Yes it is. We were aware and ready for the problems we are now facing.

03: Not quite as well. Internal competition among CCs CCs go to supervisors to resolve problems. Sometimes these are just a few squeaky wheels so supervisors think that the $C C$ program is not working. Problems are not addressed. Steering committee does not address problems, and when they tried to, no one would make a decision - too bureaucratic. Lack of authority for steering committee.

U4: Yes, because I didn't believe that management was totally behind the program - they weren't. (This view is seen as quite realistic.)

41: It is functoning a little bit different than anticipated. Initial training was difficult - there were misunderstandings: too much responsibility too quickly. I knew these problems would occur.

M2: For the most part, yes. Some CCs are taking advantage of it. CCs are not willing to work on machines.

M3: No. The idea of $\mathrm{CCs}$ is excellent. It must be done in confunction with management. Management and CCs are not working together.

us: Yes. 
04: Employees are empowered and have more skill variety. They now understand the job as an integrated process.

M1: It gives clerks more responsibility. Poor MPs are becoming CCs and using their talents.

M2: It allows MP to have a say in how things are done. MPs have some input relationship with CC. Some MPs look at CC as another layer of management.

M3 : Craft involvement - CC.

M4: CCs take a lot of pride in what they do. This has spilled over into the MPs so MPs take more pride in their work now.

WORST

01: The CC identifies more with management than with MPs.

02: Lack of communication among managers, CCs and employees. There is a delay in action.

03: There are negative vibes from problems that were not resolved. Not enough people to choose from as CCs in the initial start-up. Not enough regular employees.

04: Some CCs got the wrong idea and act like supervisors and not group leaders.

M1: It is pitting people against each other - CCs fighting with each other. There is a lot of resentment.

42: Staffing is a problem. Also, some attitudes are a problem - some don't need CC (as another layer of management).

M3: The start of the program was very ill-timed.

M4: I haven't seen any results yet (short of staff - hard to say if program is really good). Also discipline is a problem. We would have to discipline to run operations more efflciently, to run machines more effectively, and have better control over the mail flow.

7. Do you think the crew chlefs in your facility wore adequately trained to perform their new function, both technically and intexpersonally?

01: Technically the initial training was adequate. Replacements get less training; 2 days vs. 5. Interpersonally, replacements need more training. Two days of training is not enough.

U2: Technically, ccs understand operation better then most supervisors. They have been in the area so training has not really helped them. Interpersonally, they didn't get a lot of training. None on balancing between being an MP and a CC. Should spend more on philosophy of program.

03: Training was fair. Not knowing what to expect was a problem. This made training a little ambiguous; people did not see how it related since the CC program was brand new. Technical training can be improved with the experience. Interpersonal training was fair but could include more listening.

04: Original cCs were done in a large group so they had more interaction with each other. Iater CCs were not as well trained - they took more of a crash program. Selection of CCs resulted in most having pretty good interpersonal 
skills, but the training for those who weren't as good in this area were not helped by the training - no amount of training would help these people.

M1: Technically, they have the technical training. Interpersonally, you can't really train them, but could use more.

42: The CCs have good technical training. Management should see that they use their training. In regards to interpersonal training, there are some conflicts. A regular crew concept was discussed - we saw the limltations to this. Tour 2 is a special situation - more complex, need more technical training.

M3: I would hope that they were given adequate technical training. We did not do enough interpersonal training. We could have done more on money and time issues.

M4: Technically, yes. There is no question about it, Interpersonally, they have been trained as best as possible. These issues are more a result of pxe interaction. As the work progresses on the floor, interpersonal skilis more or less result from the interactions.

8. Overal1, what proportion of the current crew chlefs do you thlnk are competent to perform the crew chlef job?

U1: $90 \%$ are competent; one is in danger of being unelected. Differences in effective and ineffective $C C^{\prime}$ s stem from getting along with coworkers, gaining respect of coworkers, and working on machines.

02: 95\% are competent as far as reallzlng where their priorities are. selection by seniority may make a difference between good and bad. They need to realize the intent of the program as many of them don't see this.

U3: 100\%. Some are more competent, but all are at least good enough and meet expectations. Need awareness of the mail flow and the whole system. Need interpersonal skills to handle pressure better. Need to make contact with other CCs as well as supervisors for better communication.

04: $80 \%$ Relationships with crew and management were better. Being a CC gives some authority, but not a supervisor's authority, and this is a fine line. Staffing was another factor that affected the CCs. Better CCs were able to cope with the understaffing. They worked with what they had and dealt with having under-trained people on their machines.

H1: $75 \%$ Cooperation and lack of Napoleon effect!

M2: Mostly good, I have mixed feelings about the new CC - there are attendance problems (not setting good examples) on Tour 1. Shyness is a problem. MPs don't give new CC a fair shot.

M3: 802 Effective CCs have the ability to get along with both management and employees in addition to getting the job done. Supervisors need to spell out more directly what needs to be done to ineffective CCs.

M4: $80 \%$ are competent. Things that separate them are motivation and the ability to motivate: Show people they care and are interested, Have better leadership. Help out with work and mail flow.

9. Do the crew chlefs in your facility spend time on the machines?

01: Overall CC's work on the machines - ones that don't get unelected do. 
U2: Yes they do spend time on the machines. Employees feel that CCs may not be working when they are not on the machines. They spend as much time as they can on the machines especially when others need to use the bathroom or are taking lunch breaks.

U3: More now than before. Staffing was a big downfall. CCs had to get mail, but now they can work on machines more.

04: No, because if they are not fully staffed, they have to move mail instead of the mail handlers doing it, as it is supposed to work. If they were properly staffed, they could work on machines.

M1: Not as much as is supposed to be. This is management's fault. There are no mail handlers - 1 person to cover 9 machines. Don't cover for breaks unless you tell them so.

M2: Some tours are spending more than others. Tour 1 has the least, caused by staffing problems - they have to get mail out. Tour 2 spends the most. Actually running mail and covering breaks.

M3: Yes. CCs are getting and obtaining mail, covering restroom breaks, and have other reasons for stepping in for a few minutes.

M4: Sometimes, More before, less in the future because of stafing shortages,

PROBE Do they spend an appropriate amount of time on the machlnes? (too much/too little)

01: They spend too Iittle time on the machines. As a result, employees won't buy the program.

02: For the most part, the amount of time they spend on the machines is appropriate. Some complaints have ceased.

03: An appropriate amount of time. They know when and where to jump in.

04: Some do, some don't. Some do not work as many hours on the machines as they should. CCs are given other jobs to do - moving majl and CC also is forced to resolve personality conflicts...CCs should not do either of those things. Also, CCs might forget that $25 \%$ of the time is supposed to be on the machines.

MI : 1 hour a day at most.

M2: Tour 1 should spend more time on the machines. They are doing too many supervisory-related and Mail-handler type functions.

M3: Yes. $25 \%$ of the time on the shift (2 Hours) is spent on the machines.

144: Yes, when it was needed, they helped out. The amount of time was appropriate.

10. For each meeting below, find out frequency, formalness, purpose, and what $18 \mathrm{discussed/accomplished?}$

A. Do the crew chiefs have meetings among themselves?

01: Yes they have meetings but not often enough. There is a $1 / 2$ hour overlap in tours to make sure each is set up, but meetings within the tour are only once a month. There is a lack of communication between tours. 
U2: On the floor, impromptu meetings are the norm. The $1 / 2$ hour overlap in cours is used to discuss what is going on that day.

03: Not for months. Maybe 6 in the beginning. The meetings are informal and are to discuss what to do with mail and other technical issues. Need more meetings. Need to get out information on mall flow problems.

04: No.

M2: Not regularly. There is one with all three tours. Stressed more communication early on ("Here is what you are facing") - this has tapered off. Meetings should be happening more.

M4. Yes, intra-tour more than inter-tour - with supervisors there also. The frequency is about once a week for the intra-tour and once a month for the intertour. These meetings are more informal, but have met relatively regularly to discuss issues of mail flow, staffing - permanent teams with CCs, or move CCs and crews around.

\section{B. Do the crew chlefs have meetings with the supervisors?}

U1: Yes, there are some formal meetings where supervisors will bring all CCs in to talk. At the meetings they should discuss special problems with the mail. In the future, a union representative should be included - none have been in the past.

02: On the floor, impromptu meetings are the norm. Nothing is planned regulariy.

03: No, once in awhile or they may speak in passing.

04: Yes. These meetings are informal. It is hard to say what they discuss.

M2: Tour one will go one on one. I am not aware of any formal meetings. There are some political problems. Need more communication.

M4: The meetings included $\mathrm{CCs}$ as well as supervisors.

\section{Do the crew chiefs meet with the local steering comnittee?}

01: Yes, but not often enough. There have been two meetings in the last eight months - one at the beginning and one last week. They need to discuss Christmas planning and $204 \mathrm{~B}$ problems.

02: One meeting was held recently that had been planned by the steering committee. Management had an agenda and ironed some things out, such as unelection and blown dispatches, however, this was done too late.

03: Once, two weeks ago.

04: One of the CCs is on the steering committee, so probably discusses issues with CCs after the SC meets. Last week there was one ST/CC meeting. It was formal, with supervisors there. (1 meeting at $10 \mathrm{pm}, 1$ meeting at midnight.)

M2: No

M4, CCs met with the steering Committee in a separate meeting, once every two months. compared to meetings described above, they were more formal, with set times, agendas, and issues to discuss. 


\section{Do the crew chlefs have meetings with their crew members?}

U1: They have had some, but I don't know how regularly.

U2: During the tour, daily problems are addressed on the floor.

U3: Not at all. CCs have no authority to schedule something like that.

U4: No.

M2: Not as far as I know. There are one to one meetings.

M4: Can't say.

E. Are their any other meetings in relation to the crew chlef program?

U2: Safety meetings are held, These are helpful.

U3: No.

U4: No.

M2: No.

M4: No

11. Are chiefs assigned to a regular crew or do they have different crev members each daY? (RROBE, HOW SHOULD THEY BE ORGANIZED?)

01: At first it was not set in a pattern. In september, NTP (National Task Force) suggested a regular crew assignment, but CCs were against it because some CCs might get the best/worst people. CCs should be able to work with anybody. CCs preferred a rotating plan to a set, regular crew, and decided to stay with the rotation instead of going with the regular crew idea suggested by the NTF.

M2. It is different each day. This is the best way to go.

44: They rotate. Get details from someone closer to the shop floor.

12. Do the same people work together regularly in the OCR/BCs/DBCs unit? All three tours? Describe how they are organized.

01: They rotate machines so they aren't always on the same machines. If they have OCR one day, the next day the would have BCS, One CC for 6 employees, which is for 3 machines. To break it down, 2 employees per machine and one CC for all 3 machines. This is a total of 7 people to 3 machines.

42. No, they are rotated individually. They are not tied to the same partners. All three tours are the same.

M4: They rotate. Get details from someone closer to the shop floor.

13. How are crew chiefs organlzed to cover the 7 day a week operation? (Probe, how has that worked out?, what would you recommend?

01: Bid CCs on tours 3 and 1 full time, Sat/Sun, Sun/Mon, Fri/Sat. Three positions are full time, Relief kept their days off from the original schedule. The result is that there would never be all rellef CCs on any given day. The day tour, 2 , is 6 day. Regular CC had Sat/Sun, relief had Sun/Mon. 
Appendix C 332

42. Originally, they had certain days off. Now it is mixed - some regular CCs work on the weekends.

M4: There are permanent and back-ups. Get details from someone closer to the shop Eloor.

\section{If the crow chief program is made permanent, what changes would you suggest?}

U1: A pay differential has to be addressed. One level is not enough. This is also true for other positions. For example. T6s run window and need a bigger pay differential. For example, $\$ 0.30$ per hour more could easily make this up on overtime with little problem. A training minimum of one week should be implemented. Two weeks would be better; one week of technical/03, and one week of interpersonal/workshop. Unelection procedure should be 6 months/12 months instead of every 90 days. A better plan would be to have 90 days after 12 months.

02: Changes include better communication, weekly meetings for those most involved, monthly steering committee meetings and better financial incentives. They could txy to get better people via a different selection process.

03: There should be a permanent schedule, with rotation being permanent. Superviscrs should be in charge of CCs. Need support from management for CCs including a definition of roles. Supervisors need to handle discipline.

04: Originally, there was supposed to be 1 automation supervisor to report to. Instead, there are $204 \mathrm{Bs}$ that did a lot of things the CCs were supposed to do, which caused a lot of problems for the CCs. Should not use CCs position as a way to get to $204 \mathrm{Bs}$. The original plan would work better. As it is now, the CC ends up training the $204 \mathrm{~B}$ because the $204 \mathrm{~B}$ isn't fully knowledgeable. Need to staff people more consistently so that CCs don't have so much training to do. There is not enough cooperation from management regarding staffing. Pay needs to be higher for CCs - there is a lot of aggravation for little compensation.

M1: Changes suggested are different selections, taking a look at records, deciding who can lead, and selection on merit - not seniority. Cliques are a problem when using friends to lead friends.

M2: Need to take a hard look at how program should go. Need more standardized training. Need better staffing. This has been a problem from the start. It is worse on some tours but should get better soon. We need to stabilize staffing.

M3: First, supervisors should be trained in automation on how to work with the CC program (i.e. what it is).

M4: Need the best qualified regardless of seniority, need people with the best leadership skilis, most respected by the people they work with. Three key issues of qualification are: attendance; productlvity; ability to organize people, and work with teams effectively.

15. On a 10-point scale (with 10 being extremely supportive), how supportive of the crew chief project are you:

A. As it currently exists?; B. As it could function ideally?

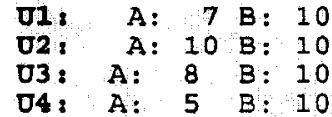




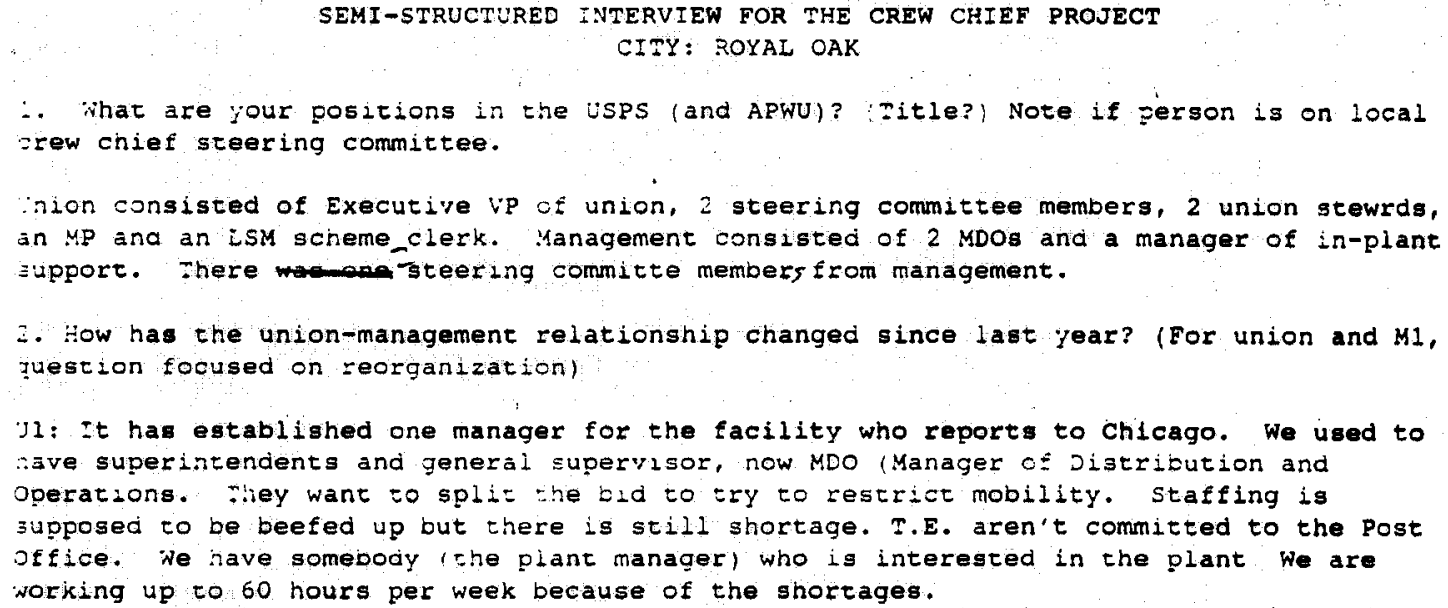

3. What has changed in automation because of the crew chief program?

U1. I think MPs like having more responsibilities. Changes in safoty lssues, they have input into problems. They have a source to take it to, that ig the steering committee. Make jobs easier, makes mail flow better. We are having problems with the unelection process. There were things about the unelection process. Some think T.E. shouldn't vote. Some think only votes of those voting should be used.

U2: In the PDC (processing and Distribution Center), people are more aware of the function of automation. I think they (MPs) are of issues. More issues have been brought to 1Lght. It depends on people (MP, CC, supervisors and MDO) There have been a lot of positives. People say there are negatives, but these were in existence before. It has been of real value. New people are discussing new issues. 
Appendix C 334

04: General Suggestion: Supervisors say that they are short staffed, but were not before. Why didn't they say they were short before the inception of the program?

M1: A: 7 B: 10

M2: $\quad$ A: 5 B: 8

M3: A: 7.5 B: 10

M4: A: 5 B: 5 


\begin{abstract}
SEMI-STRUCTURED FNTERVIEW FOR THE CREW CHIEF PROJECT CITY: ROYAL OAK

$\therefore$ What are your positions in the USPS (and APWU)? (Title?) Note if person is on local zrew chief steering committee.

inion consisted of Executive vp of union, 2. steering committee members, 2 union stewrds, an MP ano an LSM scheme_flerk. Management consiseed of 2 MDOs and a manager of in-plant zupport. There weomene Tteering committe members from management.

¿. How has the union-management relationship changed gince last year? (For union and Ml, Juestion focused on zeorganization)

11: It has eatablished one manager for the facility who reports to chicago. We used to $\therefore$ ave superiatendents and general supervisor, now MDo (Manager of Distribution and operatsons. they want to splic the bld to try to restrict mobility. Staffing is supposed to be beefed up but there 1 s still shortage. T.S. aren t committed to the Post office. We have someoody (che plant manager) who is interested in the plant we are working up to 60 hours per week because of the shortages.
\end{abstract}

2. Very little. It didnt affect us in terms of staffing. It just gave new titles to people. I don's think it accomplished the goals they wanted.

13: No great effect. No fewer supervisors than before, just gave them new titles. Reorganizing has nothing to do with the changes at Royal oak.

M1: It ellminated a level of supervision. It has eliminated the number of line supervisors, so ratio of supervisor to employees is lower. Plant manager has been given complete authority. Supervisor staffing affected; we have 45\% vacancy rates. We lost lewe than 10 employeen in early retirement. Other offices have lost more employees. Everybody is trying to hire so it makes it harder for us to hire. Emphasis is off of budget to productivity, service and employee commitment.

M2: M2 not there then. seems the same, not bad.

M3: Union representativeg and mgt now talk. We communicate well; sometimes we agree, sometimes we disagree, but this method has not reached the floor to the supervisors and MPS:

3. What has changed in automation because of the crew chief program?

U1: I think MPs 1 lke having more responsibilities. Changes in safety lesues, they have input into problems. They have a source to take it to, that ig the steering comnittee, Make jobs easier, makes mail flow better. We are having problems with the unelection process. There were things about the unelection process. some think T.E. shouldn't vote. Some think only votes of those voting should be used.

U2: In the PDC (Processing and Distribution Center), people are more aware of the function of automation. I think they (MPs) are of 1 ssues. More issues have been brought to light. It depends on people (MP, CC, supervisors and MDO) There have been a lot of positives. People say there are negatives, but these were in existence before. It has been of real value. New people are discussing new issues. 
3: Increased safety, helped people to talk to each other, zommunicate with people orher than supervisorg and somerimes have more input. Therè were some initial negative reactions but it will get better.

11: Real changes. Any issue an employee wants to bring up gers addressed in steering committee. Employees now have input. MPs see cC as another layer between them and supervisor; they see them as lower level supervisor.

Y2: Less account on part of $\mathrm{CC}$ and MP to maintain production goals. Teld less sccouncable. Not meering goals. Norse since CC started. Iine managers. not responsible for production since CC program began. Goals cause unfriendly atmosphere.

M3: We have been able to better staff and schedule because of their input. They are scheduled to help the mail flow. There are no grievances because the steering committee has been able to hear everything. The time spent is an investment for the future. Perhaps the CCs are doing about two hours daily on machines.

$\therefore$ Is the crew chief program Eunctioning the way you thougnt it would?

11: No, some managers aren't letting program function as it should. All in all with aggressive and assertive $C C$ and good supervisor, it works well. For the most part its working well. It's hard having all these meetings, the time spent in them.

U2: Yes and no. A lot of expectations were met. A lot were not. Unmet expectations have to do with tume and effort. Union and management didn't put in the effort necessary. The program is a communications program, you can make as much effort or as little as possible but it does need more.

U3: Yes, but not like I would like. Supervisors harass the crew chiefs lese (bocause they are scared of losing their authority) Getting the rlght crew chief is difflcult because the authority goes to their heads. There has been more input from the employees. They keep up with the weekly service meeting. There are follow-ups on employee's requests.

M1: I don't think it'g the way I envisioned it. I thought employees would be more empowered. They (MPs) aren't more committed. The CCs are empowered. The steering committee revlews what employees said. Employees use steering committee rather than fle grievances. That way they can get an issue with a supervisor heard.

M2: No. Agaln, there is an accountabillty problem. Employees not taking charge.

M3, I think it is going along oK. for example, an MP is not working, supervisor leaves it up to the CC to correct, CC leaves it up to the supervisor. Somebody needs to do it. They need to learn to do it together. We will try to encourage ce and supervisor to work together.

5. What do you think has hindered effective implementation of the crew chlef program in chis site? (General question first, then probe for speciflc answers)

U1: I see supervisor as a barfier. I see gteering committee having probleme getting together to meet. Some people view $c C$ as another barrier, in those cases, the wrong person is in the position. I think in some cases they try to plt cc against employee.

U2: Lack of organizatlon from day 1. Just trying to introduce it. Change is hard enough to introduce, more so if you aren't organized. Bureaucracy and org?? 
Feorganization affected CC program negatively because attention went to reorganization -nstead of CC program. Reorganization is a big thing, CC is a little thing.

3: Management as a whole. Not giving respect to crew chief. Need to work with them. There is a power struggie between crew chiefs and supervisors.

«1: Initially, people trying to understand roles. Jnderstanding by cc of their roles, The staffing shortage makes it difficult, : wonder if we oversold the program as an instant operation instead of evoiving over time. Ne shouid meet MP in groups, MPs don't now what is going on in meeting when I meet with $\mathrm{Cc}$.

12: Selection should not be based on seniority. Elections should be held. Unelection: are a negative way of getting rid of people. Some groups vote out cc continuoualy.

13: Staffing. We are still understaffed. We may have a different 204B every week. We are short 14 supervisors. (This is supervisor staffing.) It is hard to get supervisor stafing for the weexend. vp staffing is also short.

3. What would you say is the best thing about the crew chief project? The worst thing? 3EST

il: The empowerment of employees. The have a say in their job

J2: It has a chance to chanre the working environment, and it has to some extent.

J3: Helped morale some. Input on efficiency and safety. (Not much yet, but some.)

M1, The poeitive suggestions we have gotten from employees. ccs are very sincerely interested in making operation better.

M2: Like the concept. If people accepted 1t, 1t could be good.

13: It helps me get back in touch with employees and operations. We deal with probleme in the steering committee. I see what is going on.

WORST

U. Having a CC who thinks he's a supervisor.

U2: I don't see anything negative about the cc project. It has raised awareness of some negative thinge that already existed.

U3: Some anjmosity among workers. Some cCs have overstepped bounda. (Certain ones in no specific areas) More communication skilis are needed.

MI: Perception of CC as another layer of management between employee and supervlsor.

M2: Lack of accountability. CCs don't make sure people stay on machines.

M3: It takes a lot of my time and their time. It even takes up time to set up meetings.

7. Do you think the crew chiefs in your faclilty were adequately trained to perform their new function, both technically and interpersonally? 
U1: Some could use interpersonal training. sechnically, it was ok.

U2: No. Anyone outside of the firse group did not receive technical training. Ip zaining was a farce. The training course as it is set out is a pretty good layout. Fechnical slde needs to be updated, $p$ is good, but depends on trainer. Technical is tust not adequate, it telates to certain types of mail, and thus certain cities need vercain training.

13: More communication gkills are needed, although this is hard to train. Need to know how to talk to people and ask people and listen without losing tempers. Fechnically, they know their jobs well in general.

M1: Initial training was very good. Follow-up training would be useful in reemphasizing what was covered earlier.

12: Technically, yes. Interpersonally, no. There are problems because the cCs don't know how to talk to the MPs.

:13: You can never get too much training. ie are giving refresher training on November 29 and 30. Nith almost a year of program, questions may be better, discussion may be more productive. We will talk to them about our expectations. ccs are not too good on talking to MP crews in a group. It is an area of concern to us. If they do this on a regular basis, they won't be viewed as just standing around and not helping.

8. Overall, do you think most of the current crew chiefs are competent to perform the crew chief job?

U1: Yes:

U2: Yes, most of them.

U3: Yes

MI: Yes.

M2: An effective $C C$ should have a good report from employees. An effective cc should have good interpersonal skills (non-antagonistic, non-flusterable, have control.) An effective CC should have enough technical skills to function, but this is not as important as IP skilis.

43: I am very surprised. I think the majority are competent, are very good, some of them are growing. Probe: Some are in it for themselves. We heard that some are in it for the money and different days off. Some were bored, wanted to help to get mail out in a different way. It seems like Tour 1 is dolng well. Kgt there knew the goals of the program and had open communication. We have enlarged the steering committee to bring Tour 3 more on board.

9. Do the crew chiefs in your facility spend time on the machines? How much and for what reasons? PROBE: Do they spend an appropriate time on the machines? Do they relleve crew members for breaks or participate during heavy/difficult mail flow times?

U1. Yes, some spend enough, but some employees think they should spend more. They only relieve crew members for breaks if they have to. Yes, they particlpate during heary/difficult periods. 
$\because 2$ : Zes, Supervisors who are regative about CC program allow cCs to work on the machines to undermine the program. In general, the ccs spend too little time on the nacnines. CCs have been allowed to felieve crew members for breaks. cca participace juring heavy/difficuit times more than $n$ other cases or for other reasons.

3: Yes. Some too much. ccs relleve crew members for breaks. (Don't know how often jut they will when needed.) The cCs participate in heavy/difficult mail times.

11: The CCs spend very littie time on the machines. This leads to perception of cc as -ower level supervisor. The CCs pery se dom rel. Je crew members for breaks. They participate in heavy/diffieult mail fow times mucn less than we would like.

12: Some ccs relieve, some don't. Mainly, they relieve for restroom breaks and heavy nail $\leqslant 10 w$.

Y3: The CCs relieve for 2 hours per day for emergency breaks, for lunch breaks, to work t-h somebody. We are encouraging them $=0$ work on the machines more. some may work sour hours because of the staffing. They are moving mali in and out of the area and having to schedule the machines. Probe: They are spending the amount of time on the machines that we predicted. It costs money, it is an investment. As mgt, I would like to see them spend more, but for the program they are spending a proper amount.

10. What kinds of regularly scheduled meetings do the crew chiefs participate in ? What is generally the purpose of these meetings? What is discussed/accomplished?

\section{A. Meetings among crew chiefs}

U1: We have done this. We have scheduled a 10 minute overlap of ccs between tour for facilitation of mail flow.

U2: 10 minute overlap between tours to handle operational isgues, Each CC's lunch is extended by 5 minutes.

U3: They meet daily on a casual basis. They utilize each other's experience, etc. They meet with other tours, overlap time for tours, pass information, etc.

M1. Role isaue here, in some cases there had been friction among cc.

12: No. Very infrequent. There is a congtant change of CCs and supervisors.

M3: Yes, there $1 s$ a ten minute overlap between tours where they discuss things.

B. Meetings between crew chiefs and supervisors

U1: Every three weeks on Tour 1 to air any problems they were having. To keep things from going to the steering smmittee.

U2: Tour 1, but not Tour 3 Discuss issues related to that tour. To keep things from coming up in steering committee.

U3: They meet to discuss problems and what to do about them. This is a "bltch session" for the cc. They discusa how to make job easier. 
11: I meet with CC and supervisor every three weeks on Tour 1 . We bring up anything. We bring up staff from the steering committee. Union steward 1a there. (Seems to work well,

12: This is also very infrequent, although it happened before. The format was roundtable, we let the $\mathrm{CCs}$ bring up the issues. The issues consisted of machines, other fours not breaking down mail, staffing issues. Not much is accomplished at these neetings:

M3: There is a Tour I meeting with MDo and supervisor at least once a month. Everythlng from technical stuff to attitudes is digcussed. There might be griping about anything under the sun. The more meetings you have, the less they become a bitch session and the more they can focus on improving conditions.

c. Meetings between crew chiefs and local steering committee

$31:$

U2:

U3: No. Steering Comittee members will attend CC meeting. Would like to see a meeting occasionally between $C C$ and steering committee.

MI:

M2: Maybe once. Future meeting.

43: The flrst one we had wag last week. We got a lot out.

D. Meetinge between crew chiefs and Mall Proceesors

U1: No, but we could use a safety talk or a rap session. But things are very busy, we don't have a lot of time.

U2: Depends on CC and supervisor. Sometimes in safety meeting, other times as a service talk. Sometimes with supervisor, sometimes without. It has been a benefit to the supervicor having the supervisor absent. It allows employees to vent items that they might be more comfortable in bringing up without the supervisor. When people talk about their work, they are more comfortable with people who know the work.

U3: Yes, weekly, but not followed through. often postponed. tends to be a "fap" session. Some have impromptu meeting with workers for five minutes when problems occur.

MI: some give weekly talk as part of gafety talk. ren minute meeting once a week.

42: Yes, this occurs weekly. It is informal and many issues such as space, stafing are discussed.

13: Not enough meeting. Only a selected few have meetings. We plan to meet at least once a month.

B. Other

U3: Need more involvement of $\mathrm{CC}$. Need to write agenda itema beforehand. 


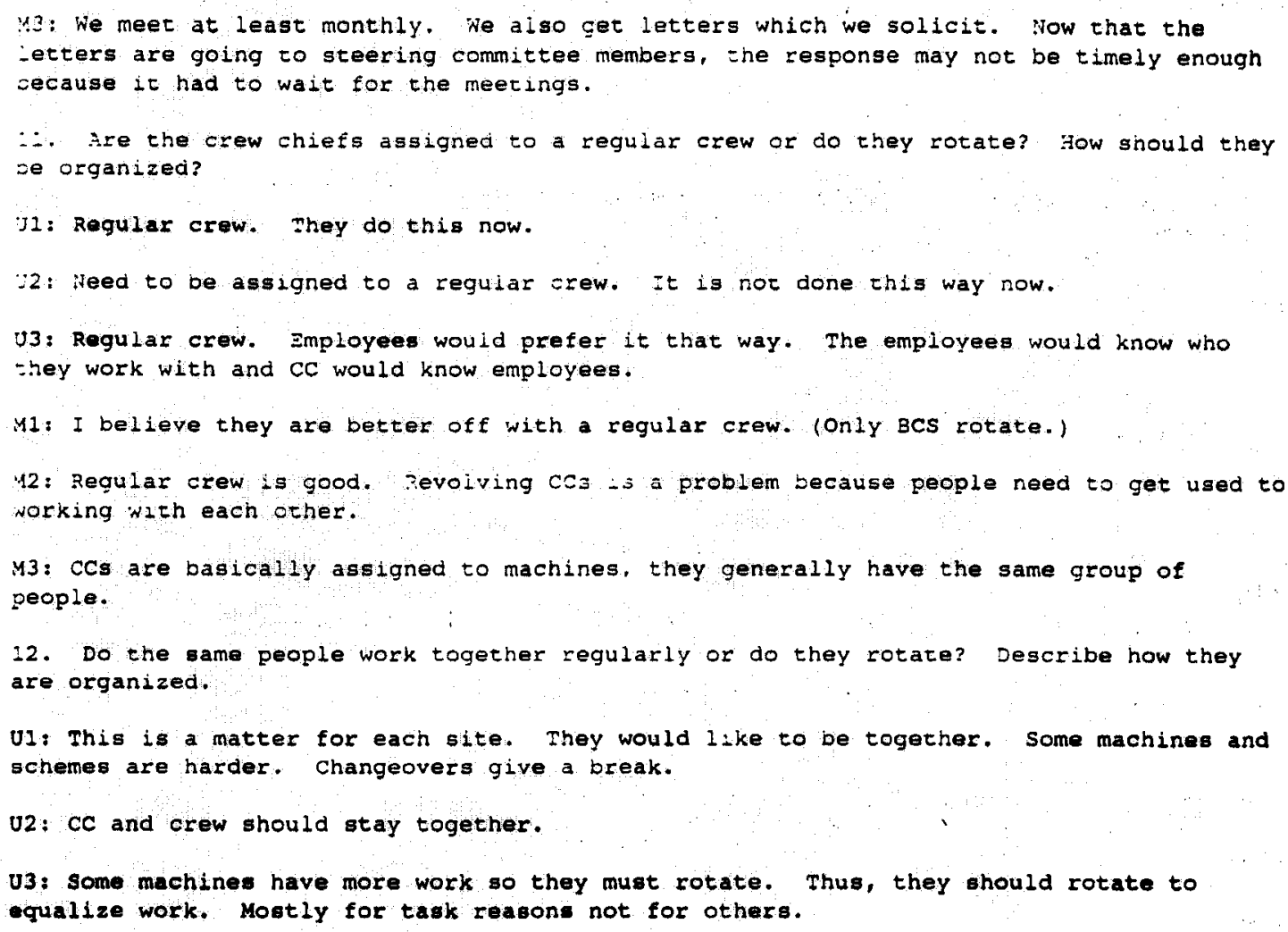

MI: I think everything needs stabllity and having same crew help. People work together. They think working together, they are peers.

M2: The same people work together regularly and this works well.

M3: They might work in a group of 20 employees regularly.

13. How are crew chiefs organized to cover the 7 day a week operation? How has that worked out? What would you recommend?

v18

U2: Regular CCs have saturday and sunday off. The relief system doesn't work. MPs work without CC. We are working a lot of overtime. CCs come in on their off days to work. U3:

41: All full-time cCo have weekend off. Rellef cCa cover days off. There might be one day where machines are only staffed six days in a week. 
12: We don't have seven day coverage, it is six day coverage. No cc on sunday, Relief on sunday. This is not a problem. Ne need stability. The chree-month unelection process is not working.

13: We have weekend coverage. We have had very little response to getting cc to bid on coverage on the weekend. We have reliefs. We are adequately staffed for heavy mail rolume. off days are a problem. The positions with Tues. and Weds. off have not been bid for. I have heard of no times when no CC is available. some relief CC will get to cover more machines on weekends because we can't get a regular cc then.

4. If the crew chief program is made permanent, what changes would you suggest?

U1: Unelections every 6 months. I'd like it to be sentor qualified (it is like this at Royal Oak,) I'd like to see CCs be in the job for 6 months. Give them more money. Make them Level 7 .

22: I) The money, The $C c$ has to be pald more. It is an insult to the individual (??) ie have individuals who won t do it because it doesn t pay enough. 2 l Training has to be done properly, MP has to be included in training so they know what is going on. Now they aren't included. It is just a pilot program so people can say they need to do something and they don't.

U3: CC should be elected. Not sentority, no guarantee best qualifled. Election would get someone with a personality. That is part of what you need. More training on communications. Tell exactly what crew chlef position is about and leave them alone to do the job. stop power games that develop. Exact rules about ccs responsibilities.

M1: Maintain some type of steering committee forum for issues that come up. Senlority only for selection is not the best way. Maybe there should be a committee that reviews applications.: Want CC more involved in bargaining unit work, working with people on machines.

M2:

43: I think some tracking on hard numbers for CC absenteeism, sick leave, productivity. The program has to be better delineated in terms of the roles of the cc and gupervisor. We need to solidify the supervisors. On the national level, NAPs feel threatened.

15. On a 10-polnt scale (with 10 being extremely supportive), how supportive of the crew chief project are you A) As it currently exists? and B) As it could function idealiy?

U1: $6 ; 10$

$\mathrm{u} 2: 6 ; 10$

U3: 8,10

M1: $4 ; 8.5$

M2: $2,8-9$

M3: 7,10 
Appendix C 343

SEMI-STRUCTURED INTERVIEW FOR THE CREW CHIEF PROJECT

CITY: St. Paul

1. What are your positions in the USPS (and APWU)? (TitIe?) Note if person is on local crew chief steering comittee.

Union personnel consist of 3 Mail Processors, and one former LSM. Two are union stewards, two are steering committee members and one has held the office of Local President.

Management personnel consist of 3 MDOs, two of which are on the steering committee.

2. How has the union-management relationship changed aince last year?

U1: It has improved a great deal on this tour, and people are trying throughout the plant.

U2: Pretty good relationship last year and this year. Restructuring has caused confusion as to who is responsible and cooperation. Need more consistent management presence. Union is only consistent presence.

U3: Involvement in CC is good. CCs are doing the job. Seen as someone to work with, not a threat. Still union-management conflict. Need new supervisors, still using ideas from 30 years ago.

U4: Between union and management, management is cooperating with the project and listening more. Some instances ok. Crew chief is ok. With other things, there are still differences.

MI : Really has improved. First cooperation signs in 34 years, statement from NAPS regarding cooperation. See copy from APWU statement. There are some negatives, but more cooperation which was surprising.

M2 It has gotten better - very intereated in making the CC program work. Things have opened up. We handle step 2 of the grievance procedure and other discipline, but they used to handle it. There is also more communication.

M3: Better, but overall trust level is low, needs to be improved. Same people now as last year at this level (MDOs). Upper level is more removed than MDOs and has improved somewhat. Before, upper level (above MDO) was even more removed than it is now.

3. What has changed in automation because of the crew chtef program?

U1: At first the CC program was not well liked at all. Now the environment has improved.

U2: M1xed results - some employee concerns have been addressed. In some ways, the CC program was a lightning rod for every automation problem (i.e. resources acquisition, $C C$ can't do everything). There are improved working conditions in this unit (more voice on tasks). Management should have had 
commitments ( 1 yr) to position as well as CC. Management disappears and points fingers (one manager assigned to that position for one year). There is a lack of consigtent management.

U3: Mail flow is smoother. More available mail on the machine when it should be there, less machine down time. They established two bridge tours with CCs to help tie tours together. Can jump on machines now, not worry about getting mail to the machines.

U4: Operations run a lot smoother. There is less conflict with supervisors and employees. Less contact is preferred on both sides.

MI: Mail processors and others have an avenue for expressing problems. They can be more vocal. They see things from different perspective. Much more communication regarding mail sorting. Ebb and flow progress has occurred, general trend is possible.

M2: The program is still very new. There were some problems early that needed ironing out. There is more flexibility with CCs. MPs have more voice in the process.

M3: People have more "stock in product" - CC has taken away some of the "edge" of supervision control over employee. CC points out where supervision can change. At this facility, Union/Management relations are formal, and $C C$ fits the way this facility runs. At other facilities, where relations are better (more open) perhaps a CC program would not be needed. Here, however, communication was very poor before the $C C$ program. There was no formal way lorganizationally sanctioned way) for employees to volce opinions, to influence how work is done. Key is participation.

4. Is the crow chief program functioning the way you thought it would?

U1: We need more CCs on this tour. It is expected, people were fearful and then liked it after they got used to it.

U2: I thought it would be better but it is doing $0 . \mathrm{k}$. Management was resistant and sees it as a threat to them (i.e. Iine managers).

U3: How would it run? Expected resentment on the part of the supervisors, but that was only true early on. Now CCs are running machines like they are supposed to. Supervisors do not resent them. CCs are in jobs where they might not otherwise be without CC project.

04: Human nature is a problem. CCs are slacking off on their duties. More supervising than working with crew (i.e. helping get the mail out, and not).

M1: No, had feeling that $\mathrm{CCs}$ would dive into work, but interpersonal problems arose. People were unhappy to begin with, and one person was a problem because of complaining some CCs thought that bossing was the main task. Training process proceeded with low staff. Not enough people in training staff. The training of the CCs was done by Washington and handled by Bruce Swanson. He said that in the 
initial training session, some CCs did not get "the message" regarding the CCs duties. Another training session was held, a "follow up", with someone from Michigan. This trainer was viewed more positively and the second session made a big impact on some CCs regarding their willingness or desire to perform the duties of the CC.

M2: Yes, somewhat. It has come around but some things still need working out. We need some way for $\mathrm{CCs}$ to be removed. Personality problems can occur and we need some system for setting new guidelines. (CC cannot just dictate what they want.)

M3: Yes. Both good things and bad. That is, he anticipated that the seniority selection process would result in some CCs not being very good, but overall the CC program has turned out very well.

5. What do you think has hindered effective implementation of the crew chief program in this site?

UI: Lack of knowledge of program - Tour I did not get information out well enough. Should have a $3 \mathrm{rd}$ party explaining it, not supervisors. Supervisors got information and then disseminated it - and they didn't like the program and having to get used to it.

U2: There is resistance from line managers and restructuring. There is a lack of understanding of the program by mail processors. The failure of CCs to work program as outlined (not enough on the machines). Good ones get feedback and it is a positive situation. We as a union could have publicized CC duties and why the CC program is good.

U3: Good ole boy network. Management fears change - longer tenure = more fear. Held reins for so long, they were afraid to let go.

U4: We are short staffed. There are not enough people to run machines and we are loosing more to the CC program. There is a lack of supervision from management. There. is a lack of proper supervision. Take human side - people slack off management must tell CC that people need to get moving.

M1 : No training for the steering committee. No training regarding the function of the $C C$ project and team functioning for steering committee. NAPs were not aware of the CC program and were hostile. More preparation and fulfilling expectations would have helped the resistance.

M2 : Removal of CCs is a problem. More questions still need to be answered. What happens with senior MPa? This may be a duplicate position as they are responsible for similar work.

M3 : Lack of communication - CC meetings were not very productive; they were gripe sessions. Choice of supervisors - management changes in supervisors was needed to coincide with changes in cC program; if possible, it would have been better to have changed supervisors. Not all supervisors mesh with the CC program as well as they should for the program to be maximally effective. 
6. What would you say is the best thing about the crew chlef project? The worst thing?

\section{Beat Thing:}

U1: More variety in work. Can ask worker, fellow worker, for help - not supervisor.

U2: Employees have more input into day to day conditions (not negotiation, but to decide on tasks and ways to do them). Can't use it to get around union and steps must be monitored by both sides. Also, promotional opportunities.

U3: Gives control to workers.

U4: The unit seems more organized (daily workload is more organized). People are more aware of what needs to be done or is left to be done.

M1 : We are giving credit for people being thinking humans and not cogs in a machine. There is more consultation - MPs know the work well and that was ignored before.

M2: It frees the supervisor to do other things like quality control. Also, a voice is given to some individuals. More voice is good.

M3 : Gets employees involved - helps them see how supervisors work is - how hard it is.

\section{Worst Thing:}

U1: CC lets it go their head, thinking they are supervisors. This has subsided with time.

U2: Lack of Commitment of line supervisors. Not trained well enough (MDOs and Plant Manager is o.k.). Mechanism to remove bad CC.

U3: The resentment from some senior employees towards CC because $\mathrm{CCs}$ tend to have less seniority. Higher seniority tended to be skeptical, therefore didn't bid on CC positions.

U4: There are no clear goals or focus of whole project.

M1: NAPs fear loosing more people. I see that fear is not founded here, but $I^{\prime} m$ not sure about nationally - much conflict, must solve the issue.

M2: If someone is fouling up the program, then they need to get them out of the system. Get rid of the CC when not working. Also, how do you deal with a negatively perceived CC?

M3 : Hearing impaired people need special accommodations; this makes it complicated for everyone.

7. Do you think the crew chiefs in your facility were adequately trained to perform their new function, both technicaliy and interpersona11y?

U1: Interpersonal training was good enough - can't be trained. It is not a training issue, it is a selection issue. Technical training was good enough.

U2: Initially, they got the right amount of training. A lot of refresher training was needed (task \& what was needed didn't get implemented because "people adjust slowly"). The package 
was good, but the job of $\mathrm{CC}$ can't be separated from individual styles.

U3: Technical training was good and has worked rather well. There is a lack of interpersonal training. Of opinion they are bosses, or agents of change. Not agents of change, however.

U4: CCs were trained adequately - I trained them.

M1: They are now trained to a great extent. We ran a second session with the first chosen CCs - later classes worked well and communication was the \#I thing to work on in dealing with people. Vince Paladino saw a link between $\mathrm{CC}$ implementation and supervisor layoffs - saw a causal link.

M2: Technical training is good - they were qualified before. Interpersonally, the training seems adequate.

M3: We don't need any more technical training. CCs for the most part are knowledgeable of the way machines run. However, not all are, and this is something that could be fixed via improved selection. Some can, and some can't be trained interpersonally; this could be improved by better selection.

8. Overall, what proportion of the current crew chiefa do you think are competent to perform the crew chlef job?

U1: $33 \%$ Those who are effective are sure, work better with people.

U2: $90 \%$ are effective and have the ability to make themselves seen as mail processors and ability to be seen as a crew member and still get the job done and get others to see that their job is important. Project an unselfish attitude.

03: $80 \%$ Those effective do decent, outstanding job regardless of tour. Ineffective took it for days off, or tour change. They are more likely to see selves as boss, less able to communicate. Too authoritative.

U4: $85 \%$ are capable. Need to remember training and work on own without direct guidance. They need to know the meaning of CC - part of the crew, work with the crew, give guidance, and work on task. Must be able to deal with people and some were bad and are gone, those now are still working on interpersonal skills.

M1: $50 \%$ or more 758 - two have resigned, but is are the same. selection is important - senior bidder took job. Because of hours or days off, were reasons for job bid. Within tour bidding would help. A good CC dives into work - knows what needs to be done and sets an example. Most match mail volume, machines and workers and match them for best results.

M2: $80 \%$ Good ones take charge of team tasks. They get things started, prioritize, and assign tasks.

M3 : 75-808 Only 1 or 2 are questionable. Some bad CCs just wanted job to get on days. "Bridge Bids", where tours are tied together, is a suggested role being considered. These people would link tours, which would help facilitate operations. Effective CCs have better communication skills that is, they are very popular. A "popularity contest" approach would work for selecting CCs. Also, CCs who are better have better knowledge of machines, and 
peculiarities/problems. Again, popularity approach would highlight better CC type people because others know who is the more knowledgeable employee.

9. Do the crew chlefs in your facility opend time on the machines?

U1: Yes, on tour I. Tour III less, Tour II do also spend time. Some days more, some days less. They fill in for breaks, lunches. This is as it should be.

U2: Yes, it took a while. Two CCs had a problem with this part. Yes, some, at least half as part of every day. Yes, to be a part of the crew, filling in for breaks, when seeing nurse, and other off the job needs.

U3: Spend their share - how much? $40 \%$ Why? Breaks, amoke, bathroom, tired of machine.

U4: Minimal time is spent on the machines,- very minimal. 5\% to 1\% of their time is spent on machines. Some see a need and they get on machines, others don't anyway for any reason. Some CCs need no guidance, others are a problem.

MI : Yes, varies widely. $1 / 2$ the time on machines, some more, some less depending on the task, schedules, etc. Breaks, some to work as part of the crew and they work on days when they are not CCs.

M2: Some do, some don't. Complaints arose about those who don't and some, with more training, got the idea. I don't know how much time they spend, but time is spent on the machines mainly to cover breaks.

M3 : 60-708 of their time is spent on the machines. The rest of the time they are chasing mail, doing CC things, etc. They are on machines when short staffing requires relief for breaks, volume of mail overloads machines, etc. They are always busy with something - CCs are always working.

PROBE Do they spend an appropriate amount of time on the machinea?

$\mathrm{U1}$ : $\mathrm{OK}$

U2: Not sure. Those that spend time on the machines are seen as good crew chiefs.

U3: They could spend more time.

M2: It depends on timing. Some are not doing enough. The $80 \mathrm{f}$ of good CCs are 0.K.

M3: On the average, I can't really say.

10. For each meeting below, find out frequency, formalnese, purpose, and what 18 discussed/accomplished?

\section{A. Do the crew chtefs have meetings among thembelves?}

01: Yes, but tour I hasn't participated. Need Tour I to mesh with other tours. The meeting was a $1 \mathrm{p} . \mathrm{m}$. when they were home sleeping. Once a month, formal thing.

U2: Not formal meetings - loop positions exist to connect two tours - this time helps communication between toura.

U3: Tried, but didn't like to do it alone. They wanted more 
structured environment because we alone have no power to change things so we need someone here in meeting who can change things.

U4: They talk every day - no formal meetings. They discuss tasks and work on going talking.

M1: No.

M2: Yes, once a month.

M3: Yes, on tour III only, there is one day for scheduling. There are informal meetings where operational issues like planning for day, working with supervisors, etc, are discussed.

\section{B. Do the crew chiefs have meetings with the supervisors?}

U1: Every night - they ask when something comes up. Informal scheduling, etc.

U2: Supposed to have a meeting - informal meetings - crew chiefs do seek supervisors out, but they hide.

U3: Once a month with CC from all tours, 2 reps from management, and 3 steering committee members.

U4: No formal meetings, they see each other every day as needed with regard to equipment and set-up.

M1: Yes.

M2: Yes, supervisors attend some. For a while, they did attend all, but later they attended on an as needed basis.

M3: Yes, in the beginning they met every day in the meetings described in 10A. As many supervisors and $\mathrm{CCs}$ met as were available - that is, the meetings were relatively informal. Whoever could make it would go, but not everyone could make it because of problems with conflicting schedules (on separate shifts).

\section{c. Do the crew chiefs meet with the local steering committee?}

U1: Informally, rightly with a member.

U2: Yes, once a month. Initially, to discuss how the program is going and what problems exist. Now discuss jobs and tasks, program changes, working condition changes, work sorting changes, etc.

U3: Yes.

U4: One per month. Discuss problems, different tasks to be done, gripes and complaints, cooperation between management and $C C$.

M1: Yes.

M2: One a month. A steering committee member attends meetings and monitors the meetings.

M3: Not all steering committee meetings have all steering committee members because of shift conflicts. There are gripe sessions with $\mathrm{CCs}$ about once a month. Ostensibiy communications, also discuss staffino, getting radiog, mail problems, technical people would attend regarding mail processing problems (machine problems), workting with other toure, etc. Meetings are not overly formal. They are gripe sessions in the sense that for the first 15 minutes, cCs vent aggravation with the bad supervisor, but after that, they are focused on operational issues. 


\section{Do the crew chlefs have meetings with thelr crew members?}

Ul: Rotate with crew. Wednesday night service talks.

U2: Service talk to inform them about program and to inform them that it is their program.

U3: Weekly safety/service talks between $C C$ and crew. Talk about smoother running job.

U4 : No.

M2: Weekly service talks for safety, but nothing formally about the task or the CC project.

M3 : Not sure. Service/safety talk (5 minutes every week) is one responsibility the CC has assumed, but other than that, it is hard to say.

E. Are their any other meetings in relation to the crew chief program?

U1: No.

U2: Any key issues (stick) Wotzack \& she meet on that special issue.. One day they and each CC meet to air any opinions.

MI: Resource people giving reports on the last Thursday of every month.

M2: No.

M3: The steering committee meets once every three months. They did a survey in-house, and discussed results. These meetings have specific agendas. It is a problem getting everyone together because of shift conflicts. Meetings were set up as needed to address specific issues and were relatively informal.

11. Are chlefo aselgned to a regular crew or do they have different crew members each day?

U2: Rotate.

U3: Rotating schedule.

U4: CC is rotated and each CC has different people each day.

M1: Scheduled rotation.

M2: Different crew men each day.

M3: Rotate. They chose this procedure. It works fine, great. In fact, the way the rotation works is complicated, but it results in people working on different machines with different people. It provides variety.

12. Do the same people work together regularly. in the oCR/BCs/DBCS unit? All three tours? Describe how they are organized.

U2: Rotate.

U3 : Rotate.

U4: Everyone is on a rotation basis and go through each position in rotation. CCs rotate on a reverse system of the members.

M1: Scheduled rotation.

M2: No, they are rotated dally.

M3 : Rotate people among crews and job assignments. All tours use this rotation policy. 
13. How are crew chlefe organized to cover the 7 day a week operation?

U1: Not on Friday/Saturday for tour I. A CC is on OT to cover Friday/Saturday.

U2: Rotate.

U3: Rotate.

U4: Some took bids with certain days off and relief, and the relief fills in when no $C C$ is around. Then if no $C C$, supervisor takes over, could be a $204 \mathrm{~B}$ or a regular supervisor.

M2: Rotate with regulars and relief.

M3: Not all days are covered (Sundays, holidays). It is hard enough to handle holidays, it is good to keep scheduling simple. Relief bids are not filled.

14. If the crew chief program ia made permanent, what changes would you suggest?

U1: Nothing in particular.

U2: Want a provision to have formal training and follow-up training. Need more involvement from steering committee in training. It worked better with the second meeting. Need more consistency in management representation. "Need a way to get rid of bad $\mathrm{CCs}$.

U3 : The biggest change would be to implement a better choice of days off, rather than weekdays off. Senior persons will not go to job with weekdays off. Make CC position more attractive to people with the best knowledge.

U4: Proper staffing. Bids filled. Open CCs exist and open MPs exist. Need a system for removal of CC is they are acting like a supervisor and not a $\mathrm{CC}$.

M1 : Awarding within tour bids. Some input of CC via crew members in regards to tenure. Sometimes CC just does not work and there is no response to that.

M2: Need some way to increase the responsibility of the cc for their tasks and remove them if they are not completing the task.

M3: Should be level 6 (up from 6). Needs to be higher grade because of potential "Senior Mail Processor" will be level 5 (this is being considered as a new designation). At a higher level, there would be more commitment to the job. Mall processors would compete to get more money. There should be better selection - the system uses seniority now. We need competition. Need interviews focusing on technical issues, interpersonal issues. Some have poor communication skills if there was peer evaluation of their leadership ability, those poor communicators would not be $\mathrm{CCs}$. 
Appendix C 352

15. On a 10-point ocale (with 10 being extremely aupportive), how supportive of the crew chief project are you:

A. As it currently exists?

U1: 8

U2: 5

U3: 10

U4: 10

M1: 8

M2: 9

M3: 7

Comments:

U1: Tour I needs more CCs. Likes program but need about 4 more CCs especially with the new machines coming in.

B. As it copld function ideally?

U1: 10

U2: 10

U3: 10

U4: 10

M1: 10

M2: 10

M3 : 10

Comments :

M1: Could be extended to other parts of the Post office. 